P.PERMAX

Shire BioChem

Pergolide Mesylate

Antiparkinsonian Agent-Dopamine Agonist

\section{ACTION and CLINICAL PHARMACOLOGY}

PERMAX (pergolide mesylate), a synthetic ergot derivative, is a dopamine receptor agonist at both $\mathrm{D}_{1}$ and $\mathrm{D}_{2}$ receptor sites. In Parkinson's disease, pergolide is believed to exert its therapeutic effect by directly stimulating postsynaptic dopamine receptors in the corpus striatum. In addition. pergolide suppresses the secretion of prolactin, causes a transient increase in serum concentration of growth hormone and a decrease in serum concentration of luteinizing hormone.

To date, only very limited pharmacokinetic data are available. Following oral administration of "C $\mathrm{C}$-pergolide, radioactivity in plasma appeared after 15 to 30 minutes, peaked at one or two hours, and was barely detectable after 96 hours. Radioactivit was eliminated as pergolide metabolites in urine $(55 \%)$, in feces $(40 \%)$ and in breath $(5 \%)$. No unchanged pergolide was detected in excreta.

At least 10 radioactive metabolites have been isolated, including $\mathrm{N}$-despropylpergolide, pergolide sulfoxide and pergolide sulfone. The latter two metabolites are dopamin agonists in animals. The other detected metabolites have not been identified and it is not known whether they are

pharmacologically active.

Pergotide is approximately $90 \%$ bound to plasma proteins. This extent of protein binding may be important to consider when pergolide is coadministered with other drugs known to affect protein binding.

\section{INDICATIONS AND CLINICAL USE}

PERMAX (pergolide mesylate) is indicated in the treatment of the signs and symptoms of idiopathic Parkinson's disease.

PERMAX may be used both as early therapy, without

concomitant levodopa, and as an adjunct to levodopa (usually with a peripheral decarboxylase inhibitor).

\section{CONTRAINDICATIONS}

PERMAX (pergolide mesylate) is contraindicated in patients who are hypersensitive to this drug or other ergot derivatives.

\section{WARNINGS}

Hydotension - PERMAX (pergolide mesylate) may cause syncope or hypotension (i. e a fall in systolic blond pressure to less than $100 \mathrm{mmHg}$ ). It is therefore important to warn patients of the risk, to begin therapy with low doses, and to increase the dosage in carefully adjusted increments over period of several weeks (see DOSAGE AND

ADMINISTRATION.

Syncope or excessive hypotension were observed in patients on PERMAX therapy, especially during initiation of treatment. Episodes of moderate hypotension also occurred. With gradual dosage titration, tolerance to hypotension usually develops.

Care should be exercised when administering PERMAX concomitantly with antihypertensive agents or other medications known to lower blood pressure.

Effect on the abilitv to drive and use of machines - Physicians should caution patients that pergolide may cause somnolence or episodes of sudden onset of sleep (see Adverse Reactions Post-marketing Reports). Patients should be cautioned about operating hazardous machinery, including motor vehicles, while taking pergolide.

Hallucinations: In controlled clinical trials in patients with early PD, hallucinations were observed in $2.4 \%$ of patients taking pergolide, as compared to $1 \%$ in those taking placebo. Treatment was discontinued due to hallucinations in about $0.8 \%$ of those enrolled. In these trials, this effect

occurred primarily some weeks into the maintenance period.

In controlled trials in patients with advanced $P D$

hallucinations were observed in about $14 \%$ of those taking PERMAX with levodopa, compared to $3 \%$ of those taking piacebo with levodopa. Treatment was discontinued due to hallucinations in about $3 \%$ of PERMAX patients; tolerance to this untoward effect was not observed.

Serous Inflammation and Fibrosis - There have been rare reports of pleuritis, pleural effusion, pleural fibrosis, pericarditis, pericardial effusion, cardiac valvulopathy involvin one or more valves or retroperitoneal fibrosis in patients taking pergolide. In some cases, symptoms or manifestations of cardiac valvulopathy improved after discontinuation of pergolide. Pergolide should be used with caution in patients with a history of these conditions, particularly those patients who experienced the events while taking other ergot derivatives. Patients with a history of such events should be carefully monitored clinically and with appropriate radiographic

and laboratory studies while taking pergolide.

\section{PRECAUTIONS}

General - The abrupt discontinuation of PERMAX (pergolide mesylate) in patients receiving it chronically as an adjunct to levodopa may precipitate the onset of hallucinations and confusion; these may occur within a span of several days Discontinuation of PERMAX should be undertaken gradually whenever possible, even if the patient is to remain on levodopa.

A symptom complex resembling the neuroleptic malignant syndrome (NMS), characterized by elevated body temperature, muscular rigidity, altered consciousness, and autonomic instability, have been reported in association with rapid dose reduction, withdrawal of, or change in antiparkinsonian therapy. Therefore, patients should be observed carefully when the dosage of PERMAX is reduced abruptly or discontinued.

The administration of PERMAX to patients receiving levodopa may cause and/or exacerbate pre-existing dyskinesia.

Cardiovascular Effects - PERMAX has not been systematically evaluated in patients with heart disease. In the multicenter clinical trial, patients with heart disease, i.e., recent angina pectoris, decompensated heart failure (New York Scale III or IV). myocardial infarction within the last 12 months, or any arrhythmia requiring antiarrhythmic therapy at the time of the study or within 12 months prior to the study were excluded. Since there is only limited experience with PERMAX in these patients, PERMAX should be administered only if in the judgement of the physician the potential benefits clearly outweigh the potential risks.

In a study comparing pergolide mesylate and placebo, patients taking pergolide mesylate were found to have significantly more episodes of atrial premature contractions (APCs) and sifius tachycardia.

Druq interactions - Dopamine antagonists such as the neuroleptics (phenothiazines, butyrophenones, thioxanthines) or metoclopramide ordinarily should not be administered concurrently with PERMAX

(a dopamine agonist) because these agents may diminish the effectiveness of PERMAX

Because PERMAX is approximately $90 \%$ bound by plasma proteins, caution should be exercised if PERMAX is coadministered with other drugs known to affect protein binding.

Use in Pregnancy - In teratology studies performed in mice and rabbits, there was no evidence of harm to the fetus due to PERMAX. There are however, no adequate and well-controlled studies in pregnant women. In a small number of women who received PERMAX for endocrine disorders, there were 33 pregnancies that resulted in healthy babies and 6 pregnancies that resulted in congenital abnormalities ( 3 major, 3 minor); causal relationship has not been established. Because human data are limited and because animal reproduction studies are not always predictive of human response, this drug should be used during pregnancy only,

if in the opinion of the treating physician, the possible benefit to the patient outweighs the potential risks to the fetus. Nursing Mothers - It is not known whether PERMAX is excreted in human milk. The pharmacologic action of PERMAX suggests that it may interfere with lactation. Because many drugs are excreted in human milk and because of the potential for serious adverse reactions to PERMAX in nursing infants, a decision should be made whether to discontinue nursing or to discontinue the drug, taking into account the importance of the drug to the mother.

Pediatric Use - Safety and effectiveness in children have not been established.

\section{ADVERSE REACTIONS}

\section{Commonly Observed in Controlled Trials.}

The most commonly observed adverse events $(\geq 5 \%)$ associated with the use of pergolide are as follows: For Early Therapy: gastrointestinal complaints, including nausea, anorexia, constipation, dyspepsia, nervous system complaints, including dizziness, insomnia somnolence and depression; and whole body complaints, including asthenia, abdominal pain, pain, and headache.

For Adjunctive Therapy: nervous system complaints, including dyskinesia, dizziness, hallucinations, dystonia, confusion, somnolence, insomnia and anxiety; gastrointestina complaints, including nausea, constipation, diarthea, and dyspepsia; cardiovascular complaints, including postura hypotension; whole body complaints, including pain, abdominal pain, accidental injury and headache; periphera edema; rhinitis; and abnormal vision.

In clinical trials for pergolide early therapy, the overal reported incidence of nausea was higher than that reported in trials for adjunctive therapy ( $38.0 \%$ vs $24.3 \%$, respectively); this nausea rate occurred despite a mandatory regimen of the anti-emetic domperidone during the initial 3 or 8 week uptitration period, for all patients in early therapy clinical trials. Certain adverse experiences (eg. dyskinesia, hail ucinations are frequently observed in patients receiving levodopa pergolide and/or other dopamine agonists. These are dose related and tend to improve with reduction of the dosage of levodopa or of pergolide. Hallucinations may infrequently persist after discontinuation of pergolide. Postural hypotension and nausea are most frequently reported during the initial titration phase.

Abnormalities in laboratory tests may include elevations AST ALT, alkaline phosphatase, creatine phosphokinase, and urea nitrogen

Adverse Reactions resulting in Discontinuation in Controlled

Early Therapy: Gastrointestinal (6\%) and CNS (2\%).

Adjunctive Therapy: CNS (15.5\%), primarily hallucinations

(7.8) and confusion (1.8\%)

Incidence of Adverse Reactions in Controlled Clinical Trials: The table that follows enumerates adverse events occurring at a frequency of $1 \%$ or more among all pergolide-treated patients who participated in controlled trials. The prescriber should be aware that these figures cannot be used to predict the incidence of side effects in the course of usual medical practice where patient characteristics and other factors differ from those which prevail in clinical trials. The cited figures, however, do provide the prescribing physician with some basis for estimating the relative contribution of drug and nondrug factors to the side effect incidence rate in the population studied.

TABLE 1: Incidence of Treatment-Emergent Adverse Experiences in Controlled Clinical Trials in Patients with Early or Advanced Parkinson's Disease

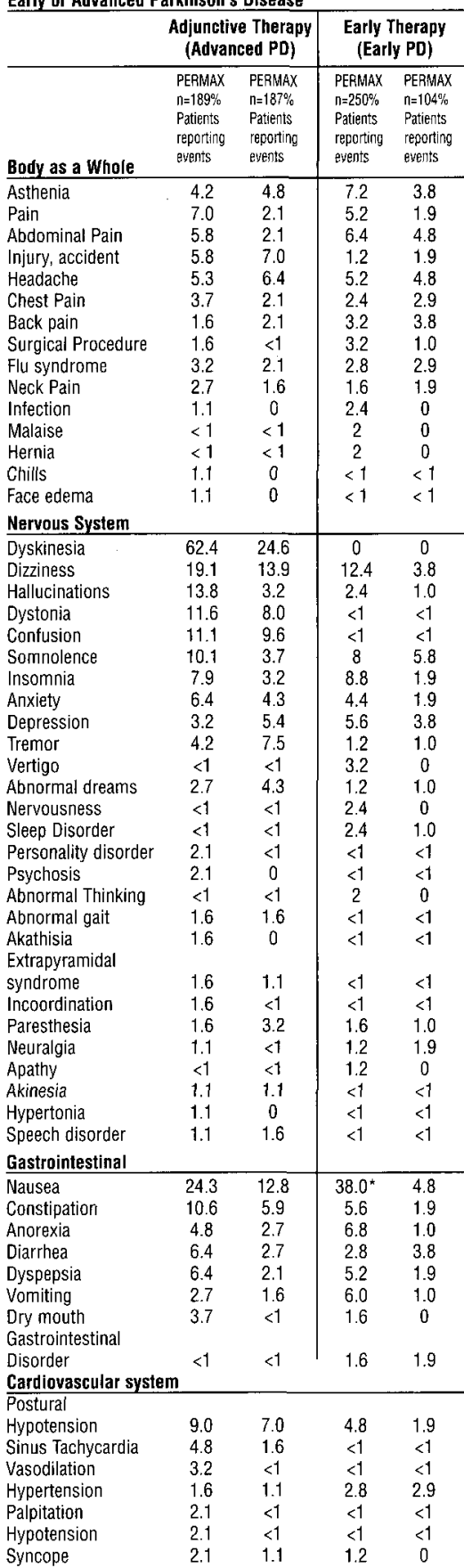




\begin{tabular}{|c|c|c|c|c|}
\hline Vascular Disorder & $<1$ & $<1$ & 1.2 & 0 \\
\hline $\begin{array}{l}\text { Peripheral Vascular } \\
\text { Disorder }\end{array}$ & $<1$ & $<1$ & 12 & 0 \\
\hline Arrhythmia & 1.1 & $<1$ & $<1$ & $<1$ \\
\hline $\begin{array}{l}\text { Myocardial infarction } \\
\text { Respiratory System }\end{array}$ & 1.1 & $<1$ & $<1$ & $<1$ \\
\hline Rhinitis & 12.2 & 5.4 & 2.4 & 0 \\
\hline Dyspnea & 4.8 & 1.1 & 3.2 & 0 \\
\hline Cough Increased & $<1$ & $<1$ & 2.8 & 1.9 \\
\hline Bronchitis & $<1$ & $<1$ & 2.4 & 2.9 \\
\hline Epistaxis & 1.6 & $<1$ & $<1$ & $<1$ \\
\hline Pharyngitis & $<1$ & $<1$ & 1.2 & 0 \\
\hline Hiccup & 1.1 & 0 & $<1$ & $<1$ \\
\hline \multicolumn{5}{|c|}{ Metabolic \& Nutritional System } \\
\hline Peripheral edema & 7.4 & 4.3 & 2.4 & 1.0 \\
\hline Edema & 1.6 & 0 & 2 & 1 \\
\hline Weight gain & 1.6 & 0 & 0 & 0 \\
\hline \multicolumn{5}{|l|}{ Special Senses } \\
\hline Abnormal vision & 5.8 & 5.4 & $<1$ & $<1$ \\
\hline Diplopia & 2.1 & 0 & $<1$ & $<1$ \\
\hline Amblyopia & $<1$ & $<1$ & 2 & 0 \\
\hline Taste perversion & 1.6 & 0 & $<1$ & $<1$ \\
\hline Eye disorder & 1.1 & 0 & $<1$ & $<1$ \\
\hline \multicolumn{5}{|l|}{ Musculoskeletal System } \\
\hline Arthralgia & 1.6 & 2.1 & $<1$ & $<1$ \\
\hline Bursitis & 1.6 & $<1$ & $<1$ & $<1$ \\
\hline Joint Disorder & $<1$ & $<1$ & 1.2 & 0 \\
\hline Myalgia & 1.1 & $<1$ & 2 & 1.9 \\
\hline Twitching & 1.1 & 0 & $<1$ & $<1$ \\
\hline \multicolumn{5}{|l|}{ Skin \& Appendages } \\
\hline Rash & 3.2 & 2.1 & 1.2 & 1.0 \\
\hline Sweating & 2.1 & 2.7 & 1.2 & 1.0 \\
\hline \multicolumn{5}{|l|}{ Urogential System } \\
\hline Urinary frequency & 2.7 & 6.4 & 1.6 & 1 \\
\hline Urinary tract infection & 2.7 & 3.7 & $<1$ & 0 \\
\hline Hematuria & 1.1 & $<1$ & $<1$ & $<1$ \\
\hline \multicolumn{5}{|c|}{ Hemic \& Lymphatic System } \\
\hline$\overline{\text { Anemia }}$ & 1.1 & $<1$ & $<1$ & $<1$ \\
\hline
\end{tabular}

$1.1<1<1<1$ Patients in the controlled clinical trials for early PD were on
mandatory regimen of the anti-emetic domperidone for the duration of the up-titration period.

Other Events Observed During the Pre-marketing Evaluation of PERMAX

This section reports event frequencies of adverse reactions that occurred in approximately 1,700 patients who took

multiple doses of PERMAX in premarketing studies worldwide. The conditions and duration of exposure to PERMAX varied greatly, involving well-controlled studies as well as experience in open and uncontrolled clinical settings. In the absence of appropriate controls in some of the studies, a causal relationship to PERMAX treatment cannot be determined.

Fatalities - In the placebo-controlled trial, 2 of 187 patients treated with placebo died as compared with 1 of 189 patients treated with PERMAX. In the latter group, three additional patients died who continued on PERMAX beyond the controlled phase of the study. Of the 2,299 patients treated with PERMAX in premarketing studies 143 died while on the drug or shortly after discontinuing the drug. The patient population under evaluation was elderly, ill, and at high risk for death. It seems unlikely that PERMAX played any role in these deaths, but the possibility that PERMAX shortens survival of patients cannot be excluded with absolute certainty.

Other Events By Body System - The following definitions of frequency are used. Frequent adverse events are defined as those occurring in at least 1/100 patients; infrequent adverse events are those occurring in $1 / 100$ to $1 / 1,000$ patients; rare events are those occurring in less than $1 / 1,000$ patients.

\section{Body as a Whole System:}

Frequent: Headache, asthenia, injury accident, abdominal pain, chest pain, back pain, fever, flu syndrome, neck pain

Infrequent: Enlarged abdomen, malaise, neoplasm, hernia, pelvic pain, facial edema, chills, sepsis, cellulitis, moniliasis abscess, jaw pain, hypothermia.

Rare: Acute abdominal syndrome, LE syndrome, erythromelalgia.

\section{Nervous System:}

Frequent: Hallucinations, psychosis, paranoid reaction personality disorder, akinesia, dyskinesia, choreoathetosis dystonia, tremor, abnormal gait, incoordination, speech disorders, dizziness, confusion, depression, anxiety, somnolence, insomnia, abnormal dreams, amnesia.

Infrequent: Neuropathy, hypertonia, delusions, convulsion, libido increased, euphoria, emotional lability, libido decrease, akathisia, vertigo, neuralgia, myoclonus, coma, apathy paralysis, neurosis, hyperkinesia, ataxia, acute brain syndrome, torticollis, meningitis, manic reaction, hypokinesia, hostility, agitation.

Rare: Stupor, neuritis, intracranial hypertension, hemiplegia, facial paralysis.

\section{Gastrointestinal System}

Frequent: Nausea, vomiting, constipation, dyspepsia, anorexia, diarrhea, dry mouth, dysphagia.

Infrequent: Flatulence, abnormal liver function tests, increased appetite, salivary gland enlargement, thirst gastroenteritis, gastritis, rectal disorder, peridontal abscess, intestinal obstruction, nausea and vomiting, gingivitis, esophagitis, cholelithiasis, tooth caries, hepatitis, stomach ulcer, melena, hepatomegaly, hematemesis, eructation. Bare: Sialadenitis, peptic ulcer, pancreatitis, colitis, cholecystitis, aphthous stomatitis.

\section{Cardiovascular System}

Frequent: Postural hypotension, hypotension, syncope, hypertension, palpitations, arrhythmia, vasodilatation, congestive heart failure.

Infrequent: Myocardial infarct, tachycardia, cardiac arrest, abnormal electrocardiogram, angina pectoris,

thrombophlebitis, bradycardia, ventricular extrasystoles, cerebrovascular accident, ventricular tachycardia, cerebral ischemia, atrial fibrillation, varicose vein, pulmonary embolus, AV block, shock.

Rare: Vasculitis, pulmonary hypertension, pericarditis migraine, heart block, cerebral hemorrhage.

\section{Respiratory System}

Frequent: Rhinitis, dyspnea, pneumonia, pharyngitis, cough increased.

Infrequent: Sinusitis, bronchitis, epistaxis, voice alteration, hemoptysis, asthma, lung edema, hiccup, pleural effusion, laryngitis, emphysema, apnea.

Rare: Pneumothorax, lung fibrosis, larynx edema, hypoxia, hypoventilation, hyperventilation, hemothorax, carcinoma of lung.

Metabolic and Nutritional Findings

Frequent: Peripheral edema, weight loss, weight gain.

Infrequent: Dehydration, hypokalemia, hypoglycemia, gout, hyperglycemia, iron deficiency anemia, hypercholesteremia. Rare: Electrolyte imbalance, cachexia, acidosis

hyperuricemia.

Special Senses System

Frequent: Diplopia

Infrequent: Otitis media, conjunctivitis, tinnitus, deafness, taste perversion, ear pain, eye pain, glaucoma, eye hemorrhage.

Rare: Blindness, cataract, retinal detachment, retinal vascular disorder.

\section{Musculoskeletal System}

Frequent: Twitching, myalgia, arthralgia.

Infrequent: Bursitis, bone pain, tenosynovitis, myositis, bone sarcoma.

Rare: Osteoporosis, muscle atrophy.

Skin and Appendages System

Frequent: Sweating, rash.

Infrequent: Skin discolouration, pruritus, acne, skin ulcer, alopecia, dry skin. skin carcinoma, seborrhea, hirsutism, herpes simplex, eczema, fungal dermatitis.

Rare: Vesiculobullous rash, subcutaneous nodule, skin nodule, skin benign neoplasm, lichenoid dermatitis, herpes zoster.

\section{Urogenital System}

Frequent: Urinary tract infection, urinary frequency, urinary incontinence, prostatic disorder, dysmenorrhea, hematuria. Infrequent: Dysuria, breast pain, menorrhagia, impotence, cystitis, urinary retention, menstrual disorder, abortion, vaginal hemorrhage, vaginitis, abnormal ejaculation, priapism, kidney calculus, fibrocystic breast, lactation, uterine hemor rhage, urolithiasis, salpingitis, pyuria, metrorrhagia, menopause, kidney failure, breast neoplasm.

Rare: Amenorrhea, bladder carcinoma, breast engorgement, epididymitis, hypogonadism, leukorrhea, nephrosis, pyelonephritis, urethral pain, uricaciduria, withdrawa bleeding.

\section{Hemic and Lymphatic System}

Frequent: Anemia.

Infrequent: Leukopenia, lymphadenopathy, leukocytosis, thrombocytopenia, petechia, megaloblastic anemia, cyanosis. Rare: Purpura, lymphocytosis, eosinophilia, acute lymphoblastic leukemia

\section{Post-marketing Reports}

Voluntary reports of adverse events temporally associated with PERMAX that have been received since market introduction and which may have no causal relationship with the drug, include the following: Pericarditis; Pericardial effusion; Pleuritis; Pleural effusion; Pleural fibrosis; Retroperitoneal fibrosis; Neuroleptic malignant syndrome (with rapid de-titration of pergolide); Sudden onset of sleep: Cardiac valvulopathy

In post-marketing experience, less than $0.01 \%$ of patients were reported for sudden onset of sleep. (see Warnings). SYMPTOMS AND TREATMENT OF OVERDOSAGE

There is no clinical experience with massive overdosage. Symptoms and signs may include vomiting, hypotension, agitation, severe hallucinations, severe involuntary movements, tingling sensations, palpitations, and ventricular extrasystoles.

Management of overdosage may require supportive measures to maintain arterial blood pressure. Cardiac function should be monitored; an antiarrhythmic agent may be necessary. If signs of CNS stimulation are present, a phenothiazine or butyrophenone neuroleptic agent may be indicated; the efficacy of such drugs has not been assessed in reversing the effects of overdose. Activated charcoal may be considered instead of or in addition to gastric emptying. There is no experience with dialysis or hemoperfusion; these procedures are unlikely to be of benefit.

\section{DOSAGE AND ADMINISTRATION}

General

The following dosage escalation recommendations apply to the use of pergolide for both early therapy (without levodopa) and late therapy (with levodopa).

These dosage escalation recommendations are derived from both clinical trial data and clinical experience, and are provided as a guide only, as individual tolerance to dose increases will vary. A slower schedule may reduce the incidence of adverse events, particularly hypotension, and $G$ and CNS symptoms (see WARNINGS, Hypotension; and ADVERSE EVENTS).

Early and Late Stage Parkinson's Disease

Administration of PERMAX (pergolide mesylate) should be initiated with a single daily dose of $0.05 \mathrm{mg}$ for the first 2 days. The dose should then be gradually increased, by 0.1 to $0.15 \mathrm{mg} /$ day every $3-4$ days over the next $2-3$ weeks of therapy.

Once a patient reaches approximately $0.75 \mathrm{mg} /$ day, the dosage may then be increased by $0.25 \mathrm{mg} /$ day every $3-4$ days until an optimal maintenance dosage is achieved. PERMAX is usually administered in divided doses 3 times/day. The satety of PERMAX, tor early Parkinson's disease, has not been systematically evaluated at doses above $3 \mathrm{mg} /$ day. In clinical studies of PERMAX for treatment of early Parkinson's disease, the average dose after one year of treatment was approximately $2.25 \mathrm{mg} /$ day

The safety of PERMAX, for advanced Parkinson's disease, has not been systematically evaluated at doses above $5 \mathrm{mg} /$ day. In clinical studies, the average therapeutic dose of PERMAX was approximately $3 \mathrm{mg} /$ day. The average concurrent levodopa/carbidopa daily dosage (expressed as levodopa) was approximately $650 \mathrm{mg} /$ day. Since

rapid escalation of PERMAX can cause severe adverse reactions, it is recommended that a slow increase of PERMAX be combined

with a concomitant gradual, cautious and limited reduction of levodopa dosage.

DOSAGE FORM

Availability: PERMAX (pergolide mesylate) tablets are modified rectangle shaped, scored and engraved with the company logo and Identi-code number. Available in amber HDPE bottles. PERMAX tablets $4131,0.05 \mathrm{mg}$ (pergolide as pergolide mesylate) are ivory coloured in bottles of 30

PERMAX tablets $4133,0.25 \mathrm{mg}$ (pergolide as pergolide mesylate) are green coloured in bottles of 100 .

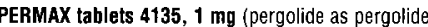
mesylate) are pink coloured in bottles of 100 .

Storage: PERMAX should be stored at room temperature.

Product Monograph available upon request

Date of revision : October 15,2003

References: 1. Barone P, et al. Pergolide monotherapy in the treatment of early PD. A randomized, controlled study. Neurology 1999;53(3):S73-S79. 2. Olanow CW, Fahn S Muenter M. et al. A multicentered double-blind placebo controlled trial of pergolide as an adjunct to Sinemet in Parkinson's Disease. Mov Disor. 1994; 9(1); 40-47.

The trademark PERMAX is under license from Eli Lilly and Company.

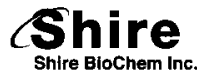




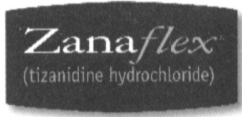

\section{Relieves Spasticity. Restores Possibilities.}

\section{Zanaflex}

(tizanidine hydrochloride) tablets $2 \& 4 \mathrm{mg}$ tizanidine Antispastic Agent

\section{CLINICAL PHARMACOLOGY}

\section{Mechanism of Action}

Tizanidine is an agonist at $\alpha_{2}$-adrenergic receptor sites and presumably reduces spasticity by increasing presynaptic inbibition of motor neurons.

Pharmacokinetics

Following oral administration, tizanidine is essentially completely absorbed and has a half-life of approximately 2.5 hours (coefficient of variation $[\mathrm{CV}]=33 \%$ ). Following administration of tizanidine peak plasma concentrations occurred at 1.5 hours ( $C V=40 \%$ ) after dosing.

Food increases $C_{\text {max }}$ by approximately one third and shortens time to peak concentration by approximately 40 minutes, but the extent of tizanidine absorption is not affected. Tizanidine has linear pharmacokinetics over a dose of 1 to $20 \mathrm{mg}$. The absolute oral bioavailability of tizanidine is approximately $40 \%(\mathrm{CV}=24 \%)$, due to extensive first-pass metabolism in the liver approximately $95 \%$ of an administered dose is metabolized. Tizanidine metabolites are not known to be active; their half-tives range from 20 to 40 hours. Tizanidine is widely distributer throughout the body; mean steady state volume of distribution is $2.4 \mathrm{~L} / \mathrm{kg}$ ( $\mathrm{CV}=21 \%$ ) following intravenous administration in healthy adult volunteers.

Following single and multiple oral dosing of ${ }^{14} \mathrm{C}$-tizanidine, an average of $60 \%$ and $20 \%$ of tota radioactivity was recovered in the urine and feces, respectively.

Tizanidine is approximately $30 \%$ bound to plasma proteins, independent of concentration over the therapeutic range.

\section{Special Populations}

Age Effects: No specific pharmacokinetic study was conducted to investigate age effects. Cros study comparison of pharmacokinetic data, following single dose administration of $6 \mathrm{mg}$ Zanaflex" (tizanidine hydrochloride) showed that younger subjects cleared the drug four times faster than the elderly subjects. Zanaflex has not been evaluated in children (see Precautions).

Hepatic Impairment: Pharmacokinetic differences due to hepatic impairment have not been studied (see WarnINGs)

Renal Impairment: Zanaflex clearance is reduced by more than $50 \%$ in elderly patients with rena insufficiency (creatinine clearance $<25 \mathrm{~mL} / \mathrm{min}$ ) compared to healthy elderly subjects; this would be expected to lead to a longer duration of clinical effect. Zanaflex should be used with caution in renally impaired patients (see PrECAUTIONS).

Gender Effects: No specific pharmacokinetic study was conducted to investigate gender effects Retrospective analysis of pharmacokinetic data, however, following single and multiple dose administration of $4 \mathrm{mg}$ Zanaflex showed that gender had no effect on the pharmacokinetics of Zanaflex

Race Effects: Pharmacokinetic differences due to race have not been studied.

Drug interactions-Oral Contraceptives: No specific pharmacokinetic study was conducted to investigate interaction between oral contraceptives and Zanaflex. Retrospective analysis of population pharmacokinetic data following single and multiple dose administration of $4 \mathrm{mg}$ Zanaflex, however, showed that women concurrently taking oral contraceptives had $50 \%$ lower clearance of Zanaflex compared to women not on oral contraceptives (see PrECAUTIONS) INDICATIONS AND CLINICAL USE

Zanaflex (tizanidine $\mathrm{HCl}$ ) is a short-acting drug for the management of spasticity. CONTRAINDICATIONS

Zanaflex (tizanidine $\mathrm{HCl}$ ) is contraindicated in patients with known hypersensitivity to Zanaflex or its ingredients.

WARNINGS

\section{Hypotension}

Tizanidine $\mathrm{HCl}$ is an $\alpha_{2}$-adrenergic agonist (like clonidine) and can produce hypotension. In a single dose study where blood pressure was monitored closely after dosing, two thirds of patients reated with $8 \mathrm{mg}$ of Zanaflex had a $20 \%$ reduction in either the diastalic or systolic BP. The reduction was seen within 1 hour after dosing, peaked 2 to 3 hours after dosing and was associated, at times, with bradycardia, orthostatic hypotension, lightheadedness/dizziness and rarely syncope. The hypotensive effect is dose related and has been measured following single doses of $\geq 2 \mathrm{mg}$. The chance of significant hypotension may possibly be minimized by titration of the dose and by focusing attention on signs and symptoms of hypotension prior to dose advancement. In addition, patients moving from a supine to a fixed upright position may be at increased risk for hypotensive and orthostatic effects.

Caution is advised when Zanaflex is to be used in patients who have a history of orthostatic hypotension or labile blood pressure or who are receiving concurrent antihypertensive therapy. Zanatlex should not be used with other $\alpha_{2}$-adrenergic agonists

Risk of Liver Injury

Zanaflex use occasionally causes drug induced liver injury, most often hepatocellular in type. In controlled clinical studies, approximately $5 \%$ of patients treated with Zanaflex had elevations of liver function tests (ALT/SGPT, AST/SGOT) to greater than 3 times the upper limit of normal (or 2 times if baseline levels were elevated). The patients usually remain asymptomatic despite ncreased aminotransferases. In occasional symptomatic cases, nausea, vomiting, anorexia and jandice have been reported. The onset of the elevated liver enzymes typically occurred within the first 6 months of treatment with Zanaflex and most resolved rapidly upon drug withdrawal with no reported residual problems. In postmarketing experience, three deaths associated with live failure have been reported in patients treated with tizanidine, including one case of fatal fulminant hepatitis. Monitoring of aminotransferase levels is recommended during the first 6 months of treatment (e.g., baseline, 1, 3 and 6 months) and periodically thereafter, based on clinical status. Because of the potential toxic hepatic effect of tizanidine, the drug should be used only with extreme caution in patients with impaired hepatic function.

Sedation

In the multiple dose, controlled clinical studies, $48 \%$ of patients receiving any dose of Zanaflex reported sedation as an adverse event. In $10 \%$ of these cases, the sedation was rated as severe compared to $<1 \%$ in the placebo treated patients. Sedation may interfere with every day activity. The effect appears to be dose related. In a single dose study, $92 \%$ of the patients receiving $16 \mathrm{mg}$, when asked, reported that they were drowsy during the 6 hour study. This compares to $76 \%$ of the patients on $8 \mathrm{mg}$ and $35 \%$ of the patients on placebo. Patients began noting this effect 30 minutes following dosing. The effect peaked 1.5 hours following dosing. Of the patients who received a single dose of $16 \mathrm{mg}, 51 \%$ continued to report drowsiness 6 hours following dosing compared to $13 \%$ in the patients receiving placebo or $8 \mathrm{mg}$ of Zanaflex.

In the multiple dose studies, the prevalence of patients with sedation peaked following the first week of titration and then remained stable for the duration of the maintenance phase of the study. Hallucinations

Zanaflex use has been associated with hallucinations. Formed, visual hallucinations or delusions have been reported in 5 of 170 patients $(3 \%)$ in two North American controlled clinical studies. Most of the patients were aware that the events were unreal. One patient developed psychoses in association with the hallucinations. One patient continued to have problems for at least 2 weeks following discontinuation of Zanaflex. Dosage reduction or discontinuation should be considered for patients who experience hallucinations while receiving Zanaflex. Particular caution should be observed if Zanaflex is administered to patients with a prior history of psychotic illness.

\section{LIMITED DATABASE FOR CHRONIC USE OF SINGLE DOSES ABOVE 8 MG AND MULTIPLE}

\section{DOSES ABOVE 24 MG PER DAY}

Clinical experience with long-term use of Zanaflex at single doses of 8 to $16 \mathrm{mg}$ or total daily doses of 24 to $36 \mathrm{mg}$ is limited. Approximately 75 patients have been exposed to individual doses of $12 \mathrm{mg}$ or more for at least one year and approximately 80 patients have been exposed to tota daily doses of 30 to $36 \mathrm{mg} / \mathrm{day}$ for at least one year. There is essentially no long-term experience with single, daytime doses of $16 \mathrm{mg}$. Because long-term clinical study experience at high doses is limited, only those adverse events with a relatively high incidence are likely to have been identified.

\section{PRECAUTIONS}

General

Zanaflex (tizanidine $\mathrm{HCl}$ ) should be used with caution in patients for whom spasticity is used to obtain increased function, such as maintenance of upright posture and balance in locomotion. Cardiovascular

Prolongation of the QT interval and bradycardia were noted in chronic toxicity studies in dogs a doses equal to the maximum human dose on a $\mathrm{mg} / \mathrm{m}^{2}$ basis. ECG evaluation was not performed in the controlled clinical studies. Reduction in pulse rate has been noted in association with decreases in blood pressure in the single dose controlled study (see Warnungs).

\section{Ophthalmic}

Dose-related retinal degeneration and corneal opacities have been found in animal studies at doses equivalent to approximately the maximum recommended dose on a $\mathrm{mg} / \mathrm{m}^{2}$ basis. There have been no reports of corneal opacities or retinal degeneration in the clinical studies.

Use in Elderly

Zanaflex should be used with caution in elderly patients because clearance is decreased four-fold Use in Children

There are no adequate and well-controlled studies to document the safety and efficacy of Zanaflex in children under 18 years in age.

\section{Use in Obstetrics}

The effect of Zanaflex on labor and delivery in humans is unknown

Reproduction studies performed in rats at a dose of $3 \mathrm{mg} / \mathrm{kg}$, equal to the maximum recommended human dose on a $\mathrm{mg} / \mathrm{m}^{2}$ basis and in rabbits at $30 \mathrm{mg} / \mathrm{kg}, 16$ times the maximum recommended human dose on a $\mathrm{mg} / \mathrm{m}^{2}$ basis did not show evidence of teratogenicity. Tizanidine at doses that are equal to and up to 8 times the maximum recommended human dose on a mg/m² basis increased gestation duration in rats. Prenatal and postnatal pup loss was increased and developmental retardation occurred. Postimplantation loss was increased in rabbits at doses of 1 $\mathrm{mg} / \mathrm{kg}$ or greater, equal to or greater than 0.5 times the maximum recommended human dose on a $\mathrm{mg} / \mathrm{m}^{2}$ basis. Zanaflex has not been studied in pregnant women. Zanaflex should be given to pregnant women only if clearly needed.

\section{Nursing Mothers}

It is not known whether Zanaflex is excreted in human milk, although as a lipid soluble drug, it might be expected to pass into breast milk.

\section{Patients with Special Diseases ano Conditions}

\section{Use in Renally Impaired Patients}

Zanaflex should be used with caution in patients with renal insufficiency ( $\mathrm{Clcr}<25 \mathrm{~mL} / \mathrm{min}$ ), as clearance is reduced by more than $50 \%$. In these patients, during titration, the individual doses should be reduced. If higher doses are required, individual doses rather than dosing frequency should be increased. These patients should be monitored closely for onset or inc rease in severity of the common adverse events (dry mouth, somriolence, asthenia and dizziness) as indicators of potential overdose.

\section{Use in Women Taking Oral Contraceptives}

Zanaflex should be used with caution in women taking oral contraceptives; as clearance of tizanidine is reduced by approximately $50 \%$ in such patients. In these patients, during titration, the individual doses should be reduced.

\section{Dependence Liability}

Monkeys were shown to self-administer tizanidine in a dose-dependent manner, and abrupt cessation of tizanidine produced transient signs of withdrawal at doses $>35$ times the maximum recommended human dose on a $\mathrm{mg} / \mathrm{m}^{2}$ basis. These transient withdrawal signs (increased locomotion, body twitching, and aversive behavior toward the observer) were not reversed by naloxone administration

\section{Drug Interactions}

In vitro studies of cytochrome P450 isoenzymes using human liver microsomes indicate that neither tizanidine nor its major metabolites are likely to affect the metabolism of other drugs metabolized by cytochrome P450 isoenzymes.

Acetaminophen: Zanaflex delayed the $T_{\text {mx }}$ of acetaminophen by 16 minutes. Acetaminophen did not affect the pharmacokinetics of Zanaflex.

Alcohol: Alcohol increased the AUC of Zanaflex by approximately $20 \%$ while also increasing its $C_{\max }$ by approximately $15 \%$. This was associated with an increase in side effects of Zanafiex. The CNS depressant effects of Zanaflex and alcohol are additive.

Oral Contraceptives: No specific pharmacokinetic study was conducted to investigate interaction between oral contraceptives and Zanaflex, but retrospective analysis of population pharmacokinetic data following single and multiple dose administration of $4 \mathrm{mg}$ Zanaflex showed that women concurrently taking oral contraceptives had $50 \%$ lower clearance of Zanaflex than women not on oral contraceptives.

Antihypertensives: In placebo-controlled clinical trials, Zanaflex has been administered concomitantly with antihypertensive medications in 30 patients. The aditition of Zanaflex to antihypertensive therapy was associated with a $20-30 \%$ increase in the incidence of clinically significant decreases in systolic or diastolic blood pressure compared with both placebo plus antihypertensive $(\mathrm{N}=36)$ and Zanaflex alone $(\mathrm{N}=226)$. 
Concurrent use of antihypertensive and Zanaflex therapy also resulted in an increase in reports of orthostatic hypotension. Lower initial doses and cautious dose titration should be considere when Zanaflex is to be administered to patients receiving antihypertensive therapy or if antihypertensive therapy is to be initiated in a patient receiving Zanaflex.

ADVERSE REACTIONS

In multiple dose, placebo-controlled clinical studies, 264 patients were treated with Zanaflex (tizanidine $\mathrm{HCl}$ ) and 261 with placebo. Adverse events, including severe adverse events, were more frequently reported with Zanaflex than with placebo.

\section{Common Adverse Events Leading to Discontinuation}

Forty five of $264(17 \%)$ patients receiving Zanaflex and 13 of $261(5 \%)$ patients receiving placebo in three multiple dose, placebo-controlled clinical studies discontinued treatment for adverse events. When patients withdrew from the study, they frequently had more than one reason fo discontinuing. The adverse events most frequently leading to withdrawal of Zanaflex treated patients in the controlled clinical studies were asthenia (weakness, fatigue and/or tiredness) (3\%), somnolence $(3 \%)$, dry mouth $(3 \%)$, increased spasm or tone $(2 \%)$ and dizziness $(2 \%)$.

\section{Most Frequent Adverse Clinical Events Seen in Association With the Use of Tizanidine}

In multiple dose, placebo-controlled clinical studies involving 264 patients with spasticity, the most frequent adverse events were dry mouth, somnolence/sedation, asthenia (weakness, fatigue and/or tiredness) and dizziness. Three quarters of the patients rated the events as mild to moderate and one quarter of the patients rated the events as being severe. These events appeared to be dose related.

\section{Adverse Events Beported in Controlled studies}

The events cited reflect experience gained under closely monitored conditions of clinical studie in a highly selected patient population. In actual clinical practice or in other clinical studies, these frequency estimates may not apply, as the conditions of use, reporting behavior, and the kinds o patients treated may differ. Table 1 lists treatment emergent signs and symptoms that were reported in greater than $2 \%$ of patients in three multiple dose, placebo-controlled studies who received Zanaflex where the frequency in the Zanaflex group was at least as common as in the placebo group. These events are not necessarily related to Zanaflex treatment. For comparison purposes, the corresponding frequency of the event (per 100 patients) among placebo treated patients is also provided.

TABLE 1: Multiple Dose, Placebo-Controlled Studies - Frequent $(>2 \%)$

\begin{tabular}{lcc} 
Adverse Events Reported for Which Zanaflex Incidence is Greater Than Placebo \\
\hline Event & Placebo & Zanaflex \\
& $\mathbf{N}=\mathbf{2 6 1}$ & $\mathbf{N = \mathbf { 2 6 4 }}$ \\
& $\%$ & $\%$ \\
\hline Dry mouth & 10 & 49 \\
Somnolence & 10 & 48 \\
Asthenia* & 16 & 41 \\
Dizziness & 4 & 16 \\
UTI & 7 & 10 \\
Infection & 5 & 6 \\
Constipation & 1 & 4 \\
Liver function tests abnormal & $<1$ & 3 \\
Vomiting & 0 & 3 \\
Speech disorder & 0 & 3 \\
Amblyopia (blurred vision) & $<1$ & 3 \\
Urinary frequency & 2 & 3 \\
Flu syndrome & 2 & 3 \\
SGPT/ALT increased & $<1$ & 3 \\
Dyskinesia & 0 & 3 \\
Nervousness & $<1$ & 3 \\
Pharyngitis & 1 & 3 \\
Rhinitis & 2 & 3 \\
\hline
\end{tabular}

dness

In the single dose, placebo-controlled study involving 142 patients with spasticity, the patients were specifically asked if they had experienced any of the four most common adverse events $d r y$ mouth, somnolence (drowsiness), asthenia (weakness, fatigue and/or tiredness), and dizziness. In addition, hypotension and bradycardia were observed. The occurrence of these adverse events are summarized in Table 2. Other events were, in general, reported at a rate of $2 \%$ or less.

\begin{tabular}{llcc} 
TABLE 2: & \multicolumn{4}{l}{ Single Dose, Placebo-Controlled Study (Common Adverse Events Reported) } \\
\cline { 2 - 5 } & $\begin{array}{c}\text { Placebo } \\
\mathbf{N = 4 8}\end{array}$ & $\begin{array}{c}\text { Zanaflex 8 } \\
\mathbf{N = 4 5}\end{array}$ & $\begin{array}{c}\text { Zanaflex 16 } \mathbf{~ m g} \\
\mathbf{N}=\mathbf{4 9}\end{array}$ \\
& $\%$ & 78 & $\%$ \\
\hline Somnolence & 31 & 76 & 92 \\
Dry mouth & 35 & 67 & 88 \\
Asthenia* & 40 & 22 & 78 \\
Dizziness & 4 & 16 & 45 \\
Hypotension & 0 & 2 & 33 \\
Bradycardia & 0 & 10 \\
\hline
\end{tabular}

\section{* weakness, fatigue and/or tiredness}

Other Adverse Events Observed During the Evaluation of Tizanidine

Zanaflex was administered to 1187 patients in additional clinical studies where adverse even information was available. The conditions and duration of exposure varied greatly, and included (in overlapping categories) double-blind and open-label studies, uncontrolled and controlled studies, inpatient and outpatient studies, and titration studies. Untoward events associated with this exposure were recorded by clinical investigators using terminology of their own choosing. Consequently, it is not possible to provide a meaningful estimate of the proportion of individuals experiencing adverse events without first grouping similar types of untoward events into a smaller number of standardized event categories.

In the tabulations that follow, reported adverse events were classified using a standard COSTARTbased dictionary terminology. The frequencies presented, therefore, represent the proportion of the 1187 patients exposed to Zanaflex who experienced an event of the type cited on at least one occasion while receiving tizanidine. All reported events are included except those al ready listed in Table 1. If the COSTART term for an event was so general as to be uninformative, it was replaced with a more informative term. It is important to emphasize that, although the events reported occurred during treatment with Zanaflex, they were not necessarily caused by it.

Events are further categorized by body system and listed in order of decreasing frequency according to the following definitions: frequent adverse events are those occurring on one or more occasions in at least $1 / 100$ patients (only those not already listed in the tabulated results from placebo-controlled studies appear in this listing); infrequent adverse events are those occurring in $1 / 100$ to $1 / 1000$ patients.

Body as a Whole: Frequent: fever: Infrequent: allergic reaction, moniliasis, malaise, abscess, neck pain, sepsis, cellulitis, death, overdose; Rare: carcinoma, congenital anomaly, suicide attempt. Cardiovascular System: Infrequent: vasodilatation, postural hypotension, syncope, migraine, arrhythmia; Rare: angina pectoris, coronary artery disorder, heart failure, myocardial infarct, phlebitis, pulmonary embolus, ventricular extrasystoles, ventricular tachycardia.

Digestive System: Frequent: abdomen pain, diarhea, dyspepsia; Infrequent: dysphagia, cholelithiasis, fecal impaction, flatulence, gastrointestinal hemorrhage, hepatitis, melena; Rare: gastroenteritis, hematemesis, hepatoma, intestinal obstruction, liver damage.

Hemic and Lymphatic System: Infrequent: ecchymosis, hypercholesteremia, anemia, hyperlipemia, leukopenia, leukocytosis, sepsis; Rare: petechia, purpura, thrombocythemia, thrombocytopenia.

Metabolic and Nutritional System: Infrequent: edema, hypothyroidism, weight loss; Rare: adrenal cortex insufficiency, hyperglycemia, hypokalemia, hyponatremia, hypoproteinemia, respiratory acidosis

Musculoskeletal System: Frequent: myasthenia, back pain; Infrequent: pathological fracture, arthralgia, arthritis, bursitis

Nervous System: Frequent: depression, anxiety, paresthesia; Infrequent: tremor, emotional lability, convulsion, paralysis, thinking abnormal, vertigo, abnormal dreams, agitation, depersonalization, euphoria, migraine, stupor, dysautonomia, neuralgia; Rare: dementia, hemiplegia, neuropathy.

Respiratory System: Infrequent. sinusitis, pneumonia, bronchitis; Rare: asthma.

Skin and Appendages: Frequent. rash, sweating, skin ulcer; Infrequent. pruritus, dry skin, acne, alopecia, urticaria; Rare; exfoliative dermatitis, herpes simplex, herpes zoster, skin carcinoma. Special Senses: Infrequent. ear pain, tinnitus, deafness, glaucoma, conjunctivitis, eye pain, optic neuritis, otitis media, retinal hemorrhage, visual field defect; Rare: iritis, keratitis, optic atrophy. Urogenital system: Intrequent: urinary urgency, cystitis, menorrhagia, pyelonephritis, urinary retention, kidney calculus, uterine fibroids enlarged, vaginal moniliasis, vaginitis; Rare: albuminuria, glycosuria, hematuria, metrorrhagia.

\section{SYMPTOMS AND TREATMENT OF OVERDOSAGE}

One significant overdosage of Zanaflex (tizanidine $\mathrm{HCl}$ ) has been reported. Attempted suicide by a 46 year-old male with multiple sclerosis resulted in coma very shortly after the ingestion of one hundred $4 \mathrm{mg}$ Zanaflex tablets. Pupils were not dilated and nystagmus was not present. The patient had marked respiratory depression with Cheyne-Stokes respiration. Gastric lavage and forced diuresis with furosemide and mannitol were instituted. The patient recovered several hours later without sequelae. Laboratory findings were normal.

Should overdosage occur, basic steps to ensure the adequacy of an airway and the monitoring of cardiovascular and respiratory systems should be undertaken. For the most recent information concerning the management of overdose, contact a poison control cente

DOSAGE AND ADMINISTRATION

A single oral dose of $8 \mathrm{mg}$ of Zanaflex (tizanidine $\mathrm{HCl}$ ) reduces muscle tone in patients with spasticity for a period of several hours. The effect peaks at approximately 1 to 2 hours and dissipates between 3 to 6 hours. Zanaflex dosing should be scheduled such that the peak effect coincides with activities for which relief of spasticity is most desirable. Effects are dose-retated. Although single doses of less than $8 \mathrm{mg}$ have not been demonstrated to be effective in controlled clinical studies, the dose-related nature of Zanaflex's common adverse events, particularly blood pressure reduction, make it prudent to begin treatment with single oral doses of $2 \mathrm{mg}$. Increase the dose gradually (2 to $4 \mathrm{mg}$ steps) to optimum effect (satisfactory reduction of muscle tone at a tolerated dose).

The dose can be repeated at 6 to 8 hour intervals, as needed to a maximum of three doses in 24 hours. The total daily dose should not exceed $36 \mathrm{mg}$.

Experience with single doses exceeding $8 \mathrm{mg}$ and daily doses exceeding $24 \mathrm{mg}$ is limited. There is essentially no experience with repeated, single, daytime doses greater than $12 \mathrm{mg}$ or total daily doses greater than $36 \mathrm{mg}$ (see WARnINGS)

PHARMACEUTICAL INFORMATION

Composition

Zanaflex (tizanidine hydrochloride) tablets are composed of the active ingredient, tizanidine hydrochloride (2.29 mg equivalent to $2 \mathrm{mg}$ tizanidine base) or ( $4.576 \mathrm{mg}$ equivalent to $4 \mathrm{mg}$ tizanidine base), and the inactive ingredients, silicon dioxide colloidal, stearic acid, microcrystalline cellulose and anhydrous lactose

Stability and Storage Recommendations

The product should be stored at $15-30^{\circ} \mathrm{C}\left(58-86^{\circ} \mathrm{F}\right)$. Dispense in containers with child resistant closure.

\section{Availability of Dosage Forms}

Zanaflex contains 2 or $4 \mathrm{mg}$ tizanidine as tizanidine hydrochloride for oral administration. The 2 mg Zanaflex has a bisecting score on one side and embossed with "A592" on the other. These white tablets are available in bottles of 150. The $4 \mathrm{mg}$ Zanaflex is embossed with "A594" on one side and cross-scored on the other. The white tablets are available in bottles of 150 .

FULL PRODUCT MONOGRAPH AVAILABLE UPON REQUEST.

References: 1. Wagstaff AJ, Bryson HM. Tizanidine: a review of its pharmacology, clinical efficacy and tolerability in the management of spasticity associated with cerebral and spinal disorders. Drugs. 1997;53(3);435-452. 2. Coward DM. Tizanidine: neuropharmacology and mechanism of action. Neurology. 1994;44(Suppl 9):S6-S11. 3. ZANAFLEX (tizanidine hydrochloride) Product Monograph. Shire BioChem Inc. 4. Nance PW, Bugaresti J, Shellenberger K, et al. Efficacy and safety of tizanidine in the treatment of spasticity in patients with spinal cord injury. Neurology. 1994:44 (Suppl 9): S44-S52. 5. Nance PW Sheremata WA, Lynch SG, et al. Relationship of the antispasticity effect of tizanidine to plasma concentration in patients with multiple sclerosis. Arch Neur. 1997;54:731-736. 6. Smith C, Birnbaum G, Carter JL, et al. Tizanidine treatment of spasticity caused by multiple sclerosis: results of a double-blind, placebo-controlled trial. Neurology 1994:44(Supp| 9):S34-S43. 7 Nance PW Tizanidine: An Alpha-2-Agonist imidazoline with antispasticity effects. Today's Therapeutic Trends. 1997;15(1):11-25.

Shire Shire Biochem Inc.
ZANAFLEX ${ }^{\text {is }}$ is a registered trademark of Elan Pharmaceuticals Inc. Shire Biochem Inc. is the Canadian distributor of ZANAFLEX 


\section{Interferon beta-1a}

\section{Rebif}

$1 \mathrm{mcg}(3 \mathrm{MIU}), 44 \mathrm{mcg}$ (12MIU) lyophilized powder for injection

$22 \mathrm{mcg}(6 \mathrm{M}) \mathrm{U}) / 0.5 \mathrm{~mL}, 44 \mathrm{mcg}$ (12MIU)/0.5mL liquid formulation for injection

\section{THERAPEUTIC CLASSIFICATION}

\section{Immunomodulator}

\section{ACTIONS AND CLINICAL PHARMACOLOGY}

Description: Rebif" (Interferon beta-1a) is a purified, sterile glycoprotein product produced by recombinant DNA techniques and formulated for use by injection. The active ingredient of Rebif is produced by genetically engineered Chinese Hamster Ovary (CHO) cells. Interferon beta-1a is a highly purified glycoprotein that has 166 amino acios and an aporoximate molecular weicht of 22,500 daltons. It contains a single $\mathbb{N}$ linked carbohydrate moiety attached to Asn-80 similar to that of natural human Interferon beta. The specific activity of Rebifi" is approximately 0.27 million international units (MIU)/mcg Interferon beta-1a. The unit measurement is derived by comparing the antiviral activity of the product to an in-house natural $\mathrm{h}$ IEN-beta $\mathrm{NH}$ standard that is obtained from human fibroblasts (BILS 11), which has been calibrated against the NIH natural hiFN-beta standard (GB 23-902-531). General: Interferons are a family of naturally nccurring proteins, which have molecular weights ranging from 15,000 to 21,000 daltons. Three major classes of interferons have been identified: alpha, beta, gamma. Interferon beta, Interferon alpha and Interferon gamma have overlapping yet distinct biologic activities.

Interteron beta-1a acts through various mechanisms:

- Immunomodulation through the induction of cell membrane components of the major histocompatibility complex i.e.. MHC Class I antigens, an increase in natural killer (NK) cell activity, and an inhibition of IFN-K induced MHC Class II antigen expression, as well as a sustained reduction in TNF level.

- Antiviral effect through the induction of proteins like 2'-5' oligoadenylate synthetase and $p 78$

- Antiproliferative effect through direct cytostatic activity and indirect through antitumoral immune response enhancement.

The mechanism of action of Rebif" in relapsing-remitting multiple sclerosis is still under investigation

\section{Relapsing-Remitting Multiple Sclerosis}

Two pivotal studies, including a total of 628 patients, evaluated the long-term safety and efficacy of Rebit when administered subcutaneously three times week y to relapsing-remitting multiple sclerosis patients. The results indicate that Rebif ${ }^{\text {a }}$ alters the natural course of relapsing-remitting multiple sclerosis. Etficacy was demonstrated with respect to the 3 maior aspects of this disease: disahilitity (patients EDSS 0-5), exacerbations, and burden of disease and activity as measured by MRI scans.

\section{PRISMS STUDY}

In the larger trial, a total of 560 patients diagnosed with clinically definite or laboratorysupported relapsing-remitting multiple sclerosis EDSS 0-5 with at least a 1-year history before study entry, were enrolled and randomized to the 3 treatments (placebo, $22 \mathrm{mcg}$ (6MUU) Rebite or $44 \mathrm{mcg}$ (12MIU) Rebif') in a ratio of 1:1:1. About 90\% of patients completed the 2 years of treatment, and very tew patients withdrew from the study due to adverse events.

The main criteria for inclusion were:

- history of 2 or more acute exacerbations in the 2 years prior to study entry

- no previous systemic treatment with interferon

- no treatment with corticosteroids or ACTH in the 2 months preceding study entry

- no exacerbation in the 8 weeks prior to study entry.

Patients were evaluated at 3 -month periods, during exacerbations and coinciding with MRI scanning. Each patient underwent cranial proton density// $T_{2}$-weighted (PD/T2) MRI scans at baseline and every 6 months during the study. $A$ subset of patients underwent PD/T2 and $T_{1}$-weighted (T1) Gd-MRI scans one month betore the start of treatment, at baseline and then monthly until the end of the first 9 months of treatment. Of those, another subset of 39 continued with the monthly scans throughout the 24 month treatment period

This study demonstrated that Rebit? at a total dose of 66 or 132 mag weekly, significantly improved all 3 major outcomes, including exacerbation rate, disease activity and burden of disease as measured by MEI scanning and progression of disability. In addition, the study showed that Rebif" is effective in delaying the progression in disability in patients with an EDSS of 4.0 or higher who are known to progress more rapidly. Also, the drug reduced the requirements for steroids to treat multiple sclerosis and, a $132 \mathrm{mcg}$ weekly Rebif" reduced the number of hospital izations for multiple sclerosis.

\begin{tabular}{|c|c|c|c|c|c|}
\hline \multirow{3}{*}{$\begin{array}{l}\text { Eftect on exacerbation } \\
\text { Efficacy parameters }\end{array}$} & \multirow{2}{*}{\multicolumn{3}{|c|}{ Treatment Groups }} & \multirow{2}{*}{\multicolumn{2}{|c|}{$p$-value }} \\
\hline & & & & & \\
\hline & Placebo & $\begin{array}{l}\text { Rebif } \\
66 \mathrm{mco} / \mathrm{wk}\end{array}$ & $\begin{array}{c}\text { Retiff } \\
1322^{\mathrm{mc} / \mathrm{wk}}\end{array}$ & $\begin{array}{l}\text { Rebis } 66 \text { moglwh } \\
\text { vs placebo }\end{array}$ & $\begin{array}{l}\text { Tebiff } 132 \text { mcgh } \\
\text { vs placebo }\end{array}$ \\
\hline \begin{tabular}{|l} 
Mean * exacerbations \\
over the 2 year study
\end{tabular} & 2.56 & 1.82 & 1.73 & 0.0002 & $<0.0001$ \\
\hline 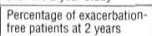 & $14.6 \%$ & $25.6 \%$ & $32.0 \%$ & 0.0140 & $<0.0001$ \\
\hline \begin{tabular}{|l}
$\begin{array}{l}\text { Medan time to first } \\
\text { exacerbation (months) }\end{array}$ \\
\end{tabular} & 4.5 & 7.6 & 9.6 & 0.0008 & $<0.0001$ \\
\hline \begin{tabular}{|l|}
$\begin{array}{l}\text { Medan time to second } \\
\text { exacerbation (monttis) }\end{array}$ \\
\end{tabular} & 15.0 & 23.4 & $>24^{x}$ & 0.0020 & $<0.0001$ \\
\hline $\begin{array}{l}\text { Mean y of moderate and } \\
\text { severef exacarbations during } \\
\text { the } 2 \text { year period }\end{array}$ & 0.99 & 0.71 & 0.62 & 0.0025 & 0.00 \\
\hline
\end{tabular}

\begin{tabular}{|c|c|c|c|c|c|}
\hline \multirow[t]{2}{*}{ Efficacy parameters } & \multicolumn{3}{|c|}{ Treatment Grou } & \multicolumn{2}{|c|}{ p-value } \\
\hline & Placebo & $\begin{array}{l}\text { Rebie" } \\
66 \text { meg/w }\end{array}$ & $\begin{array}{l}\text { Riskis } \\
132 \text { megivk }\end{array}$ & $\begin{array}{l}\text { Rebif } 66 \text { mcg/wh } \\
\text { vs placebo }\end{array}$ & $\begin{array}{l}\text { Rebif } 132 \mathrm{mag} / \mathrm{w} \\
\text { vs placteoc }\end{array}$ \\
\hline $\begin{array}{l}\text { Time to confirmed } \\
\text { progoression in disability, } \\
\text { first quartiele (montts) }\end{array}$ & 11.8 & 18.2 & 21.0 & 0.0398 & 0.0136 \\
\hline $\begin{array}{l}\text { Median change in EDSS } \\
\text { score at ? vears }\end{array}$ & 0.5 & 0 & 0 & 0.0263 & 0.0519 \\
\hline
\end{tabular}

\begin{tabular}{|c|c|c|c|c|c|}
\hline \multirow[t]{2}{*}{ Efficacy parameters } & \multicolumn{3}{|c|}{ Treatment Groups: } & \multicolumn{2}{|c|}{$\mathrm{p}$-value } \\
\hline & Placebo & $\begin{array}{l}\text { Rabirs } \\
66 \mathrm{mcg} / \mathrm{umk}\end{array}$ & $\begin{array}{c}\text { Rebif } \\
132 \text { moghwk }\end{array}$ & $\begin{array}{l}\text { Rebif } 66 \mathrm{mcy} / \mathrm{ht} \\
\text { vs placebo }\end{array}$ & $\begin{array}{l}\text { Rebif } 132 \text { mcgiwk } \\
\text { vs placeto }\end{array}$ \\
\hline $\begin{array}{l}\text { Burden of disease (BOD) } \\
\text { Median \% change }\end{array}$ & +10.9 & -1.2 & -3.8 & $<0.0001$ & $<0.0001$ \\
\hline \multicolumn{6}{|c|}{ MAl activity } \\
\hline \multicolumn{6}{|c|}{ All patients } \\
\hline $\begin{array}{l}\text { Number of attive lesions } \\
\text { (par } 6 \text { montrss }\end{array}$ & 2.25 & 0.75 & 0.5 & $<0.0001$ & $<0.0001$ \\
\hline$\%$ active scans & $75 \%$ & $50 \%$ & $25 \%$ & $<0.0001$ & 0.0001 \\
\hline \multicolumn{6}{|c|}{ Patients with monthly MRIs $<9$ months $)$} \\
\hline $\begin{array}{l}\text { Number active lesions } \\
\text { (per month) }\end{array}$ & 0.88 & 0.17 & 0.11 & $<0.0001$ & $<0.0001$ \\
\hline$\%$ active scans & $44 \%$ & $12.5 \%$ & $11 \%$ & $<0.0001$ & $<0.0001$ \\
\hline \multicolumn{6}{|c|}{ Patients with monthly MRIs throughout the study ( 2 years) } \\
\hline Number active lesions & 0.9 & 0.1 & 0.02 & 0.0905 & 0.0105 \\
\hline$\%$ octives & $52 \%$ & $10 \%$ & $2 \%$ & 092 & 2.01 \\
\hline
\end{tabular}

Requirement for steroids: The proportion of patients requiring steroids for MS (exclud ng non-MS indications) was higher in the placebo group (more than 50\%) than in either of the 2 Rebif groups (around $40 \%$ in each group).

Hospitalization for multiple sclerosis: The observed mean numbers of hospitalizations or MS in the Rebifs 66 and $132 \mathrm{mcg}$ weekly groups represented reductions of $21 \%$ and $48 \%$, respectively, from that in the placebo group.

Cohort of patients with high baseline EDSS (baseline EDSS >3.5):

Additional analyses were conducted in order to study the efficacy of Rebits in populafions of patients with adverse predictive outcome factors, who were likely to be at higher risk for progression in disability. The primary predictive factor examined was baseline EDSS >3.5. Patients in this cohort have a more severe degree of disability and are at higher risk for progression than those with lower EDSS: natural history studies have shown that patients at EDSS levels of 4.0 to 5.0 spend less time at these EDSS levels than at lower levels of disability. Treatment with Rebif" at both doses significantly reduced the mean exacerbation count per patient compared to placebo treatment. Progression in this group of patients is of particular concern, as it involves development of difficulty in ambulation. The $132 \mathrm{mcg}$ weekly dose significantly prolonged time to confirmed progression whereas the 66 mcg weekly dose did not. Both doses of Rebif" significantly affected percent change from baseline in MRI burden of disease in the high-EDSS cohort, and the $132 \mathrm{mcg}$ weekly dose significantly reduced the number of $\mathrm{T}$ active lesions in this population. The efficacy results in this cohort of patients with established disability confirms that the 132 mco weekly dose has a marked effect on progression in disability and the underlying pathology of the disease Effect on exacerbation (High-EBSS cohort)

\begin{tabular}{|c|c|c|c|}
\hline Efficacy parameters & Placebo & \begin{tabular}{|c|} 
Rebitis \\
66 mcg/week
\end{tabular} & $\begin{array}{c}\text { Rebifo } \\
132 \text { mcg/week }\end{array}$ \\
\hline Mean \# exacerbations & 307 & 1.83 & 1.22 \\
\hline$\#$ and \% of exacerbation-free patients & $2(7 \%)$ & $7(20 \%)$ & $10(32 \%)$ \\
\hline p-value * (Rebit” vs placebo) & & $p=0.0121$ & $p=0.0002$ \\
\hline
\end{tabular}

Progression in disability by one point on the EDSS (High-EDSS cohort)
\begin{tabular}{|l|c|c|c|c|}
\hline Treatment Group & $\begin{array}{c}\% \text { of } \\
\text { progressors }\end{array}$ & \multicolumn{3}{|c|}{ Time to Progression } \\
\cline { 3 - 6 } & $56 \%$ & 28 & 638 & 218 \\
\hline Placebo & patients & Median (days) & 01 (days) \\
\hline Rebiff 66 mcg wreekly & $41 \%$ & 35 & not reacthed & 225 \\
\hline Rebif 132 mcg weekly & $27 \%$ & 31 & not reactied & 638 \\
\hline
\end{tabular}

Excludes patients lost to

Progression in disability: statistical comparisons
\begin{tabular}{|l||c|c|}
\hline $\begin{array}{l}\text { Test } \\
\text { Log-rank test }\end{array}$ & 66 moup Comparison & $p$-veluek \\
& 132 mog weekly vs placebo & $p=0.4465$ \\
\hline
\end{tabular}

MRI Burden of Disease: \% Change (High-EDSS cohort)
\begin{tabular}{|l|c|c|c|}
\hline & Placebo & $\begin{array}{c}\text { Rebif } \\
66 \mathrm{mcg} / \text { week }\end{array}$ & $\begin{array}{c}\text { Rebife } \\
132 \text { mcg/week }\end{array}$ \\
\hline Burden of disease - Median \% change & 5.3 & -2.3 & 6.9 \\
\hline Burden of disease - Mean \% change & 12.2 & 13.6 & 0.7 \\
\hline p-value* (Rebif* vs placebo) & & $p=0.0146$ & $p=0.0287$ \\
\hline
\end{tabular}
p-value* (Rebif vs place be)

\section{Number of T2 Active Lesions (High-EDSS cohort)}

\begin{tabular}{|c|c|c|c|}
\hline & \multicolumn{2}{|c|}{ Number of T2 Active Lesions } & \multirow[b]{2}{*}{$p$-value ${ }^{*}$} \\
\hline Treatment Group & Median & Mean & \\
\hline Placebo & 19 & 2.6 & \\
\hline Rebift" 66 mcg weekly & 0.9 & 1.7 & $\begin{array}{l}\begin{array}{l}\text { Rebif } \\
p=0.0612\end{array} \\
p \text { mog vs placebo: }\end{array}$ \\
\hline Rebift 132 mcg weekly & 0.5 & 0.9 & $\begin{array}{l}\text { Rebif" } 132 \mathrm{mcg} \text { vs placebo } \\
p=0.0042\end{array}$ \\
\hline
\end{tabular}

\section{*ANOVA on the ranks.}

\section{CROSS-OVER STUDY}

The other study was an open cross-over design, with MRI evaluations conducted in blinded fashion. Enrolled in this study were 68 patients between the ages of 15 and 45 years, with clinically definite and/or laboratory supported relapsing-remitting MS for up to 10 years in duration. The main inclusion criteria included:

- at least 2 relapses in the previous 2 years

- EDSS score between 1-5

- no corticosteroid or plasmapheresis treatments or administration of gamma globulins within the 3 months prior to study

- no immunomodulating or immunosuppressive therapy for the 6 months prior to the study

\section{- absence of HBSAg and HIV antibodies.}

Once enrolled, patients remained under clinical observation for 6 months with assessments of their neurological status and other parameters, and extensive monitoring of exacerbations. Patients were then randomized to treatment with either $11 \mathrm{mcg}$ (3MIU) $(\mathrm{n}=35)$ or $33 \mathrm{mcg}(9 \mathrm{M} / \mathrm{U})(\mathrm{n}=33)$ of Rebif ${ }^{\text {, }}$, self-administered subcutaneously three times per week. The total dose was therefore 33 or 99 mcg weekly

\section{Six-months observation vs six-months treatment:}

Treatment with Rebite at both doses used in this study, achieved a statistically signiff cant reduction in both the MRI evidence of MS activity in the brain and the clinica relapse rate versus the corresponding observation periods. This pattern of improvement was also reflected in additional MRI measures. In the biannual $T_{2}$-weighted scans, a reduction in the mean number of new lesions and in the mean number of enlarging lesions was demonstrated

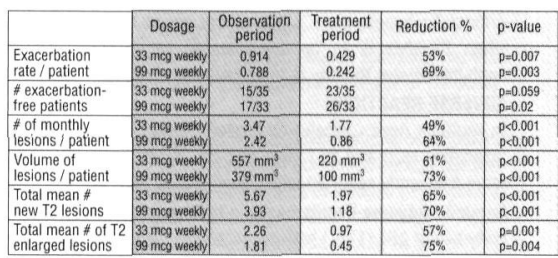

Two-year results: At the end of this study, 62 patients continued treatment for a further 18 months. Each of these patients continued to receive the dose to which they were randomized. Validation of the results of the 2 year treatment period is ongoing, however the results from the continuation of treatment at both doses demonstrate that Rebif" maintained its dose-dependent effect in reducing the relapse rate and the brain lesion volume detected by $T_{2}$ weight MRI scans compared to the observation period, which corroborates the findings of the longer, placebo-controlled study

Condyloma acuminatum: The results from four double-blind, placebo-controlled studies, including 349 patients (aged 17-62), each reveal that Rebif", when injected intralesionally at a dose of $3.67 \mathrm{mcg}(1 \mathrm{MIU}) /($ lesion 3 times per week for 3 weeks. is efficacious in the treatment of condyloma ac uminatum in men and wamen. This efficacy is evidenced by both the induction of complete disappearance of lesions as well as the reduction in the area of lesions. The majority of treated patients in these studies had recurrent warts that had failed previous treatments. The number of lesions treated per patient was between 3 and 8 , as stated in the summary table below.
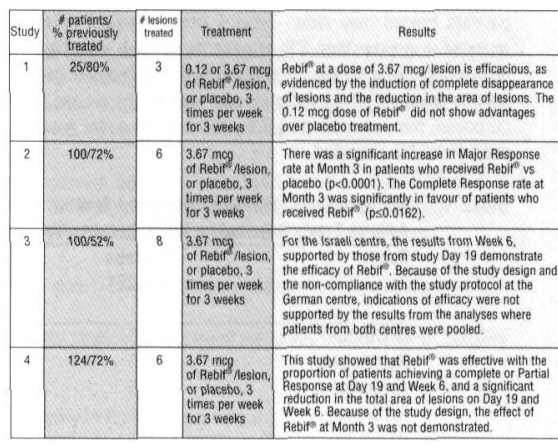

\section{INDICATIONS AND CLINICAL USE}

Multiple Sclerosis: Rebifs (Interferon beta-1a) is indicated for the treatment of relapsing-remitting multiple sclerosis in patients with an EDSS between 0 and 5.0 to reduce the number and severity of clinical exacerbations, slow the progression o physical disability, reduce the requirement for steroids, and reduce the number of hospitalizations for treatment of multiple sclerosis. The efficacy has been confirmed by $T_{1}-G d$ enhanced and $T_{2}$ (burden of disease) MRI evaluations. Evidence of efficacy beyond 2 years is not known since the primary evidence of efficacy derives from 2-year trials Condyloma acuminatum: Rebife is best suited for the patient who has less than nine lesions, and who has failed several prior treatments. In the case of patients with nine or more lesions, if the first Rebif" treatment is successful, the remaining lesions could be treated with a second course of Rebife therapy. Rebits should also be considered for the treatment of condyloma acuminatum in patients for whom the side-effects from other treatments, e.g. scarring, are of concern. While not all patients who were treated with Rebif attained a complete response, patients whose lesions decreased in size and had at least a partial response may have also benefitted from treatment because lesion shrinkage may facilitate subsequent management with other therapies, as has been reported with IFN-alpha.

CONTRAINDICATIONS: Rebifi" (Interieron beta-1a) is contraindicated in patients with a known hypersensitivity to natural or recombinant interferon beta, albumin (human), o any other component of the tormulation.

WARNINGS: Rebifi" (interteron beta-1a) should be used under the supervision of a physicia

Relapsing-Remitting Multiple Sclerosis: Depression and suicidal ideation ar known to occur at an increased frequency in the multiple sclerosis population. The us of Rebits has not been associated with an increase in the incidence and/or severity of depression, or with an increased incidence of suicide attempts or suicide. In the relapsing-remitting multiple sclerosis study, a similar incidence of depression was seen in the placebo-treated group and in the two Rebif patient groups. Nevertheless, patients with depression should be closely monitored for signs of significant worsening of depression or suicidal ideation. The first injection should be performed under the supervision of an appropriately qualified health care protessional.

Condyloma: All injections should be administered by a qualified health care profes-

\section{PRECAUTIONS}

General: Patients should be informed of the most common adverse events associated with interferon beta administration, including symptoms of the flu-like syndrome (se Adverse Reactions). These symptoms tend to be most prominent at the initiation of therapy and decrease in frequency and severity with continued treatment.

Based on the results of clinical trials of Rebif in MS, in which more than 500 patient were randomized to drug treatment, there is no indication of an increased risk of seizure disorder with Rebife therapy. However, since seizures have been reported with other interferon therapies, caution should be exercised when administering interferon-beta-1 to patients with pre-existing seizures disorder. For patients without a pre-existing seizure disorder who develop seizures during therapy, an etiologic basis should be established and appropriate anti-convulsant therapy instituted prior to considering resuming treatment with Rebife. The effect of Rebif" administration on the medical management of patients with seizure disorder is unknown

Serum neutralising antibodies against Rebits (interferon beta-1a) may develop. The precise incidence and clinical significance of antibodies is as yet uncertain (see ADVERSE REACTIONS).

Hypersensitivity reactions, both local and systemic, have developed during therapy with Rebif:

Intralesional injections can be painful to some patients treated for condyloma acuminata In such cases an anaesthetic cream such as lidocaine-prilocaine can be used.

Pregnancy and Lactation: Rebife should not be administered in case of pregnanc and lactation. There are no studies of interteron beta-1a in pregnant women. At high 
doses in monkeys, abortifacient effects were observed with other interferons. Fertile women receiving Rebifs should take appropriate contraceptive measures. Patients planning for pregnancy and those becoming pregnant should be intormed of the potent hazards of interferons to the toetus and Rebife should be discontinued. It is not known whether Rebit is excreted in human milk. Because of the potential for serious advers reactions in nursing infants, a decision should be made either to discontinue nursing or to discontinue Rebite therapy.

Pediatric use: There is no experience with Rebif in children under 16 years of ag with multiple sclerosis or condyloma and therefore Rebif" should not be used in this population

Patients with Special Diseases and Conditions: Caution should be used and close monitoring considered when administering Rebif to patients with severe renal an hepatic failure, patients with severe myelosuppression, and depressive patients

Drug Interaction: No formal drug interaction studies have been conducted with Rebif? in humans. Interferons have been reported to reduce the activity of hepatic cytochrom p450-dependent enzymes in humans and animals. Caution should be exercised when administering Rebif in combination with medicinal products that have a narro therapeutic index and are largely dependent on the hepatic cytochrome p450 system for clearance, e.g. antiepileptics and some classes of antidepressants. The interaction of Rebit' with corticosteroids or ACTH has not been studied systematically. Clinica studies indicate that multiple sclerosis patients can receive Rebif and corticosteroids or ACTH during relapses. Rebife should not be mixed with other drugs in the same syringe. Laboratory Tests

Relapsing-Remitting Multiple Sclerosis: Laboratory abnormalities are associate with the use of interferons. Therefore, in addition to those laboratory tests normally required for monitoring patients with multiple sclerosis, complete and differential white blood cell counts, platelet counts and blood chemistries, including liver and thyroid function tests are recommended during Rebif ${ }^{8}$ therapy. These tests should be pertormed at months 1,3 and 6 , and every 6 months thereatte

Condyloma acuminata: Same as relapsing-remitting multiple sclerosis but tend not to be as severe because of dose and length of treatment.

Information to be provided to the patient: Flu-like symptoms (fever, headach chills, muscle aches) are not uncommon following initiation of therapy with Rebif Acetaminophen may be used for relief of flu-like symptoms. Patients should contact their physician or pharmacist if they experience any undesirable effects. Depression may occur in patients with relapsing-remitting multiple sclerosis and may occur whil patients are taking Rebif? Patients should be asked to contact their physician should they feel depressed. Patients should be advised not to stop or modify their treatment uniess instructed by their physician. Instruction on self-injection technique and procedures: patients treated for relapsing-remitting multiple sclerosis should be instructed in the use of aseptic technique when administering Rebife. Appropriate instruction for reconstitution of Rebife and self-iniection should be given including careful review of the Rebif" patient leaflet. The first injection should be performed under the supervision of appropriately qualified healthcare professional. Injection sites should be rotated at each injection. Injections may be given prior to bedtime as this may lessen the perception of side effects. Patients should be cautioned against the re-use of needles or syringes an instructed in safe disposal procedures. A puncture resistant container for disposal of used needles and syringes should be supplied to the patient along with instructions for sate disposal of full containers. In the controlled MS trial reported injection site reactions were commonly reported by patients at one or more times during therapy. In general they did not require discontinuation of therapy, but the nature and severity of all reported reactions should be carefully assessed. Patient understanding and use of aseptic selfinjection technique and procedures should be periodically re-evaluated.

\section{ADVERSE REACTIONS}

Multiple Sclerosis: As with other interferon preparations, flu-like symptoms are not uncommon. The use of Interferon beta may cause flu-like syndrome, asthenia, pyrexia, chills, arthralgia, myalgia, headache, and injection site reactions.

Less frequent adverse reactions include cold sores, stuffy nose, light headedness, mucosal irritation, haematological disorders (leukopenia, Iymphopenia, granulocytopenia), and alterations in liver function tests such as elevated SGOT and SGPT. These effects are usually mild and reversible. Tachyphylaxis with respect to most side-effects is well recognized. Fever and flu-like symptoms can be treated with acetaminophen. Depending on the severity and persistence of the side-effects, the dose may be lowered or temporarily interrupted, at the discretion of the physician. Most injection site reactions are mild to moderate. Rare cases of skin ulceration/necrosis at the site of injection have been reported with long term treatment. The most frequently reported advers events and the most common laboratory abnormalities observed during the placeho-controlled study in relapsing-remitting multiple sclerosis ( 560 patients, 2 years treatment) are presented in the table below for patients on placebo and Rebifo (Interieron beta-1a). The rrequencies are patients who reported this event at least once during the study, as a percentage of the total number of patients, by study-arm.

\begin{tabular}{|c|c|c|c|}
\hline & Placebo & $\begin{array}{l}\text { Rebif } \\
66 \text { mcg weekly }\end{array}$ & $\begin{array}{l}\text { Rebif } \\
132 \text { mca weekly }\end{array}$ \\
\hline \multicolumn{4}{|c|}{ Adverse Events } \\
\hline Injection site disorders (all) & 38.5 & 89.9 & 92.4 \\
\hline Upper respiratory tract intections & 85.6 & 75.1 & 74.5 \\
\hline Headache & 626 & 64.6 & 70.1 \\
\hline Flu-like symptoms & 513 & 56.1 & 587. \\
\hline Fatigue & 35.8 & 32.8 & 413 \\
\hline Depression & 27.8 & 20.6 & 23.9 \\
\hline Fever & 15.5 & 24.9 & 27.7 \\
\hline Back pain & 214 & 19.6 & 23.4 \\
\hline Myalgia & 19.8 & 24.9 & 25.0 \\
\hline Nausea & 23.0 & 24.9 & 245 \\
\hline Insomnia & 21.4 & 19.6 & 23.4 \\
\hline \begin{tabular}{|l|l|} 
Diarthoea \\
\end{tabular} & 18.7 & 17.5 & 19.0 \\
\hline \multicolumn{4}{|c|}{ Laboratory Test Abnormalifites } \\
\hline Lymphopenia & 11.2 & 20.1 & 28.8 \\
\hline Leukopenia & 3.7 & 12.7 & 22.3 \\
\hline Granulocytopenia & 3.7 & 11.6 & 15.2 \\
\hline AST increase & 3.7 & 10.1 & 17.4 \\
\hline ALt increase & 4.3 & 19.6 & 27.2 \\
\hline
\end{tabular}

For the events in bold, observed differences reached statistical significance as compared to placebo

The adverse events experienced during the study are listed below, by WHOART System Organ Class. The most common amongst the injection site reactions was in the form 0 mild erythema. The majority of the other injection site reactions were also mild in the 2 Rebif groups. Necrosis was reported in 8 patients treated with Rebife. Two of these patients were in the $66 \mathrm{mcg}$ weekly and six in the $132 \mathrm{mcg}$ weekly groups. All patients completed the planned treatment period, with only 1 requiring temporary dose reductions and another patient stopping treatment for 2 weeks. Those that required treatment, received antibiotics.
Adverse events experienced by patients enrolled in the double-blind, placebo-controlled,
multiple scelerosis study

\begin{tabular}{|c|c|c|c|c|}
\hline Body System & $\begin{array}{c}\text { Preferred } \\
\text { term }\end{array}$ & $\begin{array}{l}\text { Placebo } \\
(\mathrm{n}=187)\end{array}$ & \begin{tabular}{|l|} 
Rebit' $66 \mathrm{mcg}$ \\
weekly $(\mathrm{n}=189)$
\end{tabular} & $\begin{array}{l}\text { Rebie } 112 \mathrm{mcg} \\
\text { weekly }(n=184)\end{array}$ \\
\hline \multirow{2}{*}{$\begin{array}{l}\text { Application Site } \\
\text { Disorders }\end{array}$} & \multirow{2}{*}{$\begin{array}{l}\text { Injection site } \\
\text { intlammatition(a)(b) } \\
\text { injection site reaction (a)(b) } \\
\text { injection site pain (b) }\end{array}$} & $15.0 \%$ & $65.6 \%$ & $65.8 \%$ \\
\hline & & $\begin{array}{l}13.4 \% \\
1.4 \%\end{array}$ & $\begin{array}{l}31.2 \% \\
201 \% \%\end{array}$ & $\begin{array}{l}34.8 \% \% \\
22.8 \%\end{array}$ \\
\hline $\begin{array}{l}\text { Body as a Whole - } \\
\text { General Disorders }\end{array}$ & 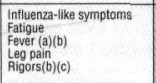 & $\begin{array}{l}51.3 \% \\
\text { 35.3\% } \\
15.5 \% \\
14.4 \% \\
5.3 \%\end{array}$ & $\begin{array}{l}561 \% \\
32.8 \% \\
249 \% \\
1091 \% \\
63 \%\end{array}$ & $\begin{array}{l}58.7 \% \\
41.3 \% \\
27.7 \% \\
13.0 \% \\
13.0 \%\end{array}$ \\
\hline $\begin{array}{l}\text { Centr \& Periph } \\
\text { Nervous System } \\
\text { Disorders }\end{array}$ & \begin{tabular}{|l} 
Headache \\
Ditriness \\
Paraesthesia \\
Hyyopaestresia
\end{tabular} & $\begin{array}{l}82.6 \% \% \\
176 \% \% \\
187 \% \\
12.8 \%\end{array}$ & $\begin{array}{l}64.6 \% \% \\
143 \% \% \\
196 \% \\
12.2 \%\end{array}$ & $\begin{array}{l}70.1 \% \\
16.3 \% \\
16.3 \% \\
7.6 \%\end{array}$ \\
\hline \begin{tabular}{|l} 
Respiratory \\
System \\
Disorders
\end{tabular} & $\begin{array}{l}\text { Rhinitits } \\
\text { Upper Resp Iract Intection } \\
\text { Praryngitis (b) } \\
\text { Coughing } \\
\text { Bronchitis }\end{array}$ & $\begin{array}{l}59.9 \% \\
32.6 \% \\
38.5 \% \\
21.1 .4 \% \\
9.6 \%\end{array}$ & $\begin{array}{l}52.4 \% \\
36.0 \% \\
34.9 \% \\
14.8 \% \\
10.6 \%\end{array}$ & $\begin{array}{l}50.5 \% \% \\
28.3 \% \\
28.3 \% \\
19.0 \% \\
9.2 \%\end{array}$ \\
\hline $\begin{array}{l}\text { Gastro-Intestinal } \\
\text { System } \\
\text { Disorders }\end{array}$ & $\begin{array}{l}\text { Nausea } \\
\text { Abdeminal pain } \\
\text { Diarthoea } \\
\text { Vomiting }\end{array}$ & $\begin{array}{l}22.0 \% \\
17.1 \% \\
187 \% \\
12.3 \%\end{array}$ & $\begin{array}{l}24.9 \% \\
22.2 \% \\
17.5 \% \\
127 \%\end{array}$ & $\begin{array}{l}24.5 \% \\
19.6 \% \\
19.0 \% \\
12.0 \%\end{array}$ \\
\hline \begin{tabular}{|l} 
Musculo-Skeletal \\
System \\
Disorders \\
\end{tabular} & 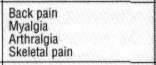 & $\begin{array}{l}198 \% \\
198 \% \\
17,17 \% \\
102 \% \\
\end{array}$ & $\begin{array}{l}23.3 \% \\
24.9 \% \\
15.3 \% \\
14.8 \%\end{array}$ & $\begin{array}{l}24.5 \% \\
25.0 \% \\
19.0 \% \\
9.8 \%\end{array}$ \\
\hline $\begin{array}{l}\begin{array}{l}\text { Psychiatric } \\
\text { Disorders }\end{array} \\
\end{array}$ & $\begin{array}{l}\text { Depression } \\
\text { Insomnia }\end{array}$ & $\begin{array}{l}27.8 \% \\
2.4 \%\end{array}$ & $\begin{array}{l}20.6 \% \\
19.6 \%\end{array}$ & $\begin{array}{l}23.9 \% \\
23.4 \%\end{array}$ \\
\hline $\begin{array}{l}\text { White Cell \& Res } \\
\text { Disorders }\end{array}$ & 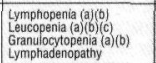 & $\begin{array}{l}31.2 \% \\
3.37 \% \\
3.7 \% \\
8.0 \%\end{array}$ & $\begin{array}{l}20.1 \% \\
12.7 \% \\
11.6 \% \\
11.1 \% \%\end{array}$ & $\begin{array}{l}28.8 \% \\
223 \% \\
15.2 \% \\
12.0 \%\end{array}$ \\
\hline \begin{tabular}{|l|} 
Skin \& \\
Appendages \\
Disorders
\end{tabular} & Pruritus & $11.8 \%$ & $9.0 \%$ & $12.5 \%$ \\
\hline $\begin{array}{l}\text { Liver \& Biliary } \\
\text { System } \\
\text { Disorders }\end{array}$ & $\begin{array}{l}\text { SGPT increased (a)(b) } \\
\text { SGT increased (a)(b)(c) }\end{array}$ & $\begin{array}{l}4.3 \% \% \\
37 \%\end{array}$ & $\begin{array}{l}19.6 \% \\
10.1 \% \%\end{array}$ & $\begin{array}{l}27.2 \% \\
17.4 \%\end{array}$ \\
\hline $\begin{array}{l}\text { Urinary System } \\
\text { Disorders }\end{array}$ & Urinary tract infection & $18.7 \%$ & $18.0 \%$ & $16.8 \%$ \\
\hline \begin{tabular}{|l|} 
Vision \\
Disorders
\end{tabular} & Vision abnormal & $7.0 \%$ & $7.4 \%$ & $13.0 \%$ \\
\hline $\begin{array}{l}\begin{array}{l}\text { Secondary } \\
\text { Terms }\end{array} \\
\end{array}$ & Fall & $160 \%$ & $16.9 \%$ & $15.8 \%$ \\
\hline
\end{tabular}

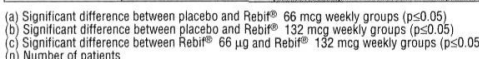

In addition to the above listed adverse events, the following events have been experienced less frequently, in one or both of the relapsing-remitting multiple sclerosis studies: asthenia, fluid retention, anorexia, gastroenteritis, heartburn, paradentium affections, dental abcess or extraction, stomatitis, glossitis, sleepiness, anxiety, Irritability, confusion, Iymphadenopathy, weight gain, bone fracture, dyspnoea, cold sores, fissure at the angle of the mouth, menstrual disorders, cystitis, vaginitis.

Immunogenicity: Antibodies to IFN-beta were tested in all patients pre-entry, and Months 6,12, 18 and 24. The results of testing for the presence of neutralizing antibodies (NAb) are shown below.

Percentage of patients positive for neutralizing antibodies
\begin{tabular}{|c|c|c|}
\hline Placebo & Rebif 66 meg weekly & Rebif 132 mcg weekly \\
\hline $0 \%$ & $24 \%$ & $12.5 \%$ \\
\hline
\end{tabular}

Due to concern about the potential impact of neutralizing antibody formation on efficacy, exacerbation counts (primary endpoint) were analysed according to patients' neutralizing antibody status. Over the 2 years of the study, there was no trend to a higher exacerbation rate in the neutralizing antibody-positive groups compared to the neutralizing antibody-negative groups. There is no clear indication that the development of serum neutralizing antibodies affected either saftety or efficacy in either of the Rebiff groups.

\section{Condyloma acuminata}

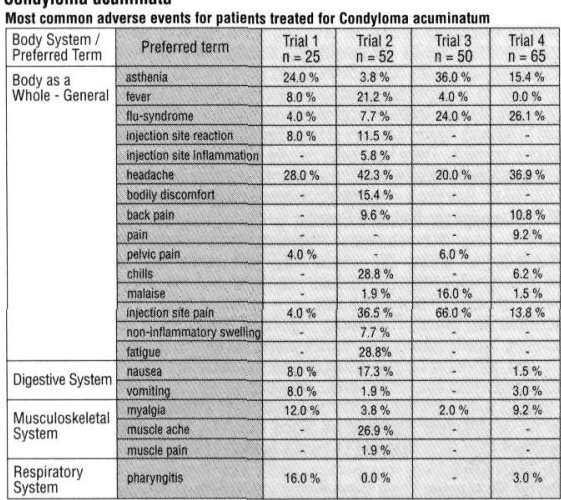

Other adverse events were experienced by less than $5 \%$ of the patients, and included eye pain, skin disorder, rinitis, bronchitis, coughing, diarnoea, abdominal pain, postural hypotension, palpitation, vasodilatation, rectal disorder, lymphocytosis, thrombocytopenia, delirium, somnolence, joint pain, joint stiffness, lightheadedness, paraesthesia distal, disorientation, irritability, sleeplessness, lethargy, bruise, purpura, sweating increased shortness of breath, upper respiratory tract infection, tachycardia flushing. urethral pain, infection, chest pain, Iymphadenopathy, PBI increased, arthralgia, dizziness, nervousness, tremor, abnormal vision, vulvovaginal disease, balanitis, penis disease, testis disease, urethritis, infection urinary tract, vaginitis, leukopenia, herpes simplex, pruritis, rash mac pap, skin neoplasia, rash.

Immunogenicity: The determination of the presence of antibodies to human IFN-beta was performed in all 4 studies. A total of four patients had anti beta-interferon antibodies at pre-entry, and 6 other patients had at least a positive result for total binding antibodies at some point during the study. Antibodies were of low titer, and none of the antibodies were neutralizing to human IFN-beta biological activity.

\section{SYMPTOMS AND TREATMENT OF OVERDOSAGE}

No case of overdose has thus far been described. However, in case of overdosage, patients should be h

\section{DOSAGE AND ADMINISTRATION:}

RELAPSING-REMITTING MULTIPLE SCLEROSIS: The recommended posology o Rebif (Interferon beta-1a) is $22 \mathrm{mcg}$ (6MIU) given three times per week by subcuta- neous iniection. This dose is eftective in the majority of patients to delay progression of the disease. Patients with a higher degree of disability (an EDSS of 4.0 or higher) may require a dose of $44 \mathrm{mcg}$ (12 MIU) $3 \times$ /weeh

Treatment should be initiated under supervision of a physician experienced in the treatment of the disease. When first starting treatment with Rebif', in order to allow tachyphylaxis to develop thus reducing adverse events, it is recommended that $20 \%$ of the total dose be administered during the initial 2 weeks of therapy, $50 \%$ of total dose be administered in week 3 and 4 , and the full dose from the fifth week onwards

At the present time, it is not known for how long patients should be treated. Safety and efficacy with Rebif have been demonstrated following 2 years of treatment. Therefore, it is recommended that patients should be evaluated after 2 years of treatment with Rebif and a decision for longer-term treatment be made on an individual basis by the treating physician.

Preparation of Solution: Lyophilized formulation (Relapsing-Remitting Multiple Sclerosis): Reconstitute the contents of a vial of Rebits with $0.5 \mathrm{~mL}$ of the accompanying sterile diluent (see table below for diluent volume and resulting concentration). The reconstituted solution should be used immediatel.

Reconstitution Table
\begin{tabular}{|l|c|c|c|}
\hline Strength & $\begin{array}{c}\text { Volume of Diluent } \\
\text { to be added to vial }\end{array}$ & $\begin{array}{c}\text { Approximate } \\
\text { avallable volume }\end{array}$ & $\begin{array}{c}\text { Nominal } \\
\text { concentration/mL }\end{array}$ \\
\hline $11 \mathrm{mcg}(3 \mathrm{MIU})$ & $0.5 \mathrm{~mL}$ & $0.5 \mathrm{~mL}$ & $22 \mathrm{mcg}(6 \mathrm{MIU})$ \\
\hline $44 \mathrm{mcg}(12 \mathrm{MIU})$ & $0.5 \mathrm{~mL}$ & $0.5 \mathrm{~mL}$ & $88 \mathrm{mco}(24 \mathrm{MU})$ \\
\hline
\end{tabular}

Preparation of the solution: liquid formulation: The liquid formulation in a pre-tilled syringe is ready for use. These syringes are graduated to facilitate therapy initiation. The pre-filled syringes contain $22 \mathrm{mcg}$ and $44 \mathrm{mcg}$ of Rebif respectively. The pre-illed syringes are ready for subcutaneous use only.

CONDYLOMA ACUMINATUM: The recommended posology is $3.67 \mathrm{mcg}$ (1MIU) per lesion three times per week for 3 weeks. The recommended route of administration is intra- or peri-lesional. The pre-filled syringes are not to be used for this indication Preparation of Solution: Lyophilized formulation (Condyloma acuminatum) Reconstitute the contents of a vial of Rebif" in sterile diluent in order to obtain a fina concentration of $3.7 \mathrm{mcg}$ per $0.1 \mathrm{~mL}$ solution. The reconstituted solution should be used immediately.

\begin{tabular}{|c|c|c|c|}
\hline Strength & $\begin{array}{l}\text { Volume of Diluent } \\
\text { to be added to vial }\end{array}$ & $\begin{array}{c}\text { Approximate } \\
\text { avaliable volume }\end{array}$ & $\begin{array}{c}\text { Nominal } \\
\text { concentration/mL }\end{array}$ \\
\hline $11 \mathrm{mcg}$ (3 MIU) & $0.3 \mathrm{~mL}$ & $0.3 \mathrm{~mL}$ & $37 \mathrm{mcg}(10 \mathrm{MIU})$ \\
\hline $44 \mathrm{mcg}$ (12 MIU) & $12 \mathrm{~mL}$ & $12 \mathrm{~mL}$ & $37 \mathrm{mcg}$ (10 MiU) \\
\hline
\end{tabular}

\section{COMPOSITION}

Lyophilized formulation: Each $3 \mathrm{~mL}$ vial of sterile lyophilized powder contains Interferon heta-1a albumin (human) mannitol and sodium acetate, as indicated in the table below. Acetic acid and sodium hydroxide are used to adiust the pH.

\begin{tabular}{|l|c|c|c|}
\hline Interferon beta-1a & Albumin (Human) & Mannitol & Sodium acetate \\
\hline $11 \mathrm{mcg}$ (3 MIU) & $9 \mathrm{mg}$ & $5 \mathrm{mg}$ & $0.2 \mathrm{mg}$ \\
\hline $44 \mathrm{mcg}$ (12 MIU) & $9 \mathrm{mg}$ & $5 \mathrm{mg}$ & $0.2 \mathrm{mg}$ \\
\hline
\end{tabular}

Rebifs (Interferon beta-1a) is supplied with a $2 \mathrm{~mL}$ diluent ampoule containing $2 \mathrm{~mL}$ of $0.9 \% \mathrm{NaCl}$ in Water for Injection. No preservatives are present. Liquid formulation

The liquid formulation is supplied in syringes containing $0.5 \mathrm{~mL}$. of solution. Each syringe contains Interferon beta-1a, albumin (human), mannitol and $0.01 \mathrm{M}$ sodium acetate buffer, as indicated in the table below. The solution does not contain preservatives.

\begin{tabular}{|l|c|c|c|}
\hline Interferon beta-1a & Albumin (Human) & Mannitol & 0.01 M Sodium acetate buffer \\
\hline $22 \mathrm{mcg}$ (6 MIU) & $2 \mathrm{mg}$ & $27.3 \mathrm{mg}$ & $4.5 .100 .5 \mathrm{~mL}$ \\
\hline $44 \mathrm{mcg}$ (12 MIU) & $4 \mathrm{mg}$ & $27.3 \mathrm{mg}$ & $9.5 .100 .5 \mathrm{~mL}$ \\
\hline
\end{tabular}

\section{STABILITY AND STORAGE RECOMMENDATIONS}

Lyophilized formulation: Refer to the date indicated on the labels for the expiry date Rebife (Interferon beta-1a) lyophilized product should be stored at 2-8 $8^{\circ} \mathrm{C}$

Liquid formulation: Reter to the date indicated on the labels for the expiry date. Rebife liquid in a pre-iilled syringe should be stored at $2-8^{\circ} \mathrm{C}$. Rebif syringes may be stored for a limited period at room temperature (up to $25^{\circ} \mathrm{C}$ ), but not more than 1 month. Do not freeze.

\section{RECONSTITUTED SOLUTIONS}

Lyophilized formulation: Lyophilized Rebif should be reconstituted with $0.9 \%$ $\mathrm{NaCl}$ in Water for Injection (supplied in $2 \mathrm{~mL}$ neutral glass ampoules containing 2.0 $\mathrm{mL}$ ). The reconstituted solution should be administered immediately. Although not recommended, it may be used later during the day of reconstitution if stored in a refrigerator $\left(2-8^{\circ} \mathrm{C}\right)$. Do not freeze. The reconstituted solution may have a yellow colouration which is a normal product characteristic.

Liquid formulation: The liquid in the prefilled syringe is ready for use

\section{PARENTERAL PRODUCT}

AVAILABILITY OF DOSAGE FORM

Rebifo (Interferon beta-1a) is available in two strengths (11 mcg (3MIU), and $44 \mathrm{mcg}$ (12MUlU) per vial) as a lyophilized sterile powder. It is accompanied by diluent $(0.9 \%$ $\mathrm{NaCl}$ in Water for Injection) in $2 \mathrm{~mL}$ ampoules. Both lyophilized strengths are supplied in cartons of 1 vial of drug and $1 \times 2 \mathrm{~mL}$ ampoule of diluent, 3 vials of drug and $3 \times 2$ $\mathrm{mL}$ ampoules of diluent, and 12 vials of drug and $12 \times 2 \mathrm{~mL}$ ampoules of diluent. Rebif is also available as a liquid formulation, in prefilled syringes ready for use. Two package strengths are avalable: $22 \mathrm{mcg}$ (6MIU)/0.5 mL and $44 \mathrm{mcg}$ (12MIU)/0.5 mL. The pre-filled syringes are supplied as single units, 3-packs and 12-packs. The prefilled syringes are ready for subcutaneous use only.

The route of administration for Relapsing-Remitting Multiple Sclerosis is subcutaneous. The route of administration for condyloma acuminatum is intra- and peri-lesional. References: 1. The PRISMS (Prevention of Relapses and Disability by Interferon Be 1a in Multiple Sclerosis) Study Group. Randomised double-blind placebo-controlled study of interferon B-1a in relapsing/remitting multiple sclerosis. Lancet, 1998;352: 1498-504. 2. Rebife Product Monograph, June 8, 2001. Serono Canada Inc. 3. IMS Canada: Canadian Compuscript March 2002, Canadian Drugstore and Hospital Audit February 2002

\section{serono}

(®) Registered trademark Serono Canada Inc., Oakville, Ontario L6M 2 G2 


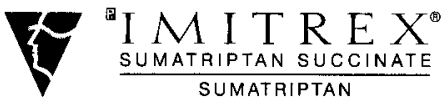

$25 \mathrm{mg}, 50 \mathrm{mg}$ and $100 \mathrm{mg}$ Tablet

tion and Autriniector

THERAPEUTIC CLASSIFICATION

PHARMACOLOGIC CLASSIFICATION

\section{INDICATIONS AND CLINICAL USES}

(5)

Mul inEx is not tor use in the management of nemiolegic, basilar, or ophthalmoplegic migraine (see CONTRAMUCICATIONS). Satety and efficacy have not
been established for cluster headache which is present in an older, predomiminently mae poDilation.
CONTRAANDICATIONS

MMTTREX (sumatriptan succinate/sumatriptan) is contraindicated in patients with history, symptoms, or signs of ischemic cardiac, palients with history, symptoms, or signs of ischemic cardiac,
cerebrovascular, or peripheral vascular syndromes, valvular heart disease or cardlac arrhythmias (especially tachycardias). In addition, pationts with other significant underlying cardiovascular diseases (e.g., atherosclerotic disease, congenittal heart disease)

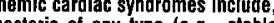
but are not limited to, angina pectoris of any type (e.g., stable angina of effort and vasospastic forms of angina such as the Prinzmelals variant), all torms of myocardial intarction, and silen myocardial ischemia. Cerebrovascular syndromes include, but are
not limited to, strokes of any type as well as transient ischemio not limited to, strokes of any type as well as transient ischemic limited to, ischemic bowel disease, or Raynaud's syndrome (see WARNINGS)

Because IMITREX may increase blood pressure, it is contraindicated in patients with uncontrolled or severe hypertension. Concurrent administration of MAO inhibitors or use within 2 weeks of discontinuation of MAO inhibitor therapy is contraindicated
(see PRECAUTIONS: Drug Interactions).

Ergot-containing drugs have been reported to cause prolonged vasospastic reactions. Because IMITREX may also cause coronary
vasospasm and these effects may be additive, the use of IMITREX within 24 hours beiore or after treatment with other 5.HT, receptor agonists, or ergotamine-containing drugs or their derivatives (eg.

IMITREX should not be administered to patients with severe
IMIT

IMITREX is contraindicated in patients with hemiplegic, basilar, or

ImhthREX is contraindicated in patients with hypersensitivity to sumatriptan or any of the ingredients of the formulations.

IMITREX Injection should not be given intravenously because of its potential to cause coronary vasospasm.

WARNING

MITREX (sumatriptan succinate/sumatriptan) should only be used where a clear diagnosis of migraine has been established.
Risk of Mrocardial Ischemia and/or intarction and Other Adverse
Cardiac Events: MITREX has been associated with transient chest and/or neck pain and tightness which may resemble angina pectoris. In rare cases, the symptoms have been identified as being the likely result of coronary vasospasm or myocardial ischemia. Rare cases of serious coronary events or arrhythmia have occurred following use of IMITREX. MITREX should not be given to pationts who have documented ischemic or vasospastic coronary artery disease (CAD) (see CONTRAINDICATIONS). It is strongly recommended that IMIrREX not be given to patients in
whom unrecognized $C A D$ is predicted by the presence of risk factors whom unrecognized CAD is predicted by the presence of risk factors (e.g. hypertension, hypercholesterolemia, smoking, obesity, physiologically postmenopausal, or male who is over 40 years of age) unless a cardiovascular evaluation provides satisfactory clinical evidence that the patient is reasonably free of coronary artery and ischemic myocardial disease or other significant underlying cardiovascular disease. The sensitivity of cardiac position to coronary artery vasospasm is unknown. If, during the cardiovascular evaluation, the patient's medical history or electroconsistent with, coronary artery vasospasm or myocardial
ischemia, MITRÉX CATIONS).

For patients with risk factors predictive of CAD, who are considered to have a satisfactory cardiovascular evaluation, the first dose of IMITREX should be administered in the setting of a physician's office or similar medically statied and equipped facility. Because cardiac ischemia can occur in the absence of clinical symptoms, consideration should be given to obtaining electrocardiograms in patients with risk factors during the interval immediately following MMITREX administration on the first occasion of use. However, an absence of drug-induced cardiovascular effects on the occasion of accurring with subseq

Intermittent long term users of IMITREX ${ }^{\circ}$ who have or acquire risk factors predictive of CAD, as described above, should recelve periodic interval cardiovascular evaluations over the course of trealment.
If symptoms consistent with angina occur after the use of IMITREX ECh evaluation should be carried out to look for ischemic changes. Tikelhood that patients with unrecounized cardiovascular disease will be inadvertently exposed to IMITREX

Cardiac Events and Fatalities Associated with 5-HT, Agonists: MMiThEX can cause coronary artery vasospasm. Serious adverse cardiac cardiac rhythm, and death have been reported within a few hours following the adrinistration of $5-\mathrm{HT}_{1}$ agonists. Considering the extent of use of 5 -HT, low. The fact that some of these events have occurred in patients with no prior cardiac disease history and with documented absence of $C A D$, and the close proximity of the events to IMITREX use support the conclusion that some of been known underlying corchary artery disease, the relationship is uncertain. Premarketing Experience With IMITREX': $0^{\prime} 6348$ patients with migraine who participated in premarketing controlled and uncontrolled clinical trials of
oral :MITREX oral :MITREX", two experienced clinical adverse events shortly after receiving
oral IMITREX" that may have reflected coronary vasospasm. Neither of these adverse events was associated with a serious clinical oucome

Among the more than 1900 patients with migraine who particioated in premarketing controlled clinical trials of subcutaneous IMITREX, there were eight IMITREX that may have refiected conary artery vasospasm Six of these eigh patients had ECG changes consistent with transient ischemia, but without accompanying clinical symptoms or signs, of these eight patients, four had either findings suggestive of $C A D$ or risk factors predictive of $C A D$ prior to
study enrollment Among approximately 4,000 patients with migraine who paticipated in premarketing controlled and uncontrolled clinical trials of IMITREX nasal spray, one
patient experienced an asymptomatic subendocardial infarction possibly subsequent to a coronary vasospastic event

Postmarketing Experience With IMITREX : Serious cardiovascular events, some resulting in death, have been reported in association with the use
of IMITREX In jection or IMITREX Tablets. The uncontrolled nature of postmarketing surveillance, however, makes it impossible to determine definiIMITRE $X^{\circledR}$ or to reliably assess causation in individual cases. On clinical grounds, the longer the latency between the administration of IMITREX and the onset of the clinical event, the less likely the association is to be causative. Accordingly, interest has focused on events beginning within 1 hour of the

Gardiac events hat have been observed to have onset within 1 hour of ischemia, myocarcial infarction, ventricular tachycardia and ventricular fibritlation, cardiac arrest, and death.

Some of these events occurred in patients who had no findings of $C A D$ and ampong reports from the USA of serious cardiac events occurfing within 1 hour of $\mathrm{CAD}$ and the presence of significant underlying $\mathrm{CAD}$ was established in most Cerebrovascular Eyents and Fatalities with 5-HT, Agonists: Cerebral hermornhage, subarachnoid hemornhage, stroke, and other cerebrovascular
events have beenn reported in patients treated with orat or subbutaneous
IMITREX these events is uncertain resulted in fatalities. The retat onsh ip of MMTREX lo cerebrovascular events were primary, IMITREX having been administered in the incorrect belief that the symptoms experienced were a consecuence of not be administered if the that patients with migraine may be at increased risk of certain cerebrovascular dose, the opportunity should be taken to review the diagnosis before a second Special Cardiovascular Pharmacology Studies: subcutaneous dose of $1.5 \mathrm{mg}$ produced an $8 \%$ increase in aortic blood pressure, an $18 \%$ increase in pulmonary artery blood pressure, and an $8 \%$ increase in by four subiects Clinically significant increases in blood pressure were experienced by three of the subjects (two of whom also had chest pain/discomfort). Diagnostic angiogram results revealed that 9 subjects had normal coronary
atteries and 1 had insignificart coronary artery disease. $n$ an additional study with this same drug, migraine patients $(n=35)$ iree of cardiovascular disease were subjected to assessments of myocardial perfusion by positron emission tomography while receiving a subcutaneous $1.5 \mathrm{mg}$ dose the absence of a migraine attack. Reduced coronary vasodilatory reserve
$(-10 \%)$, increase in coronary resistance $(-20 \%)$, and decrease in hyperemic myocardial blood flow ( $10 \%$ ) were noted. The re evance of these findings to
the use of the recommrtended oral doses of this $5-H T_{1}$ agonist is not known. he use of the recommended oral doses of this $5-\mathrm{HT}_{1}$ agonist is not known.
Similar studies have not been done with IMITREX. However, owing to the Similar studies have not been done with IMITREX
common pharmacodynamic actions of 5 - HT 1 agonist, , the possibility of cardio-
vascular effects of the nature described above should be considered for any

agent of this pharmacological class.
Hypersensitivity: Rare hypersensitivity (anaphylaxis/anaphylactoid)
reactions may occur in patients receiving $5-\mathrm{HT}_{1}$ agonists such as IMITREX. reactions may occur in patients receiving $5-\mathrm{HT}_{1}$ agonists such as MMITREX.
Such reactions can be life threatening or fatal. In general, hypersensitivity Such reactions can be life threatening or fatal. In general, hypersensitivity
reactions to drugs are more likely to occur in individuals with a history of sensitivity to multiple allergens (see CONTRAINDICATIONS). Owing to the possibi ity of cross-feactive hypersensitivity reactions, IMITREX receptor agonists. There have been reports of patients with known hypersensiivity to sulphonamides exhibiting an allergic reaction tollowing administration Other Vasospasm Related Events: $5-\mathrm{HT}_{1}$ agonists may cause vasospastic reactions other than coronary artery vasospasm. Extensive post-market reactions other than coronary artery vasospasm. Extensive post-markel
experience has shown the use of IMUTREX to be associated with rare occurrences of peripheral vascular ischemia and colonic ischemia with Increase in Blood Pressure: Significant elevation in blood pressure, including hypertensive crisis, has been reported on rare occasions in patients with and without a history of hypertension. MMITRE $X^{\circledR}$ is contraindicated patients with uncontrolled or severe hypertension (see CONTRAINDICATIONS). caution as transient increases in blood pressure and peripheral vascular resistance have been observed in a small portion of patients.

\section{PRECAUTIONS}

Cluster Headache: There is insufficient information on the efficacy and satety (Sumatriptan succinate/sumatriptan) in the treatrment of cluster need for prolonged use and the demand tor repeated medication in this Cardiovascular: Discomfort in the chest, neck, throat and jaw (including pain, pressure, heaviness and tightness) has been
reported after administration of IMITREX may cause coronary artery vasospasm, palients who experience be evaluated for the presence of CAD or a predisposition to variant angina before receiving additional doses, and should be monitored electrocardiographically if dosing is resumed and similar symploms recur. Similarly, patients who experience other symptoms or signs suggestive of decreased arterial flow, such as Ischemic bowel syndrome or Raynaud's syndrome following to vasospasm (see CONTRAINDICATIONS AND WARNINGS). Neurological Conditions: Care should be taken to exclude other potentially serlous neurologic conditions betore treating headache in patients not
previously diagnosed with migraine headache or who experience a headache that is atyoical for them. There have been rare reports where patients received 5-HT. agonists for severe headaches that were subsequently shown to have been secondary to an evolving neurologic lesion. For newly diagnosed patients or patients presenting
with atycical symptoms, the diagnosis of migraine should be reconsidered if no response is seen atter the first dose of IM TREX
Seizures: Caution should be observed if IMITREX is to be used in patients with history of epilepsy or structural brain lesions which lower the convision threshold. Psychomotor Impairment: Patients should be cautioned that drowsiness
may occur as a result of treatment with IMITREX $X^{B}$. They should be acvised no to perform skilled tasks (e.g. driving or operating machinery) if drowsiness Renal Impairment: The effects of renal impairment on the efficacy and safel of IMITREX $X^{*}$ have not been evaluated. Therefore IMITRE $X^{\infty}$ is not recommended

Hepatic Impairment: The effect of hepatic impairment on the efficacy an safery of IMITREX $X^{\text {se }}$ has not been evaluated, nowever, the pharmacokinetio
profile of sumatriptan in patients with moderate these patients, tollowing an oral dose of $50 \mathrm{mg}$, have much higher plasm sumatriptan concentrations than healthy subjects (Table 2). Theretore, an oral
dose of $25 \mathrm{mg}$ may be considered in patients with hepatic impairment.

Table 2: Pharmacokinetic Parameters After Oral Admintstration of MITREX $50 \mathrm{mg}$ to Healthy Volunteers and Moderately Hepatically

\begin{tabular}{|c|c|c|c|}
\hline Parameter & $\begin{array}{c}\text { Mean Ratio } \\
\text { (hepatic impaired/healthy) } \\
n=8\end{array}$ & $90 \% \mathrm{Cl}$ & p-value \\
\hline$A L C^{\infty}$ & $181 \%$ & $13010252 \%$ & $0.009^{*}$ \\
\hline$Q_{\max }$ & $176 \%$ & $12910240 \%$ & $0.007^{*}$ \\
\hline
\end{tabular}

\section{Statistically significant}

The pharmaccokinetic pararneters of $6 \mathrm{mg}$ subcutaneous sumatriptan do not impaired subjects. However, sumatriptan should not be administered to patients with severe hepatic impairment (see CONTRAINDICATIONS)

Drug Interactions: Single dose pharmacokinetic drug interaction studies have not shown evidence of interactions with propranolol, flunarizine, pizotifen pharmacokinetics of sumatriptan nasal spray were unaltered when preceded by a single clinical dose of the nasal decancestant $x y$ lometaraine (Otrivin's? Ergot-Containing Drugs: Ergot-containing drugs have been, reported to cause prolonged vasospastic reactions. Because there is a theoretical basis for thes prolonged vasospastic reactions. Because there is a theoretical basis ior these IMITREX administration (see CONTRAINDICATIONS)

MAO inhibitors: In studies conducted in a limited number of patients. MAO Inhibitors reduce sumatriptan cleatance, signiticantly increasing systemic inhibitors is contraindicated (see CONTRAINDICATIONS)

Other Serotonergic Drugs. Rare postmarketing reports describe patients with weakness, hyperreflexia, and incordination following the combined use of a selective serotonin reuptake inhibitor (SSRl) and 5-HT, agonists. If concomitan sertraline), tricyclic antidepressant, or other diug with serotonergic activity is clinically warranted, appropriate observation of the patient for acute and longOther 5-HT, agonists: The administration of MITREX with other 5.H agonists has not been evaluated in migraine patients. As an increased risk o coronary vasospasm is a theoretical possibility with co-administration of contraindicated

Drug/Laboratory Test Interactions: IMITREX is not known to intertere with commonly employed clinical laboratory tests. aged over 65 years is limited. Therefore the use of MMITRE $X^{(5)}$ in patients over 65 Use in Children $k 18$.

children has not been established and its use in this age group is not

Use in Pregnancy: Reproduction studies, performed in rats, have not revealed any evidence of impaired fertility, teratogenicity, or post-natal
development due to IMiTREX development due to IMITREX $X^{\text {. }}$. Reproduction studies, performed in rabbits b blood vessel configuration in the foetuses. These effects were only seen at th highest dose tested, which aftected weight gain in the dams, and at which bloos
levels were in excess of 50 times those seen in humans after therapeutic doses. A direct association with $\mid M \|^{\top T} R E X^{\mathbb{B}}$ treatment is considered unlikely but cannot be excluced. Therefore, the use of IMITREX is not recommended in pregnancy. In a rat fertility study, oral doses of IMITREX ${ }^{*}$ resulting in plasma levels approxapproximately 200 times those seen in humans after a $100 \mathrm{mig}$ oral dose wera occur during a subcutaneous study where maximum plasma levels achiever occur during a subculaneous study where maximum plasma levels achieved mately 150 times those in humans by the oral route.

sumatintar maternal-toetal outcomes of pregnant women exposed to encouraged to register patients by calling 1-800-336-2176. Lactation: Sumatriptan is excreted in human breast milk. Therefore, caution is Binding to Melanin breast feeding for 24 hours after treatment. Binding to Melanin Containing Tissues: In rats treated with a sing subcutaneous dose (0.5 mg/kg) or oral dose $(2 \mathrm{mg} / \mathrm{kg}$ ) of radiolabeled days, respectively, suggesting that sumatriptan and/or its metabolites bind to the melanin of the eye. Because there could be an accumulation in melanin rich tissues over time, this raises the possibility that sumatriptan could cause related to treatment with sumatriptan were noted in any of the oral subcutaneous toxicity studies. Although no systematic monitoring of ophthaldations for ophthalmologic monitoring are offered, prescribers should be aware of the poss ibility of long term ophthalmologic effects

to and/or after treatment with IMITREX ADVERSE REACTIONS

Serious cardiac events, including some that have been fatal, have occurred following the use of $5-\mathrm{HT}_{1}$ agonists. These events are extremely rare and most have been reported in patients with rish factors predictive of CAD. Events reported have included coronary artery vasospasm, transient myocardial ischemia, myocardial infarction, ventricular tachycardia, and ventricular fibrillations
CONTRAINDICATIONS, WARNINGS, and PRECAUTIONS) Experience in Controlled Clinical Trials with IMITREX

Typical 5-HT, Agonist Adverse Reactions: As with other 5- $\mathrm{HT}_{1}$ agonists sensations of heaviness succinate/sumatriptan) has been associated with sensations of heaviness, pressure, tightness or pain which may be intense.
These may occur in any part of the body including the chest, throat, neck, jaw Acute Satety: (14) The following tables (Tables 3-5) fist adverse events occurting in these trials a
The an incidence of $1 \%$ or more in any of the IMITRE ${ }^{(5)}$ dose groups and that

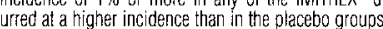

Traderark a cinaph selt Medication 
Table 3: Treatment-Emergent Adverse Events in Ora Placebo-Controlled Clinical Trials Reperted by Least $1 \%$ of Patients with Migraine

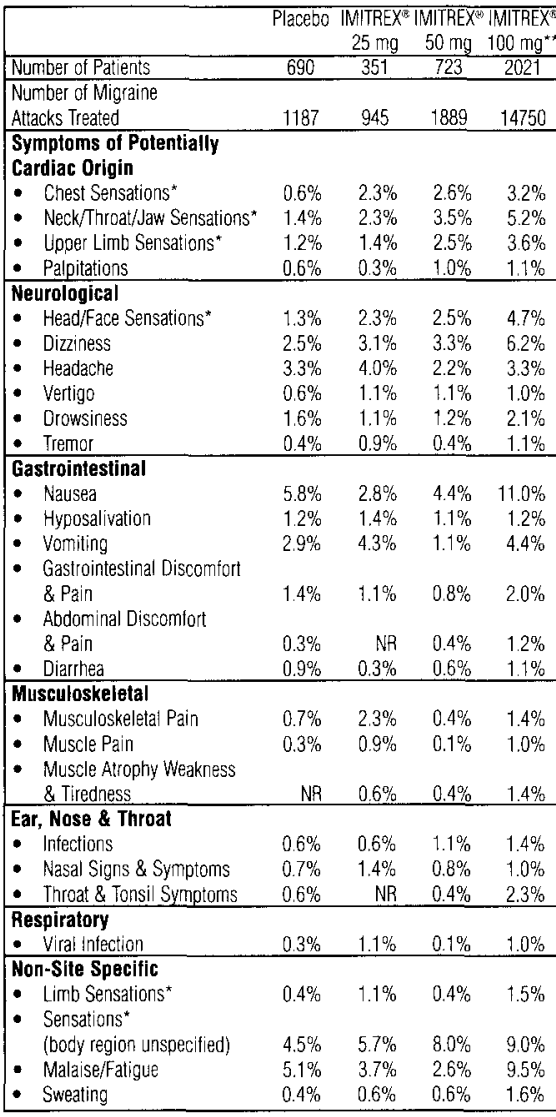

"The term "sensations" encompasses adverse events described as pain \& discomfort, pressure, heaviness, constriction, tightness, heat/burning discomfort, pressure, heaviness, constriction, tightness, heath
sensation, paresthesia, numbness, tingling, and strange sensations sensation, paresthesia, numbness, tingling, and strange

NR $=$ Not Reported

\section{Table 4: Treatment-Emergent Adverse Events in Subcutaneous} Placebo-Controlled Clinical Trials Reported by at Least $1 \%$ of Patients with Migraine

\begin{tabular}{|c|c|c|}
\hline & Placebo & MMTREX $6 \mathrm{mg}$ \\
\hline Number of Patients & 615 & 1432 \\
\hline Number of Migraine Attacks Treated & 742 & 2540 \\
\hline \multicolumn{3}{|l|}{ Symptoms of Potentially Cardiac Origin } \\
\hline Chest Sensations* & $1.6 \%$ & $5.7 \%$ \\
\hline - Neck/Throat/Jaw Sensations* & $1.3 \%$ & $12.0 \%$ \\
\hline - Upper Limb Sensations* ${ }^{\star}$ & $2.0 \%$ & $6.8 \%$ \\
\hline \multicolumn{3}{|l|}{ Neurological } \\
\hline - Head/Face Sensations ${ }^{*}$ & $3.7 \%$ & $16.6 \%$ \\
\hline - Dizziness & $3.7 \%$ & $7.9 \%$ \\
\hline - Headache & $0.7 \%$ & $3.4 \%$ \\
\hline Drowsiness & $1.8 \%$ & $2.9 \%$ \\
\hline \multicolumn{3}{|l|}{ Gastrointestinal } \\
\hline Nausea & $5.9 \%$ & $9.4 \%$ \\
\hline Hyposalivation & $2.8 \%$ & $3.3 \%$ \\
\hline \multicolumn{3}{|l|}{ Musculoskeletal } \\
\hline Muscle Atrophy Weakness \& Tiredness & NR & $1.7 \%$ \\
\hline \multicolumn{3}{|l|}{ Ear / Nose and Throat } \\
\hline Throat \& Tonsil Symptoms & $0.3 \%$ & $1.0 \%$ \\
\hline \multicolumn{3}{|l|}{ Respiratory } \\
\hline Breathing Disorders & $0.8 \%$ & $1.3 \%$ \\
\hline \multicolumn{3}{|l|}{ Non-Site Specific } \\
\hline Sensations` (body region unspecified) & $15.9 \%$ & $39.0 \%$ \\
\hline - Injection Site Reactions & $10.4 \%$ & $24.7 \%$ \\
\hline - Limb Sensations* & $1.5 \%$ & $6.0 \%$ \\
\hline - Malaise/Fatigue & $2.3 \%$ & $4.7 \%$ \\
\hline - Sweating & $1.1 \%$ & $1.7 \%$ \\
\hline Trunk Symptoms* & $0.5 \%$ & $1.4 \%$ \\
\hline
\end{tabular}

"The term "sensations" encompasses adverse events described as pain \& discomfort, pressure, heaviness, constriction, tightness, heat/burning
sensation, paresthesia, numbness, tingling, and strange sensations. sensation, pares
Table 5: Treatment-Emergent Adverse Events in Intranasa Placebo-Controlled Clinical Trials Reported by at Least $1 \%$ of Patients with Migraine

\begin{tabular}{|c|c|c|c|c|}
\hline & Placebo & IMITRE & MITREX & |MITREX \\
\hline & & $5 \mathrm{mg}$ & $10 \mathrm{mg}$ & $20 \mathrm{mg}^{* *}$ \\
\hline Number of Patients & 741 & 496 & 1007 & 1638 \\
\hline $\begin{array}{l}\text { Number of Migraine } \\
\text { Attacks Treated }\end{array}$ & 1047 & 933 & 1434 & 070 \\
\hline
\end{tabular}

Altacks trealed

\section{Cardiac Origin}

- Chest Sensations

\begin{tabular}{llll}
$0.3 \%$ & $1.0 \%$ & $0.7 \%$ & $0.6 \%$ \\
\hline
\end{tabular}

\begin{tabular}{lllll} 
- Neck/Throat/Jaw Sensations & ${ }^{*} \quad 1.2 \%$ & $0.6 \%$ & $1.6 \%$ & $2.3 \%$ \\
\hline
\end{tabular}

Neurological

- Head/Face Sensations ${ }^{*} \quad 0.8 \% \quad 1.4 \% \quad 2.4 \% \quad 2.4 \%$

\begin{tabular}{lllll} 
- Dizziness & $1.2 \%$ & $1.6 \%$ & $1.5 \%$ & $1.2 \%$ \\
\hline
\end{tabular}

\begin{tabular}{lllll} 
- Headache & $0.7 \%$ & $1.4 \%$ & $0.9 \%$ & $0.8 \%$ \\
\hline
\end{tabular}

- Migraine

Gastrointestinal

\begin{tabular}{rrrr}
$0.7 \%$ & $1.4 \%$ & $0.9 \%$ & $0.8 \%$ \\
$2.6 \%$ & $3.2 \%$ & $2.4 \%$ & $1.8 \%$ \\
\hline
\end{tabular}

- Nausea

$10.4 \% \quad 14.3 \% \quad 9.6 \% \quad 8.3 \%$

- Vomiting

\section{Ear, Nose \& Throat}

- Sensitivity to Noise

- Nasal Signs \& Symptoms

$7.6 \% \quad 11.1 \% \quad 9.6 \% \quad 6.8 \%$

- Infections

$\begin{array}{llll}0.9 \% & 1.8 \% & 1.3 \% & 0.5 \%\end{array}$

$\begin{array}{lllll}\text { - } & 0.5 \% & 1.0 \% & 0.6 \% & 0.7 \%\end{array}$

\section{Non-Site Specific}

- Sensations*

(body region unspecified)

- Mala ise/Fatigue

$1.8 \% \quad 2.4 \% \quad 2.7 \% \quad 2.4 \%$

$\begin{array}{lllll} & \end{array}$

The term "sensations" encompasses adverse events described as pain \& discomfort, pressure, heaviness, constriction, tightness, heat/burning sensation, paresthesia, numbness, ting ing, and strang
$\star \star$ Includes patients receiving up to 3 doses of $20 \mathrm{mg}$

IMITREX is generally well tolerated. Most of the events were transient in naturs and resolved within 45 minutes of subcutaneous adrministration and within 2 hours of oral or intranasal administration.

Of the 3630 patients treated with IMTREX Nasal Spray in clinical trials, there was one report of a coronary vasospasm related to IMITREX $X^{\mathscr{E}}$ administration. Minor disturbances of liver function tests have occasionally been observed with sumatriptan treatment. There is no evidence that clinically significant abnormalities occurred more frequently with sumatriptan than with placebo Patients treated with IMITREX rarely exhibit visual disorders like flickering and diplopia. Additionally cases of nystagmus scotoma and reduced vision have been observed. Very rarely a transient loss of vision has been reported.
However visual disorders may also occur during a migraine attack itself.

\section{DOSAGE AND ADMINISTRATION}

General:

IMITREX (sumatriptan succinate/sumatriptan) is indicated for the acute treakment of migraine headache with or without aura. Sumatriptan should not be used prophylactically. Sumatriptan may be given orally, subcutaneously or as a nasal spray. The safety of treating an average of more than four headaches in a 30 day period

In selecting the appropriate formulation for individual patients, consideration should be given to the patient's preference for formulation and the patient's requirement for rapid onset of relief. Sicnificant reliet begins about 10-15
minutes following subcutaneous injection, 15 minutes following intranasal minutes following subcutaneous injection, 15 minutes followin

In addition to relieving the pain of migraine, sumatriptan (all formulations) has also been shown to be effective in relieving associaled symptoms of migraine (nausea, vomiting, phoncohobia, photophobia). Sumatriptan is equally effective when administered at any stage of a migraine altack. Long term (12-24 months) clinical studies with maximum recommended doses of sumatriptan indicate that there is no evidence of the develooment of tachyphylaxis, or medication-induced freboundi headache.

Tablets:

The minimal effective single adult dose of IMITREX Tablets is $25 \mathrm{mg}$. The maximum recommended single dose is $100 \mathrm{mg}$.

The optimal dose is a single $50 \mathrm{mg}$ tablet However, denending on individuat patient's needs and response to treatment some patients may recuire 100 mo patient's needs and response to treatment, some patients may requlre $100 \mathrm{mg}$. Clinical trials have shown that approximately $50-75 \%$ of patients have further $15-25 \%$ have headache relief by 4 hours Comparator studies have shown similar efficacy rates with the $50 \mathrm{mg}$ and $100 \mathrm{mg}$ tablets. There is showin similar efficacy rates with the $50 \mathrm{mg}$ and $100 \mathrm{mg}$ lab ets. There is
evidence that doses of 50 and $100 \mathrm{mg}$ may provide greater effect than $25 \mathrm{mg}$. $I^{2}$ the migraine headache returns, or it a patient has a partial response to the initial dose the dose may be repeated after 2 hours. Not more than $200 \mathrm{mg}$ should be taken in any 24 hour period.

It a patient does not respond to the first dose of IMITREX Tabiets, a second dose should not be taken for the same attack, as it is unlikely to be of clinical benefit MITREX may be taken to treat subsequent micraine attacks.

The tablet should be swallowed whole with water, not crushed, chewed or split. Hepatic Impairment: In patients with mid or moderate hepatic impairment piasma sumatriptan concentrations up to two times those seen in hea thy subjects have been observed. Therefore, a $25 \mathrm{mg}$ dose (single tablet) may be considered in these patients (see PRECAUTIONS). Sumlatriptan should not be adrministered to patients with severe hepatic impairment (see CONTRAIND)CATIONS).

Injection:

MTREX Injection should be injected subcutaneously (on the outside of the

thigh or in the upper arm) using an autoinjector.
The recommended aduit dose of sumatriptan is a single 6 mg subcutaneous injection Clinical trials have shown that approximately $70-72 \%$ of patients have headache relief within one hour after a single subcutaneous injection. This number increases to $82 \%$ by 2 hours.

If the migraine headache returns, of if a patient has a partial response to the initial dose, the dose may be repeated after 1 hour. Not more than $12 \mathrm{mg}$ (two omg in ections) should be taken in any 24 hour period.

If a patient does not respond to the first dose of MMThEX Injection a second dose should not be taken for the same attack. as it is unlikely to be of clinical benefit. IMI TREX' may be taken for subsequent attacks.

Administration during migraine aura pricr to other symptoms occuring may not prevent the development of a headache.

Patients should be advised to read the patient instruction leaflet regarding the safe disposal of syringes and needles.

Nasal Spray:

The minimal effective single adult dose of sumatriptan nasal spray is $5 \mathrm{mg}$. The

maximum reconimented single dose is $20 \mathrm{mg}$
If the migraine headache returns, or if a patient has a partial response to the initial dose, the dose may be repeated atter 2 hours. Not more than $40 \mathrm{mg}$ should be taken in any 24 hour period.

It a patient does no: respond to the first dose of MMTREX Nasal Spray. a second dose should not be taken for the same attack, as it is unlikely to be of clinical benefit. IMITREX may be taken for subsequent attacks.

Placebo-controlled clinical trials revealed the following incidence of headache relief, defined as a decrease in migraine sever ty from severe or moderate to mild or no pain, within 2 hours alter trealment with intranasal sumatriptan at doses of 5,10 or 20 mo isee Table 6 below).

TABLE 6. Percentage of patients with headache relief at 2 hours

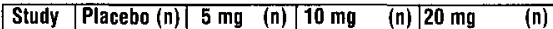
\begin{tabular}{|l|ll|ll|ll|ll|}
\hline Study $1 \cdot$ & $35 \%$ & $(40)$ & $67 \%$ & $(42)$ & $67 \%$ & (39) & $78 \%$ (40) \\
\hline
\end{tabular} \begin{tabular}{|l|ll|ll|ll|lr|}
\hline Study $2 \cdot$ & $42 \%$ & $(31)$ & $45 \%$ & $(33)$ & $66 \%$ & $(35)$ & $74 \%$ & $(39)$ \\
\hline Study 3 & $25 \%$ & $(63)$ & $49 \% \gamma$ & $(122)$ & $46 \% \gamma$ & $(115)$ & $64 \%$ & $+(119)$ \\
\hline
\end{tabular} \begin{tabular}{|l|l|l|l|l|l|}
\hline Study 4 & $25 \%(151)$ & - & $44 \%$ & $(288)$ & $55 \%+(292)$ \\
\hline Study 5 & $32 \%(198)$ & $44 \%(297)$ & $54 \%$ & $(293)$ & $60 \%+(288)$ \\
\hline
\end{tabular}

\begin{tabular}{|c|c|c|c|c|}
\hline udy 6 - & $35 \% \quad(10$ & - & $54 \% \quad(106)$ & $63 \%$ \\
\hline dy & $29 \%$ & - & $43 \%(109)$ & $\%$ \\
\hline
\end{tabular}

Headache relief was defined as a decrease in headache severity from severe or moderate to mild or none.

$n=$ total number of patients who received treatment

- comparisons between sumatriptan doses not conducted

$\checkmark p \leq 0.05$ versus placebo $\quad+p \leq 0.05$ versus lower sumatriptan doses $p \leq 0.05$ vs $5 \mathrm{mg}$ - not evaluated

As shown in the table above. optimal rates of headache relief were seen with the $20 \mathrm{mg}$ dose. Single doses above $20 \mathrm{mg}$ should not be used due to limited safety data and lack of increased efficacy relative to the $20 \mathrm{mg}$ single dose. Within the range of $5-20 \mathrm{mg}$, an increase in dose was not associated with any
significant increase in the incidence or severity of adverse events other than significant increase in the incidence or severity or

the diurbance (See ADVERSE REAC TONS). The rasal spray should be administered into one nostril only. The device is a ready to use single dose unit and must not be primed before administration.
Patients should be advised to read the patient instruction leatlet regarding the use of the nasal soray device before administration.

AVAILABILITY OF DOSAGE FORMS

AVAILABILITY OF DOSAGE FORMS Mal REX lablets are available as pink $100 \mathrm{mg}$, white $50 \mathrm{mg}$, or white $25 \mathrm{mg}$
film-coated tablets in blister packs containing 5 lablets. Four blister packs are placed in a carton.

MITREX Injection ( $6 \mathrm{mg}$; total volume $=0.5 \mathrm{~mL}$ ) is available in pre-filled syringes placed in a tamper-evident carrying case/disposal case. Two pre-filled syringes plus the MITREX STATdose Pe n'm autoinjector are oacked in an MMTREX STAT dose System" autoinjector kit. A refill pack is available containing 2 pre-filled syringes in a carlon

is also available to physicians or hospitals in a single dose vial $(6 \mathrm{mg}$; total volume $=0.5 \mathrm{~mL})$. There are 5 vials per carton.

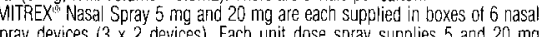

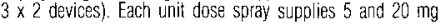
espectivaly.

Product Monograph available to physicians and pharmacists upon request.

Please contact GlaxoSmithKline Inc. 7333 Mississauga Road N. Mississauga, Ontario L5N BL4.

IMITREX $X^{5}$ is a registered trademark, used under license by GlaxoSmithkline Inc. INT The appearance, namely the colour, shape, and size of the IMITREX
Nasal Spray device and IMITREX STATdose System are trademarks, used under license by GlaxoSmithKline Inc.

Date of preparation: January 17, 1992

Date of revision: February 14, 2003

References: 1. Product Monograph of "IMITREX" (sumatriptan uccinate/sumatriptan); GlaxoSmithKline Inc. February 2003. 2. Cady R. McNeal S, O'Quinn S. Putman G. Effect of early intervention with sumatriptan on migraine pain: Retrospective analyses of data
from three clinical trials. Clinical Therapeutics 2000-22/9)-1035-1048

\section{GlaxoSmithKline}

GlaxoSmithkline

7333 Mississauga Road North

Mississauga, Ontario L5N 6L4 
BRIEF PRESCRIBING INFORMATION

CONSULT FULL PRODUCT MONOGRAPH FOR COMPLETE PRESCRIBING INFORMATION

\section{P'TOPAMAX* topiramate}

25, 100 and $200 \mathrm{mg}$ Tablets and 15 and $25 \mathrm{mg}$ Sprinkle Capsules Antiepileptic

IMDICATIONS AND CLINICAL USE

TOPAMAXX (topiramate) is indicated as adjunctive therapy for the management of patients (adults and children two years and older) with eplilepsy who are not satisfactorily

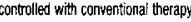

There is limited intormation on the use of TOPAMAX in monotherapy at this time.

Geriatrics (> 65 years of age)

There is imited information in patients over 65 years of age. (see WARNINGS AND PRECAUTIONS, Special Populations, Geriatrics).

CONTRAINDICATIONS

- Patients who are hypersensitive to this drug or to any ingredient in the formulation or component of the container

WARNINGS AND PRECAUTIONS

General

Antiepleptic drugs, including TOPAMAX (topiramate), should be withdrawn gradually to minimize the potential of increased seizure frequency. In adult clinical trials dosages were decreased by 100 mydday at weekly intervals.

\section{Endiocrine and Metabolism}

Ollgohidrosis and Hyperthermia
Oligohidrosis idecreased sweating and hyperthermia, infrequently resulting in hospitalization, have been reported in patients treated with topiramate. Oligohiorosis and hyperthemia may have potentially serious sequelae and may be preventable by prompt reccognition of synptoms and appropriate treatmert. Decreased sweating and

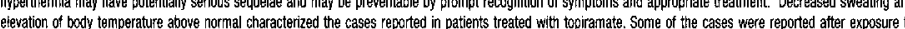
elevated envirormental temperatures.

These reports have primarly involved chiloren. Patients traated with TOPAMAX, especially pediatric patients, should be monitured closely for evidence of decreased sweating and increassod body temperature, perticulary in hot weather. Proper hydration before and during activities such as exercise or exposure to warm temperature is recommented.

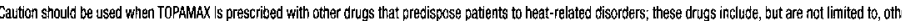
carbonic anhydrase inhibitiors and drigs with anticholinergic activity. (see ADVERSE REACTIONS, Post-Market Adverse Drug Reactions)

Nutritionat Supplementation

A cietany supplement or increased food intake may be considered if the patient is losing weight while on this medication.

Hepatic/Biliary/Pancreatic

In heaatically impaired pationts, TOPAMAX should be administered with caution as the clearance of topiramate was decreased compared with normal subjects

Neurolegic

with the asse of TOPAMAX were central nervous systen related. In adults, the most signiticant of these can be dlassified int two gere

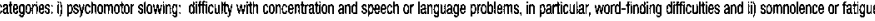

Additional nonspecific CNS effects occasionally observed with TOPAMAX as add-on therapy include dizziness or imbalance, confusion, memory problems, and exacertation of mood disturbances $(e$. g. iritiability and depression.

These events were generaliy mild to moderate, and generally occurred early in therapy. While the incidence of psychomotor slowirn does not appear to be dose related both language problems and difficulty with concentration of attention increased in freguency with increasing dosage in the six double-blind trials, suggesting that these events are dose related (see ADVERSE REACTIONS, Post-Market Adverse Drug Reactions).

Paresthesia

Paresthesia, an effect associated with the use of other carbonic anhydrase inhibitors, appears to be a common effect of TOPAMAX therapy. These events were usualy intermittent and mild. and not necessarily related to the dosage of ropAMAXX.

Ophthalmologic

\section{Acute Myopia and Secondary Angle Closure Glaucome}

A syndrome consisting of acute myopia associated with secenddary angle closure glaucoma has been reportec in patients receiving TOPAMAX. Symintoms include acute onset of decreased yisual aculty andior ocular pain. Ophthalmologic findings can include myopia, anterior chamber shallowing, ocular hypoeremia (redness) and increased intraocular pressure. Mydriasis may or may not be present. This syndrome may be associated with supracillary fefiusion resuting in anterior displacement of the lens and iris, with secondary angle closure glascoma. Symptoms typically occcur within a tew days to i month of intiating TOPAMAX therapy. In contrast to primary narrow angle glaucoma, which is rare under 40 years of age, secondary angle ciosure glaucoma associated with TOPAMAX has been reported in peciatric patients as well as adults The primary treatiment to reverse symptoms is discontinuation of TOPAMAX as rapidly as poss ble, accorring to the judgment of the treating physician. Other measures, in conjunction with discontinuation of TOPAMAX, riay be hejpifu (see ADVERSE REACTIONS, Post-Market Adverse Drug Reactions).

all cases of a dete

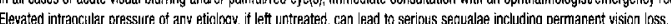

Renal

Kidney Stanes

A tota of $32: 1,715(1.5 \%)$ of patients excosed to TOPAMAX during its developmert reported the occurrence of kidney stones, an incidence about 10 times that expected in a similar, untreated population, (MFF ratio: 27/t,092 male; 5/623 fentale). in the general population, risk tactors for kidney stone formation include gender (male), ages between 20-50 years, prior stone formation, family history of nephroithiasis, and hypercalciurria. Based on logistic regression analysis of the clinical trial data, $\mathrm{n}$ comelation between maan TOPAMAX dosage, duration of TOPAMAX therafy, or age and the occurrence of kidney stones was estabished; of the risk factors evaluated only sender [malei showed a correlation with the occurrence of kidney stones. In the pediatric patients studied, there were no kidney stones observed

Carbonic anthydrase inhisitiors, e.g. acetazolamide, promote stone formation by reducing urinary citrate excretion and by increasing urinary of. Conconitant use of TOPAMAX, a weak carbonic anhycrase intibitior, with other carconic anhydrase inhibiters may create a physiclogical environment that increases the risk of kidney ston formation, and should therefore be avolice

Patents, especially those with a predisposition to neghrolititiasis, may have an increased risk of renal stone tormaticn and asssciated signs and symptoms such as rena colic, renal pain of flark pain. Increased fluid intake increases the urinary output, lowering the concentration of substances involved in stone formation. Therefor adequate hydration is recommended to reduce this risk. None of the risk factors for nephrolithiasis can reliably predict stone tormation during TOPAMAX treatmen. Adjustment of Dose in Renal Fallure

The major route of elimination of unchanged tooiramate and its metabolites is via the kidney. Renal elimination is degendent on renal function and is independent of age

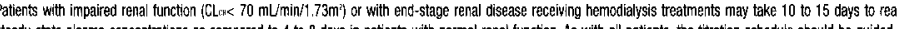
steady-state plasma concentrations as compared to 4 to 8 days in patients with rormal renal function. As with all patients, the titration schedule should be guided by state at each dose (see DOSAGE AND ADMINISTRATION, Dosing Considerations)

\section{Intormation tor Patients}

Patents, especially those vith predisposing factors, should be instructed to maintain an adequate fluid intake in orcer to minirize ti:e risk of renal stone formation. Patents also should be instructed to increase and maintain fluid intake prior to and during activities such as exercise and exposure to warn temoeratures ta help preyen complications from decreased sweating.

Effects on Ablitity to Drive and Use Machines

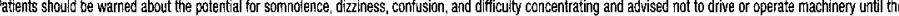
have gained sufficient experience on TOPAMAx to gauge whether it adversely affects their mental and/or motor performance.

Acute Myopia and Secondary Angle Closure Glaucoma

Patents taking TOPAMAX should be told to immediately contact their doctor and/or ga to the Energency Asom if they;their child experience(s) sudden worsening of vision, blured vision or paintul red eyeiss?.

\section{Snecial Population}

\section{Pregnant Worn:}

Pre other antiepileptic drugs, topiramate was teratogenic in mice, rats, and rabbits, In rats, topiramate crosses the placental bartier

There are no studies using TOPAMAX in pregnant women. However, TOPAMAX therapy should be used during preglancy only if the potential benefit outweighs the potent risk to the fetus.

In post-marketing experience, cases of hypospadias have been reported in male infants exposed in utero to TOPAMAX, with or without other anticonwilsants, however,

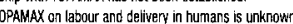

Nursing Women:

Topiramate is excreted in the milk of lactating rats. The excretion of top ramate in human milk has not been evaluated in control ed studies. Limited observations in patient suggest an extensive excretion of topicanate intt breast milk. Since the potential for serious adverse reactions in nursing intents exposed to TOPAMAXX exists, the

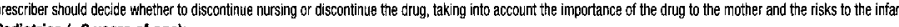

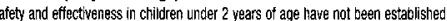

Weight Loss in Pediatrics ( $>2$ years of age

TOPAMAX administration is associated with weight loss in some chiddren that generally occurs early in therapy. Of those petiatric subjects trented in clinical trials for at least Jear who experienced weight css, $96 \%$ showed a resumpton of weight gain within the period tested. In 2-4 year-olds, the mean change in weight from baseine at 12 month

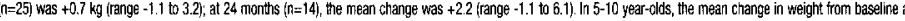

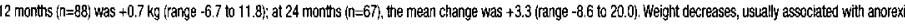
or appettite changes, were repprted as acverse events for $9 \%$ of patients treated with TOPAMAX, The long-term effects of reduced weight gain in pediaticic patients are not known. Geriatrics ( $>65$ years of age):

There is imited information in patients over 65 years of age. The possibility of age-associated rena function abnornal ties should be consideres when using TOPAMAX

\section{Monitoring and Laboratory Tests}

thas seen observed in clinical trials the
Drug Reaction Overview

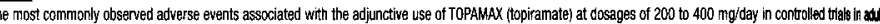
dosage range were: sommolence, dizzhess, alus

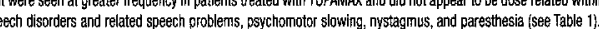

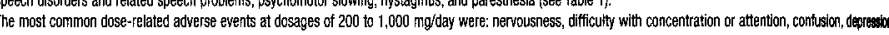
anosexia, anguage probiems, and mood problems (see Table 2)

ediatrics

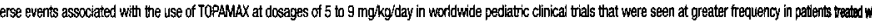

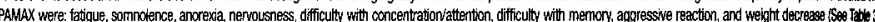
linical Trial Adverse Drug Reactions

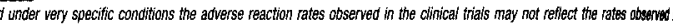

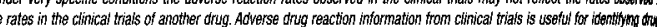
practice and should not be compared to the rates in

Table 1: Incidence of Treatment-Emergent: Adverse Events in Placebb-Controlled, Add-On Triels in ADULTS *n

(Events that occurred in $\geq 2 \%$ of patients treated with TOPAMAX and occirred more frequently in patients treated with TOPAMAX than placebo-tratites patilert

\begin{tabular}{cccc}
\hline & \multicolumn{3}{c}{ TOPAMAX Dosage (mgicay) } \\
\cline { 2 - 4 } Body System/ & Placebo & $200-400$ & $600-1,000$ \\
Adverse Event & $(n=216)$ & $(n=113)$ & $(n=414)$ \\
& &
\end{tabular}

\section{Body as a Whole}

Asthenia

Back Pain

Chest Pain

Leg Pain

Nervous System

Dizziness

Ataxia

Speech Disorders/Related Speech Prob:ems

Nystagmu

Paresthes

Fremor

Language Problems

Coordination Abnorma

Hypoaesthesia

Abnormal Gar

Gastrointestinal System

Naussea

Dyspepsia

Abdominal Pain

Constipation

Dry Mouth

Metabolic and Nutritiona

Weight Decrease

Neuropsychiatric

Somnolence

Psychomotor Slowing

Nervousness

Difficulty with Memory

Confusion

Depression

Difficully with Concentration/Attention

Anorexia

Antation

Mood Problems

Aggressive Reaction

Apatily

Depersonalization

Emoticna: Lability

Reproductive, Fema

Breast Pain, Female

Dysmenorhthea

Menstrual Disorder

Reproductive, Male

Prostatic Disorder

espiratory System

Pharyngitis

Rhinitis

Sinustis

Dyspnea

Skin and Appendages

Pruritus

$\begin{array}{lll}1.4 & 8.0 & 3.1 \\ 4.2 & 6.2 & 2.9 \\ 2.8 & 4.4 & 2.4 \\ 3.2 & 3.5 & 3.5 \\ 2.3 & 3.5 & 3.6 \\ 1.9 & 2.7 & 0.7\end{array}$

Vision

Vision Abrorm

White Cell and RES

Leukoperia

\begin{tabular}{|c|c|}
\hline 15.3 & 28.3 \\
\hline 6.9 & 21.2 \\
\hline
\end{tabular}

$\begin{array}{ll}2.3 & 16 . \\ 93 & 150\end{array}$

15.0
15.0

10.6

$6.0-10$.

0.5

0.9

0.9

$\begin{array}{rr}2.8 & \\ 9.7 & \\ 2.3 & \\ 7.4 & \\ 3.2 & \\ 4.2 & \\ 5.6 & \\ 1.4 & \\ 3.7 & \\ 1.4 & \\ 1.9 & \\ 0.5 & \\ 0 & \\ 0.9 & \\ 0.9 & \\ \text { (n)=59. } & \\ 1.7 & \\ 6.8 & \text { in } \\ 0 & \\ \text { in=157) } & \\ 0.6 & \end{array}$
Values represent the percentage of patients reporting a given adverse event. Patients may have reported more than one adverse event durim the study and can be includad in more than one adverse event category.

Table 2: Incicence (\%) of Dose-Related Adverse Events From Placebo-Controlled, Add-On Trials in ADUUTS

\begin{tabular}{|c|c|c|c|c|}
\hline \multirow[b]{2}{*}{ Adverse Event } & \multicolumn{4}{|c|}{ TOPAMAX Dosage (mg/day) } \\
\hline & $\begin{array}{l}\text { Placebo } \\
(n=216)\end{array}$ & $\begin{array}{c}200 \\
(n=45)\end{array}$ & $\begin{array}{c}400 \\
(n=68)\end{array}$ & $\begin{array}{c}600-1,000 \\
(n=414)\end{array}$ \\
\hline Fatigue & $\$ 3.4$ & 11.1 & 11.8 & 29.7 \\
\hline Nervousness & 7.4 & 13.3 & 17.6 & 19.3 \\
\hline Difficulty with Concentratio//Attention & 1.4 & 6.7 & 8.8 & 14.5 \\
\hline Contusion & 4.2 & 8.9 & 10.3 & 13.8 \\
\hline Depression & 5.6 & 8.9 & 7.4 & 13.0 \\
\hline Anorexia & 3.7 & 4.4 & 5.9 & 12.3 \\
\hline Language problems & 0.5 & 2.2 & 8.8 & 10.1 \\
\hline Anxiety & 6.0 & 2.2 & 2.9 & 10.4 \\
\hline Mood problems & 1.9 & 0 & 5.9 & 9.2 \\
\hline
\end{tabular}

In six double-blind chinical trials, $10.6 \%$ of subjects (n $=113$ ) assigned to a TOPAMAX dosage of 200 to 400 modday in addition to their standard AED therapy disconthumed due to adverse everts, compared to $5.8 \%$ of subjects (n=69) receiving placebo. The percertage of subjects discontinuing due to adverse events appeared to increase

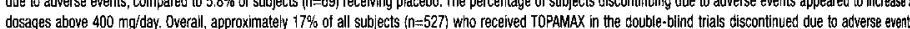
con

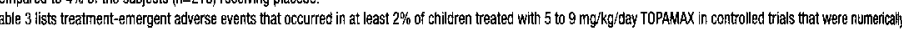
more common then in patients treatad with placebo.

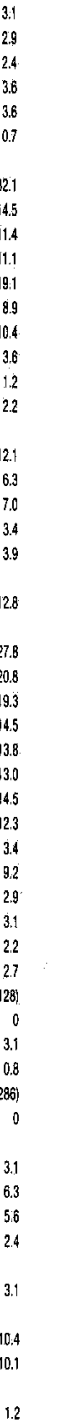



Table 3: Incidence (\%) of Treatment-Emergentr Adverse Events in Worldwide Pediatric Cllnicai Trials Experience (2-16 years of Ageje)

\begin{tabular}{|c|c|c|}
\hline $\begin{array}{l}\text { Body System/ } \\
\text { Adverse Event }\end{array}$ & $\begin{array}{l}\text { Placeno } \\
(\mathrm{n}=101\}\end{array}$ & $\begin{array}{c}\text { Topiramate } \\
(n=98)\end{array}$ \\
\hline \multicolumn{3}{|l|}{ Body as a Whole - General Disorders } \\
\hline Fatigue & 5 & 16.3 \\
\hline Iniury & 12.9 & 14.3 \\
\hline Alergic Recction & 1 & 2 \\
\hline \multicolumn{3}{|c|}{ Central and Peripheral Nervous System Disorders } \\
\hline Gait Abnormal & 5 & $8: 2$ \\
\hline Ataxia & 2 & 6.1. \\
\hline Hyperkinesia & 4 & 5.1 \\
\hline Dizziness & 2 & 4.1 \\
\hline Speech Disorders;Relatec Speech Probiems & 2 & 4.1 \\
\hline Convilsions Aggravated & 3 & 3.1 \\
\hline Hyporeflexia & 0 & 2 \\
\hline \multicolumn{3}{|l|}{ Gastrointestinal System Disorders } \\
\hline Nausea & 5 & 6.1 \\
\hline Saliva Ircreased & 4 & 6.1 \\
\hline Constipation & 4 & 5,1 \\
\hline Gastroenteritis & 2 & 3.1 \\
\hline \multicolumn{3}{|l|}{ Metabolic and Nutritional Disorders } \\
\hline Weight Decrease & 1 & 9.2 \\
\hline Thirst & 1 & 2 \\
\hline \multicolumn{3}{|l|}{ Platelet, Bleeding and Clotting Disorders } \\
\hline Purpura & 4 & 8.2 \\
\hline Epistaxis & 1 & $4 . t$ \\
\hline \multicolumn{3}{|l|}{ Nervous Disorders } \\
\hline Somnolence & 15.8 & 25.5 \\
\hline Anorexia & 14.9 & 24.5 \\
\hline Nervoustreass & 69 & 14.3 \\
\hline Personality Disorder (Behavinur Problems) & 89 & 112 \\
\hline Difficulty with Concentration/Attention & 2 & 10.2 \\
\hline Aggressive Reaction & 4 & 9.2 \\
\hline Insomnia & 6.9 & 8.2 \\
\hline Mood Probients & 6.9 & 71 \\
\hline Difficulty with Memory NOS & 0 & 5.1 \\
\hline Emotional Lability & 5 & 5.1 \\
\hline Confusion & 3 & 4.1 \\
\hline Psychiomotor Stowing & 2 & 3.1 \\
\hline \multicolumn{3}{|l|}{ Reproductive Disorders, Female } \\
\hline Leukorrhea & 0 & 2.3 \\
\hline \multicolumn{3}{|l|}{ Resistance Mochanism Disorders } \\
\hline Infection Viral & 30 & 7.1 \\
\hline Infection & 3.0 & 3 \\
\hline \multicolumn{3}{|l|}{ Respiratory System Disorders } \\
\hline Upper Respoiratory Tract Intection & 36.6 & 367 \\
\hline Fneumonia & 1.0 & 5.1 \\
\hline \multicolumn{3}{|l|}{ Skin and Appendages Disorders } \\
\hline Skin Disorder & 2.0 & 3.1 \\
\hline Alcpecia & 1.0 & 2.0 \\
\hline Dermattilis & 0 & 2.0 \\
\hline Hypentrichosis & 1.0 & 2.0 \\
\hline Rash Erythematous & 0 & 2,0 \\
\hline \multicolumn{3}{|l|}{ Urinary System D|sorders } \\
\hline Urinary Incontinence & 2.0 & 4.1 \\
\hline \multicolumn{3}{|l|}{ Vision Disorders } \\
\hline Eye Abnorrtality & 1.0 & 20 \\
\hline Vision Abrormal & 1.0 & 2.0 \\
\hline \multicolumn{3}{|l|}{ White Cell and RES Disorders } \\
\hline Leukopenta & 0 & 2.0 \\
\hline
\end{tabular}

- Patients in these add-on trials were receiving 1 to 2 concomitant antiepileptic duugs in addition to TOPAMAX or placebo.

- Values represent the percentage of patients reporting a given adverse event. Patients may have reported more than one adverse event during the study and can be induced in more than one adverse event category

"Not otherwise specifitied

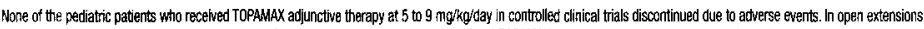
of the controlled cinical vials, approximatety $9 \%$ of the 303 pedilatic patients who received TOPAMAX at dosages up to $30 \mathrm{mg} / \mathrm{kg}$ day discontinued due to adversa events

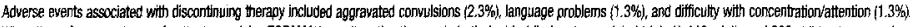
When the safety experience of patients receiving TOPAMAX as adjunctive therapy in both dousle-blind and open-label trials (1,446 aduts and 303 children) was analyzed, a similar patterf of adverse events emerged

Less Common Clinical Trlal Adyerse Drug Reactlons $(<1 \%$

Adverse events that occured less freacuently but were considered potentially medically relevant included: taste perversion, cognitive problems (not othenewise specified) and psychosisipsyychotic symptoms.

in adult and pediatric patients, nephrollitiasis was reportad rarely. Isolated cases of thromboembolic events have also been reported; a causal association with the drug nas not been establisher

In clinical trials with topisamate, the occurrence rate for all potential cases of oligohidrosis (decreased sweating) was $0.25 \%$.

Post-Market Adverse Drug Reactions

In addition to the adverse experiences reported during clinical trial testing of TOPAMAX, the following adverse experiences have been reported in patients receiving marketed TOPAMAX from worldwise use since approval. Fhere are insufficient datat to support an estimate of their incidence or to establish causation

The miost trequenty reporied adverse events in spontaneous post-makketing reports on TOPAMAX include:

Psychiatric: somnolence or sedation, hallucination(is), depression, anorexia, aggressive reaction, psychosis, thinking abnormal, insomnia, emstional lability, suicide attempt, delisioint, amnesia, contission, nervousness, agitation, concentration impaired, personality disorder, anxiety

Central and Peripheral Nervous System: convulsions aggravated, paresthesia, speech disorder, ataxia, dizziness, convulsions, headache, hyperkinesia, convulsions grand ma

Metatolic and Nutrittonal: weight decrease, metabolic acidosis, hypokalemia, hyperchiloremia

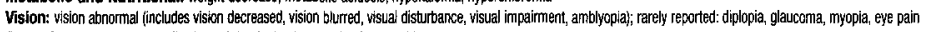
Gastrointestinal: nausea, diarnea, aboominal pain, consitipation, vomition

Body as a Whole - General Disorders: fatigue, fever, dehydration, flushing, hot tushes

Urinary System: renal calculus

\section{Skin and Appendages: rash, alopecin}

White Cell and RES Disorders: leuccopenia, thrombocytocenia

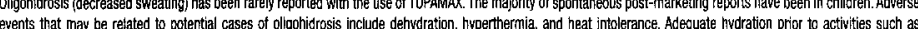
events that may oe related to potentlal cases of olloghidrosisis includede dehydration, hyperthermia, and heat intolerance. Adequate hydration

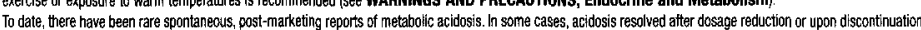
of topiramate.

Rare reports of encephalopatty with or without hyperammonemia have been recelves for patients treated with TOPAMAX while also taking valproate or other antiepileptic medications (see DRUG INTERACTIONS.

Repots of increases in liver function tests in patients taking TOPAMAX with and without other medications have been received. Isolated reports have been received of hepattisis and hepatic tailure occurring in patients taking multiple medications while being treated with TOPAM

Very rare reports have aso been received for bullous skin and mucosal raactions finclusing Stevens-Johnson syndrome, toxic epidermal necrolvsis, erythema multiforme and pemphigus) The majority of these reports have occurred in patients taking other mecications that can be associated with bullous skin and murosal reactions.

DRUG INTERACTIONS

Drug-Drug interaction

Antiepileptic, Drues

Effects of TOPAMAX on other Antieplentic Druge

Potential interactions between TOPAMAX and standard AEDS were measured in controlled clinical pharmacokinetic studies in patients with epilepsy. The addition of TOPAMAX to other antiepileptic drugs (onenytion, carbamazepine, valproic acid, phenobarbital, prinimidone) has no effect on their steady-state plasma concerritations, except in the occasional patient, where the addrition of TOPAMAX to phenylon may resultin an incease of plasma concentrations of phention.

The effect of TOPAMAX on steady-state pharmacokinetics of phenytoin may be related to the frequency of phenytoin dosing. A sight increase in steady-state phenytois plasma concentrations was observed, primarly in patients recevining phenytoin in two divided doses. The slight increase may be due to the saturable nature of phenytoin pharmacokinetics and intibition of phenytoin metabolism iCYP2C

The addition of TOPAMAX therapy to phenytoin should be guided by clinical outcome. In general, as evidenced in ciricical trials, patients do not require cose adjustments. However, any patient on phenythin showing clinical signs or symptoms of toxicity should have phenytoin levels monitored.

Effects of Other Antiepileptic Dugs on TOPAMAX

Phenytoin and carbamazepine decrease the plasma concentration of topiremate. The adsition or witthorawal of phenytoin andior carbamazepine during adjunctive therapy

with TOPAMAX may require adjustment of the dose of TOPAMAX. This should be done by titrating to clinica effect. The addition or withdrawal of valproic acid does not produce clinically significant changes in plasma concentrations of topiramate, and therefore, does not warrant dosage adjustment of TOPAMAX. antiepileptic medications. Thus, gaution is advised whan poytherapy with valproate is necessary (see ADVERSE REACTIONS, Post-Market Adverse Reactions) Table 4: Drug Interactions with TOPAMAX Therapy

\begin{tabular}{|c|c|c|}
\hline $\begin{array}{c}\text { AED } \\
\text { Co-administered } \\
\end{array}$ & $\begin{array}{c}\text { AED } \\
\text { Concentration } \\
\end{array}$ & $\begin{array}{c}\text { Topiramate } \\
\text { Concentration }\end{array}$ \\
\hline $\begin{array}{l}\text { Phenytoin } \\
\text { Carbanazepine (GBZ) } \\
\text { CBZz epoxide* } \\
\text { Yaloroic acid } \\
\text { Pnenobarbital } \\
\text { Primisone }\end{array}$ & $\begin{array}{l}\leftrightarrow * \\
\ddot{*} \\
\ddot{*} \\
\dot{\ddot{11} \%} \\
\ddot{\leftrightarrow} \\
\ddot{\leftrightarrow}\end{array}$ & $\begin{array}{l}\downarrow 59 \% \\
\downarrow 40 \% \\
\text { NS } \\
\downarrow 14 \% \\
\text { NS } \\
\text { NS }\end{array}$ \\
\hline
\end{tabular}

Is not administered but is an active nettabolite of carbamazepine

No effect on plasma concentration ( $15 \%$ e change)

Plasma concentrations increased $25 \%$ in some patients, generally those on a b.i. d. cosing regimen of phentfoin

$\downarrow$ Plasma concentrations decrease in individual patients

IS Not studied

AED Antiepileptic drug

Other Drug Interactions

Digoxin: In a single-dose study, serum digoxin AUC decreased 12\% due to conconitant TOPAMAX administration. Multiple-dose studies have not been performed, When TOPAMAX is added of withdrawn in natients on digoxin therapy, careful attention should be given to the routine monitoring of senum digoxil.

CWS Oepressants: Concomitant administration of TOPAMAX and alcohol or other CNS dapressant drugs has not been evaluated in cinical studies. It is recommended tha TOPAMAX not be used concomitantly with alcohol or other CNS depressent drugs.

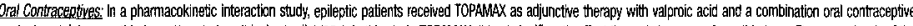

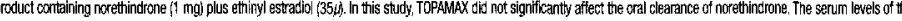

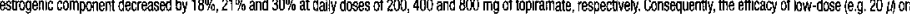

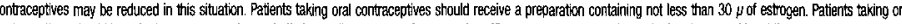

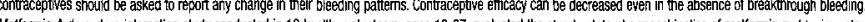

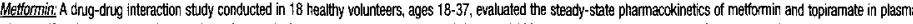

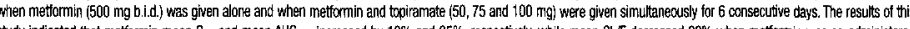

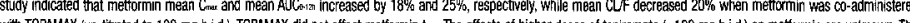

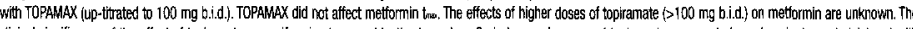
clinical significance of the effect of topiramate on metformin pharmacksinetics is unclear. Oral plasma clearance of topiramate appears to be reduced when administeresd with mettormin. The extent of change in the clearance is unkroum. The clinical significance of the effect of mettormin on topiramate phamacokinetics is unellear. When TOPAMAX

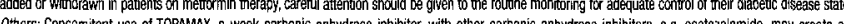

Others: Concomitant use of TOPAMAX, a weak carbonic anhydrase inhibitor, with other carbonic antydrase inthibitors, e.g. acetazolamide, may create a physiological envirorment that increases the risk of renal stone formation, and strould therétore be avoided if possibic

Orug-Foed Interactions

There was no dinicaly significant effect of food on the bipavalability of topiramate.

Drug-Herb Interactions

Deractions with herbal products have not been established,

Drug-Laboratory Interactions

There are no known interactions of TOPAMAX with commonly used laboratory tests.

DOSAGE AND ADMINISTRATION

Dosing Considerations

- Patients with renal inipaiment

- Patients undergoing hemodialysit

- Patients with hepatic disease

Recommended Dose and Dosage Adjustment

Ther or Sprikle Capsules can be taken without regard to meals.

Adults (Age 17 years ans older)

It is recommended that TOPAMAX as adjunctive therapy be initiated at 50 modday, followed by fitration as needed and tolerated to an effective dose. At weekly intervals the dose may be increased by $50 \mathrm{mg} / \mathrm{day}$ and taken in two divided doses. Some patients may benefit trom lower initial doses, e.g., $25 \mathrm{mg}$ and dor a slower titration schedule. Some patients may achieve efficacy with once-a-day cosing.

The reconmended total daily maintenance dose is $200-400 \mathrm{mg}$ diday in two divided doses. Doses above $400 \mathrm{mg}$ /day have not been shown to improver responses and have been associated with a greater incidence of adverse events. The maximum recommended c0se is $800 \mathrm{mg} /$ day. Dailly doses above $1,600 \mathrm{mg}$ have not been studiled

Children (Ages 2-16 years)

is recommended that TOPAMAX as adjunctive therapy be initiated at $25 \mathrm{mg}$ gor less, based on a range of 1 to $3 \mathrm{mg} / \mathrm{kg}$ dayy nightly for the first weak followed by titration as needed and tolerated to an effective dose. The dosage should then be increased at 1 - or 2 -week intervals by increments of 1 to 3 mgikg/day jadministored in two divided dosess). Some patients may benefit from lower initial doses andior a slower fitration schedule

The reconmended total daily maintenance dose is approximately 5 to $9 \mathrm{mg} / \mathrm{kg}$ /day in two divided doses. Daily doses up to $30 \mathrm{mo} / \mathrm{kg} / \mathrm{day}$ have been stud ed and were generally well tolerated.

Geriatrics

GQ WARNINGS AND PRECAUTIONS

Patients with Renal Impairment

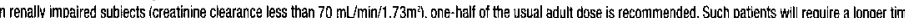
to reach steady-state at each dose.

Patients Undergoing Hemodialysis

Topitanate is cleared by hemodialysis at a rate that is 4 to 6 times greater than a normal indvicual. Accordingly a prolonged period of dialysis may cause topiramete concentration to tall below that required to maintain an antise izure effect To aveid rapid drons in topiramate plasma concentration during hematialysis, a supplement dose of TOPAMAX may be required. The actual adjustrment should take into account 1) the duration of dialysis, 2 ; the clearrance rate of the dialysis system being usec, and 3) the effective renal clearance of topiramate in the patient being dialyzed

Patients with Hepatic Disease

in hepatically impaired patients, topiramate plasma conceentrations are increased approximately $30 \%$. This moderate increase is not considered to warrant adjustment of the TOPAMAX dosing regimen. Initiate topiramate therapy with the same dose and regimen as ior patients with normal hepatic tunction. The dose thration in these patients should be guided by cilinical outcome, I.e. seizure control, and avoidance of adverse effects. Such patients will reauire a longer time to reach' steady-state at each dose Missed Dose

The missed dose should be taxen as soon as possible. If it is almost time for the next cose, the missed dose shoud not be taken. Instead, the next scheduled dose should be taken. Doses should not be doubled.

Administration

ablets should not he broken. TOPAMAX Sprtinke Capsules may be swallowed whole or may be admiristered by careftuly opening the capsule and sprinking the entite

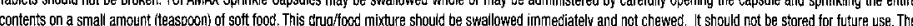

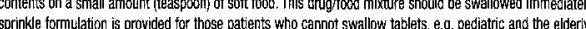

OVERDOSAGE

Ingestion of between 6 and $40 \mathrm{~g}$ topiramate has been reported in a few patients. Signs and symptoms included: headache, agitation, drowsiness, lethargy, metabo: acidosis and hypokalemia. The clinical consequences were not severer. Al patients reccovered.

A patent who ingested a dose calculated to be between 96 and $110 \mathrm{~g}$ topiramate was admitted to hospital with coma lasting 20-24 hours followed by fill secovery after 3 to 4 days.

General supportive measures are insilicated and an attempt should be made to remove undigested drug trom the gastrointestinal tract using gastric lavage or activated charcoal. Hemodialysis has been shown to be an effective means of remaving topiramate trom the body. The patient should be well hydrated.

DOSAGE FORMS AND PACKAGING

Availabitity of Dosage Form

TOPAMAX (topiramate) is availabie as embossed, round, coated tablets in the following strengths and colours: $25 \mathrm{mg}$ white, $100 \mathrm{mg}$ yellow and $200 \mathrm{mg}$ salmon. They are marked as follows.

$25 \mathrm{mg:}$ "TOP" on cres side; "25" on the other.

100 mg: "TOP" on cone side; "100" on the other.

$25 \mathrm{mg}$ ment

.

TOPAMaX itopiramatey Sprinkle Capsules contain small white to off-white spheres. The gelatin capsules are white and cibar. They are marked as follows

$15 \mathrm{mg}: \quad$ "TOP" and "15 $\mathrm{mg}$ " on the side.

Susplied: $\quad$ Bottles of 60 capsules without desiccant

TOPAMaX is a Schedule $F$ drug

Product Moncograph available uppon request

\section{JANSSEN-ORTHO}

19 Green Belt Drive

Toronto, Ontario M3C $1 \mathrm{Lg}$

Last Revised December 2003

TXBP041005A 8011

(C) 2003 JANSSEN-ORTHO ITC

"All trademark rights used under license

A-45

See pages A-8, A-9 


\section{BETASERON}

\author{
Interferon beta- $1 \mathrm{~b}$
}

\section{THERAPEUTIC CLASSIFICATION}

\section{Immunomodulator}

ATION AND CLINICAL PHARMACOLOGY

Description: BETASERON® (interferon beta-1b) is a purified, sterile, lyophilized protein product produced by recombinant DNA techniques and formulated for use by injection. Interferon beta- $-1 \mathrm{~b}$ is manufactured by bacterial fermentation of a strain of Escherichia colithat bears a genetically engineered plasm containing the gene for human interferon betasert?. The native gene was obtained from human fibroblasts and altered in a way that substitutes serine for the cysteine residue found at position 17 . Interferon beta- $1 \mathrm{~b}$ is a highly purified protein that has 165 amino acids and an approximate molécular weight 18,500 daltons. It does not include the carbohydrate side chains found in the natural materia.

General: Interferons are a family of naturally occurring proteins, which have molecular weights ranging from 15,000 to 21,000 daltons. Three major classes of interferons have been identified: alpha, beta, and gamma. Interferon beta-1b interferon alpha, and interferon gamma have overlapping yet distinct biologic activities. The activities of interferon beta are species-restricted and therefore, the most pertinent phe cological information on BETASERON (interferon beta cological information on BETASERON (interferon beta-1b) Biologic Activities: Interferon beta- $1 \mathrm{~b}$ has been shown
to possess both antiviral and immunomodulatory activities. to possess both antiviral and immunomodulatory activities. The mechanisms by which BETASERON exerts its actions in
multiple sclerosis (MS) are not clearly understood. However, multiple sclerosis (MS) are not clearly understood. However,
it is known that the biologic response-modifying properties of interferon beta-1 $1 \mathrm{~b}$ are mediated through its interactions with interferon beta-1b are mediated through its interactions with
specific cell receptors found on the surface of human cells. The binding of interferon beta- $1 \mathrm{~b}$ to these receptors induces the expression of a number of interferon-induced gene products $\left(e .9 .2^{2}, 5^{\prime}\right.$-oligoadenylate synthetase, protein kinas and indoleamine 2,3-dioxygenase) that are believed to be the mediators of the biological actions of interferon betaA number of these interferon-induced products have been readily measured in the serum and cellular fractions of bloo collected from patients treated with interferon beta- $1 \mathrm{~b}$.

\section{INDICATIONS AND CLINICAL USE}

BETASERON (interferon beta- 1 b) is indicated for:

- the reduction of the frequency of clinical exacerbations in

ambulatory patients with relapsing-remitting multipl sclerosis. Relapsing-remitting MS is characterized by recurrent attacks of neurologic dystunction followed by complete or incomplete recovery.

- the slowing of progression in disability and the reduction of the frequency of clinical exacerbations in patients with secondary-progressive multiple sclerosis.

The safety and efficacy of BETASERON in primary progressive MS have not been evaluated.

\section{CONTRAINDICATIONS}

BETASERON (interferon beta-1b) is contraindicated in patien with a history of hypersensitivity to natural or recombinant interferon beta, Albumin Human USP, or any other component of the formulation.

\section{WARNINGS}

The administration of cytokines to patients with a pre-existing monoclonal gammopathy has been associated with the development of systemic capillary leak syndrome with shocklike symptoms and fatal outcome.

In the RR-MS clinical trial, one suicide and four attempted suicides were observed among 372 study patients during a 3-year period. Al five patients received BETASERON (interferon
beta-1b) (three in the $0.05 \mathrm{mg}$ [1.6 MIU] group and two in the $0.25 \mathrm{mg}$ [8.0 MIU] group). There were no attempted suicides in patients on study who did not receive BETASERON. In the SP-MS study there were 5 suicide attempts in the placebo group and 3 in the BETASERON group including one patient in each group who committed suicide. Depression and suicide have been reported to occur in patients receiving interferon should be informed that depression and suicidal ideation may be a side effect of the treatment and should report these symptoms immediately to the prescribing physician. Patients exhibiting depression should be monitored closely and cessation of therapy should be considered.

\section{PRECAUTIONS}

General: Rare cases of cardiomyopathy have been reported. If this occurs, and a relationship to BETASERON (interferon beta-1b) is suspected, treatment should be

Rare cases of thyroid dystunction (hyper-as well as hypothyroidism) associated with the use of BETASERON have been reported.

Symptoms of flu syndrome observed with BETASERON therapy may prove stressful to patients with severe cardi conditions. Patients with cardiac disease such as angina,
congestive heart failure or arrhythmia should be monitore closely for worsening of their clinical conditions.

Information to be Provided to the Patient: Patients should be instructed in injection techniques to assure the safe self-administration of BETASERON. (See below and the SETASERONФ INFORMATION FOR THE PATIENT Section.) Instruction on Self-injection Technique and Procedure It is recommended that the first injection be administered by or under the direct supervision of, a physician. Appropriate
instructions for reconstitution of BETASERON and self-injection using aseptic techniques, should be given to the patient. using aseptic techniques, should be given to the patient.
A careful review of the BETASERON@ INFORMATION FOR AHE PATIENT section is also recommended.

Patients should be cautioned against the re-use of needles
Pation or syringes and instructed in safe disposal procedures. Inform tion on how to acquire a puncture-resistant container for disposal of used needles and syringes should be given to the patient along with instructions for safe disposal of full containe Overall, $80 \%$ of patients in the two controlled clinical trials reported injection site reactions at one or more times during therapy. Post-marketing experience has been consistent with this finding, with infrequent reports of injection site necrosis. The onset of injection site necrosis usually appears early in therapy with most cases reported to have occurred in the first two to three months of therapy. The number of sites where necrosis has been observed was variable.

Rarely, the area of necrosis has extended to subcutaneous fat or fascia. Response to treatment of injection site necrosis with antibiotics and/or steroids has been variable. In some of these patients elective debridement and, less frequently, skin grafting took place to facilitate healing which could take from three to six months.

Some patients experienced healing of necrotic skin lesions while BETASERON therapy continued. In other cases new

necrotic lesions developed even after theraoy was discontirued.

The nature and severity of all reported reactions should be

The nature and severity of all reported reactions should be

carefully assessed. Patient understanding and use of aseptic
self-injection technique and procedures should be periodically reevaluated.

Flu-like symptoms are not uncommon following initiation of herapy with BETASERON. In the controlled MS clinical trials, acetaminophen was permitted for relief of fever or myalgia. Patients should be cautioned not to change the dosage of
he schedule of administration without medical consultation. the schedule of administration without medical consultation. Awareness of Adverse Reactions: Patients should be
advised about the common adverse events associated with the advised about the common adverse events associated with the use of BETASERON,particularly, injection site reactions and
flu-like symptom complex (see ADVERSE REACTIONS). Patients should be cautioned to report depression o suicidal ideation (see WARNINGS)

Patients should be advised about the abortifacient potentia of BETASERON (see PRECAUTIONS, Use in Pregnancy Laboratory Tests: The following laboratory tests are recommended prior to initiating BETASERON therapy and at periodic intervals thereafter: thyroid function test, hemoglobin, complete and differential white blood cell counts, platelet counts and blood chemistries including liver function tests. A pregnancy test, chest roentgenogram and ECG should also be performed prior to initiating BETASERON therapy. In the controlled MS trials, patients were monitored every 3 months. The study protocol stipulated that BETASERON therapy be discontinued in the event the absolute neutrophil count fe below $750 / \mathrm{mm}^{3}$. When the absolute neutrophil count had returned to a value greater than $750 / \mathrm{mm}^{3}$, therapy could be returned to a value greater than $750 / \mathrm{mm}^{2}$, therapy could be
restarted at a $50 \%$ reduced dose. No patients were withdrawn or dose-reduced for neutropenia or lymphopenia.

Similarly, if AST/ALT (SGOT/SGPT) levels exceeded 10 times the upper limit of normal, or if the serum bilirubin exceeded Slimes the upper linit of normal, therapy was disconcinued. each instance during the controlled MS trial, hepatic enzyme abnormalites returned to normal following discontinuation of
therapy. When measurements had decreased to below these levels, therapy could be restarted at a $50 \%$ dose reduction, it levels, therapy could be restarted at a $50 \%$ dose reduction, if clinically appropriate. Dose was reduced in two patients due
to increased liver enzymes; one continued on treatment an to increased liver enzymes; one continued on treatment and one was ultimately withdrawn

Drug Interactions: Interactions between BETASERON an other drugs have not been evaluated. Athough studies designed to examine drug interactions have not been done, it was note that BETASERON patients $(n=180)$ have received corticostero or ACTH treatment of relapses for periods of up to 28 days.
BETASERON administered in three cancer patients over cose range of $0.025 \mathrm{mg}(0.8 \mathrm{MIU})$ to $2.2 \mathrm{mg}$ ( $71 \mathrm{MIU})$ led to a dose-dependent inhibition of antipyrine elimination. The effect of atternate-day administration of $0.25 \mathrm{mg}$ (8 MIU) BETASERON on drug metabolism in MS patients is unknown.

Interferons have been reported to reduce the activity of hepatic cytochrome P450-dependent enzymes in humans a animals. Caution should be exercised when BETASERON is administered in combination with agents that have a narrow therapeutic index and are largely dependent on the hepatic cytochrome $\mathrm{P} 450$ system for clearance.

Impairment of Fertility: Studies in female rhesus monkey with normal menstrual cycles, at doses up to $0.33 \mathrm{mg}$ $10.7 \mathrm{M}$ MU)/ $\mathrm{kg} /$ day (equivalent to 32 times the recommended human dose based on body surface area comparison) show no apparent adverse effects on the menstrual cycle or on when administered over 3 consecutive menstrual cycles. The extrapolability of animal doses to human doses is not known. Effects of BETASERON on women with normal menstrual Eycles are not known.

ycles are not known.

Use in Pregnancy: BETASERON was not teratogenic at doses up to $0.42 \mathrm{mg}$ (13.3 MIUU) $/ \mathrm{kg} /$ day in rhesus monkeys, but demonstrated doss-related abortifacient activity when administered toses ranging from $0.028 \mathrm{mg}\{0.89 \mathrm{Mul} / \mathrm{kg} /$ day $(2.8$ time the recommended human dose based on body surface area comparison) to $0.42 \mathrm{mg}$ (13.3 Mil)/kg/day (40 times the recommended human dose based on bocy suface area comparison. The extrapolability of animal doses to human doses is not known. Lower doses were not studied in monkeys.Spontaneous abortions while on treatment were reported in 4 patients who participated in the BETASERON RR-MS clinical trial, whereas there was one induced abortion in each of the placebo and
BETASERON groups in the SP-MS trial. BETASERON given to hesus monkeys on gestation days 20 to 70 did not cause teraogenic effects; however, it is not known if teratogenic effects exist in humans. There are no adequate and well-controlled studies in pregnant women. Women of childbearing potential should take reliable contraceptive measures. If the patient becomes pregnant or plans to become pregnant while taking BETASERON, the patient should discontinue therapy. It is not known if interferons alter the efficacy of oral contraceptives. Nursing Mothers: It is not known whether BETASERON is excreted in human milk. Given that many drugs are excreted in human milk, there is a potential for serious adverse reactions in nursing infants, therefore a decision should be made whether to discontinue nursing or discontinue BETASERON treatment

Pediatric Use: Safety and efficacy in children under

8 years of age have not been established

Dependence Liability: No evidence or experience suggests that abuse or dependence occurs with BETASERON therapy: however, the risk of dependence has not been systematically evaluated.

\section{ADVERSE REACTIONS}

The following adverse events were observed in placebocontrol clinical studies of BETASERON (intereron beta-1b at the recommended dose of $0.25 \mathrm{mg}(8 \mathrm{MU}$ ) in patients with relapsing-remitting MS ( $n=124)$ and secondary-progressive S $(n=360)$;

1. Relapsing-remitting MS: Injection site reactions ( $85 \%$ and injection site necrosis $(5 \%)$ occurred after administration of BETASERON. Inflammation, pain, hypersensitivity, necrosis, and non-specific reactions were significantly associated ( $p<0.05)$
with the $0.25 \mathrm{mg}$ ( $8 \mathrm{MU}$ ) BETASERON-treated group,compared with the $0.25 \mathrm{mg}(8 \mathrm{MU})$ BETASERON-treated group,com
to placebo. Only inflammation, pain, and necrosis were reported as severe events. The incidence rate for injection site reactions was calculated over the course of 3 years. Th incidence rate decreased over time, with $79 \%$ of patients experiencing the event during the first 3 months of treatment compared to $47 \%$ during the last 6 months. The median time to the first occurrence of an injection site reaction was 7 days. Patients with injection site reactions reported these events 183.7days per year. Three patients withdrew from the 0.25 (8 MIU) BETASERON-treated group for injection site pain. Flu-like symptom complex was reported in $76 \%$ of the patients treated with $0.25 \mathrm{mg}$ (8 MIU) BETASERON. A patient was defined as having a flu-like symptom complex if flu-like syndrome or at least two of the following symptoms were concurrently reported: fever, chills, myalgia, malaise or sweating. Only myalgia, fever, and chills were reported as severe in mor than $5 \%$ of the patients. The incidence rate for flu-like symptom complex was also calculated over the course of 3 years. The incidence rate of these events decreased over time, with $60 \%$ of patients experiencing the event during the first 3 months of treatment compared to $10 \%$ during the last 6 months. The median time to the first occurrence of flu-like symptom complex was 3.5 days and the median duration per patient was 7.5 days per year

Laboratory abnormalities included.

- lymphocyte count $<1500 / \mathrm{mm}^{3}(82 \%)$

- ALT $($ SGPT) $>5$ times baseline value (19\%,

(no patients had absolute neutrophil counts $<500 / \mathrm{mm}^{3}$ ),

- WBC $<3000 / \mathrm{mm}^{3}(16 \%)$, and

- total bilirubin $>2.5$ times baseline value $(6 \%)$

Three patients were withdrawn from treatment with $0.25 \mathrm{~m}$ (8 MIU) BETASERON for abnormal liver enzymes including on following

Twenty-one (28\%) of the 76 females of childbearing age reated at $0.25 \mathrm{mg}$ (8 MIU) BETASERON and $10(13 \%)$ of the 76 females of childoearing age treated with placebo reported menstrual disorders. All reports were of mild to moderate severity and included: intermenstrual bleeding and spotting, early or delayed menses, decreased days of menstrual flow,

and clotting and spotting during menstruation.

Mental disorders such as depression, anxiety, emotional lability, depersonalization, suicide attempts and confusion were observed in this study. Two patients withdrew for confusion. One suicide and four attempted suicides were als reported. It is not known whether these symptoms may be related to the underlying neurological basis of MS, to BETASERON treatment, or to a combination of both. Some similar symptoms have been noted in patients receiving interferon alpha and both interferons are thought to act through the same receptor. Patients who experience these symotoms should be monitored closely and cessation of herapy should be considered.

Additional common clinical and laboratory adverse events sssociated with the use of BETASERON are listed in the following paragraphs. These events occurred at an incidence
of $5 \%$ or more in the $124 \mathrm{MS}$ patients treated with $0.25 \mathrm{mg}$ 


\begin{tabular}{lcc} 
Nervous System & & \\
Dizziness & $28 \%$ & $35 \%$ \\
Hypertonia & $24 \%$ & $26 \%$ \\
Depression & $24 \%$ & $25 \%$ \\
Anxiety & $13 \%$ & $15 \%$ \\
Nervousness & $5 \%$ & $8 \%$ \\
Somnolence & $3 \%$ & $6 \%$ \\
Confusion & $2 \%$ & $4 \%$ \\
Speech disorder & $1 \%$ & $3 \%$ \\
Convulsion & $0 \%$ & $2 \%$ \\
Hyperkinesia & $0 \%$ & $2 \%$ \\
Amnesia & $0 \%$ & $2 \%$ \\
Respiratory System & & \\
Sinusitis & $26 \%$ & $36 \%$ \\
Dyspnea* & $2 \%$ & $8 \%$ \\
Larnngitis & $2 \%$ & $6 \%$ \\
Skin and Appendages & $11 \%$ & $23 \%$ \\
Sweating* & $11 \%$ \\
Alopecia & $2 \%$ & $4 \%$ \\
Special Senses & & \\
Conjunctivitis & $10 \%$ & $12 \%$ \\
Abnormal vision & $4 \%$ & $7 \%$ \\
Urogenital System & & \\
Dysmenorshea & $11 \%$ & $18 \%$ \\
Menstrual disorder* & $8 \%$ & $17 \%$ \\
Metrorrhagia & $8 \%$ & $15 \%$ \\
Cystitis & $4 \%$ & $8 \%$ \\
Breast pain & $3 \%$ & $7 \%$ \\
Menorrhagia & $3 \%$ & $6 \%$ \\
Urinary urgency & $2 \%$ & $4 \%$ \\
Fibrocystic breast & $1 \%$ & $3 \%$ \\
Breast neoplasm & $0 \%$ & $2 \%$ \\
\hline
\end{tabular}

* significantly associated with BETASERON treatment $(p<0.05)$

It should be noted that the figures cited in Table 1 cannot be used to predict the incidence of side effects in the course of usual medical practice where patient characteristics and other factors differ from those that prevailed in the clinical trials. The cited figures do provide the prescribing physician with some basis for estimating the relative contribution of drug and nondrug factors to the side effect incidence rate in the population studied.

2. Secondary-progressive MS: The incidence of adverse events that occurred in at least $2 \%$ of patients treated with 8 MIU BETASERON or placebo for up to three years, orwhere an adverse event was reported at a frequency at least $2 \%$ higher with BETASERON than that observed for placebotreated patients in the secondary-progressive study, is presented in Table 2. Adverse events significantly associated with BETASERON compared to placebo $(\mathrm{p}<0.05)$ are also indicated in Table 2.

Table 2: Incidence of Adverse Events $\geq \mathbf{2} \%$ or $>\mathbf{2} \%$ Difference (BETASERON vs. Placebo) in the Secondary

Progressive MS Study

\begin{tabular}{|c|c|c|c|}
\hline & \\
\hline Adverse Event & $\begin{array}{c}\begin{array}{c}\text { Placebo } \\
\mathrm{n}=358\end{array}\end{array}$ & $\begin{array}{l}0.25 \mathrm{mg} \\
(8 \mathrm{MIU}) \\
\mathrm{n}=360\end{array}$ & $\begin{array}{l}\text { Neuropathy } \\
\text { Paresthesia } \\
\text { Hypertonia* }\end{array}$ \\
\hline Body as a Whole & & & Abnormal gait \\
\hline Asthenia & $58 \%$ & $63 \%$ & Depression \\
\hline Flu syndrome ${ }^{*}$ & $40 \%$ & $61 \%$ & Ataxia \\
\hline Pain & $25 \%$ & $31 \%$ & Dizziness \\
\hline Fever" & $13 \%$ & $40 \%$ & Incoordination \\
\hline Back pain & $24 \%$ & $26 \%$ & Insomnia \\
\hline Accidental injury & $17 \%$ & $14 \%$ & Vertigo \\
\hline Chills* & $7 \%$ & $23 \%$ & Emotional lability \\
\hline Pain in Extremity & $12 \%$ & $14 \%$ & Paralysis \\
\hline Infection & $11 \%$ & $13 \%$ & Somnolence \\
\hline Abdominal pain* & $6 \%$ & $11 \%$ & Tremor \\
\hline Malaise & $5 \%$ & $8 \%$ & Sweating increased \\
\hline Neck pain & $6 \%$ & $5 \%$ & Neuralgia \\
\hline Abscess ${ }^{\star}$ & $2 \%$ & $4 \%$ & Movement disorder \\
\hline Laboratory test abnormal & $1 \%$ & $3 \%$ & Sleep disorder \\
\hline Allergic reaction & $3 \%$ & $2 \%$ & Anxiety \\
\hline Chills and fever* & $0 \%$ & $3 \%$ & Hypesthesia \\
\hline Thorax pain & $2 \%$ & $1 \%$ & Nervousness \\
\hline
\end{tabular}

Cardiovascular System

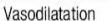

Peripheral vascular disorde

Chest pain

Migraine

Hypotension

Hypertension

Palpitation

Syncope

Tachycardia

Digestive System

Nausea

Constipation

Diarrhea

Gastroenteritis

Vomiting

Dysphagia

Gastrointestinal disorder

Tooth disorder

Dyspepsia

Anorexia

Fecal incontinence

Liver function test abnorma

Gastritis

Flatulence

Fatulence

Sore th

Gaitis

Gastrointestin

Hemic and Lymphatic System

Leukopenia*

Anemia

Ecchymosis

Lymphadenopathy

Injection Site

Injection site reaction*

njection site inflammation

Injection site pain

Injection site necrosis*
Injection site hemorrhage

Injection site hemorrhage

Peripheral edema

Weight loss

SGPT increased

Hypercholesteremia

Musculoskeletal System

Myasthenia

Arthralgia

Bone fracture (not spontaneous)

Muscle cramps

Spontaneous bone fracture

Arthritis

Joint disorde

rvous Syste

Nervousness
Speech disorder

Spastic paralysis

Convulision
Conaralss

Hyperesthesia

Amnesia

Dry mouth

Hemiplegia

Thinking abnormal

Myoclonus

Respiratory System

Rhinitis

Pharyngitis

Bronchitis

Cough increased

Sinusitis

Pneumonia

Dyspnea

Upper respiratory tract infection

Asthma

Voice alteration

Skin and Appendages

Rash*

Pruritus

Skin disorder

Eczema

Herpes simplex

Alopecia
Acne
Dry skin

Dry skin

Subcutaneous hematoma

Breast pain

Herpes zoster

Seborrhea

Special Senses

Abnormal vision

Amblyopia

Diplopia

Eye pain

Otitis media

Conjunctivitis

Eye disorder

Deafness

Ear disorder

Tinnitus
Urogenital System

Urinary tract infection

Urinary incontinence

Urinary tract disorder

Cystitis

Urinary urgency

Menstrual disorder

Increased urinary frequency

Metrorrhagia

Urinary retention

Vaginitis

Vaginitis

Amenorrh

Dysuria

Impotence

Menopause

Menorrhag

Vaginal moniliasis

Kidney pain

Prostatic disorder

"significantly associated with BETASERON treatment $(p<0.05)$

Seventy-four (74) patients discontinued treatment due to

adverse events (23 on placebo and 51 on BETASERON).Injection

site reactions were signficantly associated with early tem inat

of teatment in the BETASERON group compared to placebo

$(p<0.05)$. The highest frequency of adverse events leading to

discontinuation involved the nervous system, of which depression

( on placebo and 11 on BETASERON) was the most common.

Significantly more patients on active therapy $(14.4 \%$ vs.

$4.7 \%$ on placebo) had elevated ALT (SGPT) values ( $>5$ times baseline value). Elevations were also observed in AST (SGOT) and gamma-GT values in the BETASERON group throughout the study. In the BETASERON group, most ALT (SGPT) abnormalities resolved spontaneously with continued treatment whereas some resolved upon dose reduction or temporary discontinuation of treatment

Lymphopenia $\left(<1500 / \mathrm{mm}^{3}\right)$ was observed in $90.9 \%$ of BETASERON patients compared to $74.3 \%$ of placebo patients and neutropenia $\left(<1400 / \mathrm{mm}^{3}\right)$ was noted in $18.0 \%$ BETASERON and $5.1 \%$ placebo patients.

\section{DOSAGE AND ADMINISTRATION}

BETASERON (interferon beta-1b) should only be prescribed by (or following consultation with) clinicians who are experienced in the diagnosis and management of multiple sclerosis.

The recommended dose of BETASERON for both relapsingremitting and secondary-progressive MS patients is $0.25 \mathrm{mg}$ (8 MIU) injected subcutaneously every other day. Limited data regarding the activity of a lower dose in relapsing-remitting MS patients are presented above (see ACTION AND CUNICAL PHARMACOLOGY, Clinical Trials).

In the secondary-progressive MS study, patients initiated treatment with half the dose (4 MIU s.C. every other day) for a period of 2 weeks prior to escalating to the recommended dose of 8 MIU (s.c. every other day)

Efficacy of treatment for longer than 2 years has not been substantially demonstroted in relapsing-remitting multipie sclerosis. For secondary-progess and efficacy data beyond 3 years are not available.

To reconstitute lyophilized BETASERON for iniection, use a the sterle syringe and neede to inject $1.2 \mathrm{~mL}$ d the diluent supplied, Genty suir the via OA BETASERON

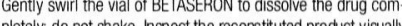
pletely, do not shake. Inspect he reconstruted prodact visualy and discard the product before use if it contains particulate matter or is discolored. After reconstiution with accompanying diluent, each mL of soluton contains 0.25 mg (8 M) interteron beta-16, 13 mg Abumin Human USP and 13 mg Mannitor USP. Withdraw $1 \mathrm{~mL}$ of reconstituted solution from the vial into sterlie syringe fitted with a 27 -gauge $/ 2$-inch needle and inject the solution subcutaneously. Sites for seff-injection indude abdomen, buttocks and thighs. A vial is suitable for single use only; unused portions should be discarded (See BETASERON [interferon beta-1b] INFORMATION FOR THE PATIENT section for SELF-INJECTION PROCEDURE.

\section{AVAILABILITY OF DOSAGE FORMS}

BETASERON (inter feron beta- $1 \mathrm{~b}$ ) is presented in single-use vials of lyophilized powder containing $0.3 \mathrm{mg}$ (9.6 MIU) interferon beta-1b, $15 \mathrm{mg}$ Albumin Human USP, and $15 \mathrm{mg}$ Mannitol, USP. BETASERON is supplied in cartons containing 15 vials of medication and 15 vials of diluent $12 \mathrm{~mL}$ of Sodium Chlor ide $0.54 \%$ solution, per vial).

Product Monograph avaliable upon reques

B10204E

REFERENCES:

Derlex Canada Inc., 1999

2. Product Monograph of PBBETASERONE (interferen beta-1b)

Berlex Canada Jine 1999

3. The IFNB Multiole Sclerosis Study Group and the University of

Bntish Columbia MSIMRI Analysis Group. Interereron beta- 16 in the treatment of multiple sclerssis: Final outcome of the randomised controled trial. Neurology 1995; 45:1227-1285.

2260 32nd Avenue, Lachine, Québec H8T 3H4

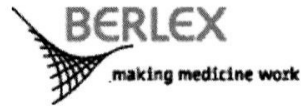




\section{Lastror}

\section{atorvastatin cakium}

\section{tablots}

\section{power you can trust}

"LIPITOR*

(atonvastatin caicium)

\section{ACTIONS AND CLINICAL PHARMACOLOGY}

LPITOR (atcrvastatin calcium) is a synthetic lipid-lowerng agent. It is a selective, comoetitive irhibitor of 3-hydroxy-3-methylghtutary-ccerzyme A (HMG-COA) reductase. This enty

LPITOR lowers plasma cholesterol and lipoprotein levels by inhibiting HMG-COA reductase and cholesterol synthesis in the live and by increasing the number of hepatic Low Densty Liocorotein (10) receptors on the cell-surface for enhanced uptake and catabolism of Low Density Lipoprotein IDL)

LIPTOR reduces LDL-Cholesterd (LCL-C) and the number of LDL. particles. LPPTTOR also reduces very Low Density Lipoprotein Cholesterol (MLDL-C), serum triglycerides (TG) and Intermediate Density Lipoproteins (IDL), as well as the number of apolipoproten B (apo B) containing particles, but increases High Density Lipoprotein-Cholesterol (HOL-C). Elevated serum cholesterol due elevated LDL-C is a major risk factor tor the developrnent of cardiovascular disease. Low serum concentration of HDL-C is also an independent risk factor. Elevated plasma TG is also a risk factor for cardiovascular disease, particularly if due to increased IDL, or associated with decreased $\mathrm{HOL}-\mathrm{C}$ or increased $\mathrm{LDL}-\mathrm{C}$

Epidemiologic, clinical and experimental sturles have established that high LDL-C, low HDL-C and high plasma TG promote human atherosclerosis and are risk factors for developing cardiovascular disease. Some stucies have also shown that the ratio of total cholestero (total-C) to HDL-C (total-C/MDL-C) is the best predictor of coronary artery disease. In contrast, increased of tevels of $\mathrm{HDL}-\mathrm{C}$ are associated with decreased cardiovascular risk. Drug therapies that reduce levels of $\mathrm{LDL}-\mathrm{C}$ or decrease $T \mathrm{G}$ while simultaneously increasing $\mathrm{HDL}-\mathrm{C}$ have demonstrated reductions in rates of cardiovascular mortality and morbidity.

\section{Pharmacokinetics}

Atovastatin is rapidly absotbed after orai administration; maximum plasma concentrations occur within 1 to 2 hours. Atonastatin tablets are $95 \%$ to $99 \%$ bioavailable compared to solutions.

Mean distribution of atorvastatin is approximately 381 liters. Atorvastatin is $298 \%$ bound to plasma proteins. Atorvastatin is extensively metabolized by cytochrome P-450 3A4 to ortho- and para-hydroxylated derivatives and to varous beta-oxidation products. Approximately $70 \%$ of circ lating inhibiton activity for

Atorvastatin and its metabolites are eliminated by biliary excretion. Less than $2 \%$ of a dose of atorvastatin is recovered in urine tollowing oral administration. Mean plasma elimination half-ife of atorvastatin in humans is approximately 14 hours, but the hallife of inhibitory activity for HMG-COA reductase is 20 to 30 hours due to the contribution of longer-lived active metabolites.

\section{INDICATIONS AND CLINICAL USE}

UPITOR (atorvastatin calcium) is indicated as an adjunct to lifestyle changes, including diet, (at least equivalent to the Adu

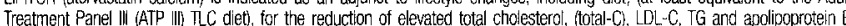
(apo B) in hyperipidernic and dyslipidemic conditions, when response to diet and other nonpharmacological measures alone has been inadequate, inciuding

- Primary hypercholesterolemia (Type lla)

- Combined (mixed) hyperlipidemia (Type llb), including familial combined hyperlipidemia, regardless of whether cholesterol or

trialycerides are the lipid abnormality of concern

- Dysbetalipoproteinemia (Type Ill):

- Hypertriglyceridemia Tipe M

- Familial hypercholesterolemia (homozycous and heterozygous). For humozygous farmilial hypercholesterolemia, LPPTOR shoul be used as an adiunct to treatments such as $L D L$ apheresis, or as monotherapy if such treatments are not available.

LPITOR also rases HDL-cholesterol and therefore lowers the LDL-CHDL -C and total-CMOL-C ratios in patients with primary hyper cholesterolemla and combined (inixed) hyperlipicemia (Fredrickson Type lla and lib dyslipidemia). In pooled cata from 24 controlled clinical triais, LPTTOR raised HCL-C levels 5\%-7\% in primary hypercholesterolemic (type lla) patients and 10\%-15\% in mixed (type ib) dyslipidemic patients

In clirical trials, $L P T T O R$ (10 to $80 \mathrm{mg} /$ day) significantly improved lipid profiles in patients with a wide variety of hyperlipicemic and dyslipicemic conditions. In 2 dose-response studies in mildy to moderately hyperlipidemic patients (Fredrickson Types lla and ib) LIPTOR reduced the levels of total cholesterol $229-45 \%)$, LDL-C (39-60\%), apo B (32-50\%), TG (19-37\%), and increased high censity lipeprotein cholesterol (HDL.C) Evels (5-9\%). Comparable responses were achieved in patients with heterorygous familial hypercholesterolemia, non-familial forms of hypercholesterolemia, combined hyperlipidemia, including tamilial combined hyper. lipidemia and patients with non-insulin dependent diabetes melltus. In patients with hypertriglyceristemia (1ype (V), LPITOR (10 to $80 \mathrm{mg}$ daly) reduced TG (25 - 56\%) and LDL-C levels (23 - 40\%). LPITOR has not been studied in canditions where the major abnormality is elevation of chyomicrons ( $T G$ levels $>11 \mathrm{mmol}$ ), i.e. types $I$ and $V$.

In an open-label study in patients with dysbetalipoprotenemia (Type II), LPTOR (10 to $80 \mathrm{mg}$ daily) reduced total-C (40-57\%), TG $(40-56 \%)$ and IDL-C + VLCL-C levels (34-58\%).

In an open label study in patients with homorycous familal hypercholesterolemia (FH) LIPTOR (10 to $80 \mathrm{mg}$ daly) reduce mean LDL.C levels $(22 \%)$. In a pilot study, LPTOR $80 \mathrm{mg} / \mathrm{day}$ showed a mean LDL-C lowering of $30 \%$ for pallents not on plasmapheresis and of $31 \%$ for patients who continued plasmapheresis. A mean LDL-C lowering of $35 \%$ was observed in receptor defective patients and of $19 \%$ in receptor negative patients (see PHARMACOLOGY Ciricica Studies).

For more details on efficacy results by pre-cefined classification and pooled data by Fredrickson types, see FHARMACOLOGY Clinical Studies.

Prior to initiating therapy with UPIOF, secondany causes shoudd be excluded for elevations in plasma lipid levels (eg. poorty controlled diabetes melitus, hypothyroidism, nephrotic syndrome, dysproteinemias, obstructive liver disease, and alcoholism), an a ipid profile performed to measure total cholesterol, $L D L-C, H D L-C$, and TG. For patients with $T G<4.52$ mmolL $(<400 \mathrm{mg} / \mathrm{dL}$ ) $\mathrm{LDL}-\mathrm{C}$ can be estimated using the following equation

$$
L D L-C(m m o / L)=\text { total-C }-[(0.37 \times(T G)+H D L-C)]
$$$$
\mathrm{LDL} \cdot \mathrm{C}(\mathrm{mg} / \mathrm{LL})=\text { total }-\mathrm{C}-[0.2 \times(T \mathrm{G})+\mathrm{HDL}-\mathrm{C}]
$$

For patients with TG levels $>4.52 \mathrm{mmol} / \mathrm{L}$ ( $>400 \mathrm{mg} / \mathrm{cL}$, this equation is less accurate and LDL-C concentrations should be measured directly or by ultracentrifugation.

Patients with high or very high triglyceride levels, $1 . e .>2.2 \mathrm{mmol} / \mathrm{L}$ (200 mg/dL) or $>5.6 \mathrm{mmo} / \mathrm{L}(500 \mathrm{mg} / \mathrm{dL})$, respectively, may require trigyceride-lowering therapy (fenofibrate, tezafibrate or nicotnic acic) alone or in combination with $L$ LITOR

In general, combination therapy with fibrates must be undertaken cautiously and only after risk-benefit analysis (see WAPN NNGS Muscle Effects. PRECAUTIONS, Pharmacokinetic nteraction Studies and Potential Orug interactions)

Elevated serum triglycerides are most often observed in patients with the metabolic syndrome (abdominal obesity, atherogenic oyslipidemia [elevated triglycerides, small dense LDL particles and low $\mathrm{HDL}$-chulesterol, insulin resistance with or without glucose intoierance, raised blood pressure and prothrombic and proinflammatory states.

(For the treatment of specific dysipidemias refer to the Report of the Canadian Working Group on Hypercholesterolemia and Other Dysipidemias or to the US NCEP Expert Panel on Detection. Evaluation. and Treatment of High Blood Cholesterol in Adults [Adult Treatment Panel III, under SELECTED BIBLIOGRAPHY.

When drugs are prescribed attention to therapeutic lifestyle changes (reduced intake of saturated fats and cholesterol, weight recuction, increased physical activity, ingestion of soluble fibers) should always be maintained and reinforcer.

The Atorvastatin Versus Revascularization Treatments (AVERT) study examined the effect of intensive lipid-lowering in patients with sta-

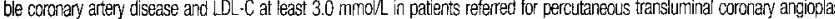
(PTCA) Patents were randomised for 18 months to LPITOR $80 \mathrm{mg}$ claily $\alpha$ to PTCA with usual medica care which could include ind metabolism regulatiors. The resits of the AVERT study shoud be considered as exploratony since several Imitations may affect its design and conduct. In the medical-treated group with LPTOR there was a trend for a reduced insidence of ischemic everts and a delayed time to first ischemic event. The results also suggest that intensive teatment to target LDL-C levels with LPTOR is additive and complementary to angioplasty and wout benefit patients referred tor this procedure (see SALECTED BIB_LOGRAPHY).

\section{CONTRAINDICATIONS}

Hypersensitivity to any component of this madication.

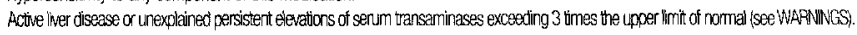
Pregnancy and lactation isee PRECALTIONSS.
Pharmacokinetic Interactions

The use of HMGG-COA reductase inhibitors has been associated with severe myopathy, incuding mabdomyolysis, which may be more frequert when they are co-administered with dougs that inhibit the cytoctrome P-450 enzyme sustem. Atoryastatin is metabolized by cytochrome P-450 isoform $3 A 4$ and as such may interact with agents that innibit this enzyme. (See WARININGS Muscle effects and PRECAUTIONS, Drug Interactions and Cytochrome P-450-mediated Interactions).

\section{Hepatic Effects}

In clirical trials, persistent increases in serum transaminases greater than three tmes the upper limt of normal occurred in $<1 \%$ of patients who received LPTIOR. When the dosage of LPTTCR was reduced, or when drug treatment was interupted or

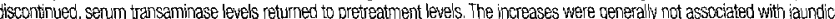
or other clinical signs or symptoms. Most patients continued treatment with a reduced dose of LIPTOR without clinicai sequelae. Liver function tests should be performed before the initiation of treatment, and periodically thereafter. Special attention should be paid to patients who develop elevated serum transarninase levels, and in these patients measurements should be repeated promptly and then performed more frequently.

If increases in alanine aminotransferase (ALT) or aspartate aminotransferase (AST) show evidence of progression, particularty if they rise to greater than 3 times the upper limit of normal and are persistent, the dosage should be reduced or the drug discontinued.

LPITOR should be used with caution in patients who consume substantal quanitites of alcohol and/or have a past history of liver disease. Active liver cisease or unexplained transaminase elevations are contraindications to the use of LIPTOR; if such a condtion should develop during therapy, the drug should be discontinued.

\section{Muscle Effects}

Myopathy, defined as muscle aching or muscle weakness in coniunction with increases in creatinine phosphokinase (CPK) value to greater than ten times the upper limit of normal, should be considered in any patient with diffuse myalgia, muscle tenderness or weakness, and/or marked elevation of CPK. Patients should be advised to report promptly unexplained muscle pain, tenderness or weakness, particuartly it accompanied by malaise or tever. LPFTOR therapy should be discontinued if markedly elevated CPK levels occur or myopathy is diagnosed or suspected.

The risk of myopatty and mabdomyolysis during treatment with HMG-COA reductase inhibitors is increased with concurrent

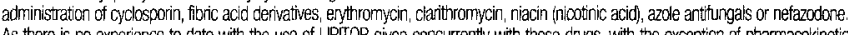
As there is no experience to date with the use of LPPTOR given concurrently with these drugs, with the exception of phamacokinetic studies conducted in healthy subjects with erythromycin and clanithromycin, the benefits and risks of such combined therapy should be carefuly considered (ses PRECAUTIONS, Pharmacokinetic Interacjion Sudides and Potential Drug Interactions)

Rhabdomyolysis has been reported in very rare cases with LIPITOR (see PRECAUTIONS, Drug Interactions).

Rhabdomydysis with renal dysfunction secondary to myoglobinuria has aiso been reported with HMG-COA reductase inhibitors. LPITOR therapy should be temporarly wittheld or discontinued in any patient with an acute serious condition suggestive of a mycpathy or having a risk factor predisposing to the development of renal failure secondary to thabdomyoysis (such a severe acute infection, hypotension, major surgery, trauma, severe metabolic, endocine and electrolyte disorders, and uncontrolled seizurest.

\section{PRECAUTIONS}

General

Before institutng therapy with LPFTOR (atorvastatin calcium), an attempt should be made to control elevated serum lipoprotein levels with aspropriate diet, exercise, and weight reduction in overweight patients, and to treat other underlying medical problem any other lipid-lowering acents.

\section{Effect on the Lens}

Current long-term data from clinical trials co not indicate an adverse effect of atorvastatin on the human lens.

Effect on Ubiquinone $\left(\mathrm{CoO}_{10}\right)$ Levels

Signifcart decreases in circulating ubiquinone levels in patients treated with atorvastatin and other statins have been observed. The clinical significance of a potential long-term statin-induced deficiency of ubiquinone has not been established. It has been reported that a decrease in myocardial ubiquinone levels could lead to impaired carciac iunction in patients with borderlin congestive heart failure (see SELECTED BIBLIOGRAPHY).

\section{Effect on Lipoprotein (a)}

in sorne patients, the beneficial effect of lowered total cholesterol and LDL-C levels may be partly blunted by a concomitant increase in Lp(a) lpoprotein concentrations. Present knowledge suggests the importance of high Lp(a) levels as an ertierging risk factor for coronary heart disease. It is thus desirable to maintain and reintorce lifestyle changes in hich risk patients placed on atorvastati therapy (SEe SELECTED BIBLLGRAPHY).

\section{Hypersensitivity}

An apparent hypersensitivity syndrome has been reported with other HMG-CoA reductase inhibitors which has included 1 or more of the following features: anaphylaxis, angicedema, lupus enythematous-like syndrome, polymyalgia ineurnatica, vasculitis purpura, thrombocytopenia leukosenia, hemolytic anemia, oositive ANA. ESR increase, eosinophilia, arthritis, arthralgia, urticaria asthenia photosensitivity, fever, chills, fusting, malaise, dyspnea, toxic epidermal necrolysis, enthema multiforme, including astrenia, photasensitivty, tever, chills, fusting, malaise, dyspnea, toxic epiderma necrolysiS, erythema multiforme, incuding
Stevens-Johnson syndrome Athough to date hypersensitvity syndrome has not been described as such, LPITCR should be discontinued if hypersensitivity is suspected.

\section{Use in Pregnancy}

\section{UPTOH is contraindicated during pregnancy (see CONTRAINDICATIONS)}

Atherosclercsis is a chronic process and discontinuation of lipid-lowering drugs during pregnancy should have litte impact on the outcome of long-term therapy of primary mypercholesterolemia. Cholesterol and other products of cholesterol biosynthesis are essential components for fetal development (nciding syrthess of steroids and cell membranes). Since HMG-CoA reductase intibitors decrease chotesterol synthesis and possibly the synthesis of other biclogically active substances derived from cholesterol they may cause harm to the fetus when administered to pregnant women.

There are no data on the use of IIPITOR during pregnancy. LPTOR should be administered to women of childbearing age only when such patients are highly unlikely to conceive and have been informed of the potential hazarcs. If the patient becomes pregnant while taking LPITOR, the dug should be ciscontirued and the patient apprised of the potential risk to the fetus.

Nursing Mothers

In rats, milk concentrations of atorvastatin are similar to those in plasma. It is not known whether this drug is excreted in human mik. Because of the potental for adverse reactons in nursing infants, women taking LPIIOR should not breast-feet (see CONTRANDICATIONS)

\section{Pediatric Use}

Treatment experience in a pediatric population is limited to doses of LPITOR up to $80 \mathrm{mg} /$ day for 1 year in 8 patients with homozygous familial rypercholesterolemia. No clinical or biochemical abrormalities were reported in these patients.

\section{Geriatric Use}

Treatment experience in adults 70 years or older $(\mathbb{N}=221)$ with doses of LPITOR up to $80 \mathrm{mg} / \mathrm{day}$ has dernonstrated that the safety and effectiveness of atorvastatin in mis population was similar to that of patients $<70$ years of age. Pharmacokinetic evaluation of atowastatin in subjects over the age of 65 years indicates an increased AIJC. As a precautionary measure, the lowest dose should be administered initially (See PHARMACOLOGY, Human Pharmacokinetics; SELECTED BIBL LOGRAPHY)

\section{Renal Insufficienc}

Plasma concentrations and LOL-C lowering efficacy of LIPTIOR was shown to be smilar in patients with moderate rena insufficiency canpared with patients with nomal renal funcion. However, since several cases of rhabdomyolysis have been reported in patients with a history of renal insufficiency of unknown severity, as a precautionary measure and pending furthe experience in teral disease, the lowest dose $110 \mathrm{mg} / \mathrm{day}$ of LPITOR should be used in these patierts. Similar precautions apply in patients with severe renal insufficiency (creatinine clearance $<30 \mathrm{~mL} / \mathrm{min}$ ( $<0.5 \mathrm{~mL} / \mathrm{sec})$;
and implemented cautiously (see WARNINGS, MUscie Effects; PRECAUTOONS, Drug Interactions)

Refer also to DOSAGE AND ADMINISTRATION.

\section{Endocrine Function}

HMG-COA reductase innibiors interfere with cholesterol synthesis and as such might theoretically biunt adrenal and/or conada steroid oroduction. Clinical studies with atorvastatin and other HMG G-COA reductase inhibitors have suggested that these agents do not reduce plasma cortisol concentration or impair acrenal reserve and do not reduce basal plasma testosterone concentration. However, the effects of $H$ MG $-C O A$ red ctase intisitors on male terility have not been studied in adeguate numbers of patients. The effects, if ary, on the pituitary-gonadal axis in premenopausal women are unkrows.

Patients treated with atorvastatin who develop clinical evidence of endocrine dystunction should be evaluated appropriatel Caution should be exercised if an HMG-CoA reductase inhibitor or other agent used to lower cholesterol levels is admiristered to patients recelving other drugs (e.g. ketconnazole, spironolactone or cimetidine) that may decrease the levels of endogenous steroid hormones 


\section{Pharmacokinetic Interaction Studies and Potential Dnug Interactions}

Pharmacckinetic interaction studies conducted with dnus in heathy subjects may not detect the possibitity of a potential drug interaction in some patients due to differences in underlying diseases and use of concomitant medications (see also Geriatric Use; Renal Insufficiency; Patients with Severe Hypercholesterolemia).

Concomitant Therapy with Other Lipid Metabolism Regulators: Combined drug therapy should be approached with caution as information from controlled studies is limited.

\section{Bile Acid Sequestrants:}

Patients with mild to moderate hypercholesterolemia: $L D L-C$ reduction was greater when LIPIOR $10 \mathrm{mg}$ and colestipol $20 \mathrm{~g}$ were coadministered (-45\%) than when either drug was acministered alone (-35\% for LPTCR and $-22 \%$ for colestipo).

Patients with severe hypercholesterolemia. LDL-C reduction was similar $(-53 \%)$ when LIPTOR $40 \mathrm{mg}$ and colestipol $20 \mathrm{~g}$ were coadministered when compared to that with LIPITOR $80 \mathrm{mg}$ alone. Plasma concentration of atorvastatin was lower (approximately 26\%) when LIPTOR $40 \mathrm{mg}$ pius colestipol $20 \mathrm{~g}$ were coadministered compared with LPPTOR $40 \mathrm{mg}$ alone.

However, the combination drug therapy was less effective in lowering the trigycerides than LPITOR monotherapy in both ypes of hyoercholesterolemic patients isee PHARMACOLOGY, Clinical Studies.

When LIPTOR is used cancurrently with colestipel or any other resin, an interval of at least 2 hours should be maintained between the two drugs, since the absorption of L.FTIOR may be impaired by the resin.

Fibric Acid Derivatives (Gemfibrozil, Fenofibrate, Bezafibrate) and Niacin (Nicotinic Acid): Although there is limited experence with the use of LPTTOR given concurrenty with fibric acid derivatives and niacin, the benefits and risks of such combined therapy should be carefully considered. The risk of myopathy during treatment with other drugs in this class, including atorvastatin, is increased with concurrent administration (see WARNINNGS, Muscile Effects and SELECTED BIBL LOGRAFHY)

Coumarin Anticoagulants: LPITOR had no clinically significant effect on prothrombin time when administered to patients receiving chronic warfarin therapy (see SELECTED BIBLIOGRAPHY).

Digoxin: In healthy subjects, digoxin phamacokinetics at steady-state were not significantly attered by coadministration of digoxin $0.25 \mathrm{mg}$ and LPITOR $10 \mathrm{mg}$ dally. However, digoxin steady-state concentrations increased approximately $20 \%$ following coadministration of digoxin $0.25 \mathrm{mg}$ and LPITOR $80 \mathrm{mg}$ daly (see Human Fharmacokinetics). Patients taking digoxin should be monitored approprately.

Anthypertensive agents (amlodipine): In cinical studies, LPITOR was used concomitantty with antihypertensive agents without evidence to date of clinically significant adverse interactions. In healthy subjects, atorvastatin pharmacokinetics were rot altered by the coadministration of LPITOR $80 \mathrm{mg}$ and amlodipine $10 \mathrm{mg}$ at steady state (see Human Pharmacokinetics)

(quinapril): In a randornized, open-label study in healthy subjects, steady-state quinapril dosing ( $80 \mathrm{mg} \mathrm{QD)}$ ) did not significanty affect the pharmacokinetic profile of atorvastatin tablets $(10 \mathrm{mg}$ QD) (see Human Phamacoknetics)

Oral Contraceptives and Hormone Replacement Therapy: Coadministration of LPITOR with an oral contraceptive, containing $1 \mathrm{mg}$ norethindrone and $35 \mu \mathrm{g}$ ethiny estradiol, increased plasma concentrations (AUC levels) of norethindrone and ethinyl estradio by approximately $30 \%$ and $20 \%$, respectively. These increases should be considereo when selecting an oral contraceptive. In cilnical studies, LIPTOR was used concomitantly with estrogen replacement therapy without evidence to date of clinically significant adverse interactions.

Antacids: Administration of aluminum and magnesium based antacids, such as Maalox, TC Suspension, with LIPITOR decreased plasma concentrations of LIPTOR by approximately $35 \%$. LDL-C reduction was not altered but the triglyceride-lowerng effect of IPTOR may be affected

Cimetidine: Administration of cimetidine with LPITOR did not alter plasma concentrations or LDL-C lowering efflcacy of LPITOR, however, the triglyceride-lowering effect of LPITOR was reduced from $34 \%$ to $26 \%$

Cytochrome P-450-mediated Interactions: Atorvastatin is metabolized by the cytochrome P-450 isoenzyme, CYP 3A4 Erythromycin, a CYF $3 A 4$ inhibitor, increased atorvastatin plasma levels by $40 \%$. Coadministration of CYP $3 A 4$ inhibitors, such as grapefruit juice, some macrolide antibiotics (l.e. enythromycin, clarithromycin), immunosuppressants (cyclosporine), azole antifungal agents (i.e. itraconazole, ketoconazole), protease inhibitors, of the antidepressant, nefazodone, may have the potential to increase plasma concentrations of HMG-COA reductase inhibitors, including LPITOR (See SELECTED BIBLIOGRAPHY). Caution should thuS be exercised with concomitant use of these agents (see WARNNNGS, Phamacokinetic Interactions, Muscle Effects; PRECALTTIONS, Renał Insutticiency and Endocrne Function; DOSAGE AND ADMINISTRATION; SELECTED BIBLLOGRAPHM

In healthy subjects, coadministration of maximum doses of both atomastatin ( $80 \mathrm{mg})$ and terfenadine $(120 \mathrm{mg})$, a CYP $3 \mathrm{A4}$ substrate was shown to produce a modest increase in tefenadine AUC. The OTC interval remained unchanced. However, since an interaction between these two drugs cannot be excluded in patients with oredisposing factors for anhythmia, ieg. preexisting prolonged QT interval, severe coronary artery disease, nypokalemia), caution should be exercised when these agents are coadministered isee WARN NGGS. Phama okinetic Interactions: DOSAGE AND ADMINISTRATION).

Antipyrine: Antioyrine was used as a non-specific model for dnugs metabolized by the microsomal hepatic enzyme system cylochrome P-450 system). LIPITOR had no effect on the pharmacokinetics of artipyine, thus interactions with other drugs metabolized via the same crochrome isozymes are not expected.

Macrolide Antibiotics (azithromycin, clarithromycin, erythromycin): in healthy adults, coadministration of $L P T T O R$ (10 mg QD) and azithromycin (500 mg QD) did rot significanty alter the plasma concentrations of atorvastatin. However, ccadministration
of atorvastatin (10 mg QD) with erythromycin (500 mg QD) or clarthromycin (500 mg BD), which are both CYP $3 A 4$ inhibitors,

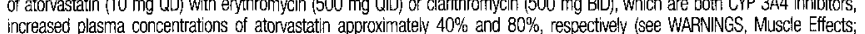
increased plasma concent
Human Pharmacckinetics).

Protease inhibitors (nelfinavir mesylate): In healthy adults, coadministration of neffinavir mesylate (1250 mg BiD), a known CYP $3 A 4$ inhibitor, and atorvastatin (10 mg QD) resulted in increased plasma concentrations of atorvastatin. AUC and Cmax of atorvastatin were increased by $74 \%$ and $122 \%$ respectively.

Patients with Severe Hvpercholesterolemia: Higher drug dosages $(80 \mathrm{mg} / \mathrm{dan})$ required for some patients with severe hypercholesterolemia (including familial hypercholesterolemia) are associated with increased plasma levels of atorvastatin. Caution should be exercised in such patients who are also severely renally impaired, elderty, or are concomitantly being administered digoxin or CYP $3 A 4$ inhibitors (see WARNINGS, Pharmacokinetic Interactions, Muscle Effects; PRECAUTIONS, Drug Interactions; DOSAGE AND ADMINISTRATION).

\section{Drug/Laboratory Test Interaction}

L.PITOR may elevate serum transaminase and creatinine phosphokinase ieves (from skeletal muscle). In the differential diagnosis of chest pain in a patient on therapy with LPITOR, cardiac and noncardiac fractons of these enzymes should be determined ADVERSE REACTIONS

LPTTOR is generally well-tolerated. Adverse reactions have usually been mild and transient. In controled clinical studies fplacebocontroled and active -controlled comparative studies with other lipid lowering agents) involving 2502 patients, <2\% of patients wer discontinued due to adverse experiences attributable to LPTTOR. Of these 2502 patents, 1721 were treated for at least 6 month and 1253 for 1 year or more.

Adverse experiences occurring at an incidence $\geq 1 \%$ in patients participating in placebo-controlied clinical studies of UPITOR and reported to be possibly, probably or definitely drug related are shown in Table 1 below.

$\frac{\text { TABLE 1. Associated Adverse Events Reported in } \geq 1 \% \text { of Patients in Placebo-Controlled Clinical Trials }}{\text { LPITOR } \% \text { in }=1122)}$

The following additional adverse events were reported in clinica trials; not all events isted below have been associated with a causal The followng additonal adverse events were reported in clinica trials; not all events isted below have been associated with a causa
relationship to LPTOR theraoy: Muscle cramps, myositis, myonathy, paresthesia, peripheral neuropathy, pancreatifis, hepatitis relationship to LPPTOR therapy: Muscle cramps, myositis, myopathy, paresthesia, peripheral neuropathy, part
cholestatic jaundice, anorexia, vomiting, a a opecia, prunitus, rash, impotence, hypergy ycemia, and hypoclycemia.

Post-marketing experience: Very rare reports: severe myopathy with or without rhabdornyolysis (see WARNNNGS, Muscle Effects PRECAUTIONS, Renal Insufficiency and Drug Interactions). Isolated reports: thrombocytoperia, atthralgia and allergic reactions including urticaria, angioneurotic edema, anaphylaxis and bullous rashes fincluding erytheme multiforme, Stevens-Johnson syndrome and toxic epidermal necroysisis]. These may have no causal relationship to atorvastatin.

Ophthalmatogic observations: see PRECAUTIONS.
Laboratory Tests: Increases in serum transaminase levels have been noted in cinical tials (see WARNINGS).

\section{SYMPTOMS AND TREATMENT OF OVERDOSAGE}

There is no specific treatment tor atorvastatn overdosage. Should an overdose occur, the patient should be treated symptomaticaly and supportive measures instituted as required. Due to extensive drug binding to plasma proteins, hemodialysis is not expected to icantly enhance atovastatin clearance.

\section{DOSAGE AND ADMINISTRATION}

Patients should be placed on a stancard cholesterol-iowering diet lat least equivalent to the Adult Treatment Panel III ATP II $T L C$ diet] before receiving LPITOR, and should continue on this diet during treatment with LPITOR. If appropriate, a program o weight control and physical exercise should be implementes.

Primary Hypercholesterolemia and Cornbined Mixed) Dysipidemia, Including Farillial Combined Hyperlipidemia

The recommended starting dose of LPITOR is 10 or $20 \mathrm{mg}$ once daly. Patients who require a large reduction in LDL-C (more than $45 \%$ ) may be started at $40 \mathrm{mg}$ once daily. The cosage range of LIPITOR is 10 to $80 \mathrm{mg}$ once daily. Doses can be given at any time of the day, wh th which tou, and should preferably be given in the evenhig. Doses should be incividualzed according to the leve of IISK; the baseline LDL-C and/or TG levels; the LCL-C, IG and/or total-C/HDL-C targets see the Detection and Management Hypercholesterolemia, Working Group on Hyperchoesterolemia and other Dyslipidemias [Canada] andjor the US Nationa Cholesterc Education Progiam (NCEP Adult Treatment Panel in); the goal of therapy; and the patent's response. A significant therapeutic response is evicent within two weeks, and the maximum response is usualy achieved within two to four weeks. The response is maintained during chronic therapy. Adjustments of cosage, if recessary, should be made at intervals of two to fou weeks. The maximum dose is $80 \mathrm{mg} /$ day.

Lipid levels should be monitored periodically and, if necessary, the dose of LPITOR adjusted based on target lipid levels recommended by guidelines.

The following reductions in total cholesterol and LDL-C levels have been obsenved in 2 dose-response studies, and may serve as a guide to treatment of patients with mild to moderate hypercholesterolemia:

TABLE 2. Dose-Response in Patients With Mild to Moderate Hypercholesterolemia Mean Percant Change from Baseline?

\begin{tabular}{|c|c|c|c|c|}
\hline \multirow{2}{*}{ Lipid Parameter } & \multicolumn{4}{|c|}{ LIPITOR Dose (mg/day) } \\
\hline & $\begin{array}{c}10 \\
\mathbb{N}=22)\end{array}$ & $\stackrel{20}{(N=20)}$ & $\begin{array}{c}40 \\
\mathbb{N}=21\}\end{array}$ & $\begin{array}{c}80 \\
\mathbb{N}=23\end{array}$ \\
\hline $\begin{array}{l}\text { Total-C: } 7.1 \mathrm{mmo} / \mathrm{L}^{\mathrm{b}} \\
\left(273 \mathrm{mg} / \mathrm{LL}^{\mathrm{b}}\right.\end{array}$ & -29 & -33 & -37 & -45 \\
\hline $\begin{array}{l}\text { LDL-C. } 4.9 \mathrm{mmo} / \mathrm{L}^{\mathrm{b}} \\
\left(190 \mathrm{mg} / \mathrm{d} \mathrm{L}^{\mathrm{D}}\right.\end{array}$ & -39 & -43 & .50 & -60 \\
\hline
\end{tabular}

a. Results are pooled from 2 dose-response studies.

b. Mean baseline value

\section{Severe Dysilipidemias}

In patients with severe dyslipidemias, including homozygous and heterozygous familial inpercholesterolemia and dysbetalipooroteinemia (Tipe III), higher dosages (up to 80 mo/day) may be required isee WARNINGS, Pharmacokinetic Interactions, Muscle Effects; PRECALTIONS, Drug Interactions.

Concomitant Therapy

See PRECAUTIONS, Drug Interactions.

Dosage in Patients With Renal Insufficiency

SOE PRECAUTIONS.

PHARMACEUTICAL INFORMATION

Drug Substance

Proper Name: Atorvastatin calcium

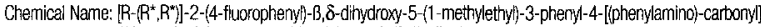
1H-pyrrole-1-heptanoic acid, calcium salt $\{2: 1\}$ trihydrate

Empirical Formula: $\left(\mathrm{C}_{3 \mathrm{~S}} \mathrm{H}_{34} \mathrm{HN}_{2} \mathrm{O}_{5}\right)_{2} \mathrm{Ca} \bullet 3 \mathrm{H}_{2} \mathrm{O}$

Molecular Weight: 1209.42

Structural Fomula:

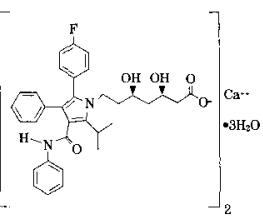

Description: Atorvastatin calcium is a white to off-white crystaline powder that is practicaly insoluble in aqueous solutions of $\mathrm{pH} 4$ and below. Atonvastatin calcium is very slightly soluble in distilled water, $\mathrm{pH} 7,4$ phosphate buffer and acetonitrile, slightly soluble in ettiand, and freely soluble in methano.

Tablet Composition:

Each tablet contains either $10 \mathrm{mg}, 20 \mathrm{mg}, 40 \mathrm{mg}$ or $80 \mathrm{mg}$ atorvastatin as the active ingredient. Each table: also contains the following non-medicinal ingredients: calcium carbonate, candelilla wax, croscarmellcse sodium, hydroxypropyl cellulose, lactose monohydrate, magnesium stearate, microcrystaline cellulose, hydroxypropyl methylcellulose, polyethylene glycol, talc, titanium dioxide, polysorbate 80 and simetticone emulsion.

Stability and Storage Recommendations:

Store at controlled room temperature 15 to $30^{\circ} \mathrm{C}$

AVALABILITY OF DOSAGE FORMS

LPITOR (atonvastatin calcium) is avaliable in dosage strengths of $10 \mathrm{mg}, 20 \mathrm{mg}, 40 \mathrm{mg}$ and $80 \mathrm{mg}$ atorvastatin per table: $10 \mathrm{mg}$ : White, elliptical, film-coated tablet, coded " 10 " on one side and "FD 155 " on the other: Avalable in bottles of 90 tablets. $20 \mathrm{mg}$ : White, eliptical, film-coated tablet, coded "20" on one side and "PD 156" on the other. Avallable in bottles of 90 tablets. $40 \mathrm{mg}$ : White, elliptica, film-ccated tablet, coded " 40 " on one side and "PD 157 " on the other. Avallable in bottles of 90 tablets. $80 \mathrm{mg}$ : White, elliptical, film-coated tablet, coded " 80 " on one side and "PD 158" on the other . Available in blisters of 30 tablets (3 strips $\times 10$.

References:

1. LIPTOR (atonvastatin caicium) Product Monograph, Pfizer Canada Inc, August 2003. 2. IMS Health MIDAS; March 1997. March 2003. 3. Pitt B, Waters D, Brown WW et al. Aggressive lipid-lowering therapy compared with angioplasty in stable coronary artery disease. N Engl $J$ Med 1999;341:70-76. 4. Data on File, Pfizer Canada Inc. 5. Simon Day. Dictionary for Clinical Trials, 1999, vonn Wiley \& Sons Lto. Pages $137-38$.

\section{(fire}

Life is our life's work

2004

Pfizer Canada Inc

Kirkland, Quebec

H9J $2 \mathrm{M}$

"TM Pfizer Ireland Pharmaceuticas

Pfizer Canada Inc, licensee 


\section{New

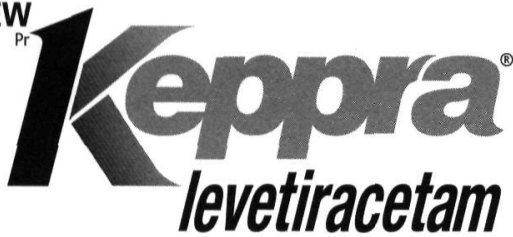

CONNECTING EXCELLENT PROFILES IN EFFICACY AND TOLERABILITY

PRESCRIBING INFORMATION

Tablets of $250 \mathrm{mg}, 500 \mathrm{mg}$, and $750 \mathrm{mg}$
Therapeutic classification: Antiepileptic

ACTIONS AND CLINICAL PHARMACOLOGY

\section{Mechanism of Action}

Levetiracetam is a drug of the pyrrolidine class chemically unrelated to existing antiepileptic drugs (AEDS). Levetiracetam exhibits antiseizure and antiepileptogenic activity in several models of chronic epilepsy in both mice and rats, while being devoid of anticonvulsant activity in the classical screening models of acute seizures.

The mechanism of action of levetiracetam has not yet been fully established, however, it appears to be unlike that of the commonly estabish, hou re commonly of up to $10 \mu \mathrm{M}$ did not result in significant ligand displacement at known receptor sites such as benzodiazepine, GABA (gammaaminobutyric acid), glycine, NMDA (N-methyl-D-aspartate), reaminobutyric acid), glycine, NMDA ( $\mathrm{N}$-methyl-D-aspartate), re-
uptake sites or second messenger systems. Furthermore, uptake sites or second messenger systems. Furthermore,
levetiracetam does not modulate neuronal voltage-gated sodium levetiracetam does not modulate neuronal voltage-gated sodium
and T-type calcium currents and does not induce conventional facilitation of the CABAergic system.

Pharmacokinetics

Summary: Single- and multiple-dose pharmacokinetics of levetiracetam have included healthy volunteers, adult and pediatric patients with epilepsy, elderly subjects, and subjects with renal and patientic impairment. Results of these studies indicate that levetiracetam is rapidly and almost completely absorbed after oral administration. The pharmacokinetic profile is linear with low intraadministration. The pharmacokinetic profile is linear with low intraand inter-subject variability. There is no modification of the clearance
after repeated administration. Food does not affect the extent of after repeated administration. Food does not affect the extent of
absorption of levetiracetam, although the rate is decreased. absorption of levetiracetam, although the rate is decreased.
Levetiracetam is not protein-bound ( $<10 \%$ bound) and its volume of distribution is close to the volume of intracellular and extracellular water. Sixty-six percent $(66 \%)$ of the dose is renally excreted unchanged. The major metabolic pathway of levetiracetam ( $24 \%$ of the dose) is an enzymatic hydrolysis of the acetamide group. It is not liver cytochrome $\mathrm{P} 450$ dependent. The metabolites have no known pharmacodynamic activity and are renally excreted. Plasma half-life of levetiracetam across studies is 6-8 hours. Plasma half-life is primarily due to impaired renal clearance.

Based on its pharmacokinetic characteristics, levetiracetam is unlikely to produce or to be subject to metabolic interactions.

The pharmacokinetic profile is comparable in healthy volunteers and in patients with epilepsy.

Due to its complete and linear absorption, plasma levels can be predicted from the oral dose of levetiracetam expressed as $\mathrm{mg} / \mathrm{kg}$ bodyweight. Therefore, there is no need for plasma level monitoring of levetiracetam.

Human Pharmacology

Pharmacokinetics: The pharmacokinetics of levetiracetam have been characterized in single and multiple dose PK studies, with doses up to $5000 \mathrm{mg}$; these studies included healthy volunteers $(n=98)$, up to $5000 \mathrm{mg}$; these studies included healthy volunteers $(n=98)$, patients with epilepsy $(n=58$ adult patients and $n=24$ pediatric
patients), elderly subjects $(n=16)$ and subjects with renal and patients), elderly subjects $(n=16)$ and subjects
hepatic impairment $(n=36$ and 16 , respectively).

Absorption and Distribution: Levetiracetam is rapidly and almost Absorption and Distribution: Levetiracetam is rapidly and almos
completely absorbed after oral administration. The ora bioavailability of levetiracetam tablets is $700 \%$. Plasma peak concentrations $\left(C_{\max }\right)$ are achieved at 1.3 hours after dosing. The extent of absorption is independent of both dose and the presence of food, but the latter delays $T_{\max }$ by 1.5 hours and decreases $C_{\max }$ by $20 \%$. The pharmacokinetics of levetiracetam are linear over the dose range of $500-5000 \mathrm{mg}$. Steady-state is achieved after two days of a twice daily administration schedule. Mean peak concentrations $\left(C_{\text {max }}\right)$ are 31 and $43 \mu \mathrm{g} / \mathrm{mL}$, respectively, following

Neither levetiracetam nor its primary metabolite is significantly Neither levetiracetam nor its primary metabolite is significantly
bound to plasma proteins $(<10 \%)$. The volume of distribution of levetiracetam is approximately 0.5 to $0.7 \mathrm{~L} / \mathrm{kg}$, a value that is close to the total body water volume. No tissue distribution data for humans are available.

Metabolism: Levetiracetam is not extensively metabolized in humans. The major metabolic pathway is the enzymatic hydrolysis of the acetamide group, which produces the pharmacologically inactive carboxylic acid metabolite, ucb L057 (24\% of dose). The production of this metabolite is not dependent on any liver cytochrome P450 isoenzymes and is mediated by serine esterase(s) in various tissues, including blood cells. Two minor metabolites were ring ( $2 \%$ of dose) and opening of the 2-oxo-pyrrolidine ring in position 5 ( $1 \%$ of dose). There is no evidence for enantiomeric position 5 ( $1 \%$ of dose). There is no evidence for en

Elimination: Levetiracetam plasma half-life in adults is $7 \pm 1$ hours and was unaffected by dose, route of administration or repeated administration. Levetiracetam is eliminated from the systemic administration. Levetiracetam is eliminated from the systemic
circulation by renal excretion as unchanged drug, which represents $66 \%$ of administered dose. The total body clearance is $0.96 \mathrm{~mL} / \mathrm{min} / \mathrm{kg}$ and the renal clearance is $0.6 \mathrm{~mL} / \mathrm{min} / \mathrm{kg}$. Approximately $93 \%$ of the dose was excreted within 48 hours. The mechanism of excretion is glomerular filtration with subsequent partial tubular reabsorption. The primary metabolite, ucb L057, is excreted by glomerular filtration and active tubular secretion with a renal clearance of $4 \mathrm{~mL} / \mathrm{min} / \mathrm{kg}$. clearance is thus reduced in patients with impaired renal function (See PRECAUTIONS and DOSAGE AND ADMINISTRATION).
Special Populations: Elderly: Pharmacokinetics of levetiracetam were evaluated in 16 elderly patients, ranging in age from $61-88$ years, with
11 of the 16 patients aged 75 years of age or over with creatinine 11 of the 16 patients aged 75 years of age or over with creatinine clearance ranging from 30 to $74 \mathrm{~mL} / \mathrm{min}$. Following oral administra-
tion of $500 \mathrm{mg}$ bid for 10 days, total body clearance decreased by tion of $500 \mathrm{mg}$ bid for 10 days, total body clearance decreased by
$38 \%$ and the half-life was increased about $40 \%$ ( 10 to 11 hours) when compared to healthy adults. This is most likely due to the decrease in renal function in these subjects. Pediatrics (6 to 12 years): Pharmacokinetics of levetiracetam were evaluated in 24 pediatric patients (age 6-12 years) after a single dose. The apparent clearance of levetiracetam adjusted to body weight was approximately $40 \%$ higher than in epileptic adults. Gender: Levetiracetam $C_{\max }$ and AUC were $20 \%$ higher in women $(n=11)$ compared to men $(n=12)$. However, clearances adjusted for body weight were comparable Race: Formal pharmacokinetic studies of the effects of race have not been conducted. Because levetiracetam is primarily renally excreted clearance, significant pharmacokinetic differences due to race are not expected.

Renal Impairment: Single dose pharmacokinetics were performed in 20 subjects with renal impairment $\left(n=7\right.$ mild $/ \mathrm{CL}_{\mathrm{cr}}$ of $50-79 \mathrm{~mL} / \mathrm{min}$ $\mathrm{n}=8$ moderate $/ \mathrm{CL}_{\text {cr }}$ of $30-49 \mathrm{~mL} / \mathrm{min} ; \mathrm{n}=5$ severe $/ \mathrm{CL}_{\mathrm{cr}}<30 \mathrm{~mL} / \mathrm{min}$ ), and $n=11$ matching healthy volunteers. Clearance of levetiracetam is correlated with creatinine clearance and levetiracetam pharmacokinetics following repeat administration were we predicted from single dose data. The apparent body clearance of the parent drug levetiracetam is reduced in patients with impaired renal
function by approximately $40 \%$ in the mild group, $50 \%$ in the moderate group, and $60 \%$ in the severe renal impairment group. For moderate group, and $60 \%$ in the severe renal impairment group. For
the primary metabolite ucb L057, the decrease in clearance values the primary metabolite ucb $\mathrm{L} 057$, the decrease in clearance values
from baseline was greater than that seen for the parent drug in all from baseline
subject groups.

In anuric (end stage renal disease) patients, the apparent body clearance was approximately $30 \%$ compared to that of norma subjects. Approximately $50 \%$ of the pool of levetiracetam in the body is removed during a standard 4-hour hemodialysis procedure. Dosage should be reduced in patients with impaired renal function receiving levetiracetam, and supplemental doses should be given to
patients after dialysis (see PRECAUTIONS and DOSAGE AND patients after dialysis

Hepatic Impairment: A single-dose pharmacokinetic study was performed in 16 subjects with hepatic impairment $(n=5$ mild/Child Pugh Grade $A ; n=6$ moderate/Grade $B ; n=5$ severe/Grade $C$ vs 5
healthy controls). For the mild and moderate subgroups neither healthy controls). For the mild and moderate subgroups neithe
mean nor individual pharmacokinetic values were clinically differen from those of controls. In patients with severe hepatic impairment, mean apparent body clearance was $50 \%$ that of normal subjects, with decreased renal clearance accounting for most of the decrease. Patients with severe hepatic impairment thus require a reduced dosage of Keppra

\section{INDICATIONS AND CLINICAL USE}

Keppra® (levetiracetam) is indicated as adjunctive therapy in the controlled by conventional therapy.

CONTRAINDICATIONS

This product should not be administered to patients who have previously exhibited hypersensitivity to levetiracetam or any of the inactive ingredients in Keppra® (levetiracetam) tablets.

\section{WARNINGS}

\section{Central Nervous System Adverse Events}

Keppra (levetiracetam) use is associated with the occurrence of central nervous system (CNS) adverse events; the most significant of these can be classified into the following categories: 1) somnolence
and fatigue, 2) behavioral/psychiatric symptoms and 3) coordination difficulties.

There was no clear dose response relationship for any of the three categories of CNS adverse events, within the recommended dose range of up to $3000 \mathrm{mg} /$ day. Somnolence/asthenia and coordination range of up to $3000 \mathrm{mg} /$ day. Somnolence/asthenia and coordination
difficulties occurred most frequently within the first four weeks of difficulties occurred most frequently within the first four weeks of
treatment and usually resolved while patients remained on treatment and usually resolved while patients remained on
treatment. In the case of behavioral/psychiatric symptoms (including treatment. In the case of behavioral/psychiatric symptoms (including
such adverse events as aggression, agitation, anger, anxiety, emotional such adverse events as aggression, agitation, anger, anxiety, emotiona
lability, hostility, irritability), approximately half of the patients reported these events within the first four weeks, with the remaining events occurring throughout the duration of the trials. See also PRECAUTIONS, Central Nervous System Adverse Events.

\section{Withdrawal of Anti-Epileptic Drugs}

As with all antiepileptic drugs, Keppra ${ }^{\circledast}$ should be withdrawn gradually to minimize the potential of increased seizure frequency.

\section{PRECAUTIONS} Hematological Abnormalities: Minor but statistically significant mean hemoglobin, and mean hematocrit in Keppra®-treated patients in controlled trials. For hemoglobin values, the percentage of Keppra® or placebo treated patients with possibly clinically significan abnormalities were less than $0.5 \%$ each. For hematocrit values, a total
of $5.1 \%$ of Keppra least one possibly significant decrease in hematocrit $(\leq 37 \%$ in male and $32 \%$ in females).

For white blood cells (WBC), $2.9 \%$ of treated versus $2.3 \%$ of placebo patients had at least one possibly clinically significant decrease in placebo patients had at least one possibly significant decrease in neutrophil count $\left(\leq 1.0 \times 10^{9} / \mathrm{L}\right)$. Of the Keppra-treated patients with a low neutrophil count, all but one rose towards or reached with a low neutrophil count, all but one rose towards or reached baseline with continued treatmen
secondary to low neutrophil counts.

Central Nervous System Adverse Events (See WARNINGS): Keppra (levetiracetam) use is associated with the occurrence of centra nervous system (CNS) adverse events; the most significant of thes can be classified into the following categories: 1) somnolence and fatigue, 2)
difficulties.

The following CNS adverse events were observed in controlled clinical trials.
Table 1:

Total Combined Incidence Rate for Each of the Three Categories of CNS Adverse Events in Placebo-controlled Add-on Clinical Trials.

\begin{tabular}{|lcc|}
\hline $\begin{array}{l}\text { Category of CNS } \\
\text { adverse event }\end{array}$ & $\begin{array}{c}\text { Keppra } \Phi^{*}+ \\
\text { AED therapy } \\
(n=672)\end{array}$ & $\begin{array}{c}\text { Placebo + } \\
\text { AED therapy } \\
(\mathbf{n}=351)\end{array}$ \\
\hline $\begin{array}{l}\text { Somnolence and fatigue } \\
\quad \text { Somnolence }\end{array}$ & $15 \%$ & $10 \%$ \\
$\quad$ Asthenia & $14 \%$ & $10 \%$ \\
\hline $\begin{array}{l}\text { Behavioral/psychiatric symptoms } \\
\quad \text { Nonpsychotic }\end{array}$ & $14 \%$ & $6 \%$ \\
$\quad$ Psychotic $^{2}$ & $1 \%$ & $0 \%$ \\
\hline Coordination difficulties $^{3}$ & $3 \%$ & $2 \%$ \\
\hline
\end{tabular}

Reflects Keppra ${ }^{\infty}$ doses of 1000 mg, 2000 mg, 3000 mg, and 4000 mg per day.

"Non-psychotic behavioral/psychiatric symptoms" encompasses the following terms: agitation, antisocial reaction, anxiety, apathy, depersonalization, depression, emotional lability, euphoria,
neurosis, personality disorder and suicide attempt.

neurosis, personality disorder and suicide attempt.
"Psychotic behavioral/psychiatric symptoms" encompasses the following terms: hallucinations, paranoid reaction, psychosis and psychotic depression

Coordination difficulties" encompasses the following terms: ataxia, abnormal gait, incoordination

See ADVERSE EVENTS, Table 2, for incidence rate of individual AEs contained within the categories.

Behavioral/psychiatric symptoms (including agitation, emotiona lability, hostility, anxiety, etc.) have been reported approximately equally in patients with and without a psychiatric history.

There was no clear dose response relationship for any of the three categories of CNS adverse events, within the recommended dose range of up to $3000 \mathrm{mg} /$ day. In a controlled study including a dose of $4000 \mathrm{mg}$, administered without titration, the incidence rate of somnolence during the first four weeks of treatment for patients
receiving the high dose was $42 \%$, compared to $21 \%$ for patients receiving $2000 \mathrm{mg} /$ day.

\section{Special Populations}

Patients with Renal Impairment: Renal excretion of unchanged drug accounts for approximately $66 \%$ of administered levetiracetam dose. Consistent with this, pharmacokinetic studies in renallyimpaired patients indicate that apparent clearance is significantly CIN CLINICAL PHARMACOLOGY, Special Populations).

In patients with renal impairment Keppra® dosage should be appropriately reduced. Patients with end stage renal disease, i.e. those undergoing dialysis, should be given supple
dialysis (See DOSAGE AND ADMINISTRATION).

Pregnancy and Nursing: There are no adequate and well-controlled studies on the use of Keppra® in pregnant women. Levetiracetam and/or its metabolites cross the placental barrier in animal species. In reproductive toxicity studies in rats and rabbits, levetiracetam induced developmental toxicity at exposure levels similar to or greater than the human exposure. There was evidence of increased
skeletal variations/minor anomalies, retarded growth, embryonic skeletal variations/minor anomalies, retarded growth, embryonic
death, and increased pup mortality. In the rat, fetal abnormalities death, and increased pup mortality. In the rat, fetal abnormalities occurred in the absence of overt maternal toxicity. The systemic
exposure at the observed no effect level in the rabbit was about 4 to 5 times the human exposure. The potential risk for humans is unknown. Keppra should not be used during pregnancy unless potential benefits to mother and fetus are considered to outweigh potential risks to both. Discontinuation of antiepileptic treatments may result in disease worsening, which can be harmful to the mother and the fetus.

Pregnancy Exposure Registry: To facilitate monitoring of fetal outcomes of pregnant women exposed to Keppra ${ }^{\circledR}$, physicians (e.g. ultrasound, results of amniocentesis, etc.). in the Antiepileptic Drug Pregnancy Registry by calling (888) 233-2334 (toll free).

Nursing Mothers: Levetiracetam is excreted in breast milk. Therefore, there is a potential for serious adverse reactions from Keppra® in there is a potential for serious adverse reactions from Keppra ${ }^{\circledR}$ in
nursing infants. Recommendations regarding nursing and epilepsy nursing infants. Recommendations regarding nursing and epilepsy the mother, and the as yet uncharacterized risks to the infant. Typically, recommendations are made in the context of the necessary prior risk-benefit judgement, regarding pregnancy and epilepsy medication

Use in Pediatric Patients: Safety and efficacy in patients below the age of 18 have not been established.

Use in the Elderly: Renal function can be decreased in the elderly and levetiracetam is known to be substantially excreted by the kidney, with impaired renal function to the drug may be greater in patients subjects (age 61-88 years) showed a decrease in clearance by about $40 \%$ with oral administration of both single dose and 10 days of multiple twice-daily dosing. This decrease is most likely due to the expected decrease in renal function in these elderly subjects. Care should therefore be taken in dose selection for elderly patients, and it may be useful to monitor renal function.

There were insufficient numbers of elderly patients in controlled trials of epilepsy to adequately assess the efficacy or safety of
Keppra in these patients. Nine of 672 patients treated with Keppra were 65 or over.

Drug Interactions

In Vitro Studies on Metabolic Interaction Potential In vitro, levetiracetam and its primary metabolite have been shown not to inhibit the major human liver cytochrome P450 isoforms (CYP3A4, $2 \mathrm{~A} 6,2 \mathrm{C} 8 / 9 / 10,2 \mathrm{C} 19,2 \mathrm{D} 6,2 \mathrm{E} 1$ and $1 \mathrm{~A} 2)$, glucuronyl transferase (paracetamol UGT, i.e. UGT 1A6, ethinyl estradiol UGT, i.e.UGT 1AT, and p-nitrophenol UGT, i.e.UGT [pI6.2]) and epoxide hydrolase activities. In addition, levetiracetam does not affect the in vitro
glucuronidation of valproic acid. In human hepatocytes in culture, glucuronidation of valproic acid. In human hepato
levetiracetam did not cause enzyme induction.

Levetiracetam circulates largely unbound ( $<10 \%$ bound) to plasma proteins; therefore clinically significant interactions with other drugs through competition for protein binding sites are unlikely.

Thus in-vitro data, in combination with the pharmacokinetic characteristics of the drug, indicate that Keppra® is unlikely to produce, or be subject to, pharmacokinetic interactions 
Clinical Pharmacokinetic Data

Other Antiepileptic Drugs (AEDs): Potential drug interactions between Keppra ${ }^{\circledR}$ and other AEDs (phenytoin, carbamazepine valproic acid, phenobarbital, lamotrigine, gabapentin and primidone) were assessed by evaluating the serum concentrations of levetiracetam and these AEDs during placebo-controlled clinical studies. These data suggest that levetiracetam may not significantly influence the plasma concentrations of these other AEDs, and that the other AEDs may not significantly influence the plasma concentrations of levetiracetam.

For two of these AEDs - phenytoin and valproate - formal pharmacokinetic interaction studies with Keppra ${ }^{\circledR}$ were performed. Keppra ${ }^{\circledast}$ was co-administered with either phenytoin or valproate at doses of $3000 \mathrm{mg} /$ day and $1000 \mathrm{mg} /$ day respectively. No clinically significant interactions were observed.

Other Drug Interactions

Oral Contraceptives: A pharmacokinetic clinical interaction study has been performed in healthy subjects between the oral contraceptive containing $0.03 \mathrm{mg}$ ethinyl estradiol and $0.15 \mathrm{mg}$ levonorgesterol, and the lowest therapeutic dose of Keppra ${ }^{\circledR}(500 \mathrm{mg}$ bid). No clinically significant pharmacokinetic interactions were observed.

However, pharmacokinetic interaction studies using Keppra ${ }^{\circledR}$ as adjunctive therapy and covering the recommended dosage range, have not been conducted. Therefore, physicians should advise their female patients to be alert to any irregular vaginal bleeding or spotting, and to immediately report to them any occurrences.

Digoxin: Keppra ${ }^{\oplus} 1000 \mathrm{mg}$ bid) did not influence the pharmacoDigoxin: Keppra $(1000 \mathrm{mg}$ bid) did not influence the pharmaco-
kinetics and pharmacodynamics (ECC) of digoxin given as a $0.25 \mathrm{mg}$ dose every day. Coadministration of digoxin did not influence the pharmacokinetics of levetiracetam

Warfarin: Keppra ${ }^{\oplus}(1000 \mathrm{mg}$ bid) did not influence the pharmacokinetics of R and S warfarin ( $2.5 \mathrm{mg}, 5 \mathrm{mg}$, or $7.5 \mathrm{mg}$ daily). Prothrombin time was not affected by levetiracetam. Coadministration of warfarin did not affect the pharmacokinetics of levetiracetam.

Probenecid: Probenecid, a renal tubular secretion blocking agent, administered at a dose of $500 \mathrm{mg}$ four times a day, did not change the pharmacokinetics of levetiracetam $1000 \mathrm{mg}$ bid. $C_{\text {ssmax }}$ of the metabolite, ucb L057, was approximately doubled in the presence of probenecid and the renal clearance of the metabolite ucb L057 was decreased by $60 \%$; this alteration is likely related to competitive inhibition of tubular secretion of ucb L057. The effect of Keppra® on probenecid was not studied.

\section{ADVERSE EVENTS}

Commonly Observed

In well-controlled clinical studies, the most frequently reported adverse events associated with the use of Keppra ${ }^{\circledR}$ in combination with other AEDs, not seen at an equivalent frequency among placebo-treated patients, were somnolence, asthenia, dizziness and infection. Of the most frequently reported adverse events, asthenia, somnolence and dizziness appeared to occur predominantly during the first four weeks of treatment with Keppra®.

Incidence of AEs in Controlled Clinical Trials

Table 2:

Incidence (\%) of Treatment-emergent Adverse Events in Placebocontrolled, Add-on Studies by Body System. (Adverse Events Occurred in at least $1 \%$ of Keppra ${ }^{\oplus}$-treated Patients and Occurred More Frequently than Placebo-treated Patients.)

(Studies N051, N052, N132 and N138)

\begin{tabular}{|l|c|c|}
\hline $\begin{array}{l}\text { Body system/ } \\
\text { adverse event }\end{array}$ & $\begin{array}{c}\text { Keppra }{ }^{\oplus}+ \\
\text { AED therapy } \\
(n=672)(\%)\end{array}$ & $\begin{array}{c}\text { Placebo + } \\
\text { AED therapy } \\
(n=351)(\%)\end{array}$ \\
\hline Body as a whole & 14 & 10 \\
Asthenia & 13 & 7 \\
Infection & & 1 \\
\hline Digestive system & 2 & \\
Tooth disorders & & 1 \\
\hline Hemic and & 2 & \\
lymphatic system & & 0 \\
Ecchymosis & 2 & 1 \\
\hline Nervous system & 2 & 2 \\
Amnesia & 3 & 4 \\
Anxiety & 4 & 0 \\
Ataxia & 9 & 1 \\
Depression & 2 & 2 \\
Dizziness & 2 & 0 \\
Emotional lability & 4 & 10 \\
Hostility & 1 & 1 \\
Nervousness & 15 & 1 \\
Personality disorders & 2 & 4 \\
Somnolence & 3 & 3 \\
Thinking abnormal & & 1 \\
Vertigo & & \\
\hline Respiratory system & & \\
Pharyngitis & & \\
Rhinitis & & \\
Sinusitis & & \\
\hline & & \\
\hline
\end{tabular}
"In levetiracetam-treated patients, the majority of "infection" events
$(93 \%)$ were coded to reported terms of "common cold" or "infection $(93 \%)$ were coded
upper respiratory".

\section{Additional Events Observed in Placebo Controlled Trials}

Lack of Dose-related incidence within Therapeutic Range: Based on the data from the controlled clinical trials, there was no evidence of dose relationship within the recommended dose range of 1000 to $3000 \mathrm{mg} /$ day.

Discontinuation or Dose Reduction in Well-controlled Clinical Studies: In well-controlled clinical studies, $14.3 \%$ of patients receiving Keppra ${ }^{\Phi}$ and $11.7 \%$ receiving placebo either discontinued or had a dose reduction as a result of an adverse event. The adverse events most commonly associated $(>1 \%)$ with discontinuation or dose reduction in either treatment group are presented in Table 3.
Table 3:

Adverse Events Most Commonly Associated with Discontinuation or Dose Reduction in Placebo-controlled Studies in Patients with Epilepsy

\begin{tabular}{|lcc|}
\hline & $\begin{array}{c}\text { Keppra } \\
(\mathrm{n}=672)\end{array}$ & $\begin{array}{l}\text { Placebo } \\
(\mathrm{n}=351)\end{array}$ \\
\hline Asthenia & $9(1.3 \%)$ & $3(0.9 \%)$ \\
\hline Headache & $8(1.2 \%)$ & $2(0.6 \%)$ \\
\hline Convulsion & $16(2.4 \%)$ & $10(2.8 \%)$ \\
\hline Dizziness & $11(1.6 \%)$ & 0 \\
\hline Somnolence & $31(4.6 \%)$ & $6(1.7 \%)$ \\
\hline Rash & 0 & $5(1.4 \%)$ \\
\hline
\end{tabular}

The overall adverse experience profile of Keppra ${ }^{\circledR}$ was similar between females and males. There are insufficient data to support a statement regarding the distribution of adverse experience reports by age and race.

\section{Post-marketing Experience}

In post-marketing experience, nervous system and psychiatric disorders have most frequently been reported. In addition to adverse reactions during clinical studies, and listed above, the following adverse reactions have been reported in post-marketing experience. Data are insufficient to support an estimate of their incidence in the population to be treated.

Blood and lymphatic disorders: leukopenia, neutropenia, pancytopenia, thrombocytopenia.

\section{Symptoms}

\section{SYMPTOMS AND TREATMENT OF OVERDOSE}

The highest reported Keppra® overdose is approximately 10 times the therapeutic dose. In the majority of overdose cases, multiple drugs were involved. Somnolence, agitation, aggression, depressed level of consciousness, respiratory depression, and coma were observed with Keppra overdoses. The minimal lethal oral dose in rodents is at least 233 times the maximum clinically studied dose. Treatment

There is no antidote for overdose with Keppra ${ }^{\circledR}$; treatment is symptomatic and may include hemodialysis. If indicated, elimination of unabsorbed drug should be attempted by emesis or gastric lavage; usual precautions should be observed to maintain airway. General supportive care of the patient is indicated including monitoring of vital signs and observation of the clinical status of the patient. Standard hemodialysis procedures result in significant removal of levetiracetam (approximately 50\% in 4 hours) and should be considered in cases of overdose. Although hemodialysis has not been performed in the few known cases of overdose, it may be indicated by the patient's clinical state or in patients with significant renal impairment.

\section{DOSAGE AND ADMINISTRATION}

General

Renal excretion of unchanged drug accounts for approximately $66 \%$ of administered levetiracetam dose. Consistent with this, reduced doses are recommended for patients with renal impairment.

Keppra is given orally with or without food.

Adults

Treatment should be initiated at a dose of $1000 \mathrm{mg} /$ day, given as twice daily dosing ( $500 \mathrm{mg}$ bid). Depending on clinical response and tolerability, the daily dose may be increased every two weeks by increments of $1000 \mathrm{mg}$, to a maximum recommended daily dose of $3000 \mathrm{mg}$

In clinical trials, daily doses of $1000 \mathrm{mg}, 2000 \mathrm{mg}$, and $3000 \mathrm{mg}$, given as twice a day dosing, were shown to be effective. Although there was a tendency toward greater response rate with higher dose, a consistent statistically significant increase in response with increased dose has not been shown. There are limited safety data from controlled clinical trials at doses higher than $3000 \mathrm{mg} /$ day (approximately 40 patients), therefore these doses are not recommended.

Patients with Impaired Renal Function

Keppra ${ }^{\oplus}$ dosage should be reduced in patients with impaired renal function (see Table 4 below). Patients with end stage renal disease should receive supplemental doses following dialysis. To use this dosing table, an estimate of the patient's $\mathrm{CL}_{c}$ in $\mathrm{mL} / \mathrm{min}$ is needed $\mathrm{CL}_{c r}$ in $\mathrm{mL} / \mathrm{min}$ may be estimated from serum creatinine $(\mathrm{mg} / \mathrm{dL}$ ) determination using the following formula:

$\mathrm{CL}_{\mathrm{cr}}=\frac{[140 \text {-age }(\text { years })] \times \text { weight }(\mathrm{kg})}{72 \times \text { serum creatinine }(\mathrm{mg} / \mathrm{dL})}(\times 0.85$ for female patients $)$

Table 4

Dosing Adjustment for Patients with Impaired Renal Function

\begin{tabular}{|c|c|c|}
\hline Group & $\begin{array}{l}\text { Creatinine } \\
\text { clearance } \\
\text { (mL/min) }\end{array}$ & $\begin{array}{l}\text { Dosage and } \\
\text { frequency }\end{array}$ \\
\hline Normal & $\geq 80$ & 500 to $1500 \mathrm{mg}$ twice daily \\
\hline Mild & $50-79$ & 500 to $1000 \mathrm{mg}$ twice daily \\
\hline Moderate & $30-49$ & 250 to $750 \mathrm{mg}$ twice daily \\
\hline Severe* & $<30$ & 250 to $500 \mathrm{mg}$ twice daily \\
\hline $\begin{array}{l}\text { End-stage renal } \\
\text { disease patients } \\
\text { undergoing dialysis? }\end{array}$ & - & 500 to $1000 \mathrm{mg}$ once daily \\
\hline
\end{tabular}

${ }_{*}^{1}$ Following dialysis, a 250 to $500 \mathrm{mg}$ supplemental dose is recommended * or according to best clinical judgement

Patients with Impaired Hepatic Function

No dose adjustment is needed in patients with mild-to-moderate hepatic impairment. In patients with severe hepatic impairment, the creatinine clearance may underestimate the renal insufficiency. Therefore a $50 \%$ reduction of the daily maintenance dose is recommended when the creatinine clearance is $<70 \mathrm{~mL} / \mathrm{min}$. Elderly Patients

Dose selection and titration should proceed cautiously in elderly patients, as renal function decreases with age.
PHARMACEUTICAL INFORMATION

Drug Substance

U.S. AN: levetiracetam

Chemical Name: (-)-(S)- $\alpha$-ethyl-2-oxo-1-pyrrolidine acetamide Structural Formula:<smiles>CC[C@H](C(N)=O)N1CCCC1=O</smiles>

Molecular Formula: $\mathrm{C}_{8} \mathrm{H}_{14} \mathrm{~N}_{2} \mathrm{O}_{2}$

Molecular Weight: 170.21

Physical Form: A white to off-white crystalline powder with a faint odor and a bitter taste.

Solubility: It is very soluble in water ( $104.0 \mathrm{~g} / 100 \mathrm{~mL}$ ). It is freely soluble in chloroform $(65.3 \mathrm{~g} / 100 \mathrm{~mL})$ and in methanol $(53.6 \mathrm{~g} / 100 \mathrm{~mL})$, soluble in ethanol $(16.5 \mathrm{~g} / 100 \mathrm{~mL})$, sparingly soluble in acetonitrile $(5.7 \mathrm{~g} / 100 \mathrm{~mL})$ and practically insoluble in $\mathrm{n}$-hexane.

$\mathrm{pKa}$ and $\mathrm{pH}$ values: The $\mathrm{pKa}$ of levetiracetam is $<-2$ and cannot be determined with accuracy due to the chemical instability of the protonated form.

The protonation of ucb L059 starts at $\mathrm{H}_{0}$ values between -1 and -2 . Partition Co-efficient: $\Delta \log P\left(\log P_{\text {octanol }}-\log P_{\text {cyclohexane }}\right)$ was Partition Co-efficient: $\Delta \log P\left(\log P_{\text {octanol }}-\log \mathrm{P}_{\text {cyclohexane }}\right)$ was
calculated at $\mathrm{pH} 7.4$ using phosphate buffered saline and at $\mathrm{PH} 1.0$ using KCl/HCl. The $\Delta \log \mathrm{P}$ at $\mathrm{pH} 7.4$ is 3.65 and at $\mathrm{pH} 1.0$ is 3.10. using KCl/ $/ \mathrm{HCl}$. The $\Delta \log \mathrm{P}$ at $\mathrm{PH}$
Melting Range: $115-119^{\circ} \mathrm{C}$

Melting Range: $115-119^{\circ} \mathrm{C}$
Composition: Keppra ${ }^{\circledR}$ tablets contain the labeled amount of levetiracetam. Inactive ingredients include colloidal silicon dioxide, corn starch, hydroxypropyl methylcellulose, magnesium stearate, polyethylene glycol 4000, povidone, talc, titanium dioxide and coloring agents.

The individual tablets contain the following coloring agents:

$250 \mathrm{mg}$ tablets: FD\&C Blue No. 2 ,

500 mg tablets: FD\&C Blue No. 2 and yellow iron oxide,

750 mg tablets: FD\&C Blue No. 2, FD\&C Yellow No. 6 and red iron oxide.

Stability and Storage Recommendations

Store between $15-30^{\circ} \mathrm{C}\left(59-86^{\circ} \mathrm{F}\right)$. AVAILABILITY OF DOSAGE FORMS

Keppra ${ }^{\circledR}$ (levetiracetam) tablets, $250 \mathrm{mg}$ are blue, oblong-shaped film-coated tablets debossed with "ucb" and "250" on one side. They are supplied in bottles of 120 tablets.

Keppra (levetiracetam) tablets, $500 \mathrm{mg}$ are yellow, oblong-shaped film-coated tablets debossed with "ucb" and "500" on one side. They are supplied in bottles of 120 tablets.

Keppra (levetiracetam) tablets, $750 \mathrm{mg}$ are orange, oblong shaped, film-coated tablets debossed with "ucb" and "750" on one side. They are supplied in bottles of 120 tablets.

For more information, please refer to the complete Keppra ${ }^{\circledast}$ Product Monograph.

References: 1. Cereghino JJ, Biton V, Abou-Khalil B, et al. Levetiracetam for partial seizures: results of a double-blind, randomized clinical trial. Neurology 2000;55:236-4. 2. Keppra Product Monograph. UCB Pharma, Inc.

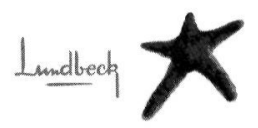

(1) Keppra is a registered trademark of UCB SA.

Keppra ${ }^{\circledR}$ is distributed by Lundbeck Canada Inc., 413 St-Jacques St. West, Suite FB-230, Montreal, Quebec H2Y 1 N9 


\section{6 (Rev. July 2003)}

\section{Immune Globulin Intravenous (Human), 10\%}

\section{GAMUNEX'M}

\section{Manufactured by Chromatography \\ THERAPEUTIC CLASSIFICATION}

PASSIVE IMMUUNIZING AGENT

ACTION AND CLINICAL PHARMACOLOGY

GAMUNEX (Immune Globulin Intravenous [Hurman], 10\%) manufactured by a patented chromatography process is a ready-touse sterile solution of human immune globulin protein for intrat
in $0.16-0.24 \mathrm{M}$ glycine. GAMUNEX

GAMUNEX'" is made from large pools of human plasma by a combination of cold ethanol fractionation, caprylate precipitation and filtration, and anion-exchange chromatograpry. The proy a

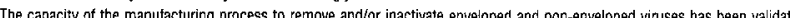
The capacity of the manufacturing process to remove and/or inactivate enveloped and non-enveloped viruses has been validate turing process. virus inactivation and/or removal is achieved by way of caprylate precipitation and cloth filtration, caprylat incubation, column chromatography, and final container low p p incubation, evaluated independently and in combination to
identity those steps which are mechanistically distinct. Each step was verified to provide robust virus reduction across the identity those steps which are meehanistically distinct. Each step was verififed to provide robust virus reduction across the Furthermore, data derived from prion spiking studies have shown that the GAMUNEX' process has the potential to remove anima

The buffering capacity of GAMUNEX' is $35.0 \mathrm{mEg} / \mathrm{L}(0.35 \mathrm{mEq} / \mathrm{g}$ protein). A dose of $1000 \mathrm{mg} / \mathrm{kg}$ body weight therefore represents an acid load of $0.35 \mathrm{mEg} / \mathrm{kg}$ body weight. The total butfering capacity of whole blood in a normal individual $\mathrm{i}$
$45-50 \mathrm{mEa} / \mathrm{L}$ of blood, or $3.6 \mathrm{mEg} / \mathrm{kg}$ body weight. would be neutralized by the butfering capacity of whole blood alone, even if the dose was infused instantaneously. Gilycin (aminioacetic acldy) is a nonessential am In patients with limited or compromised acid-base compensatory mechanisms, and in patients in whom there is already an
gxpanded fluid volume (e.g. during pregnancy) consideration should be given to the effect the additional acid and/or protein load
that may oceur The pharmacokinetic parameters AUC and $C_{\max }$ of GAMUNEX $X^{\text {tu }}$ in a randomized clinical trial involving Primary Immunodeficienc (PlD) patients were determined to be approximately $6746 \mathrm{mg} \mathrm{g}^{*} \mathrm{~h} / \mathrm{mL}$ and $19 \mathrm{mg}$ "h/mL respectively The IgG concentration/time
curve tollows a biphasic siope with a distribution phase of about 5 days characterized by a tall in serum IgG levels to about Curve tollows a biphasic siope with a distribution phase of about 5 days characterized by a fall in serum IgG levels to about
$65.75 \%$ of the peak levels achieved innediately post-infusion. This phase is followed by the elimination phase with a half-llite of

Primary Hurnoral Immunodeficieney

Immune Globulin Intravenous (Human), 10\% supplies a broad spectrum of opsonic and neutrailzing lgg antibodies against bacteria. Viluses or their toxins, that have been cemonstrated to be effective in the prevertions in animal models. Immune Globulin Intravenous (HUman), 10\% has proven to be effective in preventing infections in patients
with Primary Humoral Immurnodeficiency (PID). In randomized pharmacokinetic trials. GAMUNEX Idlopalhic Thrombocylopenic Purpura

The mechanism of action of high coses of immunoglobulins in the treatment of ldiopathic Thrombocytopenic Purpura (ITP) has not been fully elucidated. It is postulated that the mechanisms of action may be the fc-receptor blockade of phagocytes as well as the down regulation of auto-reactive B-colls

The mechanism of action of Immune Globulin Intravenous (Human), 10\% in protecting immune-compromised patients with Allogeric Bone Marrow Transplantation (BMT) from serious bacterial infections is similar to the anti-infective mechanism of action
in PID."1 The immunamodilatory mechanism of action of Immune Globulin Intravenous (Human), $10 \%$ in suppressing acute gratt

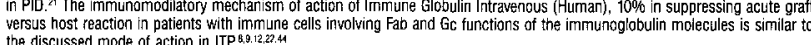
Pedlatric HIV Intectlon

Children with HIV infections, particularly when acquired through vertical transmission, are prone to recurrent serious bacterial infections. Types of infection seen in these children are similar to those with primary hypogammagiobulinemia The replacement

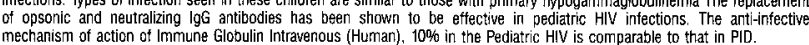
INDICATIONS AND USAGE

GAMUNEX'; (Immune Gilobulin Intravenous [Human], 10\%) is indicated in:

Primary Humoral Immunodeficiency

GAMUNEX' is indicated as replacement therapy of primary humoral immunodeficiency states in which severe irrmpairment of

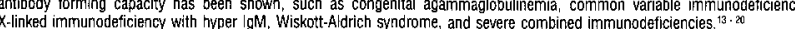
In a double-blind, randomized, paralle! group clinical trial in patients with primary humoral immunodeficiencies GAMUNEX ${ }^{\text {tu }}$ was demonstrated to be at least as efficacious as GAMMMUNE $\mathrm{N}, 10 \%$ in the prevention of infections during a nine month treatment compared to 0.43 ( $p=0.023)$ and $3.26(p=0.287)$ respectively with the control group.

Itiopathic Thrombocytopanic Purpura

GAMUNEX is indicated in Iciopathic Thrombocytopenic Purpura (ITP) to rapidly raise platelet counts to prevent bleeding or to allow a patient with ITP to undergo surgery.

A double-bind, randomized, parallel group clinical trial with 97 acute or chronic ITP patients (adults and children). GAMUNEX"

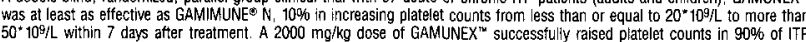
$50^{\circ} 109 / \mathrm{L}$ within 7 days after treatment. A $2000 \mathrm{mg} / \mathrm{kg}$ dose of GAMUNE $X^{\text {th }}$ successfully yaised platelet counts in $90 \%$ of ITP
patients by day 7 and day 23 compared to $83 \%$ and $86 \%$ respectively, in the control group. A sustained 7 day response was Allogenelc Bone Marrow Transplantation

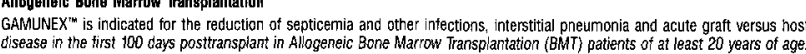

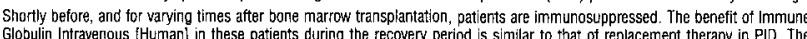

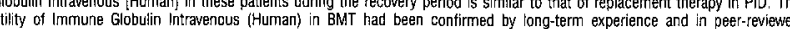
utilly of Immune
published reports.

Gratt-versus-host-disease (GVHD) is a frequent complication of BMT. Immune Globulin Intravenous (Human) has been
dem-onstrated to sign ficantly reduce the incidence of acute GrHD 21,22 Pedlatric HIV Infection GAMUNEX'tw is indicated for the reduction of recurrent serious bacterial infections in those children who do not respond to or
cannot tolerate antiretroviral combination therapy. Children with HIV infections, particularly when acquired through vertical
transmission, are prone to recurrent serious bacterial infections, although they have apparently normal or supranormal IgG levels. In well controlled clinical trials, Immune Globulin Intravernous (Hurnani) has been shown to significantity decrease serious and

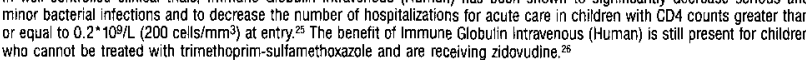

CONTRAINDICATIONS

GAMUNEX' (IImmune Globulin Intravenous [Hurnar], 10\%) is contraindicated in individuals with known anaphylactic or sever

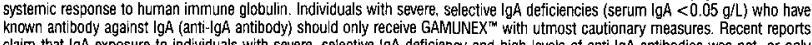
claim that IgA exposure to individuals with severe, selective IgA deficiency and nigh leveis of anti-lgA antibodies was not, or only

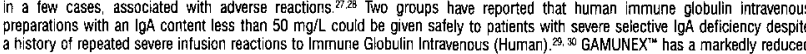

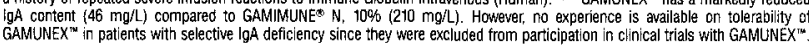
WARNINGS

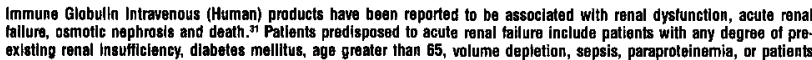

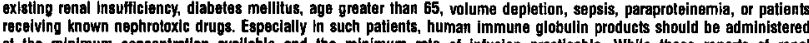

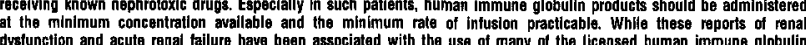
products, those containing sucrose as a stabillzer atcounted tor a disproportionate share of the total number. GAmivNEX products, those containing sucrose as a stabillzer atcounted for a disprop
IImmuna Globulin Intravenous (Human), 10\%] does not contain sucrose.

See PRECAUTIONS and DOSAGE AND ADMINISTRATION sections for important information intended to reduce the risk of aciste renal failure.

GAMUNEX $X^{m}$ is made from human plasma. Products made trom human plasma may contain infectious agents, such as viruses, that can cause diseasa. The risk that such products will transmit an infectious agent has been redueed by screenin plasma donors lor prior exposure to cortain viruses, by testing for the presence of certain current virus infections, and by Tnactlvatlng andior removing certain viruses. Despite these measures, such products can still potentially transmit disease.
There is also the possiblity that unknown infectlous agents may be present in such products. Indiviouals who receive intusions of blood or plasma products may develop signs and/or symptoms of some viral infectlons, particularly hepattitis C. All infections thought by a physician possibly to heve been transmitted by this product should be reported by the physician or other healthcare providar to Bayer Inc. [1-800-265-7382]. The physicien ather

GAMUNEX'Th should be administered intravenously only. On rare occasions, treatment with an immune globulin preparation may to immune grobulin preparations. Epinephrine should be available for the treatment of an acute anaphylactic reaction. PRECAUTIONS

General

Any vial that has been punctured should be used promptly. Partially used vials should be discarded. Visually inspect each bottle

An aseptic meningitis syndrome (AMS) has been reported to occur infrequently in association with Immune Globulin Intravenous (Human) treatment. The syndrome usually begins within several hours to two days following Immune Globulin Intravenous
(Human) treatment. it is characterized by symptoms and signs including severe headache, nuchal rigidity drowsiness, fever photophobia, painful eye movements, nausea and vomiting. AMS may occur more frequently in association with high dose (2000 mig/kg) Immune Giobulin Introverious (Hurnan) treatiment, Discontinuation of Immune Globulin Intravenous (Human) Periodic monitoring of renal function and urine output is particularly important in patients judged to have a potential increased
risk tor developing acute renal failure. Renal function, including measurement of blood urea nitrogen iBUNy/serum creatinine shouid be assessed prior to the initial intusion of GAMUNEX $X^{\prime \prime}$ and again at appropriate intervals thereafter If renal function ceteri. orates, discontinuation of the product should be considered. For patients judged to be at risk for deveioping renal dystunction,
it may be prudent to reduce the amount of product infused per unit time by infusing GAMUNEX" «Im:mune Glosulin intravenous it may be prudent to reduce the amount of product intused per uni.
[Human! $10 \%$ at a rate less than $8 \mathrm{mg} / \mathrm{kg} / \mathrm{min}(0.08 \mathrm{~mL} / \mathrm{kg} / \mathrm{min})$.

Assure that all patients are not volume depleted prior to the initiation of the infusion of Immune Glooulin Intravenous

In some patients, administration of GAMUNEX'" results in a transitory rise of passively transferred antibodies which may produce There is a possible association between thrombo-embolic $(T E)$ events and administration of Immune Globulin Intravenous

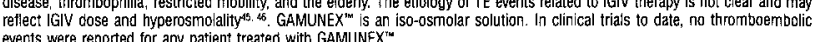
events were reported for

Antibodies in GAMUNEX' may interfere with the response to live viral vaccines such as measles, mumps and rubella. Therefore.
use of such vaccines should be deferred until approximately 6 months atter GAMUNEX" administration. (See DOSAGE AND ADMINISTRATION for other relevant interactions).

Prognancy

Animal reproduction studies have not been conducted with GAMUNEX"', It is not known whether GAMUNEX" can cause fetal harm when administered to a p
woman only if clearly needed.

ADVERSE REACTIONS

General

Increases in creatinine and blood urea nitrogen (BUN) have been observed as soon as one to two days following infusion, predominantly with other human immune globulin products, stabilized with sucrose. Progression to oliguria and anuria requiring dialysis has been observed, although some patients have improved spontaneously following cessation of treatment..$^{35}$ GAMUNEX

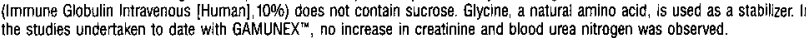
Although not all adverse effects previously reported with intravenous and intramuscular immunoglobulin administration have been observed for GAMUNEX'w, adverse effects mayy be expected to be similar to those reported with these products. Potential

True anaphylactla reactions to GAMUNEX' may occur in recipients with documented prior histories of severe allergic reactions to intramuscular inmunnoglobulin, but $\mathrm{Xome}$ patients may tolerate cautiousiy administered intravenous immunoglobulin without
adverse effects. ${ }^{36}$ Very rarely an anaphylactoaid reaction may occur in patients with no prior history of severe allergic reactions to either intramuscular or intravenous immunoglobulin.

Direct antiglobin tests (DAT or direct Coombs tests), which are carried out in some centers as a safety check prior to red brood

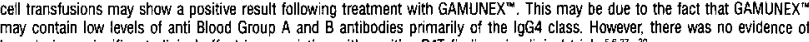

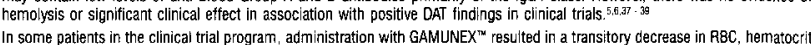
In some patients in the clinical trial program, administration with GAMUNEX'tresu
and hemoglobin with no evidence of hemo ysis or significant clinical outcome.

Prlmary Humoral Immunodeficiency

Adverse events were monitored in three randomized clinical trials, involving more than 200 primary humoral immunodeficiency patients. In two trials, Involvirg 18-20 patients each, patients received 100-600 mg/kg GAMUNEX" or GAMMMUNEE $\mathrm{N}, 10 \%$ for three subsequent infusions on a 3 or 4 week infusion interval and were then crossed over to three intusions of the alternate

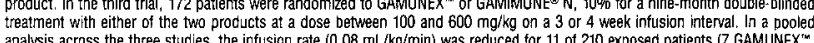
analysis across the three stud pros site, anxiety or headache was the main reason for reduction in intusion rate. There was one case of severe chilits. There were no anaphylactic or anaphylactoid reactions.

In the pivotal chinical trial, the most trequently recorded drug related adverse events $(-0.5 \%)$ normalized per patient and infusion are given in the table below:

\begin{tabular}{|c|c|c|}
\hline Drug Related Adverse Events & GAMUNEX' ${ }^{\text {tm }}$ No. of Infusions: 825 & GAMIMUNE ${ }^{3} N, 10 \%$ No. of infusions: $\overline{865}$ \\
\hline Cough increased & $14(1.7 \%)$ & $11(1.3 \%)$ \\
\hline Headache & $7\{0.8 \%)$ & $11(1.3 \%)$ \\
\hline Fever & $1(0.1 \%)$ & $9(1.0 \%)$ \\
\hline Pharyngitis & $7(0.8 \%)$ & $9(1.0 \%)$ \\
\hline Nausea & $4\{0.5 \%)$ & $4(0.5 \%)$ \\
\hline Urticaria & $4(0.5 \%)$ & $5(0.6 \%)$ \\
\hline
\end{tabular}

At various time points atter the infusion of Immune Globulin Intravenous (Human), $10 \%$, serum samples were drawn to monitor the virat safety of the PID patients. Viral markers of hepatitis $\mathrm{C}$, hepatitis $\mathrm{B}$. HIV-1, and parvovirus B19 were monitored by nucleic,
acid testing (NAT, Polymerase Chain Reaction [PCR]), and serological testing. There were no treatment restated emergent findings
of viral transmission $5,5,37$

Similar adverse reactions as for PID are expected for the Immune Globulin Intravenous [Human], 10\% treatment of patients with pediatric HIV infection or Allogeneic Bone Marrow Transplantatlon due to the similar mechanism of action and cose schedule. Id iopathic Thrombocylopenic Purpura (ITP)

Adverse reactions were monitored in two randomized clinical trials with more than 100 patients with acute or chronic ITP.

In the first study (randomized and double-blind), 97 ITP patients were randomized to a single dose of 2000 mg/kg of
GAMUNEX or GAMIMUNE' $\mathrm{N}, 10 \%$. The total dose was divided into two $1000 \mathrm{mg} / \mathrm{kg}$ doses given on two consecutive days at a maximum intusion rate of $0.08 \mathrm{~mL} / \mathrm{kg} / \mathrm{min}$

As expected, the adverse event rate for Immune Globulin Intravenous [Humanl, 10\% in this ITP trial was higher than observed in the replacement theraoy for Primary Humoral Immunodeticiencies (PID), but was within the range reported earlier for Inmun on two consecutive days rather than on five consecutive days. which is associated with a higher adverse event rate.' Finally, $\mathrm{no}$ pre-medication with corticosteroids was permitted in the study protoco events were of mild to moderate severity and of transient nature.
The most frequently recorded drug related adverse events $(22.0 \%)$ are given in the table below:

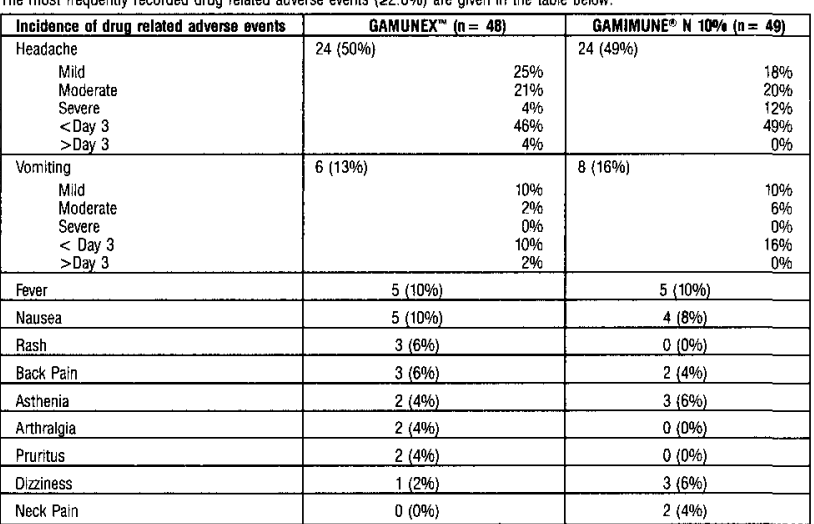


The infusion rate was reduced for only 4 of the 97 treated patients ( 1 GAMUNEEX', 3 GAMIMUNEE⿱乛龰 $N$, 10\%) on 4 occasions.
Mild to moderate headache, nausea, and fever were the reported reasons. There were no anaphylactic or anaphylactoid reactions. At various time points after the infusion of Imrnune Giobulin Intravenous (Human). 10\%, serum samples were drawn to monitor

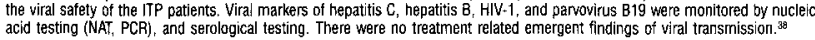
A second trial was carried out in 28 chronic ITP patients who received $1000 \mathrm{mg} / \mathrm{kg}$ GAMUNEX on three occasions for treatment of relapses to determine tolerabilily of various infusion rates. The maximum infusion rate on the three occasions was random assigned to $0.08,0.11$, or $0.14 \mathrm{~mL} / \mathrm{kg} / \mathrm{min}(8,11$ or $14 \mathrm{mg} / \mathrm{kg} / \mathrm{min}$ ) in which each patient was to receive Immune Globul
Intravenous (Hurrani), $10 \%$, at all 3 rates. No ore-medication with corticosteroids to alleviate infusion-related intolerability was permirted. Seven patients did not complete the study for the following reasons: one adverse event (hives) at the $0.08 \mathrm{~mL} / \mathrm{kg} / \mathrm{min}$ level. one patient withdrew because he refused to participate without a forbidden concomitant medication (prednisone) and five patients did not require additionai treatment.

The number of patients who experienced at least one adverse event tor the $0.08,0.11$, and $0.14 \mathrm{~mL} / \mathrm{kg} / \mathrm{min}$ infusion rates was
$12(46 \%), 13(59 \%)$, and $11(46 \%)$. respectively. The most commonly reported adverse more trequently during the higher infusion rates $(4 \%$ in $0.08 \mathrm{~mL} / \mathrm{kg} / \mathrm{min}$ patients $\mathrm{vs} .23 \%$ in $0.11 \mathrm{~mL} / \mathrm{kg} / \mathrm{min}$ patients vs. $13 \%$ in $0.14 \mathrm{~mL} / \mathrm{kg} / \mathrm{min}$ patients). Imponantly, all of the headaches were mild except for one severe headache at the $0.08 \mathrm{~mL} / \mathrm{kg} / \mathrm{m} / \mathrm{m}$ rate. Otherwise, the incidence rates of adverse events and drug-related adverse events generally appeared to be similar among results except for slightly decreased heart rates following all intusion rates. ${ }^{39}$

\section{DOSAGE AND ADMINISTRATION}

General

For introvenous use only. Dosages for specific indications are indicated below, but in general, it is recommended that Immunne Globulin Intravenous (Human), $10 \%$ be infused by itself at an initial rate of 0.01 to $0.02 \mathrm{~mL} / \mathrm{kg}$ body weight per minute for investigations indicate that Immune Globulin Intravenous (Human), $10 \%$ is wetl-tolerated and less likely to produce side effects when intused at the recommended rate. If side etfects occur, the rate may be recuced, of the intusion interrupted until symptoms subside. The infusion may ther, be resumed at the rate which is comfortable for the patient. Parenteral drug products should
inspected visually for particulate matter and discoloration prior to administration, whenever solution and container permit.

For patients judged to be at increased risk for developing renal dysfunction, it may be prudent to reduce the amount of product infused per unit time by infusing GAMUNEX'" (Immune Globulin Intravenous [Hurnan], 10\%) at a rate less than $8 \mathrm{mg} / \mathrm{kg} / \mathrm{m}$ (0.08 $\mathrm{mL} / \mathrm{kg} / \mathrm{min}$ ). No prospective data are presently avalabe to ideritify a maximum safe dose, concentration, and rate of
infusiun in patients determined to be at increased risk of acute renal failure. In the absence of prospective data, recommended doses should not be exceeded and the concentration and infusion rate should be the minimum level practicable. Reduction in
dose, concentration, and/or rate of administration in patients at risk of acute renal faliure is suggested in order to reduce the risk
of acutg renal tafture" of acute renal taiture."

\section{Primary Humeral Immunodeficiency} GAMUNEX' doses between 100 and $600 \mathrm{mg} / \mathrm{kg}(1$ and $6 \mathrm{~mL} / \mathrm{kg}$ administered every 3 or 4 weeks) may be used for infection
prophylaxis. The dose should be individuaized taking into account dosing intervals (e.g. 3 or 4 weeks) and GAMUNEX' dose
(between 100 and $600 \mathrm{mg} / \mathrm{kg}$ ). The goal should be to achieve serum igG levels at trough (i.e. prior to the next infusion) of at 50

\section{Idiopathic Thrombocytopenic Purpura}

GAMUNEX ${ }^{\text {tw }}$ may be administered at a total dose of $2000 \mathrm{mg} / \mathrm{kg}$, diviced into two doses of $1000 \mathrm{mg} / \mathrm{kg}$ (10 mL/kg) given on two consecutive days, or into five doses of $400 \mathrm{mg} / \mathrm{kg}$ ( $4 \mathrm{~mL} / \mathrm{kg}$ ) given on five consecutive days. If after administration of the
first of two daily $000 \mathrm{mg} / \mathrm{kg}$ (10 $\mathrm{mL} / \mathrm{kg}$ ) doses, an adequate increase in the platelet count is observed at 24 hours, the second

The high dose regimen ( $1000 \mathrm{mg} / \mathrm{kg} \times 1.2$ days) is not recommended for individuals with expanded fluid volumes or where fluid

Allogeneic Bone Marrow Transplantation (BMT)
An equivalent dosage of $500 \mathrm{mg} / \mathrm{kg}$ GAMUNEX (5 $\mathrm{mL} / \mathrm{kg}$ ) is recommended beginning on days 7 and 2 prior to transplantation should be administered by itself through a Hickman line while it is in place, and thereatter through a perioheral vein. Pediatric HIV Infection

An equivalent dosage of GAMUNEX'" is recommended in doses of $400 \mathrm{mg} / \mathrm{kg}$ ( $4 \mathrm{~mL} / \mathrm{kg}$ ) body weight every 28 days.

Administration

It is recommended that GAMUNEX'm should initially be infused at a rate of 0.01 to $0.02 \mathrm{~mL} / \mathrm{kg}$ per mirute (1 to $2 \mathrm{mg} / \mathrm{kg}$ per minute) tor the first 30 minutes. It well tolerated, the rate may be gradually increased to a maximum of $0.14 \mathrm{~mL} / \mathrm{kg}$ per minute (14 mg/kg per min unte). If side effects occur, the rate may be reduced, or the int
infusion may then be resumed at the rate, which is cormortable for the patient.

In a clinical tral with 28 chronic adult ITP patients receiving $1000 \mathrm{mg} / \mathrm{kg}$ GAMUMEX to treat relapses, the infusion rate coul be safely increased up $100.14 \mathrm{~mL} / \mathrm{kg}$ per minute (14 mg/kg per minute) ${ }^{35}$ Caution should be exercised when an Intusion rate higher than $0.08 \mathrm{~mL} / \mathrm{kg}$ per minute (8 $\mathrm{mg} / \mathrm{kg}$ per minute) is administered for the first time

Only 18 gauge needles should be used to penetrate the stopper for dispensing product from $10 \mathrm{~mL}$ vial sizes; 16 gauge needles or dispensing pins should only be used with $20 \mathrm{~mL}$ vial sizes and larger. Needles or dispensing pins should only be inserted
within the stopper area delineated by the raised ring. The stopper should be penetrated perpendicular to the plane of the stopper
within the ring.

Content of vials may be pooled under aseptic conditions into sterile infusion bags and infused within 8 hours after pooling. It is recommended to intuse GAMUNEX'm using a separate line by itself, without mixing with other intravenous fluids of medications the patient might be receiving. GAMUNEX"'s should not be mixed with any other Immune Globulin Intravenous

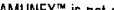

compatible with saine. If dilution is required, GAMUNEX"' may be cilluted with $5 \%$ dextrose in water (D5W) No other drug interactions or compatibilities have been evaluated.

A number of factors beyond our control could reduce the efticacy of this product or even result in an ill effect tollowing its use. These include improper storage and handling of the product after it laves our hands, diagnosis, dosage, method of adminis-
tration, and biological differences in individual patients. Because of these factors, it is importart that this product be stored properly and that the directions be followed carefilly during use

\section{PHARMACEUTICAL INFORMATION}

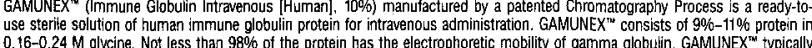
has low levelis of $\lg$ ( Noverage of $0.046 \mathrm{~g} / \mathrm{L}$ ). . IgM levels were at or below the limit of quantiation ( $0.002 \mathrm{~g} / \mathrm{L}$ ). The distribution of lgG subclasses is similar to that found in normal serum. The measured buffer capacity is $35 \mathrm{mEE} / \mathrm{L}$ and the osmolality is GAMUNEX'tis made from large pools of human plasma by a combination of cold ethanol fractionation, caprylate precipitation and filtration, and anion-exchange chromatography. Fart of the fractionation may be performed by another licensed man ufacture of the log molecule are retained, but do not activate complement or pre-Katilikrein activity in an unspecific manner. The protein is stabilized during the process by adjusting the $\mathrm{pH}$ of the solution to $4.0-4.5$. Isotonicity is achieved by the addition of glycine.
GAMUNEX product is intended for intravenous administration.

The capacity of the manufacturing process to remove and/or inactivate enveloped and non-enveloped viruses has been validatec by laboratory spiking studies on a scaled down process model, using the following enveloped and non-enveloped viruses:

\begin{tabular}{|l|l|}
\hline Spliking Study Virus used: & As a model lor: \\
\hline Human Immunodeficiency Virus Type 1 (HIV-1) & HIV-1 and HIV-2 \\
\hline Bovine Viral Diarthea Virus (BVDV) & Hepatitis C virus \\
\hline Pseudorabies Virus (PRV) & Hepatitis B and herpes virus \\
\hline Reo virus type 3 (Reo) & non enveloped virus \\
\hline Hepaitits A virus (HAV) & non enveloped virus \\
\hline porcine parvovirus (PPV) & human parvovirus B19 \\
\hline
\end{tabular}

The following process steps contribute to virus inactivation and/or removal: caprylate precipitation and cloth filtration, caprylate incubation, column chromatography and final container low $\mathrm{pH}$ incubation. The table below indicates how the viruses are affected by the different steps. A number of virus rerrovial steps were evaluated independently and in combination to identify those steps which are mechanistically distinct. Overall virus reduction was calculated only trom steps that are mechanistically
independent from each other and truly additive. In addition, each step was verified to provide robust virus reduction across the
production range for $k$ ky operating parameters.

\begin{tabular}{|c|c|c|}
\hline Process step & Envaloped viruses & Non-enveloped viruses \\
\hline \begin{tabular}{|l} 
Caprylate precipitation and cloth filtration \\
\end{tabular} & Robust removal of BVDV; not ctaimed for other enveloped viruses' & Robust removal \\
\hline Caprylate incubation & Dedicated step robust inactivation* & No effect \\
\hline Depth Filtration & Not claimed ${ }^{2}$ & Not claimed $^{3}$ \\
\hline Column chromatography & Robust removal $^{*}$ & Fiobust removal $\left.\right|^{*}$ \\
\hline Final container low pH incubation & Dedicated step, robust inactivation ${ }^{*}$ & No effect \\
\hline
\end{tabular}

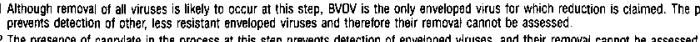

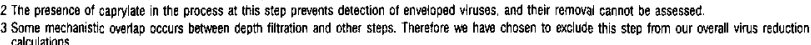

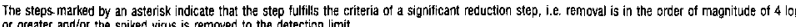
Oata derived from prion spiking studies have shown that the GAMUNEX" process has the potential to remove animal model

Gycine taminoacetic acid) is a nonessential amino acid normally present in the body. Glycine is a major ingredient in armino acid solutions employed in intravenous alimentation. ${ }^{4}$ While toxic effects of glycine adrninistration have been reported, the toeses
and fates of administration were $3-4$ fold greater than those for GAMUNEEX intravenous bolus doses of $0.44 \mathrm{~g} / \mathrm{kg}$ glycine were not associated with serious adverse effects ${ }^{43} \mathrm{GAMMUNEX^{ \textrm {m } }}$ dosteses of $1000 \mathrm{mg} / \mathrm{kg}$, usually infused over $2-3$ hours, amount to corresponding glycine concentrations of $0.15 \mathrm{~g} / \mathrm{kg} .0 .2 \mathrm{M}$
has been used safely in other Bayer Immune Globulin Intravenous (Human), 10\% preparations since 1992 .
The buffering capacity of GAMUNEX'm is $35.0 \mathrm{mEq} / \mathrm{L}(0.35 \mathrm{mEE} / \mathrm{g}$ protein). A dose of $1000 \mathrm{mg} / \mathrm{kg}$ body weight therefore represents an acic load of $0.35 \mathrm{mEg} / \mathrm{kg}$ body weight. The total butfering capacity of whole blood in a normal individual is

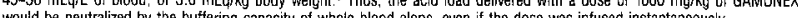
Storags

GAMUNEX'm may be stored for 36 months at $2-8^{\circ} \mathrm{C}\left(36-46^{\circ}\right)$ ). AND product may be stored at room temperature not to exceed $25^{\circ} \mathrm{C}\left(77^{\circ}\right)$ ) for up to 5 months during the first 18 morths from the date of manufuacture, after which the product must be AVAILABILITY OF DDSAGE FORMS

GAMUNEX'"' (Immune Giobulin Intravenous [Human], 10\%) is supplied in the following sizes:

$\begin{array}{cc}\text { Size. } & \text { Protain (g) } \\ 10 \mathrm{~mL} & 1.0 \\ 25 \mathrm{~mL} & 2.5 \\ 50 \mathrm{~mL} & 5.0 \\ 100 \mathrm{~mL} & 10.0 \\ 200 \mathrm{~mL} & 20.0\end{array}$

REFERENCES

1. Lee $\mathrm{DC}$, Stenland $\mathrm{CJ}$, Hartweil $\mathrm{RC}$, Ford EK, Cai K, Miller JL, et ai. Monitoring plasn
blot assay for the detection of the prion protein. I Viroi Methods $2000: 84(1): 77-89$ 2. LeE $\mathrm{DC}$, Stenland $\mathrm{CJ}$, Miler $\mathrm{JL}$, Cai $\mathrm{K}$, Ford EK, Gilligan KJ, et al . A direct relationship between the partitioning of the pathogenic
prion protein and transmissible spongiform encephalopathy infectivity during the purification of plasma proteins. Transtusion
$2001 ; 41(4): 449-55$.

3. Guyton AC. Clinical measurements for study of acid-base abnormalities. In: Textbook of Medicai Physiology. 5 ed. Philadelphia 4. Wretlind A. Complete intravenous nutrition. Theoretical and experimental background. Mutr Metab 1972:14/Suppl):1.57.

5. Bayever $E$. Monteagudo F, Sundaresan $P$. Collins $S$. A randomized, doubleblind, multicenter, repeat dosing, cross-over trial

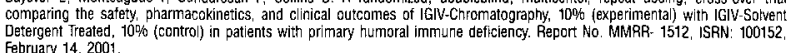

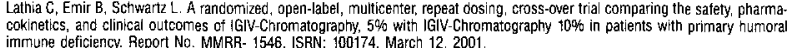
7. Blanchente vS, Kirby MA. Turner C. Role of intravenous immunoglobulin $G$ in autoimmune hematologic disorders. Semin Hematol,

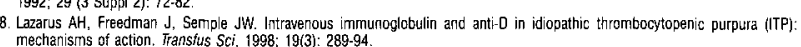
9. Semple $J W$, Lazarus AH, Freedman J. The cellular immunology associated with autoimmune thrombocytopenic purpura: an update. 9. Fanstus Sci 1998; 19(3): 245-5t.
. 10. Imbach PA. Harmful and beneficial antibodies in immune tinombocytopenic purpura. Cin Exp immunot 1994;
11. Bussel JB. Fc receptor bockade and immune thrombocytopenic purpura. Semin Hemator 2000; 37(3): 261-6.

2. Imbach P, Akatsuka J, Blanchette V, Burek-Kozlowska A, Busssel J, Gaecicke G, et al. Imm unthrombocylopenic purpura as a model tor pathogenesis and treatment of autoimmunity. Eur J Pediatr 1995;154(9 Suppl 4):S60-4.

13. Ammann AJ, Ashman RF, Buckley RH, Hardie WR, Krantmann HJ, Nelson J, et at. Use of intravencus gamma-globulin in antibody

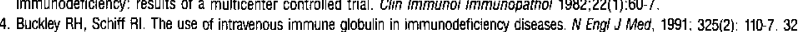
15. Cunningham--Rundles $\mathrm{C}$. Bodian $\mathrm{C}$. Common variable immunodeficiency: clinical and immunological teatures of 248 patients. Cin

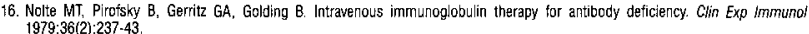
17. Pruzanski W, Susssnan G, Dorian W, Van $T$, Ibanez $D$, Redelmeier D. Relationship of the dose of intravenous gam
the prevention of infections in adults with common variable immunodeficiency. Intiammation 1996:20(4):353-9.

18. Rolfman CM. Levison H. Gelfand EW. High-dose versus low-dose intravenous Immunoglobulin in hypogammagiobulinaemia and 19. Sorensen RU, Polmar SH. Etficacy and safety of high-dose intravenous immune giobulin therapy for antibody deficiency syndromes. 20. Stephan JL, Vlekova V. Le Deist $F$, Blanche $S$, Donadieu J, De Saint-Basile $G$, et al. Severe combirned immunodeficiency: a

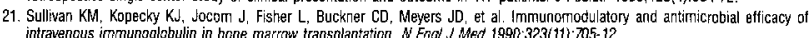
22. Sullivan KM. Immunomodulation in aliogeneic marrow transpiantation: use of intravenous immune globulin to suppress acute
gratt-versus-host disease. Clin Exp /rimmunol 1996, 104(Suppl 1):43-8. 23. Spitzer TR, Cottler-Fox M, Sullivan $P$, Lynch M, Tefft MC, Pickle LW, et al. Continuous intusion intravenous immunoglobulin is associated with a reduced incidence of infection and achieves higher serum immunog obulin $\mathrm{G}$ levels than intermitient infusion 24. Bass EB, Powe NR, Goodrnan SN, Graziano SL, Griffith RI, Kickler TS, et al. Efficacy of immune globulin in preventing compli25. Intravenous immune globutin for the prevention of bacteral intections in children with symptomatic human immunodeficiency
virus infection. The National Institute of Child Heatth and Human Developments Intravenous Immunogolobulin Study Group. in: WEngl J Med; 1991. p. 73-80.

26. Spector SA, Gelber RO, MCGrath N, Wara D, Barzilai A. Abrams E, e: al. A controlled trial of intravenous immune globulin for the prevention of serious bacterial infections in, crildren receiving zidovudine
Pediatric AIDS Clinical Trials Group. $N$ Engi $J$ Med 1994:331(18): 1181-7.

27. de Aibuquerque Campos $\mathrm{B}$, Sato MN, da Silva Duarte AJ. IgG anti-IgA subclasses in common variable immunodeficiency and

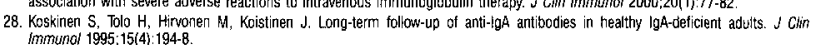
29. Cunningham-Runcles $\mathrm{C}$, Zhou Z, Mankarious $\mathrm{S}$, Courter $\mathrm{S}$. Long-term use of IgA-depleted intravenous immunoglobulin in

30. Litzman J, Broz P. Kral V, Lokaj J. [Successtul garnma globulin therapy in a patient with anti-lgA antibodies]. Vnitr Lek
$1997 ; 43(2): 102-4$. 31. Cayco AVV Perazella MA, Hayslet JP. Rena insulficiency after intravenous immune globulin therapy: a report of two cases and an

32. Casteels-Van Daele M. Windaele L, Hanninck K. Gillis $P$. Intravenous immune globulin and acute aseptic meningitis. $N$ Engl $d$
Med $1990 ; 323(9): 614-5$.

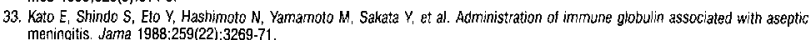
34. Scribner CL. Kapit RM, Prillips ET. Rickles NM. Aseptic meningtis and intravenous immunoglabulin therapy. Ann intern Med 35. Winward DB, Brophy MT. Acute renal fallure after administration of intravencus immunoglobulin: review of the literature and case 36. Peerless AG, Stiehm ER. Intravenous gammaglobulin for reaction to intramuscular preparation. Lancet 1983:2[8347]).461.

37. Kelleher J, Faith G, Cyrus P, Schwartz L. A Randomized, Double-Blind, Multicenter, Paraliel Group Irial Comparing the Safety and
Efficacy of IGiv-Chromatography, 10\% (Experimental) with IGIV-Solvent Detergert Treated, $10 \%$ (Control) in Patients with Primary Immune Deficiency (PID). Bayer Report, 2000 .

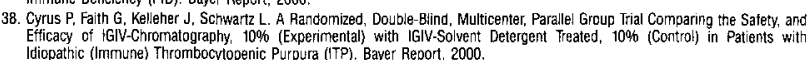

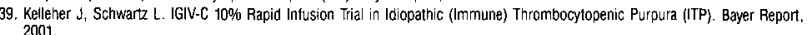

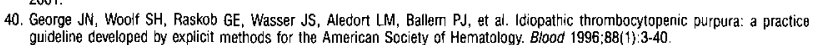
41. Tan $E_{1}$ Hajinazarian $M, B a y$. Neff $J$, Mendell JR. Acute renal tail ure resulting from intravenous immunoglobulin therapy. Arch
Neurol $1993 ; 50(2): 137-9$. 42. Hahn RG. Stalberg HP, Gustatsson SA. Intravenous infusion of irrigating fluids containing glycine or mannitol with and withour 43. Tai VM, Mitchell EJ, Lee-Brothertion V Manley JS, Nestmann ER, Daniels JM. 15. Safety evaluation of intravenous glycine in 44. Kazatchkine MD. Kaveri SV. Immunomodulation of autoimmune and inflammatory diseases with intravenous immune globulin. $N$ 44. Kazatchkine MD, Kaveri SV. Immun

45. Koski CL. Therapy of CIOP and celated immune-mediated neuropathies. Neurolocy 2002;59(12 Suppi 6): S22.7.

46. Lemm $G$. Composition and properties of IMg preparations that affect tolerability and therapeutic efficacy. Neurology 2002:58
(t2 Supp 6): $228-32$. 08841856 (Rev. July 2003)

\section{Product Monograph available upon request.}

References for advertisement on adjacent pages:

1. Gamunex ${ }^{\text {TM }}$ Product Monograph, August 11, 2003. Bayer Inc

2. Data on File, Bayer Inc.

Imported by:

(APि. Bayer HealthCare

(RED PAB

Bayer Inc.
77 Belfield Road.

Toronto, Ontario
M9W 1 Ǵ6 CANADA Bayer and Bayer Cross ase registered trademarks of Bayer AG, used under license. 
between 2 and 24 hours, it was considered a relapse and the patient was instructed to take a second dose of study medication. Associated sy
vomiting, photophobia, and phongephobia were also eyaluated.

Axert almotriptan malate tablets

\author{
PAXERT* \\ almotriptan malate tablets \\ $6.25 \mathrm{mg}$ and $12.5 \mathrm{mg}$ \\ almotriptan \\ 5-HT, Receptor Agonist \\ Migraine Therapy
}

ACTION AND CLINICAL PHARMACOLOGY

\section{Mechanism of Action}

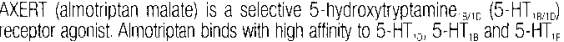
receptors. Amotriptan has a weak affinity for $5-\mathrm{HT}_{1}$ and $5-\mathrm{HT}$, receptors, but has alipha or beta adrenergic; adenosine $\left(A_{1}, A_{2}\right)$; angiotensin (AT, , AT 2$)$ dopamine

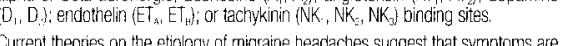
Culfrent theories on the etiology of migrane headaches suggest that symptoms are due to local crantal vasodiatation and/or to the reease of vasuacive and prosystem. The therapeutic activity of almotriptan in migraine can most likely be blood vessels that become dilated curing a migraine attack and on the nerve terminals in the ticerninal system. Activation of these receotors results in crania vessel constriction, inhibition of the neuropeotide release, and reduced transmission in the trigeminal pain pathways

\section{Pharmacokinetics}

Aosorption

Almutriptan is well absorbed following oral administation. The mean oral absolute biodvailatility is approximately $70 \%$, and peak plasma concentrations of approximately
$40 \mathrm{ng} / \mathrm{mL}$ are reached 1 to 3 hours after a single $+2.5 \mathrm{mg}$ dose. The rate and extent of absorption ale not affected by tood irtake or by administration during a migraine of ausorption ale not affected by tood irtake or by administraton du

Distribution

Almotriptan is extensively distributed. Amotriptan is minimally protein bound apploximalely $35 \%$, and the mean apparent volume of distribution is approximately Metabolism

Almotriptan is metabolized by one minor and two major pathways. Monoamine oxidase (MAOH-mediated oxidative deamination (approximately $27 \%$ of the dose) and
cylochrome $\mathrm{P} 450$-nediated oxidation (approximately $12 \%$ of the dcse) are the maior oytochrome $\mathrm{P} 450$-nedlated oxidation (approximately $12 \%$ of the dose) are the major
routes of metabolism, while flavin mono-oxygenase is the minor route. MAO-A is responsible tor the tormation of the indoleacetic acid metabolite, whereas cytochron int50 (3A4 and 206) catalyzes the hydroxylation of the pyroblidine ring to an
intermediate that is further oxidized by aldehyde dehydrogenase to the gammaintermediate that is further oxidized by aldehyde dehydoge
aminobutyric acid derivative Both metabolites are irractive.

Excretion

The mean half-life of almotripten is between 3 and 4 hours. The primary route of elimination is via renal clearence, accounting for $75 \%$ of the administered dose. Approximately $40 \%$ of an administered dose is excreted unchanged in urine. Rena an active mechanism. Approximately $13 \%$ of the administered dose is excreted vi
ieces both unchanged and metaboized.

Special Populations

Geriatric

Rentl thd total clectlance, and amount of drug excreted in the urine $\langle 10 \mathrm{~L} / \mathrm{h}, 33 \mathrm{~L}$ and $30 \%$ respectively) were lower in elderly non-migraineur volunteers (aced 65 to in longer terminal half-ife ( $3.7 \mathrm{~h}$ vs. $3.2 \mathrm{~h}$ ) and higher area under the plasm concentration-time curve $(405 \mathrm{ng} . h / \mathrm{mL}$ vs. $325 \mathrm{mg} . \mathrm{h} / \mathrm{mL}$ ) in the elderly subject However, the differences do not appear to be clinically significant.

Pediątric

The pharmacokinetics of almotrigtan have not been eval ated in pediatric patients. Gender

No significant gender cifferences have been observed in pharmacokinetc parameters. Race

No sicnilicant differences have been observed in the pharmacokinetic parameters between Caucasian and

The pharmacokinetics of almotriptan have not been assessed in this population Eased on the known mechanisms of the clearance of almotriptan, the maximum decredse in expected amotiptan clearance due to hepatic impairment would be FRECAITIONS

Renal Impairment

The clearance of alrnutriftan was approximately $65 \%$ lower in patients with severe remal impaimment $\langle C / F=19.8 \mathrm{~L} / \mathrm{h}$; creatinine clearance between 10 and $30 \mathrm{~mL} / \mathrm{m}$ and aporoximately $40 \%$ lower in patients with moderate renal impaiment (Cl/F
$34.2 \mathrm{~L} / \mathrm{h}$; creatinine clearance between 31 and $71 \mathrm{~mL} / \mathrm{min}$ ) compared to healthy volumteers. Maximum plasma concentrations of almotriptan increased by
auproximately $80 \%$ in these patients (see DOSAGE AND ADMINISTRATION and ajproximately $80 \%$ in these patients (s)
Renal impairment in PRECAUTIONS)

\section{CLINICAL STUDIES}

The pharmacologicat activity of almotriptan in the treatment of migraine has been assessed in Pllase $\|$ and Phase III clinical trials

The efficaCy of AXERT (almotriptan malate) tablets was established in 3 multicentre were primarily fermale ( $86 \%$ ) and Caucasian imore than $98 \%$ ), with a mean age of 41 years (range of 18 to 72 ). Patients were instructed to treat a moderate to severe mgraine headache. Two hours atter taking one dose of study medication, patien evaluated their headache pain. It the pain had not decreased in seventy to mild or
to ing pain, the patient was allowed to take an escape medication. If the pair had decreased to mild or to no pain at 2 hours but subsequently increased in severity
In these studies, the percentage of patients achieving a response (mild or no pain) 2 hours after treatment was signifcantly greater in patients who received eith almotrintan 125 mg was superior to placebo as early as 30 minutes after dr dministration (2.5ning comparison $p=0.0485$ ) A richer percentage of reported pan relief atter treatment with the $12.5 \mathrm{mg}$ dose than with the $6.25 \mathrm{mg}$
dose. Doses greater than $12.5 \mathrm{mg}$ did not lead to significantly better response.
These results are summarized in Table 7 .

Table 1. Pain Relief Rates 2 Hours Following Treatment of Initia Headache

\begin{tabular}{|c|c|c|c|}
\hline & Placebo & $\begin{array}{l}\text { AXERT } \\
6.25 \mathrm{mg}\end{array}$ & $\begin{array}{c}\text { AXERT } \\
12.5 \mathrm{mg}\end{array}$ \\
\hline Study 1 & $\begin{array}{l}32.5 \% \\
\{n=80\}\end{array}$ & $\begin{array}{l}56.3 \%^{*} \\
{[n=167\}}\end{array}$ & $\begin{array}{l}58.5 \% \\
\langle n=164)\end{array}$ \\
\hline Study? & $\begin{array}{l}42.4 \% \\
(n=98)\end{array}$ & - & $\begin{array}{l}56.5 \% \\
(n=184)\end{array}$ \\
\hline Study 3 & $\begin{array}{c}33.9 \% \\
(n=176)\end{array}$ & $\begin{array}{l}57.3 \% \\
(n=360)\end{array}$ & $\begin{array}{l}64.6 \% \\
(\mathrm{n}=373\end{array}$ \\
\hline
\end{tabular}

\section{$p$ value 0.002 in comparison to placebo}

to value 0.008 in comparison to placebo

These results cannot be validly compared with results of anti-migraine treatments amples of patients, by different investigators emploving different criteria and samples of patents, by different investigators, employing different criteria and/or egimen, etc.), quantitative estimates of treatment responses and
eesponses may be expected to vary considerably from study to study

For patients with migraine-associated photophobia, phonophobia, nausea, and vom:ting at baseline, there was a decreased incidence of these symptoms following it compared with placeb

wo to 24 hours following the initial dose of study medication, patients were allowed to take an escape medication or a second dose of study medication for pain
resoonse. Escape medication was taken more frecuently by patients in the placeto response. Escape medication was taken more frequently by patiensis in than those in the active almotriptan treatment groups.

The efficacy of AXERT was unaffected by the presence of aura; by gender, weigh or age of the patent; or by concomitant use of common migraine prophylactic dfugs (e.g. beta-blockers, calcium channel blockers, tricyclic antidepressants), or ora
contraceptives. There were insufficient data to assess the effect of race on efficacy.

\section{INDICATIONS AND CLINICAL USE}

AXERT is not intended for the prophylactic therapy of migraine or for use in the management of hemiplegic, ophthalmoplegic or basilar migraine (se establshed for cluster headache, which presents in an older, predominantly male population.

CONTRAINDICATIONS

AXERT (almotriptan malate) is contraindicated in patients with histor symptoms, or signs of ischemic cardiac, cerebrovascular or peripher vascular syndromes, valvular heart disease or cardiac arrhythmias (especially tachycardias). In addition, patients with other significan underlying cardiovascular diseases (e.g., atherosclerotic disease, congenital heart disease) should not receive AXERT. Ischemic cardiac syndromes include, but are not restricted to, angina pectoris of any type (e.g., stable angina of effort and vasospastic forms of angina such as the Prinzmetal's variant), all forms of myocardial infarction, and silent myocardial ischemia. Cerebrovascular syndromes include, attacks (TIAs). Peripheral vascular disease includes, but is not limited attacks (TIAs). Peripheral vascular disease includes, but is not limited
to, ischemic bowel disease, or Raynaud's syndrome (see WARNINGS) Because AXERT may increase blood pressure, it should not be given to patients with uncontrolled hypertension (see WARNINGS)

AXERT should not be administered within 24 hours of treatment with another 5-HT $\mathrm{T}_{1}$ agonist, or an ergotamine-containing or ergot-type medication, such as dihydroergotamine or methylsergide.

AXERT should not be given to patients with hemiplegic, ophthalmoplegic or basilar migraine.

AXERT is contraindicated in patients who are hypersensitive to AXERT is contraindicated in patients who a
almotriptan or any other ingredients in AXERT.

\section{WARNINGS}

AXERT (almotriptan malate) tablets should only be used where a clee diagnosis of migraine has been established.

Risk of Myocardial Ischemia and/or Infarction and Other Adverse Cardiac Events

Because of the potential of this class of compounds (5-HT $\mathrm{TH}_{1 \mathrm{~B} / \mathrm{p}}$ agonists) to cause coronary vasospasm, AXERT should not be glven to patients with documented ischemic or vasospastic coronary artery disease (se CONTRAINDICATIONS), It is strongly recommended that 5-HT, agonist (including AXERT) not be given to patients in whom unrecognized coronary artery disease (CAD) is predicted by the presence of risl factors such as: hypertension, hypercholesterolemia, smoker, obesity diabetes, strong family history of CAD, female with surgical or physiological menopause, or male over 40 years of age, unless the patient is reasonably free of coronary artery and ischemic myocardia disease or other significant underlying cardiovascular disease. The sensitivity of cardiac diagnostic procedures to detect cardiovascular diseases or predisposition to coronary artery vasospasm is modest a best. If, during the cardiovascular evaluation, the patient's medica history, electrocardiogram (ECG) or other evaluations reveal finding indicative of, or consistent with, coronary artery vasospasm, or myocardial ischemia,

These evaluations, however, may not identify every patient who has cardiac disease, and in very rare cases, serious cardiac events, such as myocardial infarction or coronary ischemia have occurred For patients with risk factors predictive of CAD, who are determined to have a satisfactory cardiovascular evaluation, it is strongly ecommended that administration of the first dose of AXERT tak place in a clical setting, such as the physician's office or a simelerly staffed medical facility, unless the patient has previously received administation (parisse comparison, $p=0.0485$ ). A hicher percentage of patien

AXERT (almotriptan malate) tablets are indicated for the acute treatment of migrain with or without aura in adults clinical symptoms, consideration should be given to obtaining an the interval immediately following the first use of AXER in a patient with risk factors. However, an absence of drug-induced cardiovascular effects on the occasion of the initial dose does not
preclude the possibility of such effects occurring with subsequent administrations.

If symptoms consistent with angina occur after the use of AXERT, ECG evaluation should be carried out to look for ischemic changes.

It is recommended that pationts who are intermittent long-term users of AXERT and who have or acquire risk factors predictive of CAD as described above undergo pe

The systematic approach described above is intended to reduce the likelihood that patients with unrecognized cardiovascular disease are inadvertently exposed to AXERT.

Cardiac Events and Fatalities Associated with $5-\mathrm{HT}_{1}$ Agonist

Serious adverse carcliac events, including acute myccardial infarction have been following the administration of other $5-\mathrm{HT}$, agonists Due to the common oharmacodynamic actions of $5-\mathrm{HT}_{1}$ agonists, the possibility of cardiovascular effects of the nature described below should be considered for all agents of this class. Considering
the extent of use of $5-\mathrm{HT}$, aconists in patients with migraine, the incidence of these the extent of use of 5 -

AXEFT can cause coronary vasospasm; at least one of these events occurred in patient with no cardiac history and with documented absence of coronery antery disease.

Patients with symptomatic Wolff-Parkinson-White syndrome or arrhylhmias associated with

\section{Premarketing experience with almotriptan}

Th in premarketing cinica rials, one patient was hospitalized for observation after a schediled ECG was fourid $6.25 \mathrm{mg}$ dose of AXERT. The patient, a 48 -year-old temale, had previously takeri ther doses for earlier migrane atachs. Mycadial enzynes al he time of the (a) An EOG performed? days later was normal, as was a tollow-up coronary anglography. The patient recovered without incident.

Postmarketing experience with almotriptan

Serious cardiovascular events have been reported in association with the use o AXERT. The uncontroled hature of post harketing survetlance, however, makes impossible to definitely determine the proportion of the reported cases that were

Cerebrovascular Events and Fatalities with 5-HI ${ }_{1}$ Agonists

Cerebral hemorhage, subarachnoid hemorrhage, stroke and other cerebrovascilla events have been reported in patients treated with other $5 . H T$; agonists, and some cerebrovascular events were primary, the agonist havirg been administered in the beliet that the symptons experienced were a consequence of migraine, when they were not. It should be noted, however, that patients who suffer from migraine make

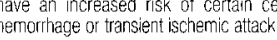

Other Vasospasm-Related Events 5-HT, agonists may cause vasospastic reactions other than coronary artery
yasospasm. Both perioheral wascular ischemia and colonic ischemia with abdornirial pain and bloody oiarrhea have been reported with 5 -HT, agonists.

Increases in Blood Pressure

Significant elevations in systemic blood pressure, including hypentensive crisis, have been reported on rare cccasions in patients with and without a history of thypertension ncontrolled hypertension (See CONTPAINDICATIONS). in volunteers, small iricreases n mean systolic and diastolic blood pressure relative to placebo were seen over the first 4 hours after administration of $12.5 \mathrm{mg}$ of almotiptan ( 0.21 and $1.35 \mathrm{~mm} \mathrm{Hg}$ with hypertension contralled by medication. In this population, mern increases systolic and diastolic blood pressure relative to placebo over the first 4 trours aft: administration of $12.5 \mathrm{mg}$ of almotiptan were 4.87 and $0.26 \mathrm{~mm} \mathrm{Hg}$, respectively,y
The slight increases in biood pressure in both volunteers and controled hyperensive patents were not considered clinicaly significant (see ADVERSE REACTIONS and

Special Cardiovascular Pharmacology Studles With Another 5-HT Agonist

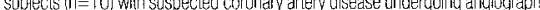
artic blood pressure, an $18 \%$ increase in pulmonary artery blood oressure, and an $8 \%$ increase in systemic vascular resistance, in addtion, mild chest pain or tightres was reported by tour subjects, Cinically significant increases in blood pressure were experienced by three of the subjects (two of whom also had chest pain/discomtorit)
Diagnostic angiogram results revealed that 9 subjects had normal corngary arteries and 1 had insigrificant coronary artery disease

In an additionat study with this same ofrug, migraine patients (n=35) Tree of cardiovascula disease were subjected to assessments of myocarcial perfusiors by posititon enissicn attack. Reduced coronary vasodilatory reserve $(\sim 10 \%$, increased coronary resistance $-20 \%$, and decreased hyperaemic myocarcial blood flow $(-10 \%)$ were riotery. The gonist is not known.

Similar studies have not been done with AXERT. However, owing to the common of the nature described above should be considered for any agent of this tharmacological class

Hypersensitivity

Rare hypersensitivity (anaphylaxis/anaphylactoid) reactions have occurred in patient eceiving other $5-\mathrm{HT}_{1}$ agonists. Such reactions can be lite threatening or fatal. In general, hypersensitivity reactions to drugs are more likely to occur in individuals with
a history of sensitivity to multiple allergens. Owing to the possibility of tross-reactive
hypersensitivity reactions, AXERT should not be used in patients hiving a history of hypersensitivity to chemicaly-related $5-\mathrm{HT}_{\text {, receptor agonists. See ADVERSE }}$
REACTIONS and PAECALTIONS).

\section{PRECAUTIONS}

General

ne administered with caution to patients with diseases that may atte the absorption, metabolisrry or excretion of drugs, such as those with impares hepatic or renal function (see ACTION AND CLINICAL
Populations and DOSAGE AND ADMINISTRATION).

Cardiovascular

As with other $5-\mathrm{HT}_{\text {. }}$ agonists, sensations of tightness, pain, pressire, and heavines the precordium, throat, neck and jaw hive been reponed anter trearnent with arrhythmias or ischemic ECG charges in clirical trials. Because drugs in this class 
inciucing AXERT, inay cause coronary artery vasospasm, patients who experience signs or symitoms suggestive of angina tollowing dosing should be evaluated tor receiving additional doses of the medication, and should be monitored electrocardiographically if desing is resumed and similar symptoms recur. Smilarly paterents who experience other symptoms or signs suggestive of cecreased artena flow Such as ischemic bowel syndrome or Raynaud's syndrome following the use of any 5 WARINUG

\section{Neurologic Conditions}

Care should be taken to exclude other potentially serious neurologic condition before treating headache in patients not previously diagnosed with migraine or wh patients received 5 . HT anorists for severe headache that ware reports wh

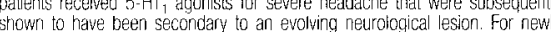
silumin to have been secondary to an evolving neurobgical esion. For new migraine should be reconsidered if no response is seen atter the first dose of

\section{Corneal Opacities}

Three male dogs (out of a total of 14 treated) in a 52-weck toxicity study of ora (a)

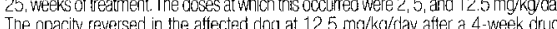
tree period. Systemic exposure (plasma AUC) to parent drug at $2 \mathrm{mo} / \mathrm{kg} / \mathrm{day}$ was apornkimately 2.5 times the exposure in humans receiving the maximum

\section{Binding to Melanin-Containing Tissues}

When pigrnented rats were gyven a single oral dose of $5 \mathrm{mg} / \mathrm{kg}$ of radiolabetted almotriptan, the ellmination halt-ife of radioactivity from the eye was 22 days, suggesting that almotriptan and/or its metabolites may bind to the melanin of the eye. Because almotriptan could accumblate in the melanin-rich tissues over time,
there is the possibility that it could cause toxicity in these tissues over extended use there is the possionity that it could cause toxicity in these tissues over extended use
However, no adverse ocular effects related to treatment with a motriptan were noted ir any of the toxicity studies. A Athough no systemic monitoring of ophthal mic function was undertaken in dinical trials and no snecitic recommendations for onthalmic monitoring are offered, prescitibers should be aware of the possibility of long-term Carcinogenesis

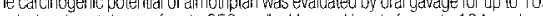
weeks in mice at coses of up to $25 \mathrm{umg} / \mathrm{kg} / \mathrm{day}$, and in rats for up to 104 weeks doses up to $75 \mathrm{mg} / \mathrm{kg} / \mathrm{day}$. These doses were associated with plasma exposures
(AvC) to parent drug that were aporoximately 40 and 78 times, in mice and rat respectively, the plasina AUC observed in humans receiving the MRDD of $25 \mathrm{mo}$. Because of high montality rates in both studies, which reached statistical significance in high-diose female mice, all fernale rats, al male mice and high-dose female mice
were terminated between weeks 96 and 98 . There was no increase in tumors

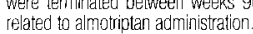

\section{Mutagenesis}

Aimotriptarl was not mutagenic, with or without metabolic activation, when tested in two gene mutation assays, the Ames test and the in vitro thymidine locus mouse

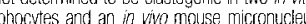
assay. Aimotriptan produced an equivocal weakly positive response in in vitho cytogenetics assays in human lymphocytes.

\section{Impairment of Fertility}

When female rats received amotriptan by oral gavage prior to and during mating the estrous cycle was observed at a dose of $100 \mathrm{mg} / \mathrm{kg} / \mathrm{day}$ (exposure, based on $\mathrm{mg} / \mathrm{m}$, was approximately 40 times exposure in humans receiving the maximum
recommended daily dose (MRDI) of $25 \mathrm{mc}$ ). No effects on fet litity were noted female rats at $25 \mathrm{mg} / \mathrm{kg} /$ day (exposure approximately 10 times human exposure
at MROD). No adverse effects were noted in male rats at $400 \mathrm{mg} / \mathrm{kg} / \mathrm{day}$ (160 times the humarl exposure based on $\mathrm{mg} / \mathrm{m}$

\section{Pregnancy}

When almotriptan was administered orally during organogenesis to pregnant rats dosen at the 1000 m $10 \mathrm{~kg} /$ day dose (maternal exposure [based on plasma AUC of parent drug] was approximately 958 times the humban exposure at MRDD of 25 $\mathrm{mg}$. ficreased incidencas of fetal skeletal variations idecreased ossification) were
rioted at doses greater than the no-observed-effect level in rats of $125 \mathrm{mg} / \mathrm{kg} / \mathrm{day}$ imaternal exposue 80 times human exposure at MRDO). Similar studies in rabbi concucted witt almotriptan at doses of 5,20 and $60 \mathrm{mg} / \mathrm{kg} /$ day demensitrated increases in embryolethality at $60 \mathrm{mg} / \mathrm{kg} /$ day \{maternal exposure, based on mg/m,
50 imes human exposure at MROOC. When a motiptan was administered to rat 50 irmes human exposure at MROO). When amotr ptan was acministered to rats
throughout the periods of gestation and lactation at doses of 25,100 and 400 mg/kg/day, gestation lenthth was increased and litter size and offspring body weight were decreased at the high dose (maternal exposure, based on mo/ $\mathrm{m}^{2}, 160$ times lactation. The ro-observed-effect level in this study was $100 \mathrm{mg} / \mathrm{kg} /$ day imaterna exposure 40 times humarn exposure at MRDD)

There have been no adequate and weth-controlled studies in pregnant women therefore AXERT should only be used during pregnancy if the potential benef Hepatic Impairment

AXERT shoulf be used with caution in patients with hepatic imparment. The maximum daly dose should not exceed $12.5 \mathrm{mg}$ over a 24 -hrur period, and a
starting dose of $6.25 \mathrm{mg}$ is recominended (see ACTION AND CLINICAL PHAFMACOLOGY, Special Fopulations and DOSAGE AND ADMINISTRATON).

\section{Renal Impairment}

AXERT should be used with caution in patients with severe renal impairment. The maximum daiy dose should not exceed $12.5 \mathrm{mg}$ over a 24 -hour period, and a
starting dose of $6.25 \mathrm{mg}$ should be used (see ACTION AND CLINICAL PHAFMACOLOGY, Specia Populations and DOSAGE AND ADMINISTRATION).

\section{Psychomotor Effect}

Patients should be advised to avoid driving a car or operating hazardous machiner Use in the Elderly

Clinical studies of AXERT did not include sufficient numbers of subjects over 65 years of age to deterririre whether they respond differenty from younger subjects
Renal and tutal clearance, and amount of drug excreted in the urine, were lower in Renal and tutal clearance, and amount of drug excreted in the urine were lower in
elderly non-migraineur yolunteers (ace 65 to 76 years) than in youncer nonelderly non-migraineur volunteers (age 65 to 76 years) than in younger non-
migraineur wolunteers (age 19 to 34 years), resulting in longer terminal haff-life and migraineur wolunteers (age 19 to 34 years), resulting in longer terminat hall-lie and
higher arga under the plasma concentration-time curve. Although clearance of almotriptan was iower in elderly volunteers, there were no differences in the safel PHARMACOLOGY, Special Populations). In general, dose selection for an elderly patient should be cautious, usually stating at the low end of the dosing range reflecting the greater frequency of decreased renal, cardiac, and hepatic function Use in Children

The safety and effectiveness of AXERT in pediatric patients has not been established; therefore, AXERT is not recommended tor use in patients under 18
years of age. Post-marketing experience with other tsptans include a limited number of reports age describe pediatric (under 12 years of agej and adolescent $\{12$ - 17 years of nature to those reported as rare occurences in adults.

Use during Lactation

$t$ is not known whether almotriptan is excreted in human milk. Since many drugs are excreted in hiuman milk, caution should be exercised when AXERT is

\section{Dependence Liability}

Athough the abuse potential of AXERT has not been specifically assessed, no abuse of, tolerance to, withdrawal from, or drug-seeking behaviour was observed in agonists, as a class, have not been associated with drug abuse.

\section{Drug Interactions}

All orug interaction studes were performed in healthy volunters using a single 12 $\mathrm{mig}$ dose of a motiptan and mutiple doses of the other drug.

Ergot-containing drugs

These drugs have been reported to cause prolonged vasospastic reactions. As there is a theoretical basis that these effects may be additive, use of ergotamine containing or ergot -lype medications (dihydroergotamine or methylsergide) and AXERT Within 24 hOH

\section{Monoamine oxidase inhibitors}

Caadministration of almotriptan and moclobemide (150 mg bi.d, for 8 days) resulted in a $27 \%$ decrease in almotriptan clearance

Propranolol

Coadritisistration of almotsiptan and propranolol (80 $\mathrm{mg}$ bi.d. for 7 days) resulted in no sigrificant changes in the pharmacrkinetics

Coadministration of almotiptan and fuoxetine (60 mig dalisy for 8 days), a potent inhibitor of CYP206, had no effect on almotriptan clearance, but maxima concentrations of almotriptan were increased by $18 \%$. This difference is not clinically significant. SSFls (e. g, fluoxetine, fluvoxamine, paroxetine, sertraline) have been rafely reported to cause weakness, hyperreflexia and incoord natlon when
coadministered with 5 -HT. aggrists. It concomitant treatment with AXERT and an SSRI is clinicaly warranted, appropriate observation of the patient, for both acute and long term adverse events, is advised.

Verapamil

Coadministration of almotiptan and verapamil $120 \mathrm{mg}$ sustained-release tablets bid, for 7 days), an inhibitor of CYP4503A4, resulted in a $20 \%$ increase in the area
under the plasma concentration-time curve, and in a $24 \%$ increase in maxima plasma concentrations of almotiptan. Neither of these changes is clinically significant. Other 5-hT 1 B/10 agonists

Concomitant uSe of other $5-\mathrm{HT}_{\text {1R/10 }}$ agonists within 24 hours of treatment with
AXERT is contraindicated (see CONTRANIDICATIONS). Ketoconazole and other potent CYP3A4 inthibitors

Cradministration of almotriptan and the potent CYP3A4 inhibitor ketoconazole 4400 mg q.d. for 3 days) resulted in an approximately 60\% increase in the area under the plasma concentration-time curve and maximal plasma concentrations of amotriptan. Although the interaction between almotriptan and other potent CYP $3 A 4$ inhibitors (e.g. itraconazole, ritonavir, and erythromycin) has not been studied increased exposures to almotriptan man
concomitantly with these medications.

\section{Laboratory Tests}

Almotriptan is not known to interfere with any commonly employed clinica laboratory

\section{ADVERSE REACTIONS}

Serious cardiac events, including some that have been fatal, have occurred following use of other $5-\mathrm{HT}_{1}$ agonists. These events are extremely rare and most have been reported in patients with risk factors predictive of CAD. Events reported have included coronary artery vasospasms, transient myocardial ischemia, myocardial infarction, ventricular tachycardia, and
ventricular fibrillation (see CONTRAINDICATIONS, WARNINES and CAUTIONS).

Serious cardiac events, including myocardial infarction, coranary artery vasospasm and intermediate coronary syndrome, have occurred following the use of AXERT tablets. These events are extremely rare and have been reported mostly in patients with cardiovascular risk
factors (see WARNINGS and POST-MARKETING ADVERSE REACTIONS). Experience in Controlled Clinical Trials with AXERT (almotriptan) Typical 5-HT ${ }_{1}$ Agonist Adverse Reactions

As with other 5-HT, agonists, AXERT has been associated with sensations of heaviness, pressure, tightness or pain which may be intense. These may occur
any part of the body inclucing the chest, throat, nedk, jaw and upper limbs.

\section{Increases in Blood Pressure}

Significant elevations in systemic blood pressure, including hypertensive crisis, have beer reported on rare occasions in patients with and without a history of hypertension treated with other 5 -HT 1 agonists. AXERT is contraindicated in patients
with uncontrolled hypertension (see CONVAINDICAIONS). In volunteers, small increases in mean systolic and diastolic blood pressure relative to placebo were
seen over the first 4 hours after administration of $12.5 \mathrm{mg}$ of almotriptan $(0.21$ and seen over the first 4 hour's after administration of $12.5 \mathrm{mg}$ of almotriptan $(0.21$ and
$1.35 \mathrm{~mm} \mathrm{Hg}$, respectively). The effect of AXERT on blood pressure was also $1.35 \mathrm{~mm} \mathrm{Hg}$, respectivelyy. The effect of AxER on blood pressure was also assessen in patents in wysth hysers in systolic and diastolic blood pressure relative to placebo over the first 4 hours after administration of $12.5 \mathrm{mg}$ of aimotriptari were 4.87 and $0.26 \mathrm{~mm}$ $\mathrm{Ha}$, resoectvely. The slight increases in blood pressure in both volunteers and controled hypertensive patients were not considered dinically significant (see also CONTRANOICATIONS and WARNNNGSI.

\section{Acute Safety}

Adyerse events were assessed in controlled clinical trials that included 1840 386 patents who received placebo

The most common adverse events during treatment with AXERT were nausea. somnolence, headache, paresthesia, and dry mouth. In long. erm, open-label $5 \% 163$ out of 1347 patents) withdrew due to adverse experiences.

Table 2 lists the adverse events that occurred in at least $1 \%$ of the patients treated with AXERT, and at an incicence greater than in patients treated with placebo, regardess of drug relationship. These events retlect experience gained under in actual clinical practice or in other clinical trials, these frequency estimates may not apply, as the conditions of use, reporting behaviour, and the kinds of patients treated may differ.
2. Incidence of Adverse Events in Controlled Clinical Trials incidence Greater than Placebo)

Adverse Event Percentage of Pationts Figponting the Event

\section{Digestive}

Nausea

Nervous

\section{Paresthesia}

AXERT is generally well tolerated. Most adverse exents were mild in intensity and were transient, and did not lead to long-lasting effects The inciderice of advers

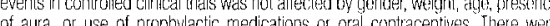
insuticient data to assess the eftect of race on the incidence of adverse everills.

Other Events

The frequencies of less commonly reported adverse cyents are presented betow However, the role of AXERT in their callsation cannot he reliably determined used to

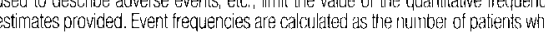
used AXERT in controled clinical trials and reported an event, divided by the tot number of patients exposed to AXERT in these sildies. All reported events aro included, except the ones already listed in the previous table, and those uniksty be drug related, Events are further classitied within body system categories ant enumerated in order of decreasing trequency using the following detinitions: trequent adverse events are those occurfing in at least $1 / 100$ paticents; ifferequent adverse events are those occuring in $1 / 100$ to $1 / 1000$ pa:
events are those occurning in fewer than $1 / 1000$ patients.

Total Body System: Frequent was headache, Inffequent? were abdomin ial clamp or pain, asthenia, chills, back pain, chest pain,
Rare were fever and photosensitivity reaction.

Cardiovascular: Infrequent were vasodiation, palutitetions and tachycurdia, fiat were intermediate coronary syndrome, abnomal cardiac mythm, hyvertension, and Digestive

Digestive infequen were diarhea, vomiting, and dyspepsict. Rare were decreased appetite, increased appetite, colitis, gastrils, gastroenter tilis, escophlige

Metabolic. Infequent were hyperglycemia and increased serum creatint hypercholesteremia

Musculoskeletal: infrequent were myalaia and nilusculdar weakness. Rire when atthralia, arthrits, and myopathy.

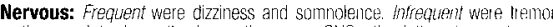
vertigo, anxiety, hypesthesia, restlessness, CNS stimulation. insermulia, int coordingtion, Rare were change in creams, impailed concentration, almom coordination, depressive symptoms, euphorlat,
nervousness, neurocathy nilohtmares, and mustagmus.

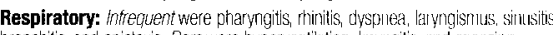
bronchitis, and epistaxis. Rere were hyperventiliation, lankingitis, and sicezili

Skin: intequent were diaphoresis, derrnatitis, enythema, pruritus. and rasil.

Special Senses: Infrequent were car pain, conjunctivivitis, eve in ritation, hyperacusis, and taste alteration. Rare were diplopia, dry eyes, eye pairl, otitis meedilit
parosnia, scotoma, and tinnitus.

Urogenital: Dysmenormea was infequent

\section{Long-Term Safety}

In a long term open label study, 762 patients treated 13,751 migraine attacks with

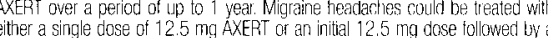
second 12.5 mg dose if needed in this study, $3 \%$ (24 of 762 ) of palients wittidsew due to an adverse experience. The most cormmon adverse events (defined a occurring in more than $3 \%$ of patents) in descending order frequency were as
follows: back pain $(8 \%)$, bronchitis $(6.4 \%)$, intluenza like symptoms $(5.8 \%)$,

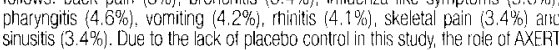
sinusitis (3.4\%). Due to the lack of placebo

\section{POST-MARKETING ADVERSE REACTIONS} In addition to the adverse experiences reported during clinical trials uf AXERT, the from worldwide use since approval. Due to the uncontrolled nature of postmarketing surveillance, it is not possible to definiteiby determine the pruportion of the
reported cases that were actually caused by AXEPT or to reliably assess causation. Serious cardiovascular adverse events, including acite myocardial intarction, coronary vasospasm and angina pectoris have been reported wittin a few houl following administration of $A X E R T$.

Athough very rare, AXERT can cause coronary vasospasm; at least one of these events occurred in a patient with no cardiac history and with doculmented absence REACTIONS and PRECALTIONS).

\section{SYMPTOMS AND TREATMENT OF OVERDOSAG}

作 not experience significant adverse events. During the illinical trials, one patier 38-hour period. Neither patient experienced adverse reactions.

Based on the pharmacology of 5 . HT, agonists, hypertension or other more selious cardiovascular symptoms could occur alter uverdosage. Gastrointestiri decontamination (i.e. gastric lavage tollowed by actlvated charcoal) should be electrocardiograaphic monitoring should be continued tor at least 20 hours, eventl it elirical symptoms are not observed.

The effects of hemodialysis or peritoneal dialysis on plasma concentrations of almotriptan are unknown

\section{DOSAGE AND ADMINISTRATION}

In controlled cinical trials, single doses of $6.25 \mathrm{mg}$ anid $12.5 \mathrm{mg}$ of $A X E R T$ (almotriptan malate) were effective for the acule treatment of migraine iri adulths with the $12.5 \mathrm{mg}$ dose tending to be a more effective dose (see CLINICAL STLDIES) therefore be made on an individual basis

If the headache returns, the dose may be repeated after 2 hours, but no more than two doses should be given within a 24 -hour period. Controled trials have not adequately estabilished the effectiveness of a seconid dose it the initial dose day period has not been established 
PRESCRIBING INFORMATION

QReminyl

PrREMINYL*

galantamine hydrobromide tablets

$4 \mathrm{mg}, 8 \mathrm{mg}, 12 \mathrm{mg}$ galantamine base

Cholinesterase Inhibitor

CLINICAL PHARMACOLOGY

Although the etiology of cognitive impairment in Alzheimer's Disease (AD) is not fully understood, it has been reported that acetylcholine-producing neuron degenerate in the brains of patients with Alzheimer's Disease. The degree of this degenerate in the brains of patients with Alzheimer's Disease. The degree of this
cholinergic loss has been correlated with degree of cognitive impairment and density of amyloid plaques (a neuropathological hallmark of Alzheimer's Disease).

REMINYL (galantamine hydrobromide), a tertiary alkaloid, is a competitive and reversible cholinesterase inhibitor. While the precise mechanism of galantamine's action is unknown, it is postulated to exert its therapeutic effect by enhancing cholinergic function. This is accomplished by increasing the concentration of acetylcholine through reversible cholinesterase inhibition. It has also been postulated, based on in vitro data, that galantamine enhances the action of acetylcholine through binding to an allosteric site on the nicotinic receptors (see PRECAUTIONS). The clinical relevance to humans of these in vitro findings is unknown.

If these mechanisms are correct, galantamine's effect may lessen as the diseas process advances and fewer cholinergic neurons remain functionally intact. There is no evidence that galantamine alters the course of the underlying dementing process

\section{Pharmacokinetics}

Absorption

The summary of related pharmacokinetic parameters in healthy subjects is presented in Table 1. After oral intake of a single $8 \mathrm{mg}$ galantamine solution in 12 healthy males, absorption is rapid, with a peak plasma concentration $\left(\mathrm{C}_{\mathrm{m}}\right.$ of $43 \pm 13 \mathrm{ng} / \mathrm{mL}$, which is reached atter 1.2 hours (T $\left.T_{\max }\right)$ and a mean AUC. of $427 \pm 102 \mathrm{ng} . \mathrm{h} / \mathrm{mL}$.

The absolute oral bioavailability of galantamine is $88.5 \%$. Bioavailability of the tablet was the same as the bioavailability of an oral solution in 27 healthy males. Food did not affect the AUC of galantamine but $\mathrm{C}_{\text {max }}$ decreased by $25 \%$ and $\mathrm{T}_{\text {. }}$ was delayed by 1.5 hours after repeated oral dosing of $12 \mathrm{mg}$ galantamine b.i. $\mathrm{d}$. in 24 healthy elderly subjects.

The maximum inhibition of anticholinesterase activity of about $40 \%$ was achieved about one hour after a single oral dose of $8 \mathrm{mg}$ galantamine in healthy male subjects.

Table 1. Pharmacokinetic parameters of galantamine after single or multiple dos

Elimination

The elimination of galantamine is bi-phasic, with a terminal half-life in the order of 7-8 hours in young healthy subjects ( $n=4$ males). Two studies in healthy elderly subjects indicated that the terminal half-life of galantamine is 8.5 hours ( $n=13$ males and 16 females) and 9.7 hours ( $n=10$ males and 14 females) after administering a single oral dose of $10 \mathrm{mg}$ galantamine. Up to 8 hours post-dose, unchanged galantamine accounted for $39-77 \%$ of the total radioactivity in the plasma, and galantamine glucuronide accounted for $14-24 \%$. Seven days after a single oral dose of $4 \mathrm{mg}{ }^{3} \mathrm{H}$-galantamine, $93-99 \%$ of the radioactivity had been recovered, with about $95 \%$ in urine and about $5 \%$ in feces. Total urinary recovery of unchanged galantamine accounted for, on average, $32 \%$ of the dose, and that of galantamine glucuronide for another $12 \%$ on average.

After i.v. and oral administration, about $20 \%$ of the dose was excreted as unchanged galantamine in the urine in 24 hours, with a renal clearance of about $65 \mathrm{~mL} / \mathrm{min}$, which represents $20-25 \%$ of the total plasma clearance of about $300 \mathrm{~mL} / \mathrm{min}$

\section{CYP2D6 Poor Metabolizers}

Approximately $7 \%$ of the normal population has a genetic variation that leads to reduced levels of activity of the CYP2D6 isozyme. Such individuals have been referred to as poor metabolizers. After a single oral dose of $4 \mathrm{mg}$ or $8 \mathrm{mg}$ galantamine, CYP2D6 poor metabolizers demonstrated a similar $\mathrm{C}_{\max }$ and about $35 \%$ AUC. increase of unchanged galantamine compared to extensive metabolizers.

A total of 356 patients with Alzheimer's disease enrolled in two Phase III studies were genotyped with respect to CYP2D6 ( $\mathrm{n}=210$ hetero-extensive metabolizers, 126 homo-extensive metabolizers, and 20 poor metabolizers). Population pharmacokinetic analysis indicated that there was a $25 \%$ decrease in median clearance in poor metabolizers compared to extensive metabolizers. Dosage adjustment is not necessary in patients identified as poor metabolizers as the dos of drug is individually titrated to tolerability due to observed inter-patient variability. Hepatic Impairment

Following a single $4 \mathrm{mg}$ dose of galantamine, the pharmacokinetics of galantamine in subjects with mild hepatic impairment $(n=8$; Child-Pugh score of 5-6) were similar to those in healthy subjects. In patients with moderate hepatic impairment ( $n=8$; Child-Pugh score of 7-9), AUC and half-life of galantamine were increased by about 30\% compared to normal subjects (see PRECAUTIONS and DOSAGE AND ADMINISTRATION

Renal Impairment

In patients with renal insufficiency, elimination of galantamine decreases with decreasing creatinine clearance. Following a single $8 \mathrm{mg}$ dose of galantamine AUC increased by $37 \%$ and $67 \%$ in moderately ( $n=8 ;$ creatinine clearance of 30 to $\left.60 \mathrm{~mL} / \mathrm{min} / 1.73 \mathrm{~m}^{2}\right)$ and severely $(n=9$; creatinine clearance of 5 to $29 \mathrm{~mL} / \mathrm{min} / 1.73 \mathrm{~m}^{2}$ ) renal-impaired patients compared to normal volunteers $(n=8)$ (see PRECAUTIONS and DOSAGE AND ADMINISTRATION).

Patients with Alzheimer's Disease

Data from clinical trials in patients indicate that there is a difference in tota clearance after oral administration between patients with Alzheimer's Diseas and healthy subjects (13.2 L/h versus $19.4 \mathrm{~L} / \mathrm{h})$ based on pooled population analysis. Therefore, the plasma concentrations of galantamine in elderly patients

\begin{tabular}{|c|c|c|c|c|c|c|}
\hline & $\begin{array}{c}\mathrm{C}_{\max } \\
(\mathrm{ng} / \mathrm{mL})\end{array}$ & $\begin{array}{l}t_{\max } \\
\text { (h) }\end{array}$ & $\begin{array}{c}C_{\text {ssav }} \\
(\mathrm{ng} / \mathrm{mL})\end{array}$ & $\begin{array}{c}\mathrm{C}_{\min } \\
(\mathrm{ng} / \mathrm{mL})\end{array}$ & $\begin{array}{c}\mathrm{AUC}^{\dagger} \\
(\mathrm{ng} . \mathrm{h} / \mathrm{mL})\end{array}$ & $\begin{array}{l}T_{1 / 2} \\
\text { (h) }\end{array}$ \\
\hline \multicolumn{7}{|c|}{ Single dose, 12 healthy males } \\
\hline $8 \mathrm{mg}$, solution p.o. & $42.6 \pm 13.1$ & $1.2 \pm 0.6$ & - & - & $427 \pm 102$ & $7.3 \pm 1.7$ \\
\hline $8 \mathrm{mg}, 1 \mathrm{hr} \mathrm{i.v.} \mathrm{infusion}$ & - & - & - & - & $482 \pm 112$ & $7.4 \pm 1.7$ \\
\hline \multicolumn{7}{|c|}{ Food effect, single dose, 24 healthy elderly } \\
\hline Fasted, $8 \mathrm{mg} \mathrm{p.0.}$ & $57.5 \pm 15.8$ & $1.1 \pm 0.5$ & - & - & $562 \pm 180$ & $9.7 \pm 3.1$ \\
\hline Non-fasted, $8 \mathrm{mg} \mathrm{p.o.}$ & $42.5 \pm 7.5$ & $2.6 \pm 1.4$ & - & - & $543 \pm 176$ & $9.7 \pm 3.3$ \\
\hline \multicolumn{7}{|c|}{ Multiple oral dose, 27 healthy males } \\
\hline $12 \mathrm{mg}$ b.i.d. tablet & $89.4 \pm 18.3$ & $1.0 \pm 0.6$ & $51.9 \pm 12.2$ & $30.7 \pm 10.3$ & $623 \pm 147$ & - \\
\hline $12 \mathrm{mg}$ b.i.d. solution & $87.6 \pm 20.5$ & $1.1 \pm 0.5$ & $50.5 \pm 13.0$ & $29.8 \pm 10.2$ & $606 \pm 156$ & - \\
\hline \multicolumn{7}{|c|}{ Dose-proportionality, multiple oral dose, 18 healthy subjects } \\
\hline $4 \mathrm{mg}$ b.i.d. tablet & $30.7 \pm 6.2$ & $1.9 \pm 0.8$ & $17.7 \pm 4.6$ & $10.6 \pm 4.0$ & $212 \pm 56$ & - \\
\hline $8 \mathrm{mg}$ b.i.d. tablet & $63.8 \pm 14.2$ & $1.7 \pm 0.8$ & $36.6 \pm 9.8$ & $20.6 \pm 6.8$ & $439 \pm 117$ & - \\
\hline $12 \mathrm{mg} \mathrm{b.i.d.} \mathrm{tablet}$ & $97.4 \pm 31.4$ & $1.9 \pm 1.1$ & $53.1 \pm 12.7$ & $29.1 \pm 9.3$ & $637 \pm 152$ & - \\
\hline $16 \mathrm{mg}$ b.i.d. tablet & $137 \pm 36$ & $1.7 \pm 0.9$ & $76.5 \pm 20.3$ & $41.5 \pm 14.2$ & $918 \pm 244$ & $7.9 \pm 0.8$ \\
\hline
\end{tabular}
median age 75 with Alzheimer's Disease are $30-40 \%$ higher than in health young subjects (median age 28). Gender and Race No specific pharmacokinetic study was performed to investigate the $g$ e $n$ d e population pharmacokinetic $\mathrm{n}$ a I y s i s $(n=539$ males and 550 females suggests that galantamin

t $A U C=$ AUC , after single dose and AUC $=$ AUC after multiple dose Distribution

Galantamine is a low-clearance drug (plasma clearance of approximately $300 \mathrm{~mL} / \mathrm{min}$ ) with a moderate volume of distribution (average $\mathrm{Vd}_{\mathrm{ss}}$ of $175 \mathrm{~L}$ ) after a one-hour i.v. infusion of $8 \mathrm{mg}$ galantamine in 12 healthy males.

The plasma protein binding of galantamine is $18 \%$ at therapeutically relevan concentrations. In whole blood, galantamine is mainly distributed to blood cells $(52.7 \%)$ and plasma water $(39.0 \%)$, whereas the fraction of galantamine boun to plasma proteins is only $8.4 \%$. The blood-to-plasma concentration ratio of galantamine is 1.2

Metabolism

Galantamine is metabolized by hepatic cytochrome P450 enzymes glucuronidated and excreted unchanged in the urine. In vitro studies indicate th cytochrome CYP2D6 and CYP3A4 are the major cytochrome P450 isoenzymes involved in the metabolism of galantamine, and inhibitors of both pathways increase oral bioavailability of galantamine modestly (see PRECAUTIONS, Drug Drug Interactions). 0-demethylation, mediated by CYP2D 6 is greater in extensive Drug Interactions). 0-demethylation, mediated by CYP2D6 is greater in extensive
metabolizers of CYP2D6 than in poor metabolizers. In plasma from both poor and metabolizers of CYP2D6 than in poor metabolizers. In plasma from both poor and accounted for most of the sample radioactivity. clearance is about $20 \%$ lower in females than in males, which is explained by lower body weight in females.

Pharmacokinetic differences due to race have not been identified in a population pharmacokinetic analysis ( $n=1029$ White, 24 Black, 13 Asian and 23 other).

\section{Clinical Trials}

Efficacy data for REMINYL (galantamine hydrobromide) in the symptomatic treatment of patients with Alzheimer's Disease were derived from 4 randomized double-blind, placebo-controlled clinical trials in patients with probable Alzheimer's Disease [diagnosed by NINCDS-ADRDA criteria, with Mini-Menta State Examination Scores that were $\geq 10$ and $\leq 24]$. Doses studied were started on a low dose of $8 \mathrm{mg}$, then titrated weekly by $8 \mathrm{mg} /$ day to 24 or $32 \mathrm{mg}$ as assigned (GAL-USA-1, GAL-INT-1, GAL-INT-2). In the fourth study (U.S. 4-week Dose-Escalation Fixed-Dose Study, GAL-USA-10) dose escalation of $8 \mathrm{mg} /$ day occurred over 4 week intervals. The mean age of patients participating in the 4 REMINYL trials was 75 years with a range of 41 to 100 . Approximately $62 \%$ of patients were women and $38 \%$ were men. The racial distribution was White $94 \%$, Black $3 \%$ and other races $3 \%$. Two other studies examined a three times daily dosing regimen; these also showed or suggested benefit but did not suggest an advantage over twice daily dosing. 8-32 mg/day given as twice daily doses. In 3 of the 4 studies, patients were
Results for 2 of these studies are presented in this section. The data shown below were obtained from the Intent-To-Treat population (ITT analysis, i.e. all patients who were randomized to treatment, regardless of whether or not they were able to complete the study. For patients unable to complete the study, their last observation while on treatment was carried forward and used at endpoint). Study Outcome Measures: In each study, the primary efficacy of REMINYL was evaluated using a dual outcome assessment strategy as measured by the Alzheimer's Disease Assessment Scale (ADAS-cog) and the Clinician's Interview Based Impression of Change (CIBIC-plus).

The ability of REMINYL to improve cognitive performance was assessed with the cognitive subscale of the Alzheimer's Disease Assessment Scale (ADAS-cog), a multi-item instrument that has been extensively validated in longitudinal cohorts of Alzheimer's Disease patients. The ADAS-cog examines selected aspects of cognitive performance, including elements of memory, orientation, attention, reasoning, language and praxis.

The patients recruited as participants in each study had mean scores on the ADAS-cog of approximately 27 units, with a range from 5 to 69 . Experience gained in longitudinal studies of ambulatory patients with mild to moderate Alzheimer's Disease suggests that they gain 6 to 12 units a year on the ADAS-cog. Lesser degrees of change, however, are seen in patients with very mild or very advanced disease because the ADAS-cog is not uniformly sensitive to change over the course of the disease. The annualized rate of decline in the placebo patients participating in REMINYL trials was approximately 4.5 units per year.

The ability of REMINYL to produce an overall clinical effect was assessed using a Clinician's Interview Based Impression of Change that required the use of caregiver information, the CIBIC-plus. The CIBIC-plus used in the trials was a semi-structured instrument based on a comprehensive evaluation at baseline and subsequent time-points of 4 major areas of patient function: general, cognitive, behavioural and activities of daily living. Clinical trials for investigational drugs have used a variety of CIBIC formats, each different in terms of depth and structure. As such, results from a CIBIC-plus reflect clinical experience from the trial or trials in which it was used and cannot be compared directly with the results of CIBIC-plus evaluations from other clinical trials.

Among the secondary measures of efficacy, the Alzheimer's Disease Cooperative Study. Activities of Daily Living Inventory (ADCS/ADL) was used. The ADCS/ADL is a caregiver-rated evaluation which yields a compound score derived from a categorical scale of 23 items concerning participation in activities of daily living. U.S. Twenty-One-Week Fixed-Dose Study (GAL-USA-10)

In a study of twenty-ane weeks' duration, 978 patients were randomized to doses of 8,16 , or $24 \mathrm{mg}$ of REMINYL per day, or to placebo, each given in 2 divided doses. Treatment was initiated at $8 \mathrm{mg} /$ day for all patients randomized to REMINYL, and increased by $8 \mathrm{mg} /$ day every 4 weeks. Therefore, the maximum dose-escalation phase was 8 weeks and the minimum maintenance phase was 13 weeks (in patients randomized to $24 \mathrm{mg} /$ day of REMINYL)

Effects on the ADAS-cog: Figure 1 illustrates the time course for the change from baseline in ADAS-cog scores for all four dose groups over the 21 weeks of the study. At 21 weeks of treatment, the mean differences in the ADAS-cog change scores for the REMINYL-treated patients compared to the patients on placebo were $0.8,2.9$ and 2.9 units for the 8,16 and $24 \mathrm{mg} /$ day treatments, respectively. The $16 \mathrm{mg} / \mathrm{day}$ and $24 \mathrm{mg} / \mathrm{day}$ treatments were statistically significantly superior to placebo and to the $8 \mathrm{mg} /$ day treatment. There was no statistically significant difference between the $16 \mathrm{mg} /$ day and $24 \mathrm{mg} /$ day dose groups.

Figure 1: Time-course of the Changes from Baseline in ADAS-cog Score (ITT Population)

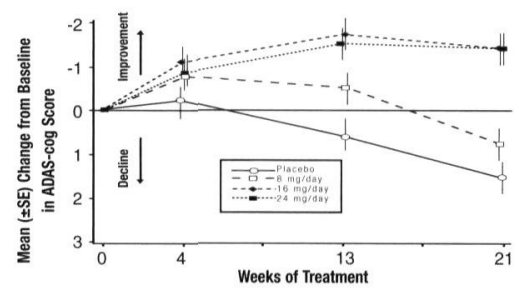

Figure 2 illustrates the cumulative percentages of patients from each of the four treatment groups who had attained at least the measure of improvement in ADAS-cog score shown on the $X$-axis. Three change scores (10-point, 7-point and 4-point reductions) and no change in score from baseline have been identified for illustrative purposes, and the percentage of patients in each group achieving that result is shown in the inset table

The curves demonstrate that both patients assigned to galantamine and placebo have a wide range of responses, but that the REMINYL groups are more likely to show the greater improvements.

Figure 2: Cumulative Percentage of Patients with Specified Changes from Baseline in ADAS-cog Scores (ITT Population)

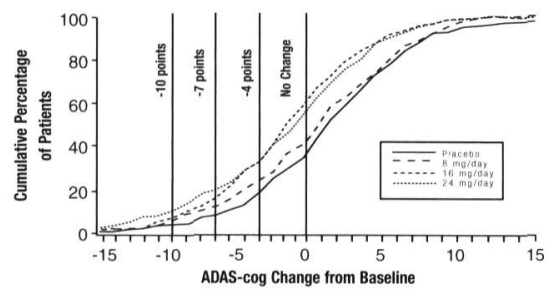




\begin{tabular}{lcccc}
\hline Treatment & -10 & \multicolumn{4}{c}{ Change in ADAS-cog } \\
\hline Placebo & $3.7 \%$ & $7.8 \%$ & -4 & 0 \\
$8 \mathrm{mg} /$ day & $4.5 \%$ & $11.4 \%$ & $22.7 \%$ & $43.9 \%$ \\
$16 \mathrm{mg} /$ day & $6.4 \%$ & $15.0 \%$ & $33.1 \%$ & $67.7 \%$ \\
$24 \mathrm{mg} /$ day & $8.8 \%$ & $19.8 \%$ & $32.4 \%$ & $62.6 \%$ \\
\hline
\end{tabular}

Effects on the CIBIC-plus: Figure 3 is a histogram of the percentage distribution of CIBIC-plus scores attained by patients assigned to each of the four treatment groups. The REMINYL-placebo differences for these groups of patients in the mean rating were $0.10,0.32$ and 0.38 units for the 8,16 and $24 \mathrm{mg} / \mathrm{day}$ treatments, respectively. The $16 \mathrm{mg} /$ day and $24 \mathrm{mg} /$ day treatments were statistically significantly superior to placebo. The differences vs. the $8 \mathrm{mg} / \mathrm{da}$ treatment for the 16 and $24 \mathrm{mg} /$ day treatments were 0.22 and 0.28 respectively. There were no statistically significant differences between the $16 \mathrm{mg} /$ day and $24 \mathrm{mg} /$ day dose groups.

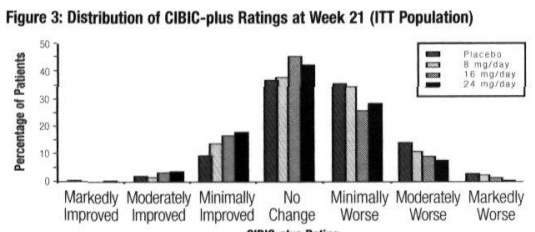

Markedly Moderately Minimally No Mi Moved
Improved Improved Improved Change Worse

cliBI-plus Rating

Effects on ADCS/ADL Inventory: The Alzheimer's Disease Cooperative Study, Activities of Daily Living Inventory was used as a secondary efficacy measure. A baseline, mean ADCS/ADL scores (mean \pm SE) were for the placebo group: 52.3 \pm 0.89 units; for the $16 \mathrm{mg} /$ day group: $51.6 \pm 0.93$ units; for the $24 \mathrm{mg} / \mathrm{day}$ group: $51.9 \pm 0.98$ units. At Week 21, the placebo group declined an average of $3.9 \pm 0.55$ units, and the $16 \mathrm{mg} /$ day and $24 \mathrm{mg} /$ day groups deteriorate minimally at $1.0 \pm 0.51$ units and $1.6 \pm 0.56$ units, respectively. The difference between the placebo group and the galantamine treatment groups (16 mg/day or $24 \mathrm{mg} /$ day) was statistically significant.

U.S. Twenty-Six-Week Fixed-Dose Study (GAL-USA-1)

In a study of 26 weeks' duration, 636 patients were randomized to either a dose of $24 \mathrm{mg}$ or $32 \mathrm{mg}$ of REMINYL per day, or to placebo, each given in two divide doses. The 26-week study was divided into a 3-week dose-escalation phase an a 23-week maintenance phase.

Effects on the ADAS-cog: Figure 4 illustrates the time course for the change from baseline in ADAS-cog score for all three dose groups over the 26 weeks of the study. At 26 weeks of treatment, the mean difference in the ADAS-cog chang scores for the REMINYL-treated patients compared to the patients on placebo were 3.2 and 2.8 units for the $24 \mathrm{mg} / \mathrm{day}$ and $32 \mathrm{mg} /$ day treatments, respectively. Both treatments were statistically significantly superior to placebo, but were not statistically significantly different from each other.

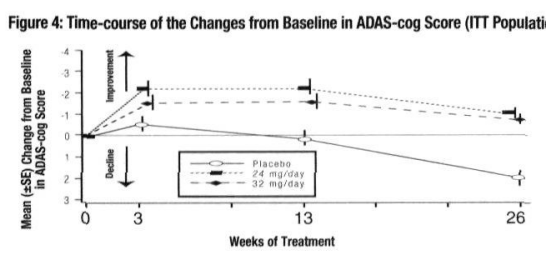

Figure 5 illustrates the cumulative percentages of patients from each of the three treatment groups who had attained at least the measure of improvement in ADAS-cog score shown on the $X$-axis. Three change scores (10-point, 7-poin and 4-point reductions) and no change in score from baseline have been identified for illustrative purposes, and the percent of patients in each group achieving that result is shown in the inset table.

The curves demonstrate that both patients assigned to galantamine and placebo have a wide range of responses, but that the REMINYL groups are more likely to show the greater improvements. Curve for an effective treatment would be shifted to the left of the curve for placebo, while an ineffective or deleteriou treatment would be superimposed upon, or shifted to the right of the curve for placebo, respectively.

Figure 5: Cumulative Percentage of Patients with Specified Changes from Baseline in ADAS-cog Scores (ITT Population)

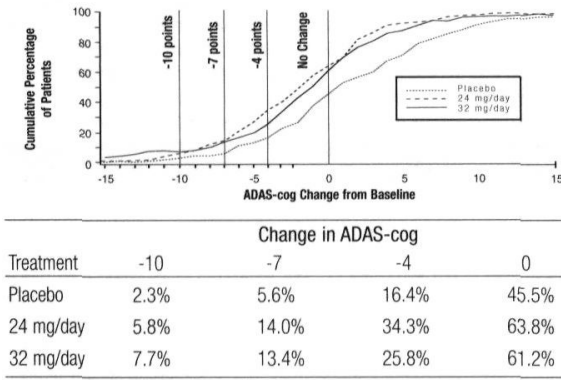

Effects on the CIBIC-plus: Figure 6 is a histogram of the percentage distribution of CBIC-plus scores attained by patients assigned to each of the three treatment of CBIC-plus scores attained by patients assigned to each of the three treatment
groups. The mean REMINYL-placebo differences for these groups of patients in the mean rating were 0.22 and 0.17 units for 24 and $32 \mathrm{mg} /$ day of REMINYL respectively. The mean ratings for both groups were statistically significantly superior to placebo, but were not significantly different from each other.

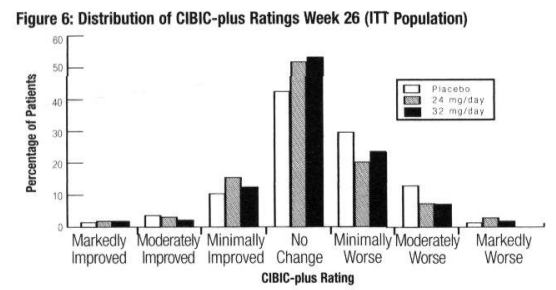

Age, gender and race: Patient's age, gender or race did not predict outcome of treatment.

\section{INDICATIONS AND CLINICAL USE}

REMINYL (galantamine hydrobromide) is indicated for the symptomatic treatment of patients with mild to moderate dementia of the Alzheimer's type. REMINYL has not been studied in controlled clinical trials for longer than 6 months.

REMINYL should only be prescribed by (or following consultation with) clinicians who are experienced in the diagnesis and management of Alzheimer's Disease

\section{CONTRAINDICATIONS}

REMINYL (galantamine hydrobromide) is contraindicated in patients with known hypersensitivity to galantamine hydrobromide, other tertiary alkaloid derivatives or to any excipients used in the formulation.

\section{WARNINGS}

Anesthesia

REMINYL (galantamine hydrobromide), as a cholinesterase inhibitor, is likely to exaggerate succinylcholine-type muscle relaxation during anesthesia.

\section{Neurological Conditions}

Seizures: In placebo-controlled trials with REMINYL, cases of seizure were reported; there was no increase in incidence compared with placebo. Cholinomimetics are believed to have some potential to cause generalized convulsions. However, seizure activity may also be a manifestation of Alzheimer's Disease. The risk/benefit of REMINYL treatment for patients with a history of seizure disorder must therefore be carefully evaluated.

REMINYL has not been studied in patients with moderately severe or severe Alzheimer's Disease, non-Alzheimer dementias or individuals with Parkinson's Disease features. The efficacy and safety of REMINYL in these patient populations is unknown

\section{Pulmonary Conditions}

Like other cholinomimetic drugs, REMINYL should be prescribed with care for patients with a history of asthma or obstructive pulmonary disease.

\section{Cardiovascular Conditions}

Because of their pharmacological action, cholinesterase inhibitors have vagotonic effects on the sinoatrial and atrioventricular nodes, leading bradycardia and heart block. These actions may be particularly important to patients with "sick sinus syndrome" or other supraventricular cardiac conduction disorders, or to patients taking other drugs concomitantly which significantly slow heart rate In clinical trials, patients with serious cardiovascular diseas were excluded. Caution should be exercised in treating patients with active coronary artery disease or congestive heart failure. It is recommended tha REMINYL not be used in patients with cardiac conduction abnormalities (excep for right bundle branch block) including "sick sinus syndrome" and those with unexplained syncopal episodes.

In randomized controlled trials, bradycardia was reported at 2-3\% for galantamine doses up to $24 \mathrm{mg} /$ day compared with $<1 \%$ for placebo, and rarely led to treatment discontinuation. No increased incidence of heart block was observed at the recommended doses. Patients treated with galantamine up to $24 \mathrm{mg} /$ day at the recommended dosing schedule showed a dose-relate increase in risk of syncope (placebo, $0.7 \%$ [2/286]; $4 \mathrm{mg}$ b.i.d., $0.4 \%$ [3/692]; $8 \mathrm{mg}$ b.i.d., $1.3 \%$ [7/552]; $12 \mathrm{mg}$ b.i.d., $2.2 \%$ [6/273]).

A 6-week cardiovascular safety clinical trial (GAL-USA-16;n=139) wa performed to investigate the effect of galantamine at doses up to $32 \mathrm{mg} / \mathrm{day}$ This dosing regimen was: $8 \mathrm{mg} /$ day in Week $1,16 \mathrm{mg} /$ day in Week $2,24 \mathrm{mg} /$ day in Weeks 3 and 4 , and $32 \mathrm{mg} /$ day in Weeks 5 and 6 . Heart block/pauses greater than two seconds were more common in galantamine-treated patients than in placebo-treated patients. It should be noted that a forced 1-week dose escalation was used in this study, which is not recommended. Whether these cardiac effects are attenuated by slower titration rates is not known. Particula caution is warranted during titration where the majority of pauses occurred in the above study.

\section{Gastrointestinal Conditions}

Through their primary action, cholinesterase inhibitors may be expected to increase gastric acid secretion due to increased cholinergic activity. Therefore, patients should be monitored closely for symptoms of active or occult gastrointestinal bleeding, especially those with an increased risk for developing ulcers, e.g. those with a history of ulcer disease or patients using concurren nonsteroidal anti-inflammatory drugs (NSAIDs). In controlled clinical studies with REMINYL, patients with symptomatic peptic ulceration were excluded. Clinical studies of REMINYL have shown no increase, relative to placebo, in the incidence of either peptic ulcer disease or gastrointestinal bleeding (see ADVERSE REACTIONS).

REMINYL, as a predictable consequence of its pharmacologica properties, has been shown to produce nausea, vomiting and diarrhea, anorexia and weight loss. These effects appeared more frequently at higher doses (see ADVERSE REACTIONS), with nausea and vomiting being more prevalent in women and patients with lower body weight and correspondingly higher plasma drug concentrations. Females are more sensitive to the cholinergic adverse effects associated with cholinesteras inhibitors and in general are more likely to experience nausea and vomiting than are males. In most cases, these effects were of mild to moderate intensity and transient and have resolved during continued REMINYL treatment or upon treatment discontinuation

\section{Weight Loss}

Cholinesterase inhibitors as well as Alzheimer's Disease can be associated with significant weight loss. In controlled clinical trials, the use of REMINYL was associated with weight loss. Weight decrease occurred early during treatment and was related to dose. Weight loss of $\geq 7 \%$ occurred more frequently in patients treated with REMINYL and in female patients than in patients receiving placebo. Where weight loss may be of clinical concern, body weight should be monitored

\section{Genitourinary}

Although not observed in clinical trials of REMINYL, cholinomimetics may cause bladder outtlow obstruction.

Concomitant Use with Other Drugs

Use with Anticholinergics

Because of their mechanism of action, cholinesterase inhibitors have the potential to interfere with the activity of anticholinergic medications.

Use with Cholinomimetics and Other Cholinesterase Inhibitors

A synergistic effect may be expected when cholinesterase inhibitors are given concurrently with succinylcholine, similar neuromuscular blocking agents or cholinergic agonists such as bethanecho

Use with other Psychoactive Drugs

Few patients in the REMINYL (galantamine hydrobromide) clinical trials received neuroleptics, antidepressants or anticonvulsants, there is thus limited information concerning the interaction of REMINYL with these drugs.

\section{Use in Patients $>85$ Years Old}

In controlled clinical studies, the number of patients aged 85 years or over who received REMINYL at therapeutic doses of 16 or $24 \mathrm{mg} /$ day was 123 . Of these patients, 70 received the maximum recommended dose of $24 \mathrm{mg} /$ day. There is limited safety information for REMINYL in this patient population.

Since cholinomimetics as well as Alzheimer's Disease can be associated with significant weight loss, caution is advised regarding the use of REMINYL in elderly patients with low body weight, especially in those $\geq 85$ years old

\section{Use in Elderly Patients with Serious Comorbid Disease}

There is limited information on the safety of REMINYL treatment in patients with mild to moderate Alzheimer's Disease and serious/significant comorbidity. The use of REMINYL in Alzheimer's Disease patients with chronic illnesses common among the geriatric population, should be considered only after careful risk/benefit assessment and include close monitoring for adverse events. Dose escalation in this patient population should proceed with caution.

\section{Renally and Hepatically Impaired Patients}

There is limited information on the pharmacokinetics of REMINYL in renally and hepatically impaired patients (see CLINICAL PHARMACOLOGY Pharmacokinetics). It is therefore recommended that dose escalation with REMINYL in Alzheimer's Disease patients with renal impairment (creatinine clearance of 9 to $60 \mathrm{~mL} / \mathrm{min}$ ) or hepatic impairment be undertaken with caution and under conditions of close monitoring for adverse effects (see DOSAGE AND ADMINISTRATION, Special Populations). Since no data are available on the use of REMINYL in patients with a creatinine clearance of less than $9 \mathrm{~mL} / \mathrm{min}$ and in patients with severe hepatic impairment (Child-Pugh score of 10-15). REMINYL is not recommended for these populations.

\section{Drug-Drug Interaction}

Multiple metabolic pathways and renal excretion are involved in the elimination of galantamine so no single pathway appears predominant. Based on in vitr studies, CYP2D6 and CYP3A4 were the major enzymes involved in the metabolism of galantamine. CYP2D6 was involved in the formation of 0-desmethyl-galantamine, whereas CYP3A4 mediated the formation of galantamine- $\mathrm{N}$-oxide

\section{Effect of Other Drugs on the Metabolism of REMINYL}

Pharmacokinetic studies to assess the potential of REMINYL for interaction with cimetidine, ranitidine, ketoconazole, erythromycin, paroxetine, warfarin and digoxin were limited to short-term, mostly single-dose studies in young healthy volunteers. Similar studies in elderly patients were not done.

In vitro

CYP3A4 and CYP2D6 are the major enzymes involved in the metabolism of galantamine. CYP3A4 mediates the formation of galantamine-N-oxide, whereas CYP2D6 is involved in the formation of 0-desmethyl-galantamine. Because galantamine is also glucuronidated and excreted unchanged in urine, no single pathway appears predominant

In vivo

Cimetidine and Ranitidine: Galantamine was administered as a single dose of $4 \mathrm{mg}$ on Day 2 of a 3 -day treatment with either cimetidine $(800 \mathrm{mg}$ daily $n=6$ males and 6 females) or ranitidine ( $300 \mathrm{mg}$ daily; $n=6$ males and 6 females) Cimetidine increased the bioavailability of galantamine by approximately $16 \%$ Ranitidine had no effect on the pharmacokinetics of galantamine

Ketoconazole: Ketoconazole, a strong inhibitor of CYP3A4 and an inhibitor of CYP2D6, at a dose of $200 \mathrm{mg}$ b.i.d. for 4 days, increased the AUC of galantamine by $30 \%$ when subjects were treated with galantamine $4 \mathrm{mg}$ b.i.d. for 8 days ( $n=8$ males and 8 females).

Erythromycin: Erythromycin, a moderate inhibitor of CYP3A4 at a dose of $500 \mathrm{mg}$ q.i.d. for 4 days increased the AUC of galantamine by $10 \%$ when subjects received galantamine $4 \mathrm{mg}$ b.i.d. for 6 days ( $\mathrm{n}=8$ males and 8 females) Paroxetine: Paroxetine, a strong inhibitor of CYP2D6, increased the AUC of $4 \mathrm{mg}$ b.i.d. $8 \mathrm{mg}$ b.i.d. and $12 \mathrm{mg}$ b.i.d. galantamine by $40 \%, 45 \%$ and $48 \%$, respectively, in 16 healthy volunteers (8 males and 8 females) who received galantamine together with $20 \mathrm{mg} / \mathrm{day}$ paroxetine 
Effect of Galantamine on the Metabolism of Other Drug

In witro

Galantamine did not intibit the metabolic pathways catalyzed by CYP1A2 CYP2A6, CYP3A4, CYP4A, CYP2C, CYP2D6 or CYP2E1. This indicates that the inhibitory potential of galantamine towards the major forms of cytochrome $\mathrm{P} 450$ is very low.

Invive

Warfarin: Galantamine at $12 \mathrm{mg}$ b.i.d. had no effect on the pharmacokinetics o 8- and $S$-warfarin (25 mg single dose) or on the prothrombin time ( $n=16$ males) The protein binding of wartarin was unaffected by gatantamine.

Digoxin: Galantamine at $12 \mathrm{mg}$ bi.d. had no effect on the steady-state pharmacokinetics of digoxin (0.375 mg once daily) when they were 60 administered, in this study, however, one healthy subject was hospitalized for $2^{\text {nt }}$ and $3^{\text {rl }}$ cegree heart block and bradycardia ( $n=8$ males and 8 temales).

Nicotinic Receptor Modulation

Single in vitro appl cations of galantamine dose-dependently modulate the effect on nicotinic receptors, havino a positive allosteric (sensitizing) effect at concentrations helow $0.28 \mu \mathrm{g} / \mathrm{mL}$. $(1 \mu \mathrm{M})$ and an inhibitory effect at higher concentrations. Chronic in vitro or in vivo studies on nicotinic receptor modulation have not been conducted.

It is unknown whether galantamine has an effect on the pharmacodynamic action of other druas that act on cholinergic nicotinic receptors isee CLINICAL PHARMACOLOGY)

\section{Carcinogenesis, Mutagenesis and impairment of Fertility}

In a 24-month oral carcinogenicity study in rats, a slight increase in endometria adenocarcinomas was observed at $10 \mathrm{mg} / \mathrm{kg} / \mathrm{clay}$ (4 times the Maximum Recommended Human Dose [MRHD] on a $\mathrm{mg} / \mathrm{m}^{2}$ basis or 6 times on an exposure [AUC] basis\}, and $30 \mathrm{mg} / \mathrm{kg} / \mathrm{day}$ (12 times the MRHD on a mg/m? basis or 19 times on an AUC basis). No increase in neoplastic changes was observed in temales at $2.5 \mathrm{mg} / \mathrm{kg} /$ day (equivalent to the MRHD on a mg/m² basis or 2 times on an AUC basis) or in males up to the highest dose tested of $30 \mathrm{mg} / \mathrm{kg} /$ day (12 times the MRHO on a mg/mi' and AUC basis).

Galantamine was not carcinogenic in a 6 -month oral carcinogenicity study in transgenic (P 53-deficient) mice up to $20 \mathrm{mg} / \mathrm{kg} / \mathrm{day}$, or in a 24 -month oral carcinogenicity study in male and female mice up to $10 \mathrm{mg} / \mathrm{kg} /$ cay 12 times the MRHD on a $\mathrm{mg} / \mathrm{m}^{\prime}$ basis and equivalent on an AUC basis).

Galantamine produced no evidence of genotoxic potential when evaluated in the in vitro Ames $S$. typhimuirium or $E$. coll reverse mutation assay in vitro mouse lymphema assay in vivo micronucleus test in mice, or in vitro chromosome aberration assay in Chinese hamster ovary cells.

No impairment of fertility was seen in rats given up to $16 \mathrm{mg} / \mathrm{kg} /$ day 7 times the MRHD on a mg/m" basis) for 14 days prior to mating in females and for 60 days prior to mating in males.

\section{Pregnancy}

In a teratolong study in which rats were dosed from Day 14 (females) or Day 60 (tinalest prior to mating throught the period of organogenesis a sifintly increased incidence of skeletal variations was observed at doses of $8 \mathrm{mg} / \mathrm{kg} / \mathrm{day}$ (3 times the MRHD on a mg/m" basisy and $16 \mathrm{mg} / \mathrm{kg} / \mathrm{day}$. In a study in which pregnant rats were dosed from the beginning of organogenesis through Day 21 postpartum, pup weights were decreased at 8 and $16 \mathrm{mg} / \mathrm{kg} / \mathrm{day}$, but no adverse effects on other postnatal developmental parameters were seen. The doses calusing the ahove effects in rats produced slight maternal toxicity No major malformations were caused in rats given up to $16 \mathrm{mg} / \mathrm{kg} /$ day. No drug related teratogenic effects were observed in rabbits given up to $40 \mathrm{mg} / \mathrm{kg} / \mathrm{day}$ ( 32 times the MRHD on a $\mathrm{mg} / \mathrm{m}^{3}$ basis) during the period of organogenesis.

The safely of REMINYL in pregnant women has not been established. REMINYL should not be used in women of childbearing potential unlass in the cpinion of the physician, the potential benefit to the patient justifies the potential risk to the fetus.

\section{Nursing Mothers}

It is not known whether REMINYL is excreted in human breast milk and therefore REMINYL should not be used in nursing mothers.

Pediatric Use

The satety and effectiveness of REMINYL in any illness occurring in pediatric patients have not been establisher.

\section{ADVERSE REACTIONS}

A total of 2287 patients with mild to moderate Alzheimer's Disease were treater with PEMINYL (oalantamine hydrobromidey in Phace III controlled dinical studies sing either a 1-week or 4-week dose-escalation period, and 761 patients received FEMINYL 24 mg/day, the maximum recommended maintenance dose. The number of patients who completed the studies was $1686(72 \%)$. The mean duration of treatment for all REMINYL groups was 130 days (range 1-214 days).

\section{Adverse Events Leading to Discontinuation}

Overall, 19\% (441/2287) of patients treated with REMINYL discontinued from Phase II controlled clinical trials due to adverse events compared to $8 \%$ $(98 / 1159$ ) in the placebo group. For patients treated with REMINYL, the rate of discontinuation due to adverse events was $14 \%$ for males and $22 \%$ for females. In the 4-week dose-escalation fixed-dose study (GAL-USA-10), 8\% (55/692) of patients treated with REMINYL withdrew due to adverse events compared to $7 \%$ (20/286) in the placebo group. During the dose-escalation phase of this study the incidence of discontinuations cue to adverse eyents was $4 \%$ for placeho, $5 \%$ for REMINYL $16 \mathrm{mg} / \mathrm{day}$ and $6 \%$ for REMINYL $24 \mathrm{mg} /$ day. During the maintenance phase, $4 \%$ of patients who received placebo, $3 \%$ of patients who eceived REMINYL $16 \mathrm{mg} /$ day and $4 \%$ of patients who received REMINYL $24 \mathrm{mg} /$ day withdrew from this study due to adverse events.

Table 1 shows the most frequent adverse events leading to discontinuation for study GAL-USA-10, in which the recommended 4-week dose-escalation schedule was used.
Table :: Most frequent adverse events leading to discontinuation in a placebocontrolled, double-blind trial with a 4-week dose-escalation schedule (GAL-USA-10)

\begin{tabular}{|l|c|c|c|}
\hline \multirow{2}{*}{ Adverse Events } & \multicolumn{3}{|c|}{ Recommended 4-week dose escalation } \\
\cline { 2 - 4 } & $\begin{array}{c}\text { Placebo } \\
\mathrm{n}=286\end{array}$ & $\begin{array}{c}16 \mathrm{mg} / \text { day } \\
\mathrm{n}=279\end{array}$ & $\begin{array}{c}24 \mathrm{mg} / \text { day } \\
\mathrm{n}=273\end{array}$ \\
\hline Nausea & $<1 \%$ & $2 \%$ & $4 \%$ \\
\hline Vomiting & $0 \%$ & $1 \%$ & $3 \%$ \\
\hline Anorexia & $<1 \%$ & $1 \%$ & $<1 \%$ \\
\hline Dizziness & $<1 \%$ & $2 \%$ & $1 \%$ \\
\hline Syncope & $0 \%$ & $0 \%$ & $1 \%$ \\
\hline
\end{tabular}

Most Frequent Adverse Clinical Events Seen in Association with the Use of REMINYL

The most frequent adverse events, defined as those cccurting at a frequency of at least $5 \%$ and at least twice the rate of placebo in study GAL-USA-10, in whic the recommended 4-week dose-escalation schedule was used are shown in Table 2. These events were primarily gastrointestinal and tended to occur at a lower rate with $16 \mathrm{mg} / \mathrm{day}$, the initial recommended maintenarice dose.

\begin{tabular}{|c|c|c|c|c|c|c|}
\hline \multirow[b]{2}{*}{$\begin{array}{l}\text { Adverse } \\
\text { Events }\end{array}$} & \multicolumn{3}{|c|}{ Week $1-12^{\dagger}$} & \multicolumn{3}{|c|}{ Week 1321 } \\
\hline & $\begin{array}{c}\text { Placebo } \\
n=286\end{array}$ & $\begin{array}{c}16 \mathrm{mg} / \mathrm{day} \\
\mathrm{n}=279\end{array}$ & $\begin{array}{c}24 \mathrm{mg} / \mathrm{day} \\
\mathrm{n}=273\end{array}$ & $\begin{array}{c}\text { Placebo } \\
n=259\end{array}$ & $\begin{array}{c}16 \mathrm{mg} / \mathrm{day} \\
\mathrm{n}=243\end{array}$ & $\begin{array}{c}24 \mathrm{mg} / \mathrm{day} \\
\mathrm{n}=241\end{array}$ \\
\hline \begin{tabular}{|l|} 
Nausea \\
\end{tabular} & $5 \%$ & $11 \%$ & $13 \%$ & $<1 \%$ & $4 \%$ & $6 \%$ \\
\hline Vomiting & $<1 \%$ & $5 \%$ & $6 \%$ & $<1 \%$ & $2 \%$ & $6 \%$ \\
\hline Diarrhea & $5 \%$ & $9 \%$ & $4 \%$ & $2 \%$ & $5 \%$ & $2 \%$ \\
\hline Anorexia & $2 \%$ & $5 \%$ & $5 \%$ & $1 \%$ & $2 \%$ & $5 \%$ \\
\hline
\end{tabular}

$\dagger$ Dose escalation occurred with 4 weeks per dose increment.

The majority of these adverse events occurred during the dose-escalation period. Nausea and vomiting, the most frequent adverse events, occurred more frecuently at higher doses, lasted 5-7 days in most cases, and the maiority of patients had one episode. The incidence of weight loss in this study was, during dose escalation (Weeks 1-12): placebo, $1 \% ; 16 \mathrm{mg} / \mathrm{day}, 3 \% ; 24 \mathrm{mg} / \mathrm{day}, 2 \%$; and during the maintenance phase (Weeks 13-21): placebo, <1\%; $16 \mathrm{mg} / \mathrm{day}$, $3 \% ; 24 \mathrm{mg} / \mathrm{day}, 3 \%$

Dose escalation should be cautious and maintenance dosing should remain flexible and be adjusted accord.ng to individual needs.

\section{Adverse Events Reported in Controlled Trials}

The reported adverse events in REVINYL trials reflect experience gained under closely monitored conditions in a highly selected patient population, in actuat practice or in other clinical trials, these frequency estimates may not apply, as the conditions of use, reporting behaviour and the types of patients treated may differ. Table 3 lists the most common adverse events (adverse events occurring with an incidence of $2 \%$ with REMINYL treatment and in which the incidence was greater than with placebo treatment) for four placebo-controled trials for patients treated with 16 or 24 mo/day of REMINYL. The combined values presented in Table 3 were derived from trials using a 1-week or the recommended 4-week dose-escalation period.

Table 3: Adverse events reported in at least $2 \%$ of patients with Alzheimer's Disease administered REMINYL and at a trequency greater than with placebo (combined 1- and 4-week dose-escalation data)

\begin{tabular}{|l|l|l|}
\hline Body System / Adverse Events & $\begin{array}{l}\text { Placebo } \\
(n=801)\end{array}$ & $\begin{array}{l}\text { REMINYL' } \\
(n=1040)\end{array}$ \\
\hline
\end{tabular}

\begin{tabular}{|l|c|c|}
\hline Body as a whole-general disorders & & \\
\hline Fatigue & $3 \%$ & $5 \%$ \\
\hline Syncope & $1 \%$ & $2 \%$ \\
\hline Central \& peripheral nervous system disorders & & \\
\hline Dizziness & $6 \%$ & $9 \%$ \\
\hline Headache & $5 \%$ & $8 \%$ \\
\hline Tremor & $2 \%$ & $3 \%$ \\
\hline Gastro-intestinal system disorders & & \\
\hline Nausea & $9 \%$ & $24 \%$ \\
\hline Vomiting & $4 \%$ & $13 \%$ \\
\hline Diarnea & $7 \%$ & $9 \%$ \\
\hline Abdominal pain & $4 \%$ & $5 \%$ \\
\hline Dyspepsia & $2 \%$ & $5 \%$ \\
\hline Heart rate and inythm disorders & & \\
\hline Bradycardia & $1 \%$ & $2 \%$ \\
\hline Metabolic and nutritional disorders & & \\
\hline Weight decrease & $2 \%$ & $7 \%$ \\
\hline$P_{\text {Sychiatric disorders }}$ & & \\
\hline Anorexia & $3 \%$ & $9 \%$ \\
\hline Depression & $5 \%$ & $7 \%$ \\
\hline Insomnila & $4 \%$ & $5 \%$ \\
\hline Somnotence & $3 \%$ & $4 \%$ \\
\hline Red blood cell disorders & & \\
\hline Anemia & $2 \%$ & $3 \%$ \\
\hline Respiratory system disorders & & \\
\hline Rhinitis & $3 \%$ & $4 \%$ \\
\hline Urinary system disorders & & \\
\hline Urinary tract infection & $7 \%$ & $8 \%$ \\
\hline Hematuria & $2 \%$ & $3 \%$ \\
\hline
\end{tabular}

Adverse events in patients treated with 16 or 24 mgtday of BEMNNYi in three placebocontrolled trias with a 1-week dose-escalation period and a 26-week fixed-dose REMINS controlled trials with a 1-week dose-escalation period and a 26-week fixed-dose REMMNYL
treatment, and one placebo-controlled triai with the reconmended 4-week dase-escalation period and a 21 -weth fixed-dose REviltiv' treatment are included.
No clinically relevant abnormalities in laboratory values were observed. In carciovascular safety clinical trial (GAL-USA-16), pauses greater than two treated patients during the dose-escalation period (see WARNINGS).

Other Adverse Events Observed During Clinical Trials

REMINYL has been administered to 3055 patients with Alzheimer's Diseas

A total of 2357 patients recelved galantamine in placebo-controlled trials and 761 patients with Aizhelmer's Disease received galantamine $24 \mathrm{mg} / \mathrm{day}$, the maximum recommended maintenance dose. About 1000 patients received galantamine for at least one year and approximately 200 patients receive galantamine for two years. To establish the rate of adverse events, data from al patients for any dose of REMINYL in 8 placebo-controlled trials and 6 open-labe extension trials were pooled. The methodology to gather and codify these adverse events was standardized across trials, using WHO terminology. All events occurring in approximately $0.1 \%$ of patients are included, except for those already listed elsewhere in label ing, WHO terms too general to be informative, or relativel minor events. Events are classified by body system and listed using the following detinitions: frequent adverse events - those occurring in at least 1/100 patients; infrequent adverse events - those occuring in $1 / 100$ to $1 / 1000$ patients These adverse events are not necessarily related to REMINYL treatment and in most cases were observed at a similar frecuency in placebo-treated patients in most cases were ob

Body as a Whole - General Disorders: Frequent: chest pain.

Cardiovascular System Disorders: Frequent: hypertension; infrequent: postural hypotension, hypotension, dependent edema, cardiac fail ure.

Central \& Peripheral Nervous System Disorders: Infrequent: vertico, hypertonia convulsions, involuntary muscle contractions, paresthesia, ataxia, hyprokinesia hyperkinesia, apraxia, aphasia.

Gastrointestinal System Disorders: Frequent: flatulence; Infrequent: gastritis melena, dysphagia, rectal hemorrhage, dry mouth, sa liva increased, diverticuliti. gastroenteritis, hiccup; Rare: esophageal perforation.

Heart Rate \& Rhythm Disorders: Infrequent: AV block palpitation, atria fibrillation, QT prolonged, bundle branch block, supraventricular tachycardia, T-wave inversion, ventricular tachycardia.

Mettabolic \& Nutritional Disorderş: Infrequent: hyperglycemia, alkaline phosphatase increased, NPN increased

Platelet, Bleeding \& Clotting Disorders; Infrequent: purpura, epistaxi thrombocytopenia

Sychiatric Disorders: Infrequent: apathy, paroniria, paranoid reaction, libido ncreased, delirium

Urinary System Disorders: Frequent: incontinence; Infrequent: herraturia, micturition frequency, cystifis, urinary retention, nocturia, renal calcull.

\section{SYMPTOMS AND TREATMENT OF OVERDOSAGE}

\section{Symptom}

Overdosage with cholinesterase inhibitors can result in cholinergic crisi characterized by severe nausea, vomiting, salivation, sweating, bradycardia, hypotension, respiratory depression, collapse and convulsions. increasing muscle weakness is a possibility and may result in death if respiratory muscles are involved. In a postmarketing report, one patient who had been taking $4 \mathrm{mg}$ of galantamirie daily inadvertently ingested eight $4 \mathrm{mg}$ tablets (32 $\mathrm{mg}$ totall) on the tenth day of treatment. Subsequently, she developed bradycardia, QT prolongation, ventricular tachycardla and torsades de pointes accompanied by a brief loss of consciousness for which she required hospital treatment. ECG obtained just prior to initiation of galantamine treatment was normal.

\section{Treatment}

REMINYL (galantamine hydrobromide) has a plasma half-life of approximatel $7-8$ hours. It is recommended that, in case of asymptomatic overdose, no further dose of REMNAYL should be administered and the patient should be monitored.

As in any case of overdose, general supportive measures should be utilized Signs and symptoms of significant overdosing of galantamine are predicted to be similar to those of overdosing of other cholinomimetics. These effects system, and the neuromuscular junction. In addition to muscle weakness or fasciculations, some or all of the following signs of cholinergic crisis may cevelop: severe nausea, vomiting, gastrointestinal cramping, salivation, lacrimation, urination, defecation, sweating bradycardia, hypotension, respiratory depression, collapse and convul sions. Increasing muscle weakness is a possibility and may result in death if respiratory muscles are involved.

Tetiany anticholinergics such as atropine may be used as an antidote for REMNNYL cverdosage Intravenous atropine suphate titrated to ettect is recommended at an intial dose of 0.5 to $1.0 \mathrm{mg}$ iv with subsequent doses based upon clinica respense. Aypoical responses in blood pressure and heart rate have been reported with other cholinomimetics when co-administered with quaternary anticholinergics t is not kาown whether REMINYL and/or its metabolites can be removed by dialys s hemodialysis, peritoneal cialysis, or hemofittration. Dose-related signs of toxicity in animals included hypoactivity, tremors, clonic convulsions, salivation, lacrimation, chromodacryorthea, mucoid teces, and dyspnea seconds were more common in galantamine-treated patients than in placeboduring clinical trials worldwide. generally involve the central nerwous system, the parasympathetic nerwous 


\section{${ }^{\circ}$ COPAXONE (glatiramer acetate injection)}

$20 \mathrm{mg}$, single use vials and $20 \mathrm{mg} / 1.0 \mathrm{~mL}$, pre-filled syringes for Subcutaneous Injection THERAPEUTIC CLASSIFICATION Immunomodulator

ACTION AND CLINICAL PHARMACOLOGY

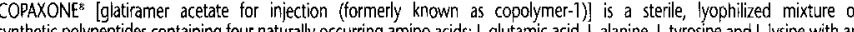
synthetic polypeptides containing tour naturally occurring amino acids: $\mathrm{L}$-glutamic acid, $\mathrm{L}$-alanine, $\mathrm{L}$-tyrosine and $\mathrm{L}$-lysine with an average molar fraction of $0.141,0.427,0.095$ and 0.338 , respectively. it is thought to act by modifying immune processes that are currently believed to be responsible for the pathogenesis of MS. This hypothesis is supported by findings of studies that have been carried out to explore the pathogenesis of experimental allergic encephalomyelitis (EAE), a condition induced in animals that is generally accepted as an experimental model of $M S$

Studies in animals and in vifro systems suggest that upon its administration glatiramer acetate specific suppressor $\mathrm{T}$ cells are induced and activated in the periphery.

Because the immunological profile of glatiramer acetate remains to be fully elucidated, concerns exist about its potential to alter naturally occurring immune responses (see PRECAUTiONS).

Pharmacokinetics: Results obtained in pharmacokinetic studies performed in humans (healthy volunteers) and animals support the assumption that a substantial fraction of the therapeutic dose delivered to patients subcutaneously is hydrolyze locally. Nevertheless, larger fragrnents of glatiramer acetate can be recognized by glatiramer acetate reactive antibodies. Some fraction of the injected material, either intact or partialy hydrolyzed, is presumed to enter the lymphatic circulation, enabling it to reach regional ymph nodes, and some, may enter the systemic circulation intact.

Clinical Studies: The efficacy of COPAXONE (glatiramer acetate for injection) was evaluated in two placebo-controlle trials in patients with Relapsing-Remitting MS (RR-MS). In a third placebo-controlled study the effects of glatirarmer acetate on MRI parameters were assessed. In these studies, a dose of $20 \mathrm{mg} /$ day was used. No other dose or dosing regimen has been studied in placebo-controlled trials of RR-MS.

The first trial was a pilot study Trial I (Trial BR-I) which was conducted at a single-center and was a double-blind, randomized matched-pair paralel group placebo-controlled trial. Fifty patients with RR-MS were randomized to receive $20 \mathrm{mo} / \mathrm{d}$ a glatiramer acetate $(n=25)$ or placebo $(n=25)$ subcutaneously. The protocol-specified primary outcome measure was the proportion of patients who were relapse free during the 2 -year duration of the trial, but two additional relevant outcomes were also specified as endpoints: requency of attacks during the trial, and the change in the number of attacks compared to the rate of attacks in the 2 years prior to study entry. Results from this study (see Table 1) show that there was a statistically significant effect of glatiramer acetate on number of relapses.

TABLE 1 - Trial BR-1: Efficacy Results

\begin{tabular}{|l|c|c|c|}
\multicolumn{1}{|c|}{ Outcome } & \multicolumn{3}{c|}{ Trial r } \\
\hline & $\begin{array}{c}\text { Glatiramer acetate } \\
\mathbf{n = 2 5}\end{array}$ & $\begin{array}{c}\text { Placebo } \\
\mathbf{n = 2 5}\end{array}$ & p-Value \\
\hline \% Relapse Free Patients & $\mathbf{1 4 / 2 5 ( 5 6 \% )}$ & $7 / 25(28 \%)$ & 0.085 \\
\hline Mean Relapse Frequency & $0.6 / 2$ years & $2.4 / 2$ years & 0.005 \\
\hline Reduction in Relapse Rate compared to pre-study & 3.2 & 1.6 & 0.025 \\
\hline Median Time to First Relapse (days) & $>700$ & 150 & 0.03 \\
\hline$\%$ of Progression-Free* Patients & $20 / 25(80 \%)$ & $13 / 25(52 \%)$ & 0.07 \\
\hline
\end{tabular}

The primary efficacy measure for Trial I was the proportion of patients who were rel

of the trial (\% Relapse Free). Analyses were based on the intent-to-treat population.

Trial II (01-9001) was a multicenter double-blind, randomized, placebo-controlled trial. Two hundred and fifty-one patients with RR-MS were randomized to receive $20 \mathrm{mg} /$ day glatiramer acetate $(n=125)$ or placebo $(n=126)$ subcutaneously. Patients were diagnosed with RR-MS by standard criteria, and had at least 2 exacerbations during the 2 years immediately preceding
enrolliment. Patients had a score of no more than 5 on the Kurtzke Expanded Disability Scate Score (EDSS) enrollment. Patients had a score of no more than 5 on the Kurtzke Expanded Disability Scale Score (EDSS), a
standard scale ranging from 0 (normal) to 10 (death due to MS). A score of 5 is defined as one at which a patient is still standard scale ranging from 0 (normal) to 10 (death due to MS). A score of 5 is defined as one at which a patient is still
ambulatory but for whorn full daily activities are impaired due to disability, a score of 6 is defined as one at which the patient ambulatory but for whorn full daily activities are impaired due to disability, a score of 6 is defined as one at which is still ambulatory but requires assistanice dnd a score well as within several days of a presumed exacerbation. In order for an exacerbation to be confirmed, a blinded neurologist had to document objective neurologic signs, as well as document the existence of other criteria (e.g., the persistence of the lesion for at least 48 hours).

The protocol-specified primary outcome measure was the mean number of relapses during treatment. Table 2 shows results of the analysis of primary as well as several secondary outcome measures at two years based
TABLE $\mathbf{2}$ - Core (24-month) Double-Blind Study: Effect on Relapse Rate

\begin{tabular}{|l|c|c|c|}
\hline \multicolumn{1}{|c|}{ Outcome } & \multicolumn{3}{c|}{ Trial II } \\
\hline & $\begin{array}{c}\text { Clatiramer acetate } \\
\mathbf{n = 1 2 5}\end{array}$ & $\begin{array}{c}\text { Placebo } \\
\mathbf{n = 1 2 6}\end{array}$ & p-Value \\
\hline Mean No. of Relapses/2 years ${ }^{b}$ & $\mathbf{1 . 1 9}$ & 1.68 & 0.055 \\
\hline \% Relapse Free Patients & $42 / 125(34 \%)$ & $34 / 126(27 \%)$ & 0.25 \\
\hline Median Time to First Relapse (days) & 287 & 198 & 0.23 \\
\hline$\%$ of Patients Progression Free' & $98 / 125(78 \%)$ & $95 / 126(75 \%)$ & 0.48 \\
\hline Mean Change in EDSS & -0.05 & +0.21 & 0.023 \\
\hline
\end{tabular}

The primary efficacy measure for Trial II was the number of relapses during treatment. Analyses were based on the intent-to-treat population.

Baseline adjusted mean.

Progression defined as an increase of at least 1 point on the EDSS that persists for at least 3 consecutive months.

The effects of glatiramer acetate on relapse severity were not evaluated in either trial.

Both studies showed a beneficial effect of glatiramer acetate on relapse rate, and on this basis glatiramer acetate is

Considered effective.
The third study (9003) was a multi-national, multi-center, MRl-monitored study. A total of 239 patients with RR-MS (119 on glatiramer acetate and 120 on placebo) were randomized. Inclusion criteria were similar to those in Trial II (Study 01-9001) with the additional criteria that patients had to have at least one Cd-enhancing lesion on the screening MRl. The patients were treated initially in a double-blind manner for nine months, during which they underwent monthly MRI scanning. The primary
endpoint for the double-blind phase was the total cumulative number of $T 1$ Cd-enhancing lesions over nine months. Other MRI parameters were assessed as secondary endipoints. Table 3 summarizes the results for the parameters monitored during the nine-month double-blind phase for the intent-to-treat cohort. Because the link between MRI findings and the clinical status of patients is contentious, the prognostic valie of the following statistically significant findings is unknown.

TABLE 3 - Nine-Month Double-Blind Phase: MRI Endpoints - Results

\begin{tabular}{|c|c|c|c|c|}
\hline No. & Outcome & $\begin{array}{c}\text { Glatiramer } \\
\text { acetate } n=113\end{array}$ & 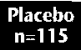 & p-Value \\
\hline \multicolumn{5}{|c|}{ Primary Endpoint } \\
\hline 1. & $\begin{array}{l}\text { Medians of the Cumulative Number of T1 } \\
\text { Gd-Enhancing Lesions }\end{array}$ & 12 & 17 & 0.0037 \\
\hline \multicolumn{5}{|c|}{ Secondary Endpoints } \\
\hline 2. & $\begin{array}{l}\text { Medians of the Cumulative Number of New T1 } \\
\text { Gd-Enhancing Lesions }\end{array}$ & 9 & 14 & 0.0347 \\
\hline 3. & Medians of the Cumulative Number of New T2 Lesions & 5 & 8 & 0.01 \\
\hline 4. & $\begin{array}{l}\text { Medians of the Cumulative Change from Baseline } \\
\text { in volumes ( } \mathrm{mL} \text { ) of } T 1 \mathrm{Cd} \text {-Enhancing Lesions }\end{array}$ & -0.309 & 0 & 0.0248 \\
\hline 5. & $\begin{array}{l}\text { Medians of the Cumulative Change from Baseline } \\
\text { in volumes }(\mathrm{mL}) \text { of } \mathrm{T} 2 \text { Lesions }\end{array}$ & 8.852 & 13.566 & 0.0229 \\
\hline 6. & $\begin{array}{l}\text { Medians of the Cumulative Change from Baseline } \\
\text { in volumes }(\mathrm{mL}) \text { of } T 1 \text { Hypointense Lesions }\end{array}$ & 1.642 & 1.829 & 0.7311 \\
\hline 7. & Proportion of $\mathrm{Tl} \mathrm{Gd}$-Enhancing Lesion-Free Patients & $46.4 \%$ & $32.2 \%$ & 0.0653 \\
\hline
\end{tabular}

The mean number of relapses in this 9 -month study was 0.50 for the COPAXONE group and 0.77 for the placebo group $(\mathrm{p}=0.0077)$.
INDICATIONS AND CLINICAL USE

政

The safety and efficacy of COPAXONE⿱⿱乛龰灬 in chronic progressive MS have not been established. CONTRAINDICATIONS

COPAXONE' (glatiramer acetate for injection) is contraindicated in patients with known hypersensitivity to glatiramer acetate WARNiNCS

menced route of administration of COPAXONEs (glatiramer acetate for injection) injection is the subcutaneous route. COPAXONE*s should not be administered by the intravenous route

Symptoms of Potentially Cardiac Origin: Approximately $26 \%$ of COPAXONE patients in the pre-marketing multicenter controlled trial (compared to $10 \%$ of placebo patients) experienced at least one episode of what was described as transient chest pain (see ADVERSE REACTIONS: Chest Pain). While some of these episodes occurred in the context of the Immediate Post-Injection Reaction (see ADVERSE REACTIONS: Immediate Post-Injection Reaction), many did not. The pathogenesis of this symptom is unknown. Patients in controlled clinical trials were free of significant cardiovascular problems (Now York Heart
Association Class I and II) and thus the risks associated with COPAXONE" treatment for Multiple Sclerosis patients with Association Ciass I and II) and thus the risks
comorbid cardiovascular disease are unknown.

COPAXONE ${ }^{\circ}$ has been associated with an Immediate Post-Injection Reaction consisting of a constellation of symptoms appearing immediately after injection that could include flushing, chest pain, paipitations, anxiety, dyspnea, constriction of the throat and uricaria (see ADVERSE REACTION

COPAXONE has not been studied in patients with a history of severe anaphylactoid reactions, obstructive pulmonary disease or asthma, nor in patients under treatment for either of these two latter conditions. Particular caution is therefore advised regarding the use of COPAXONE" in such patients.

Anaphylactoid reactions associated with the use of COPAXONEE have been reported in rare instances $(<1 / 1000)$ during the post-marketing period. Some cases required treatment with epinephrine and other appropriate medical treatment.

PRECAUTIONS

General: Patients should be instructed in aseptic reconstitution and self-injection techniques to assure the safe administration of COPAXONE $E^{\text {g }}$ (glatiramer acetate for injection) (see INFORMATION FOR THE PATIENT). The first injection should be performed under the supervision of an appropriately qualified health care professional. Patient understanding and use of aseptic self-injection techniques and procedures should be periodically re-evaluated. Patients should be cautioned against the re-use of needles or syringes and instructed in safe disposal procedures. A puncture-resistant container for disposal of used needles and syringes should be used by the patient. Patients snould be instructed on the safe disposal of full containers.

Considerations !nvolving the Use of a Product Capable of Modifying immune Responses: COPAXONE' is an antigenic substance and thus it is possible that detrimental host responses can occur with its use. Whether COPAXONE $\mathrm{can}$ alter normal human immune responses, such as the recognition of foreign antigens is unknown. It is therefore possible that treatment with COPAXONE may undermine the body's defenses against infections and tumor surveillance. Systematic assessments of these risks have not been done. Continued alteration of cellular immunity due to chronic treatment with glatiramer acetate might result in untoward effects.

Clatiramer acetate-reactive antibodies are formed in practically all patients exposed to dally treatment with the recommended dose. Studies in both the rat and monkey have suggested that immune complexes are deposited in the renal glomeruli. Furthermore, in a controlled clinical trial of 225 RR-MS patients given glatiramer acetate $20 \mathrm{mg}$ for 2 years, serum lgG levels reached at least 3 times baseline values in $80 \%$ of patients by 3 months of initiation of treatment. By 12 montns of treatment, however, 30\% of patients still had IgC levels at least 3 times baseline values, and $90 \%$ had levels above baseline by 12 months. The antibodies are exclusively of the lgG subtype - and predominantly of the lgG-1 subtype. No lgE
type antibodies could be detected in any of the 94 sera tested. Nevertheless, anaphylaxis can be associated with the administration of almost any foreign substance and, therefore, this risk cannot be excluded.

Preclinical studies to assess the carcinogenic potential of glatiramer acetate in mice and rats do not suggest any evidence of carcinogenic potential related to glatiramer acetate administered subcutaneously at dose levels of up to $30 \mathrm{mg} / \mathrm{kg} / \mathrm{day}$ in rats and $60 \mathrm{mg} / \mathrm{kg} /$ day in mice (see TOXICOLOCY: Carcinogenicity). The relevance of these findings for humans is unknown (see PRECAUTIONS: Considerations Involving the Use of a Product Capable of Modifying Immune Responses).

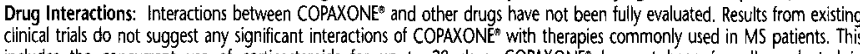
includes the concurrent use of corticosteroids for up to 28 days. COPAXONE has not been formally evaluated in combination with interferon beta. However, 246 patients who failed on or who did not tolerate therapy with Interferon beta and were later treated with COPAXONE' within the framework of an open clinical trial did not report any serious or unexpected adverse events thought to be related to treatment.

Use in Pregnancy: There are no adequate and well-controlled studies in pregnant women. No evidence of reproductive toxicity was observed in preclinical studies (see TOXICOLOCY: Reproduction and Teratology). Because animal reproduction studies are not always predictive of human response, this drug should be used during pregnancy only if clearly needed. During pre-marketing clinical trials with COPAXONE", seven women conceived while being treated with the active drug. One case was lost to follow-up. Three of the patients electively discontinued pregnancy. Three patients stopped treatment 1,1.5 and 2 months after learning they were pregnant; all delivered healthy babies.

Nursing Mothers: It is not known whether this drug is excreted in human milk. Because many drugs are excreted in human milk, treating a nursing woman with COPAXONE' should only be considered after careful risk/benefit assessment and be used with caution.

Use in Children: The safety and effectiveness of COPAXONE' have not been established in individuals below 18 years of age Use in the Elderly: COPAXONE" has not been studied in the elderly ( $>65$ years old)

Use in Patients with Impaired Renal Function: The pharmacokinetics of COPAXONE $E^{\circ}$ in patients with impaired renal function have not been determined.

ADVERSE REACTIONS

In the pre-marketing clinical trials, approximately 900 individuals have received at least one dose of COPAXONER (glatirame cetate for injection) in controlled and uncontrolied clinical trials Total patient exposure to COPAXONEe in clinical triats ranged from 6 months (693 patients) to 2 years \{306 patients\}, and to over 7 years ( 69 patients) at a daily dose of $20 \mathrm{mg}$.

In controlled clinical trials, the most commonly observed adverse events associated with the use of COPAXONE- which occurred at a higher frequency than in placebo treated patients were: injection site reactions, vasodilation, chest pain, asthenia, infection, pain, nausea, arthralgia, anxiety and hypertonia.

Of a total of 844 patients who could be evaluated for safety, approximately $8 \%$ discontinued treatment due to an adverse event. The adverse events most commonly associated with discontinuation were: injection site reaction (6.5\%), vasodilation, unintended pregnancy, depression, dyspnea, urticaria, tachycardia, dizziness and tremor. Treatment discontinuation due to a serious adverse

Immedlate Post-Injection Reaction: Approximately $10 \%$ of Multipie Scierosis patients exposed to COPAXONE⿺ pre-marketing studies reported a post-injection reaction immediately following subcutaneous injection of COPAXONE Symptoms experienced could include flushing, chest pain, palpitations, anxiety, dyspnea, constriction of the throat and urticaria. These symptoms were invariably transient, self-imited, did not require specific treatment and in general, arose several months after initiation of treatment, although they may occur earlier in the course of treatment. A given patient may experience one or several episodes of these symptoms during treatment with COPAXONE. Whether these episodes are mediated by an immunologic or non-immunologic mechanism, and whether several similar episodes seen in a given patient have identical mechanisms is unknown. In fact, whether or not this constellation of symptoms actually represents a
speific syndrome is unknown. During the post-marketing period, there have been reports of patients with similar specific syndrome is unknown. During the post-marketing pertiod,
symptoms who received emergency medical care (see WARNINCS).

Chest Pain; Aoproximately $26 \%$ of glatiramer acetate patients in the multicenter pre-marketing controlled trial (compared to $10 \%$ of placebo patients) experienced at least one episode of what was described as transient chest pain. While some of these episodes occurred in the context of the Immediate Post-Injection Reaction described above, many did not. The tempor relationship of the chest pain to an injection of glatiramer acetate was not always known, although the pain was transien (usually lasting only a few minutes), often unassociated with other symptoms, and appeared to have no important clinica sequelae. Some patients experienced more than one such episode, and episodes usually began at least 1 month after the initiation of treatment. The pathogenesis of this symptom is unknown. There has been only one episode of chest pain during which a full ECC was performed; the ECG showed no evidence of ischemia. Patients in clinical trials were free of significant cardiovascular disease (New York Heart Association Class I or II); therefore, the risks associated with glatiramer acetate treatment for Multiple Sclerosis patients with comorbid cardiovascular disease are unknown (see WARNINCS: Symptoms of Potentially Cardiac Origin).

Table 4 lists the adverse experiences after up to 35 months of treatment ( $>27.33$ months: COPAXONE", $n=84$; Placebo $\mathrm{n}=75$; $>33$ months: COPAXONE', $n=12$; Placebo, $n=24$ ) in the pre-marketing multicenter placebo-controlled study (Trial II) in relapsing-remitting Multiple Sclerosis patients that occurred at an incidence of at least $2 \%$ among patients who received COPAXONE and at an incidence that was at least $2 \%$ more than that observed in the same trial for placebo patients regardless of their causal relationship to treatment. No laboratory adverse experiences that met these criteria were reported.

It should be noted that the figures cited in Tabie 4 cannot be used to predict the incidence of side effects during the course of usual medical practice, where patient characteristics and other factors differ from those that prevailed in the clinical trials. However, the cited figures do provide the prescribing physician with some basis for estimating the relative contribution of drug and non-drug factors to the adverse event incidence rate in the population studied. 
TABLE 4

\begin{tabular}{|c|c|c|c|c|}
\hline \multirow[b]{2}{*}{ Adverse Experience } & \multicolumn{2}{|c|}{$\begin{array}{c}\text { COPAXONE }_{n=125} \\
.\end{array}$} & \multicolumn{2}{|c|}{$\begin{array}{c}\text { Placebo } \\
n=126\end{array}$} \\
\hline & n & $\%$ & $n$ & $\%$ \\
\hline $\begin{array}{l}\text { Body as a Whole } \\
\text { Injection Site Pain } \\
\text { Asthenia } \\
\text { Injection Site Erythema } \\
\text { Injection Site Pruritus } \\
\text { Flu syndrome } \\
\text { Injection Site Inflammation } \\
\text { Back pain } \\
\text { Chest pain } \\
\text { Injection Site Mass } \\
\text { Injection Site Induration } \\
\text { Injection Site Welt } \\
\text { Neck pain } \\
\text { Face Edema } \\
\text { Injection Site Urticaria } \\
\text { Injection Site Hemorrhage } \\
\text { Chills } \\
\text { Cyst } \\
\text { Injection Site Reaction } \\
\text { Injection Site Atrophy } \\
\text { Abscess }\end{array}$ & $\begin{array}{l}83 \\
81 \\
73 \\
48 \\
38 \\
35 \\
33 \\
33 \\
33 \\
25 \\
19 \\
16 \\
11 \\
9 \\
8 \\
5 \\
5 \\
4 \\
3 \\
3\end{array}$ & $\begin{array}{l}66.4 \\
64.8 \\
58.4 \\
38.4 \\
30.4 \\
28.0 \\
26.4 \\
26.4 \\
26.4 \\
20.0 \\
15.2 \\
12.8 \\
8.8 \\
7.2 \\
6.4 \\
4.0 \\
4.0 \\
3.2 \\
2.4 \\
2.4\end{array}$ & $\begin{array}{c}46 \\
76 \\
17 \\
17 \\
5 \\
34 \\
9 \\
28 \\
13 \\
10 \\
1 \\
1 \\
5 \\
9 \\
2 \\
0 \\
4 \\
1 \\
1 \\
1 \\
1 \\
0 \\
0\end{array}$ & $\begin{array}{c}36.5 \\
61.9 \\
13.5 \\
4.0 \\
27.0 \\
7.1 \\
22.2 \\
10.3 \\
7.9 \\
0.8 \\
4.0 \\
7.1 \\
1.6 \\
0 \\
3.2 \\
0.8 \\
0.8 \\
0.8 \\
0 \\
0\end{array}$ \\
\hline $\begin{array}{l}\text { Cardiovascular } \\
\text { Vasodilatation } \\
\text { Palpitation } \\
\text { Migraine } \\
\text { Syncope }\end{array}$ & $\begin{array}{c}34 \\
14 \\
9 \\
8 \\
\end{array}$ & $\begin{array}{l}27.2 \\
11.2 \\
7.2 \\
6.4 \\
\end{array}$ & $\begin{array}{c}14 \\
6 \\
5 \\
4 \\
\end{array}$ & $\begin{array}{r} \\
11.1 \\
4.8 \\
4.0 \\
3.2\end{array}$ \\
\hline $\begin{array}{l}\text { Digestive } \\
\text { Nausea } \\
\text { Vomiting } \\
\text { Anorexia } \\
\text { Castroenteritis } \\
\text { Oral Moniliasis } \\
\text { Tooth Caries }\end{array}$ & $\begin{array}{c}29 \\
13 \\
6 \\
6 \\
3 \\
3 \\
\end{array}$ & $\begin{array}{l}23.2 \\
10.4 \\
4.8 \\
4.8 \\
2.4 \\
2.4 \\
\end{array}$ & $\begin{array}{l}22 \\
7 \\
3 \\
2 \\
0 \\
0\end{array}$ & $\begin{array}{c}17.5 \\
5.6 \\
2.4 \\
1.6 \\
0 \\
0\end{array}$ \\
\hline $\begin{array}{l}\text { Hemic and Lymphatic } \\
\text { Lymphadenopathy } \\
\text { Ecchymosis }\end{array}$ & $\begin{array}{l}23 \\
15\end{array}$ & $\begin{array}{l}18.4 \\
12.0\end{array}$ & $\begin{array}{l}12 \\
12\end{array}$ & $\begin{array}{l}9.5 \\
9.5\end{array}$ \\
\hline $\begin{array}{l}\text { Metabolic and Nutritional } \\
\text { Peripheral Edema } \\
\text { Weight gain } \\
\text { Edema }\end{array}$ & $\begin{array}{l}14 \\
7 \\
5\end{array}$ & $\begin{array}{l}11.2 \\
5.6 \\
4.0\end{array}$ & $\begin{array}{l}7 \\
0 \\
1 \\
\end{array}$ & $\begin{array}{c}5.6 \\
0 \\
0.8\end{array}$ \\
\hline $\begin{array}{l}\text { Musculo-Skeletal } \\
\text { Arthralgia }\end{array}$ & 31 & 24.8 & 22 & 17.5 \\
\hline $\begin{array}{l}\text { Nervous System } \\
\text { Hypertonia } \\
\text { Tremor } \\
\text { Agitation } \\
\text { Confusion } \\
\text { Nystagmus } \\
\end{array}$ & $\begin{array}{l}44 \\
14 \\
7 \\
5 \\
5 \\
\end{array}$ & $\begin{array}{l}35.2 \\
11.2 \\
5.6 \\
4.0 \\
4.0 \\
\end{array}$ & $\begin{array}{l}37 \\
37 \\
7 \\
4 \\
1 \\
2\end{array}$ & $\begin{array}{c}29.4 \\
5.6 \\
3.2 \\
0.8 \\
1.6 \\
\end{array}$ \\
\hline $\begin{array}{l}\text { Respiratory } \\
\text { Rhinitis } \\
\text { Dyspnea } \\
\text { Bronchitis }\end{array}$ & $\begin{array}{l}29 \\
23 \\
18\end{array}$ & $\begin{array}{l}23.2 \\
18.4 \\
14.4\end{array}$ & $\begin{array}{c}26 \\
8 \\
12 \\
12\end{array}$ & $\begin{array}{l}20.6 \\
6.4 \\
9.5\end{array}$ \\
\hline $\begin{array}{l}\text { Skin and Appendages } \\
\text { Sweating } \\
\text { Erythema } \\
\text { Skin Disorder } \\
\text { Skin Nodule } \\
\text { Wart }\end{array}$ & $\begin{array}{l}15 \\
8 \\
5 \\
4 \\
3\end{array}$ & $\begin{array}{l}12.0 \\
6.4 \\
4.0 \\
3.2 \\
2.4\end{array}$ & $\begin{array}{l}10 \\
4 \\
2 \\
1 \\
0\end{array}$ & $\begin{array}{c}7.9 \\
3.2 \\
1.6 \\
0.8 \\
0\end{array}$ \\
\hline $\begin{array}{l}\text { Special Senses } \\
\text { Ear Pain } \\
\text { Eye Disorder }\end{array}$ & $\begin{array}{c}15 \\
8\end{array}$ & $\begin{array}{c}12.0 \\
6.4\end{array}$ & $\begin{array}{c}12 \\
1 \\
\end{array}$ & $\begin{array}{l}9.5 \\
0.8\end{array}$ \\
\hline $\begin{array}{l}\text { Urogenital System } \\
\text { Urinary Urgency } \\
\text { Vaginal Moniliasis } \\
\text { Dysmenorhea } \\
\text { Unintended Pregnancy } \\
\text { Impotence }\end{array}$ & $\begin{array}{l}20 \\
16 \\
12 \\
4 \\
3\end{array}$ & $\begin{array}{l}16.0 \\
12.8 \\
9.6 \\
3.2 \\
2.4\end{array}$ & $\begin{array}{l}17 \\
9 \\
9 \\
0 \\
0\end{array}$ & $\begin{array}{c}13.5 \\
7.1 \\
7.1 \\
0 \\
0\end{array}$ \\
\hline
\end{tabular}

Other events which occurred in at least 2\% of patients but were present at equal or greater rates in the placebo group included: Body as a whole: Headache, injection site ecchymosis, accidental injury, abdominal pain, allergic rhinitis and malaise. Digestive System: Dyspepsia, constipation, dysphagia, fecal incontinence, flatulence, nausea and vomiting, gastritis, gingivitis, periodontal abscess, and dry mouth. Musculo-Skeletal: Myasthenia and myalgia. Nervous System: Dizziness, hypesthesia, paresthesia, insomnia, depression, dysesthesia, incoordination, somnolence, abnormal gait, amnesia, emotional lability, Lhermitte's sign, abnormal thinking, twitching, euphoria, and sleep disorder. Respiratory System: Pharyngitis, sinusitis, increased cough and laryngitis. Skin and Appendages: Acne, alopecia, and nail disorder. Special Senses: Abnormal vision, diplopia, amblyopia, eye pain, conjunctivitis, tinnitus, taste perversion, and deafness. Urogenital System: Urinary tract infection, urinary frequency, urinary incontinence, urinary retention, dysuria, cystitis, metrorrhagia, breast pain, and vaginitis. Data on adverse events occurring in the controlled clinical trials were analyzed to evaluate gender related differences. No clinically significant differences were identified. In these clinical trials $92 \%$ of patients were Caucasian, which is representative of the population of patients with Multiple Sclerosis. In addition, the vast majority of patients treated with COPAXONEs were
between the ages of 18 and 45 . Consequently, inadequate data are available to perform an analysis of the incidence of adverse events related to clinically relevant age subgroups.

Laboratory analyses were performed on all patients participating in the clinical program for COPAXONE. Clinically significant

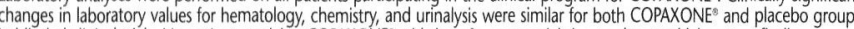
in blinded clinical trials. No patient receiving COPAXONE

Other Adverse Events Observed During All Clinical Trials

COPAXONE" has been administered to approximately 900 individuals during clinical trials, only some of which were placebocontrolled. During these trials, all adverse events were recorded by clinical investigators using terminology of their own choosing. To provide a meaningful estimate of the proportion of individuals having adverse events, similar types of events were grouped into a smaller number of standardized categories using COSTART II dictionary terminology. All reported events that occurred at least twice and potentially important events occurring once, are included except those already listed in the previous
table, those too general to be informative, trivial events, and other events which occurred in at least $2 \%$ of treated patients and were present at equal or greater rates in the placebo group

Events are further classified within body system categories and enumerated in order of decreasing frequency using the following definitions: Frequent adverse events are defined as those occurring in at least 1/100 patients; infrequent adverse events are those occurring in 1/100 to 1/1000 patients. Body as a whole: Frequent: Injection site edema, injection site atrophy, abscess and injection site hypersensitivity. Infrequent: Injection site hematoma, injection site fibrosis, moon face, cellultis, generalized edema, hernia, injection site abscess, serum sickness, suicide attempt, injection site hypertrophy, injection site melanosis, lipoma and photosensitivity reaction. Cardiovascular: Frequent: Hypertension. Infrequent: Hypotension, midsystolic click, systolic murmur, atrial fibrillation, bradycardia, fourth heart sound, postural hypotension and varicose veins. Digestive: Infrequent: Dry mouth, stomatitis, burning sensation on tongue, cholecystitis, colitis, esophageal uker, esophagitis, gastrointestinal carcinoma, gum hemorrhage, hepatomegaly, increased appetite, melena, mouth ulceration, pancreas disorder, pancreatitis, rectal hemorrhage, tenesmus, tongue discolouration and duodenal ulcer. Endocrine: Intrequent: Coiter, hyperthyroidism, and hypothyroidism. Gastrointestinal: Frequent: Bowel urgency, oral moniliasis, salivary gland enlargement, tooth caries, and ulcerative stomatitis. Hemic and Lymphatic: Infrequent: Leukopenia, anemia, cyanosis, eosinophilia, hemateme sis, lymphedema, pancytopenia, and splenomegaly. Metabolic and Nutritional: Infrequent: Weight loss, alcohol intolerance, Cushing's syndrome, gout, abnormal healing, and xanthoma. Musculoskeletal: Infrequent: Arthritis, muscle atrophy, bone pain, bursitis, kidney pain, muscle disorder, myopathy, osteomyelitis, tendon pain, and tenosynovitis. Nervous: Frequent: Abnormal dreams, emotional lability, and stupor. Infrequent: Apnasia, ataxia, convulsion, circumoral paresthesia, depersonalization, halucinations, hostility, hypokinesia, coma, concentration disorder, tacial paralysis, decreased libido, manic reac.
tion, memory impairment, myoclonus, neuralgia, paranoid reaction, paraplegia, psychotic depression and transient stupor.
Respiratory: Frequent: Hyperventilation, hay-fever. Infrequent: Asthma, pneumonia, epistaxis, hypoventilation, and voice alteration. Skin and Appendages: Frequent: Eczema, herpes zoster, pustular rash, skin atrophy and warts. Infrequent: Dry skin, skin hypertrophy, dermatitis, furunculosis, psoriasis, angioedema, contact dermatitis, erythema nodosum, fungal dermatitis, maculopapular rash, pigmentation, benign skin neoplasm, skin carcinoma, skin striae, and vesiculobullous rash. Special Senses: Frequent: Visual field defect. Infrequent: Dry eyes, otitis externa, ptosis, cataract, corneal ulcer, mydriasis, optic neuritis, photophobia, and taste loss. Urogenital: Frequent: Amenorrhea, hematuria, impotence, menorrhagia, suspicious Papanicolaou smear, urinary frequency and vaginal hemorrhage. Infrequent: Vaginitis, flank pain (kidney), abortion, breast engorgement, breast enlargement, breast pain, carcinoma cervix in situ, fibrocystic breast, kidney calculus, nocturia, ovarian

\section{Adverse Events Reported Post-Marketing and Not Previously Noted in Clinical Trials}

Post-marketing experience has shown an adverse event profile similar to that presented above. Reports of adverse reactions occurring under treatment with COPAXONE" (glatiramer acetate for injection) not mentioned above, that have been received since market introduction and that may have or not have causal relationship to the drug include the following: Body as a whole: Sepsis, LE syndrome, hydrocephalus, enlarged abdomen, injection site hypersensitivity, allergic reaction anaphylactoid reaction, bacteria infection, ever, infection. Cardiovascular: Thrombosis, peripheral vascular disease, pericardial effusion, myocardial infarct, deep thrombophlebitis, coronary occlusion, congestive heart failure, cardiomyopathy cardiomegaly, arrhythmia, angina pectoris, tachycardia. Digestive: Tongue edema, stomach ulcer hemorrhage, liver function abnormality, liver damage, hepatitis, eructation, cirhosis of the liver, choleilthiasis, diarrhea, gastrointestinal disorder Hemic and Lymphatic: Thrombocytopenia, Iymphoma-like reaction, acute leukemia. Metabolic and Nutritional: Hypercholesteremia. Musculoskeletal: Rheumatoid arthritis, generalized spasm. Nervous: Myelitis, meningitis, CNS neoplasm, cerebrovascular accident, brain edema, abnormal dreams, aphasia, convulsion, neuralgia, anxiety, foot drop, nervousness, speech disorder, vertigo. Respiratory: Pulmonary embolus, pleural effusion, carcinoma of lung, hay fever, laryngismus. Skin and Appendages: Herpes simplex, pruritis, rash, urticaria. Special Senses: Claucoma, blindness, visual field defect. Urogenital: Urogenital neoplasm, urine abnormality, ovarian carcinoma, nephrosis, kidney failure, breast carcinoma, bladder carcinoma, urinary frequency.
SYMPTOMS AND TREATMENT OF OVERDOSAGE

Overdose with COPAXONE" has been reported in three patients. One patient injected four doses ( $80 \mathrm{mg}$ total) of COPAXONE at once. No sequelae were noted. Two other patients, a 28 -year old male and a 37 -year old female, were given 3 injections of $20 \mathrm{mg}$ of COPAXONE* at one half hour intervals by error. Neither patient evidenced any change in blood pressure, heart rate, or temperature. Telephone follow-up seve

DOSACE AND ADMINISTRATION
COPAXONE should only be prescribed by (or following consultation with) clinicians who are experienced in the diagnosis and man-

The recommended dose of COPAXONE" (glatiramer acetate for injection or glatiramer acetate injection) for the treatment of relapsing-remitting MS is a daily injection of $20 \mathrm{mg}$ given subcutaneously.

Instructions for Use: To reconstitute lyophilized COPAXONE* for injection, use a sterile syringe and adapter to transfer $1.1 \mathrm{~mL}$ of the diluent supplied, Sterile Water for Injection, into the COPAXONE "vial. Gently swir the vial of COPAXONE" and let stand at room temperature until the solid material is completely dissolved. Inspect the reconstituted product visually and discard or return the product to the pharmacist before use if it contains particulate matter. Use within 8 hours after reconstitution. Withdraw $1.0 \mathrm{~mL}$ of the solution into a sterile syringe. Remove the adapter, connect a 27 -gauge needle and inject the solution
subcutaneously. Sites for self-injection include arms, stomach (abdomen), buttocks, and thighs. A vial is suitable for single use subcutaneously. Sites for self-injection include arms, stomach (abdomen), buttocks, and thighs. A vial is suitable
only; unused portions should be discarded (see INFORMATION FOR THE PATIENT: Reconstituted product).

only; unused portions should be discarded (see INFORMATION FOR THE PATIENT: Reconstituted product).
For the pre-filled syringe of COPAXONE", please see the INFORMATION FOR THE PATIENT: pre-filled syringe for For the pre-illed syringe of COPAXONE", please see the
instructions on the preparation and injection of COPAXONE

\section{instructions on the preparation and in}

\section{Drug Substance:}

Clatiramer acetate

Chemical Name: Clatiramer acetate is the acetate salt of synthetic polypeptides.

Description: Glatiramer acetate is prepared by chemically reacting the activated derivatives of four amino acids: L-glutamic acid (L-Clu), L-alanine (L-Ala), L-tyrosine (L-Tyr), and L-lysine (L-Lys) in a specified ratio. The molar fraction of each amino acid residue ranges as follows: L-Clu 0.129-0.153, L-Ala 0.392-0.462, L-Tyr 0.086-0.100 and L-Lys $0.300-0.374$.

Molecular Weight: The average molecular weight of the polypeptide is between 4,700 and 11,000 daltons, with at least 68 Molecular Weight: The average molecular weight of the polypeptide is between 4,700 and

Physical Form: White to slightly yellowish lyophilized material.

Solubility: $\quad$ Sparingly soluble in water, insoluble in acetone.

Composition: COPAXONE ${ }^{\circ}$ (glatiramer acetate for injection) is a sterile, ilyophilized drug product, intended for subcutaneous injection following reconstitution with Sterile Water for Iniection. Each vial of lyophilized drug product contains $20 \mathrm{mg}$ injection following reconstitution with Sterile Water for Injection. Each vial of lyophilized drug product contains $20 \mathrm{mg}$ Water for Injection contains $1.1 \mathrm{~mL}$ of Sterile Water for Injection plus a $0.35 \mathrm{~mL}$ overage to allow for losses in reconstitution and transfer.

COPAXONE" (glatiramer acetate iniection) is a single-use $20 \mathrm{mg} / 1.0 \mathrm{~mL}$ pre-filled syringe containing a sterile solution equivalent with the COPAXONE' reconstituted solution (i.e., $20 \mathrm{mg} / \mathrm{mL}$ glatiramer acetate and $40 \mathrm{mg}$ mannitol in sterile water for iniection) Stability and Storage Recommendations: Vials of lyophilized COPAXONE" should be stored under refrigeration $\left(2^{\circ}-8^{\circ} \mathrm{C}\right)$. COPAXONE may also be stored at room temperature $\left(15^{\circ}-30^{\circ} \mathrm{C}\right.$ ) for up to 14 days. The vials of diluent (Sterile Water for InAX may also be stored at room temperatre

The pre-filled syringes of COPAXONE FREEZE. If you cannot have refrigerator storage, pre-filled syringes of COPAXONE ${ }^{B}$ can be stored at room temperature FREEZE. If you cannot have refrigerator storage, pre-filled syringes of COPAXONE ${ }^{8}$ can be stored at room temperature
$\left(15^{\circ}-30^{\circ} \mathrm{C}\right)$ for up to one week. Do not store pre-filled syringes at room temperature for longer than one week. Note: this drug is light sensitive, do not expose to light when not iniecting. Each pre-filled syringe is for single use only.

Reconstituted Solutions: To reconstitute lyophilized COPAXONE', prior to iniection, use a sterile syringe and adapter to Reconstituted Solutions:
transfer the diluent supplied, Sterile Water for Injection, into the COPAXONE let stand at room temperature until the solid material is completely dissolved. Inspect the reconstituted product visually and discard or return the product to the pharmacist if it contains particulate matter. Soon after the product is completely dissolved withdraw $1.0 \mathrm{~mL}$ of the solution into a sterile syringe. Remove the adapter, connect a 27-gauge needle and inject the solution subcutaneously. A vial is suitable for single use only; unused portions should be discarded. The reconstituted solution should not be left

Parenteral Products: COPAXONE's should be reconstituted only with the provided diluent, Sterile Water for Injection.

\begin{tabular}{|c|c|c|c|}
\hline Vial Size & $\begin{array}{c}\text { Volume of Diluent } \\
\text { to be Added }\end{array}$ & $\begin{array}{c}\text { Volume to be } \\
\text { Injected }\end{array}$ & $\begin{array}{c}\text { Nominal } \\
\text { Concentration per } \mathrm{mL}\end{array}$ \\
\hline $2 \mathrm{~mL}$ & $1.1 \mathrm{~mL}$ & $1.0 \mathrm{~mL}$ & $20 \mathrm{mg}$ \\
\hline
\end{tabular}

\section{AVAILABIUTY OF DOSAGE FORM}

COPAXONE (glatiramer acetate for injection) is supplied as a $20 \mathrm{mg}$ dose of sterile lyophilized glatiramer acetate with mannitol, packaged in single use $2 \mathrm{~mL}$ amber vials. A separate vial, containing $1.1 \mathrm{~mL}$ of diluent (Sterile Water for Injection) plus $0.35 \mathrm{~mL}$ of overage of diluent is included in the Self Injection Administration Package for each vial of drug. COPAXONE glatiramer acetate for injection) is available in packs of 32 amber vials of sterile lyophilized material for subcutaneous injection.
The diluent (Sterile Water for Iniection) for COPAXONE" is supplied in packs of 32 clear vials and is located in the Self lnjection Adme diluent (Sterile Water

Administration Package.
COPAXONE" (glatiramer acetate injection) is a single-use $20 \mathrm{mg} / 1.0 \mathrm{~mL}$ pre-filled syringe containing a sterile solution equivalent COPAXONE
with the COPAatiramer acetate injection) is a single-use $20 \mathrm{mg} / 1.0 \mathrm{~mL}$ pre-filled syringe containing a sterile solution equivalent
(n) reconstituted solution (i.e., $20 \mathrm{mg} / \mathrm{mL}$ glatiramer acetate and $40 \mathrm{mg}$ mannitol in sterile water for with the COPAXONE
injection). COPAXONE (glatiramer acetate injection) is available in packs of 30 single-use $20 \mathrm{mg} / 1.0 \mathrm{~mL}$ pre-filled glass syringes
with 33 alcohol preps (swabs).

\section{REFERENCES}

1. COPAXONE* (glatiramer acetate) Product Monograph, Teva Neuroscience

Product monograph available upon request.

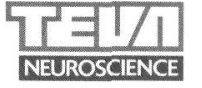

Teva Neuroscience

999 de Maisonneuve West, Suite 550

$\overparen{\overparen{P A B}}$ 


\section{COPAXONE (acétate de glatiramère injectable)}

$20 \mathrm{mg}$, flacons unidoses et $20 \mathrm{mg} / 1,0 \mathrm{~mL}$, seringues préremplies pour injection sous-cutanée CLASSIFICATION THÉRAPEUTIQUE Immunomodulateu

ACTION ET PHARMACOLOGIE CLINIQUE

COPAXONE [acétate de glatiramère pour injection (connu auparavant sous le nom de copolymère1)] es un mélange lyophilise sterile de polypeptides synthétiques renfermant quatre acides amines naturels : I'acide L-glutamique, la L-alanine, la L-tyrosine et

de 0,427 , de 0,095 et de 0,338 , respectivement. Le mode daction de l'effet de l'acétate de glatiramère dans la sclérose en plaques (SEP) n'est pas encore complètement élucidé. On croit cependant que l'acétate de glatiramère exercerait un effet modulateur sur les processus imm que l'on associe actuellement a la pathogenèse de la SEP. Cette hypothèse est étayée mentale (EAE), affection qui peut être déclenchée chez plusieurs espèces animales et qui est généralement mentaie (EAE), allection qui peut etre declenchee che

les études expérimentales sur animaux et les systèmes in vitro laissent supposer que l'administration de l'acétate de glatiramère induit et active des lymphocytes $T$ suppresseurs spécifiques dans cang periphérique.

comsche le l'acétate de glatiramère n'est pas encore complètement élucidé, il est Charma

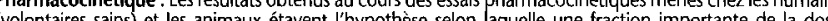
thérapeutique délivrée au patient par voie sous-cutanée est hydrolysée localement. Neanmoins, de grands fragments d'acêtate de glatiramère peuvent être reconnus par les anticorps réactifs contre l'acétate de glatiramère. Une certaine proportion de la dose injectée, intacte ou partiellement hydrolysée, passerait régionaux, de plus, il est possible qưune partie du produit intact passe dans la circulation générale Essais cliniques : Leeficacité de COPAXONE (acétate de glatiramere pour injection) a été evaluee dans essai comparatif (avec placebo) a évalue les effets de l'acétate de glatiramère sur les paramètres IRM. Dan ces essais, on a eu recours à une dose de $20 \mathrm{mg}$ /jour. Aucune autre dose ou schéma posologique n'ont été cétudiés dans des essais comparatifs (avec placebo) sur la SEP rémittente.

Le premier essai Essai I (Essai BR-1) était un essai pilote comparatif (avec placebo) à répartition aléatoire en paires appariées, à groupes parallèles et à double insu qui a été mené dans un seul centre $e^{15}$. Cinquante patients atteints de SEP rémittente ont reçu, au hasard, $20 \mathrm{mg}$ /jour d'acétate de glatiramère $(n=25)$ ou un placebo $(n=25)$ par voie sous-cutanée. Selon le protocole, le paramétre primaire de l'essai consistait en la proportion de patients exempts de poussee pendant les deux ańs de l'essai. Deux autres résultats pertinents la variation de la fréquence des poussées par comparaison à la fréquence des poussées pendant les deux années précédant l'entrée à l'essai. Les résultats de cet essai (tableau 1) démontrent que l'acétate de glatiramère exercait un effet statistiquement significatif sur le nombre de poussées.

TABLEAU 1 - Essai BR-1 : résultats quant à l'efficacité

\begin{tabular}{|c|c|c|c|}
\hline Résultats & \multicolumn{3}{|c|}{ Essai I" } \\
\hline & $\begin{array}{c}\text { Acétate de glatiramère } \\
n=25\end{array}$ & $\begin{array}{c}\text { Placebo } \\
n=25\end{array}$ & Valeur de $p$ \\
\hline$\%$ de patients exempts de poussée & $14 / 25(56 \%)$ & $7 / 25(28 \%)$ & 0,085 \\
\hline Fréquence moyenne des pousssées & $0,6 / 2$ ans & $2,4 / 2$ ans & 0,005 \\
\hline $\begin{array}{l}\text { Réduction de la tréquence des poussées } \\
\text { comparativement aux données avant l'essai }\end{array}$ & 3,2 & 1,6 & 0,025 \\
\hline Délai médian avant la première poussée (jours) & $>700$ & 150 & 0,03 \\
\hline$\%$ de patients exempts de progression* & $20 / 25(80 \%)$ & $13 / 25(52 \%)$ & 0,07 \\
\hline
\end{tabular}

Le paramètre primaire de l'efficacité de l'Essai I consistait en la proportion de patients exempts de poussée pendant les deux ans de l'essai (\% de patients exempts de poussée). Les analyses portaient sur l'ensemble des sujets retenus au début de l'essal.

progression se définissait comme une augme

L'Essai ll (01-9001) était un essai comparatif (avec placebo), multicentrique, à double insu et à répartition léatoire. Deux cent cinquante et un patients atteints de SEP rémittente ont reçu, au hasard, $20 \mathrm{mg} / \mathrm{jou}$ lacétate glatiamere $n=125$ ) ou un placebo $(n=126)$ par voie sous-cutanee Pousse poussen pendant les deux annes précécant inmediatement lentree à lessal. Les patients devaient

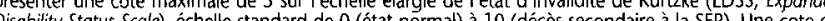

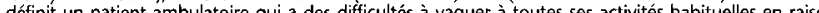
d'une invaliditée . une cote de 6 définit un patient ambulatoire qui a besoin d'aide pour vaquer à ses orcupations, tandis qu'une cote de 7 signifie que le sujet est confiné à un fauteuil roulant.

les patients ont été examinés tous les trois mois pendant deux ans ainsi que dans les quelques jours Les patients ont éte examines tous les trois mols pendant deux ans ainsi que dans les quelques jouns traitement reçu et qui devait noter la présence de signes neurologiques objectifs ainsi que d'autres critères (p. ex la persistance de la lésion pendant au moins 48 heures).

Le protocole précisait que le paramètre primaire de l'essai était le nombre moyen de poussées pendant e traitement. 2 présente les résultats de l'analyse du paramètre primaire et de plusieurs paramètres secondaires de l'Essai II à deux ans, analyse portant sur l'ensemble des sujets retenus au début de l'essai.

\begin{tabular}{|l|c|c|c|}
\hline \multicolumn{2}{|c|}{ RABLésultats } & \multicolumn{3}{c|}{ Essai II } \\
\hline & $\begin{array}{c}\text { Acétate de glatiramère } \\
\mathbf{n = 1 2 5}\end{array}$ & $\begin{array}{c}\text { Placebo } \\
\mathbf{n = 1 2 6}\end{array}$ & Valeur de $\mathbf{p}$ \\
\hline Nombre moyen de pourssées (2 ans) & 1,19 & 1,68 & 0,055 \\
\hline$\%$ de patients exempts de poussée & $42 / 125(34 \%)$ & $34 / 126(27 \%)$ & 0,25 \\
\hline Délai médian avant la première poussée (jours) & $\mathbf{2 8 7}$ & 198 & 0,23 \\
\hline$\%$ de patients exempts de progression & $98 / 125(78 \%)$ & $95 / 126(75 \%)$ & 0,48 \\
\hline Variation moyenne de la cote EDSS & $-0,05$ & $+0,27$ & 0,023 \\
\hline
\end{tabular}

Les analyses portaient sur l'ensemble des sujets retenus au début de l'essai.

Moyenne ajustée de départ

La progression se définissait comme une augmenta

"La progression se définissait comme une augmenta

persistant pendant au moins trois mois consécutifs.

Les deux essais ont révélé que l'acétate de glatiramère avait un effet bénéfique sur la fréquence des poussées; on considère donc que l'acétate de glatiramère est un produit efficace à cet égard.

Le troisième essai (9003) était un essai multicentrique, multinational, avec surveillance IRM. Au total, 239 patients atteints de SEP rémittente (119 traités par l'acétate de glatiramère et 120 par un placebo) ont été répartis au hasard. Les critères d'inclusion étaient similaires à ceux de l'Essai II (Essai 01-9001) avec en plus le critère selon lequel les patients devaient presenter au moins une iésion rehaussee par le Gd à 'examen IRM de sélection. Les patients ont été d'abord traités à double insu pendant neuf mois, au cours desquels ils ont subi des examens IRM mensuels. Le paramètre primaire de la phase à double insu était le nombre cumulatí total dé lésions rehaussées par le Gd en pondération Tl pendant les neuf mois. $D^{\prime}$ autres paramètres IRM ont
été évalués à titre de paramètres secondaires. Le tableau 3 résume les résultats obtenus pour les paramètres surveillés pendant la phase à double insu de neuf mois pour l'ensemble des sujets retenus au début de l'essai. Compte tenu que le lien entre les résultats IRM et l'état clinique du patient fait l'objet d'une discussion, on ignore la valeur pronostique des résultats statistiquement significatifs suivants.

\begin{tabular}{|c|c|c|c|c|}
\hline $\mathbf{N}^{\circ}$ & Résultats & $\begin{array}{c}\text { Acétate de } \\
\text { glatiramère } n=113\end{array}$ & $\begin{array}{c}\text { Placebo } \\
n=115\end{array}$ & $\begin{array}{l}\text { Valeur } \\
\text { de } p\end{array}$ \\
\hline \multicolumn{5}{|c|}{ Paramètre primaire } \\
\hline$\overline{1}$. & $\begin{array}{l}\text { Médianes du nombre cumulatif de lésions } \\
\text { rehaussées par le Gd en } T 1\end{array}$ & 12 & 17 & 0,0037 \\
\hline \multicolumn{5}{|c|}{ Paramètres secondaires } \\
\hline 2. & $\begin{array}{l}\text { Médianes du nombre cumulatif de nouvelles } \\
\text { lésions rehaussées par le Gd en Tl }\end{array}$ & 9 & 14 & 0,0347 \\
\hline 3. & Médianes du nombre cumulatif de nouvelles lésions en $\mathrm{T2}$ & 5 & 8 & 0,01 \\
\hline 4. & $\begin{array}{l}\text { Médianes de la variation cumulative par rapport aux valeurs de } \\
\text { départ du volume (mL) des lésions rehaussées par ie } G d \text { en } T 1\end{array}$ & $-0,309$ & 0 & 0,0248 \\
\hline 5 . & $\begin{array}{l}\text { Médianes de la variation cumulative par rapport aux } \\
\text { valeurs de départ du volume (mL) des lésions en } T 2\end{array}$ & 8,852 & 13,566 & 0,0229 \\
\hline 6. & $\begin{array}{l}\text { Médianes de la variation cumulative par rapport aux valeurs } \\
\text { de départ du volume }(\mathrm{m} L \text { ) des lésions hypo-intenses en } \mathrm{Tl}\end{array}$ & 1,642 & 1,829 & 0,7311 \\
\hline 7. & Proportion de patients exempts de lésion rehatssáe par le Gd en T1 & $46,4 \%$ & $32,2 \%$ & 0,0653 \\
\hline
\end{tabular}

Le nombre moyen de poussées au cours de cet
et de 0,77 pour le groupe placebo $(p=0,0077)$.

INDICATIONS ET UTILISATION CLINIQUE Pour utilisation chez les patients ambulatoires atteints de sclérose en plaques rémittente en vue de réduire la fréquence des poussées.

L'innocuité et l'efficacité de COPAXONE ${ }^{*}$ dans la sclérose en plaques chronique progressive n'ont pas

CONTRE-INDICATIONS COPAXONE' (acétate de glatiramère pour iniection) est contre-indiqué chez patients présentant une hypersensibilité avérée à l'acétate de glatiramère ou au mannitol.

MISES EN CARDE La seule voie d'administration recommandée de COPAXONE* (acétate de glatiramère pou injection) est la voie sous-cutanée. COPAXONE ${ }^{\Im}$ ne doit pas être administré par voie intraveineuse. Symptômes

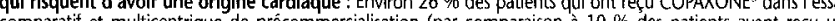
placebo) ont subi au moins un épisode de ce qui a été décrit comme une douleur thoracique transitoire (voir EFFETS INDÉSIRABLES: Douleur thoracique). Seulement certains de ces épisodes sont survenus dans le cadre de la réaction apparaissant immédiatement après l'injection (voir EFFETS INDÉSIRABLES : Réaction suivant l'injection), Aucune surveillance de l'ECG n'a été réalisée pendant l'un de ces épisodes, et la pathogenèse de Ce symptôme demeure inconnue. Comme les patients des essais comparatifs ne présentaient pas de troubles cardiovasculaires significatifs (classe I ou II selon la New York Heart Association), on ignore les risques que courent les patients qui souffrent d'une atteinte cardiovasculaire et qui reçoivent COPAXONE $E^{x}$ dans le traitement de la sclérose en plaques.

L'administration de COPAXONE" a été associée à une réaction suivant l'injection consistant en un ensemble de congestives, la douleur thoracique, les palpitations, l'anxiété, la dyspnée, la constriction de la gorge et l'urticaire Congestives, la douleur thoracique, les palpitations, lanxiete,
(voir EFFETS INDESSIRABLES : Réaction suivant l'injection).

COPAXONE ${ }^{g}$ 'a pas été étudié chez des sujets présentant des antécédents de réactions anaphylactoïdes graves, de bronchopneumopathie chronique obstructive ou d'asthme ni chez des patients qui reçoivent des médicaments dans le traitememt de 'une de ces deux dernieres affections. Itients.

De rares cas de réactions anaphylactö́des $(<1 / 1000)$ ont été rapportés en association avec l'utilisation de COPAXONE au cours de la période de postcommercialisation. Certains cas ont nécessité un traitement par PRÉCAUTIONS Cénérales: Les patients doñoprie.

PRECAUTIONS Generales : Les patients doivent connaitre les techniques de reconstitution et d'auto-injection respectant l'asepsie de sorté que COPAXONE's (acétate de glatiramère pour injection) soit administré de façon
sûre (voir INFORMATION Â L'INTENTION DU PATIENT). La première injection doit être effectuée sous la supervision d'un professionnel de la santé qualifié. II convient de vérifier périodiquement si les patients comprennent Vision d'un professionnel de la santé qualifié. II convient de verifier periodiquement si les patients comprennent tiliser les aiguilles et les seringues et leur expliquer les procédures de mise au rebut appropriées. Les patients doivent jeter les aiguilles et les seringues utilisées dans un contenant non perforable. On doit en outre expliquer doivent jeter les aiguiles et les seringues utilisees dans un contenant non perforable. On

Considérations en matière d'utilisation d'un produit capable de modifier les réactions immunitaires : COPAXONE ${ }^{3}$ étant une substance antigénique, son utilisation risque de déterminer des réaction délétères pour l'hôte. On ignore en outre si COPAXONE ${ }^{\oplus}$ peut modifier les réactions immunitaires
normales de l'être humain, comme la reconnaissance des antigènes étrangers. Il est donc possible que le normales de l'être humain, comme la reconnaissance des antigenes étrangers. Il est donc possible que le
traitement par COPAXONE traitement par COPAXONE
ainsi que les mécanismese aitérer les mécanismes de défense de l'organisme contre les infections des tumeurs. Aucune évaluation systématique de ces risques $n^{\prime} a$ ainsi que les mécanismes de surveillance des tumeurs. Aucune évaluation systématique de ces risques n'a l'acétate de glatiramere pourrait entraíner des effets indésirables.

Des anticorps réactifs contre l'acétate de glatiramère sont formés chez presque tous les patients exposés au traitement quotidien avec la dose recommandee. Selon des essais menés chez le rat et le singe, des complexes immun se déposent dans les glomérules rénaux. De plus, dans un essai comparatif portant sur 125 patients atteints de des taux au moins trois fois plus êlevés que les taux de départ chez $80 \%$ des patients trois mois après le début du traitement. Après 12 mois de traitement, cependant, $30 \%$ des patients avaient toujours des taux $\mathrm{d}^{\prime} \operatorname{lgC}$ au moins trois fois plus élevés que les taux de départ et $90 \%$ avaient des taux plus élevés que les taux de départ après 12 mois. Les anticorps sont uniquement de sous-type igG, et surtout de sous-type lgG-1. Aucun anticorps de apres lgE n'á été détecté chez aucun des 94 sérums testés. Néanmoins, compte tenu que l'anaphylaxie peut ètre
tyssociee à l'administration de presque toutes les substances étrangères, ce risque ne peut être exclu.

Des essais précliniques visant à évaluer le potentiel carcinogène de l'acétate de glatiramère chez la souris et le rat n'ont fait ressortir aucun signe de potentiel carcinogène associé á l'administration sous-cutanée de l'acétate de glatiramère des doses allant jusqu'à $30 \mathrm{mg} / \mathrm{kg} /$ jour chez le rat et jusqu'à $60 \mathrm{mg} / \mathrm{kg} / \mathrm{jour}$ chez la souris (voir TOXICOLOCIE
Potentiel carcinogène). On ignore si ces résultats sont extrapolables à thumain (voir PRECAUTIONS : Considérations en matière d'utilisation d'un produit capable de modifier les réactions immunitaires).

Interactions médicamenteuses : Les interactions médicamenteuses entre COPAXONE ${ }^{n}$ et d'autres produits Interactions médicamenteuses : Les interactions médicamenteuses entre COPAXONE ${ }^{*}$ et d'autres produits
$n^{\prime}$ 'ont pas fait l'objet d'une évaluation complète. Les résultats des essais cliniques à ce jour ne font pas ressortir n'ont pas fait l'objet d'une évaluation complète. Les résultats des essais cliniques à ce jour ne font pas ressortir
$d^{\prime}$ 'interaction significative entre COPAXONE d'interaction significative entre COPAXONE et les traitements habituels de la SEP, y compris l'administration
concomitânte de corticostéroïdes pendant un maximum de 28 jours. COPAXONE ${ }^{\circ} n^{\prime}$ a pas été évalué de façon formelle en association à l'interféron bêta. En revanche, 246 patients chez lesquels le traitement par l'interféron cadre d'un essai clinique ouvert n'ont pas signalé l'apparition d'effets indésirables graves ou inattendus pouvant être liés au traitement.

Grossesse : Aucun essai comparatif rigoureux portant sur des femmes enceintes n'a été réalisé. Les essais prédériquente et tératologie). Etant donne que les essais de reproduction chez les animaux ne permettent pas toujours de
prévoir les effets d'un produit chez l'être humain, ce médicament ne doit etre administré pendant la grossesse que si son utilité a été clairement établie. Dans le cadre des essais cliniques de précommercialisation portant sur fommes a été perdue de vue pendant le suivi , trois femmest le traitement par le produit actif. L'une de ces autres ont cessé de prendre le produit un mois, un mois et demi et deux mois après avoir découvert qu'elles étaient enceintes. Ces trois femmes ont donné naissance à des enfants en bonne santé.

Allaitement : On ignore si le produit passe dans le lait maternel. Étant donné qu'un grand nombre de médicaments passent effective produt pase dins le liit madme femme qui allaite ne doit etre envisagee qu apres une evaluation soigneuse du rapport risques-avantages, et le produit doit être utilisé avec prudence.

Enfants : L'innocuité et l'efficacité de COPAXONE' n'ont pas été établies chez les sujets de moins de 18 ans.

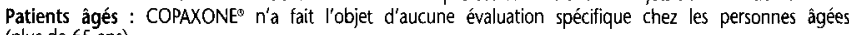

Insuffisants rénaux : Les paramètres pharmacocinétiques de COPAXONE" n'ont pas été déterminés chez les EFFETS INDÉSIRABLES AU COUS des Es:

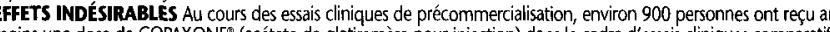
ou non. L'exposition totale des patients à COPAXONE au cours d'essais cliniques s'échelonne de six mois $(693$ patients) à deux ans ( 306 patients), et à plus de sept ans ( 69 patients) à raison d'une dose quotidienne de $20 \mathrm{mg}$. Au cours des essais comparatifs, les effets indésirables le plus fréquemment associés à l'utilisation de COPAXONE" et dont l'incidence était supérieure à celle qui a été observée chez les sujets qui recevaient le placebo étaient les
suivants : réactions au point d'injection, vasodilatation, douleur thoracique, asthénie, infection, douleur, nausées, 
arthralgie, anxiété et hypertonie.

Sur un total de 844 patients qui pouvaient faire l'objet d'une évaluation de l'innocuité du produit, environ $8 \%$ des sujets ont abandonne le traitement en raison d'effets indésirables. Les effets indésirables le plus fréquemment associés à 'abandon du traitement étaient les suivants : réactions au point d'injection $(6,5 \%)$, vasodilatation, grossesse accidentelle, depression, dyspnée, urticaire, tachycardie, étourdissements et tremblement. Au nombre des effets I'administration de COPAXONEE, on compte un cas de maladie du sérum ayant menacé la survie du patient. Réaction sulvant I'Injection : Environ $10 \%$ des patients atteints de sclérose en plaques qui ont reçu COPAXONE ${ }^{\mathrm{E}}$ dans le cadre des essais précédant la commercialisation du produit ont signalé une réaction apparaissán immédiatement après l'injection sous-cutanée de COPAXONE', Les symptômes ressentis pouvaient comprendre les bouffées congestives, la douleur thoracique, les palpitations, l'anxiéte, la dyspnée, la constriction de la gorge et l'urticaire. Ces symptómes étaient toujours transitoires et spontanément résolutifiss et n'exigeaient pas de traitement particulier. Ils survenaient en général plusieurs mois après Y'etablissement du traitement et parfois plus tôt. Un patient particulier pouvait subir un seul ou plusieurs de ces épisodes pendant son traitement par COPAXONE.' On ne sait pas
si ces épisodes sont liés à des mécanismes immunologiques ou non, ni si plusieurs épisodes semblables survenant chez si ces épisodes sont liés à des mécanismes immunologiques ou non, ni si plusieurs épisodes semblables survenant chez un même patient relèvent de mécanismes identiques. En fait, on ignore si cet ensemble de symptômes représente
veritablement un syndrome spécifique. Au cours de la période de postcommercialisation, des patients ont signalé avoir veritablement un syndrome spécifique. Au cours de la période de postcommercialisation, des par
subi des symptômes similaires et reçu des soins médicaux d'urgence (voir MISES EN GARDE)

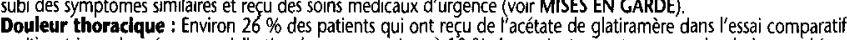
multicentriarique : Environ $26 \%$ des patients qui ont reçu de (acélate de glatiramere dans l'essai comparati multicentrique de précommercialisation (par comparaison à $10 \%$ des patients ayant reçu un placebo) ont subi au moins un épisode de ce qui a ete decrit comme une douleur thoracique transitoire, Seulement certains de ces episodes sont survenus dans le cadre de la reaction apparaissant immediatement apres l'injection decrite dans paragraphe précedent. Lellen temporel entre la douleur thoracique et minjection d acetate de glatiramere $n$ etait pas souvent seule et ne semblait pas laisser d'importantes séquelles cliniques. Aucune surveillance de l' l'ECC n'a ét réalisée pendant l'un de ces épisodes. Certains patients ont subi plus d'un épisode de douleur thoracique, et ces épisodes commençaient à apparaître, en règle générale, au moins un mois après l'établissement du traitement. La pathogenèse de ce symptôme demeure inconnue. Il y a eu un seul épisode de douleur thoracique au cours duquel
un EC complet a été effectué; l'ECG n'a révélé aucun signe d'ischémie. Comme les patients des essais cliniques ne
présentaient pas de troubles cardiovasculaires significatifs (classe I ou ll selon la New York Heart Association) on ignore présentaient pas de troubles cardiovasculaires significatifs (classe I ou II selon la New York Heart Association), on ignore les risques que courent les patients qui souffrent d'une atteinte cardiovasculaire et qui recoivent l'acétate de
glatiramère dans le traitement de la sclérose en plaques (voir MISES EN GARDE : Symptomes qui risquent d'avoir glatiramère dans le traiteme origine cardiaque).

une origine cardiaque).
Le tableau 4 dresse la liste des effets indésirables observés après un maximum de 35 mois de traitement (plus de 27 mois à tableau 4 dresse la liste des effets indésirables observés après un maximum de 35 mois de traitement (plus de 27 mois
33 mois : COPAXONE à 33 mois : COPAXONE, $n=84$; placebo, $n=75$; plus de 33 mois : COPAXONE', $n=12$; placebo, $n=24$ ) dans le cadre
de l'Essai il (essai comparatif [avec placebol multicentrique de précommercialisation portant sur des patients atteints de de l'Essai ll (essai comparatif lavec placebol multicentrique de précommercialisation portant sur des patients atteints de
sclérose en plaques rémittente) et dont 'lincidence était d'au moins $2 \%$ parmi les sujets qui recevaient COPAXONE ${ }^{\$}$ et sclau moins $2 \%$ de plus que l'incidence observée parmi les sujets du méme essai qui recevaient le placebo, peu importe
le lien de cause à effet entre la réaction et le traitement. Aucun résultat des épreuves de laboratoire répondant à ces critères n'a été signalé

est a noter que les données du tableau 4 ne peuvent pas servir à prévoir linncidence des effets indésirables du traitement dans le cadre de l'exercice normal de la médecine, étant donné que les caractéristiques des patients ainsi que d'autres facteurs risquent de ne pas être les mêmes que ceux des essais cliniques. Ces données fournissent tout de même et non liés au médicament en ce qui a trait a l'incidence des effets indésirables dans la population étudiée.

\section{TABLEAU 4}

Essal comparatif de précommercialisation chez des patients atteints de SEP
Effets indésirables dont l'incidence est $\geq 2 \%$ et $\geq 2 \%$ supérieure à celle du placebo

\begin{tabular}{|c|c|c|c|c|}
\hline \multirow{2}{*}{ Effets indésirables } & \multicolumn{2}{|c|}{$\begin{array}{c}\text { COPAXONE" } \\
n=125\end{array}$} & \multicolumn{2}{|c|}{$\begin{array}{c}\begin{array}{c}\text { Placebo } \\
n=126\end{array} \\
\end{array}$} \\
\hline & $n$ & $\%$ & $n$ & $\%$ \\
\hline $\begin{array}{l}\text { Organisme dans son ensemble } \\
\text { Douleur au point d'injection } \\
\text { Asthénie } \\
\text { Érytheme au point d'injection } \\
\text { Prurit au point d'injection } \\
\text { Syndrome pseudo-grippal } \\
\text { Inflammation au point d'injection } \\
\text { Douleur dorsale } \\
\text { Douleur thoracique } \\
\text { Masse au point d'injection } \\
\text { Induration au point d'injection } \\
\text { Papule au point d'injection } \\
\text { Douleur au cou } \\
\text { Fdème du visage } \\
\text { Urticaire au point d'injection } \\
\text { Hémorragie au point d'injection } \\
\text { Frissons } \\
\text { Kyste } \\
\text { Réaction au point d'injection } \\
\text { Atrophie au point d'injection } \\
\text { Abcès }\end{array}$ & $\begin{array}{l}83 \\
81 \\
73 \\
48 \\
38 \\
35 \\
33 \\
33 \\
33 \\
25 \\
19 \\
16 \\
11 \\
9 \\
8 \\
5 \\
5 \\
4 \\
3 \\
3\end{array}$ & $\begin{array}{l}66,4 \\
64,8 \\
58,4 \\
38,4 \\
30,4 \\
28,0 \\
26,4 \\
26,4 \\
26,4 \\
20,0 \\
15,2 \\
12,8 \\
8,8 \\
7,2 \\
6,4 \\
4,0 \\
4,0 \\
3,2 \\
2,4 \\
2,4\end{array}$ & $\begin{array}{c}46 \\
78 \\
17 \\
5 \\
34 \\
9 \\
28 \\
13 \\
10 \\
1 \\
5 \\
9 \\
2 \\
0 \\
4 \\
1 \\
1 \\
1 \\
0 \\
0\end{array}$ & $\begin{array}{c}36,5 \\
61,9 \\
13,5 \\
4,0 \\
27,0 \\
7,1 \\
22,2 \\
10,3 \\
7,9 \\
0,8 \\
4,0 \\
7,1 \\
1,6 \\
0 \\
3,2 \\
0,8 \\
0,8 \\
0,8 \\
0 \\
0\end{array}$ \\
\hline $\begin{array}{l}\text { Appareil cardiovasculaire } \\
\text { Vasodilatation } \\
\text { Palpitations } \\
\text { Migraine } \\
\text { Syncope } \\
\end{array}$ & $\begin{array}{c}34 \\
14 \\
9 \\
8 \\
\end{array}$ & $\begin{array}{l}27,2 \\
11,2 \\
7,2 \\
6,4 \\
\end{array}$ & $\begin{array}{l}14 \\
6 \\
5 \\
4 \\
\end{array}$ & $\begin{array}{r}11,1 \\
4,8 \\
4,0 \\
3,2 \\
\end{array}$ \\
\hline $\begin{array}{l}\text { Appareil digestif } \\
\text { Nausées } \\
\text { Vomissements } \\
\text { Anorexie } \\
\text { Castro-entérite } \\
\text { Candidose orale } \\
\text { Carie dentaire } \\
\end{array}$ & $\begin{array}{r}29 \\
13 \\
6 \\
6 \\
3 \\
3 \\
\end{array}$ & $\begin{array}{l}23,2 \\
10,4 \\
4,8 \\
4,8 \\
2,4 \\
2,4\end{array}$ & $\begin{array}{l}22 \\
7 \\
3 \\
2 \\
0 \\
0\end{array}$ & $\begin{array}{c}17,5 \\
5,6 \\
2,4 \\
1,6 \\
0 \\
0\end{array}$ \\
\hline $\begin{array}{l}\text { Systèmes hématopoiétique et lymphatique } \\
\text { Adénopathie } \\
\text { Ecchymose }\end{array}$ & $\begin{array}{l}23 \\
15\end{array}$ & $\begin{array}{l}18,4 \\
12,0\end{array}$ & $\begin{array}{l}12 \\
12\end{array}$ & $\begin{array}{l}9,5 \\
9,5\end{array}$ \\
\hline $\begin{array}{l}\text { Troubles métaboliques et nutritionnels } \\
\text { GEdème périphérique } \\
\text { Gain pondéral } \\
\text { GEdème }\end{array}$ & $\begin{array}{c}14 \\
7 \\
5\end{array}$ & $\begin{array}{l}11,2 \\
5,6 \\
4,0\end{array}$ & $\begin{array}{l}7 \\
0 \\
1\end{array}$ & $\begin{array}{c}5,6 \\
0 \\
0,8\end{array}$ \\
\hline $\begin{array}{l}\text { Appareil musculosquelettique } \\
\text { Arthralgie }\end{array}$ & 31 & 24,8 & 22 & 17,5 \\
\hline $\begin{array}{c}\text { Systeme nerveux } \\
\text { Hypertonie } \\
\text { Tremblement } \\
\text { Agitation } \\
\text { Confusion } \\
\text { Nystagmus }\end{array}$ & $\begin{array}{c}44 \\
14 \\
7 \\
5 \\
5\end{array}$ & $\begin{array}{l}35,2 \\
11,2 \\
5,6 \\
4,0 \\
4,0\end{array}$ & $\begin{array}{l}37 \\
7 \\
4 \\
1 \\
2\end{array}$ & $\begin{array}{l}29,4 \\
5,6 \\
3,2 \\
0,8 \\
1,6\end{array}$ \\
\hline $\begin{array}{l}\text { Appareil respiratoire } \\
\text { Rhinite } \\
\text { Dyspnée } \\
\text { Bronchite }\end{array}$ & $\begin{array}{l}29 \\
23 \\
18\end{array}$ & $\begin{array}{l}23,2 \\
18,4 \\
14,4\end{array}$ & $\begin{array}{c}26 \\
8 \\
12\end{array}$ & $\begin{array}{l}20,6 \\
6,4 \\
9,5\end{array}$ \\
\hline $\begin{array}{l}\text { Peau et annexes cutanees } \\
\text { Hypersudation } \\
\text { Erythème } \\
\text { Troubles dermatologiques } \\
\text { Nodule cutane } \\
\text { Verrue } \\
\end{array}$ & $\begin{array}{c}15 \\
8 \\
5 \\
4 \\
3 \\
\end{array}$ & $\begin{array}{l}12,0 \\
6,4 \\
4,0 \\
3,2 \\
2,4\end{array}$ & $\begin{array}{l}10 \\
4 \\
2 \\
1 \\
0\end{array}$ & $\begin{array}{c}7,9 \\
3,2 \\
1,6 \\
0,8 \\
0\end{array}$ \\
\hline $\begin{array}{c}\text { Organes des sens } \\
\text { Douleur auriculaire } \\
\text { Troubles oculaires } \\
\end{array}$ & $\begin{array}{c}15 \\
8 \\
\end{array}$ & $\begin{array}{l}12,0 \\
6,4\end{array}$ & $\begin{array}{c}12 \\
1 \\
\end{array}$ & $\begin{array}{l}9,5 \\
0,8 \\
\end{array}$ \\
\hline $\begin{array}{l}\text { Voies urogénitales } \\
\text { Miction impérieuse } \\
\text { Carrdidose vaginale } \\
\text { Dysménorrhée } \\
\text { Crossesse accidentelle } \\
\text { Impuissance }\end{array}$ & $\begin{array}{c}20 \\
16 \\
12 \\
4 \\
3\end{array}$ & $\begin{array}{c}16,0 \\
12,8 \\
9,6 \\
3,2 \\
2,4\end{array}$ & $\begin{array}{c}17 \\
9 \\
9 \\
0 \\
0\end{array}$ & $\begin{array}{c}13,5 \\
7,1 \\
7,1 \\
0 \\
0\end{array}$ \\
\hline
\end{tabular}

Voici les autres effets qui sont survenus chez au moins $2 \%$ des patients mais dont l'incidence dans le groupe placebo etait équivalente ou supérieure:

Organisme dans son ensemble: Céphalées, ecchymose au point d'injection, blessure accidentelle, douleur abdominale, rhinite allergique et malaise.

Appareil digestif : Dyspepsie, constipation, dysphagie, incontinence fécale, flatulence, nausées et vomissements, :

Appareil musculosquelettique : Myasthénie et myalgie.

Système nerveux : Étourdissements, hypoesthésie, paresthésie, insomnie, dépression, dysesthésie, troubles de la coordination, somnolence, troubles de la démarche, amnésie, instabilité emotionnelle, signe de Lhermitte, anomalies de la pensée, secousses musculaires, euphorie et troubles du sommeil.

Appareil respiratoire : Pharyngite, sinusite, aggravation de la toux et laryngite.

Peou ot annexes cutonées: Acné, alopécie et troubles des ongles.

Organes des sens : Anom
dysqueusie et surdité.

Voles urogénitales : Infection des voies urinaires, augmentation de la fréquence des miction Les donnees portant sur les effets indesirables qui sont apparus au cours d'essais cliniques comparatifs ont éte analysees dans l'optique d'evaluer les différences entre les sexes. Or, aucune différence cliniquement significative n'a eté relevée. Dans ces essais cliniques, $92 \%$ des patients étaient de race blanche, ce qui est representatif de la population de patients atteints de sclérose en plaques. De plus, la vaste majorité des patients traités par
COPAXONE une analyse de l'incidence des effets indésirables en fonction de groupes d'âge cliniquement pertinents.

Tous les patients ayant pris part aux essais cliniques sur COPAXONE ${ }^{*}$ ont subi des analyses de laboratoire. Les variations des paramètres de laboratoire (hématologie, biochimie sanguine et analyse des urines) qui étaient significatives sur le plan dinique étaient comparables entre les patients du groupe COPAXONE" et ceux du
groupe placebo, dans le cadre des essais cliniques à l'insu. Aucun patient ayant reçu COPAXONE" ne s'est retiré d'un essai en raison d'une anomalie des résultats des épreuves de laboratoire

Autres effets indésirables observés durant tous les essals cliniques

COPAXONE ${ }^{\circledR}$ a été administré à environ 900 personnes dans l'ensemble des essais cliniques, dont seulement certains étaient comparatifs (avec placebo). Au cours de ces essais, tous les effets indésirables ont été enregistrés par les chercheurs cliniques à l'aide de leur propre terminologie. De façon à donner une estimation efficace de la proportion des patients qui ont subi des effets indésirables, les effets semblables ont été regroupés en un plus petit nombre de catégories normalisées faisant appel à la terminologie du dictionnaire COSTART II. Tous les effets
signalés qui sont survenus à au moins deux reprises ainsi que les effets potentiellement graves qui sont survenus une seule fois sont inclus dans cette compilation, à l'exception des effets déjà inscrits au tableau précédent, les effets dont le caractère trop général ne procurait aucune information, les effets sans importance et les autres effets
qui se sont manifestés chez au moins $2 \%$ des patients traités et qui étaient présents à une fréquence égale ou qui se sont manifestés chez au moins $2 \%$ de
plus grande que dans le groupe placebo.

Les effets indésirables ont éte de plus classés en fonction des systèmes ou des appareils et énumérés en ordre décroissant de fréquence selon les définitions suivantes : les effets indésirables tréquents sont ceux qui sont survenus chez au moins un patient sur $100(1 / 100)$, tandis que les effets indésirables peu fréquents sont ceux gui sont survenus dans une proportion de un patient sur $100(1 / 100)$ à un patient sur $1000(1 / 1000)$. Organisme dans son ensemble : Fréquents: (Edème au point d'injection, atrophie au point d'injection, bcès et hypersensibilité au point d'injection.

Pou fréquents : Hématome au point d'injection, fibrose au point d'injection, faciès lunaire, cellulite, œedème généralisé, hernie, abcès au point d'injection, maladie du sérum, tentative de suicide, hypertrophie au point d'iniection, mélanose au point d'injection, lipome et réaction de photosensibilité.

Appareil cardiovasculaire : Frequent : Hypertension. Peu fréquents : Hypotension, claquement systolique, souffle systolique, fibrillation auriculaire, bradycardie, apparition d'un quatrième bruit du cœur, hypotension orthostatique et varices.

Appareil digestif : Peu fréquents : Sécheresse de la bouche, stomatite, sensation de brûlure sur la langue, hépatomégalie, augmentation le l'œsophage, œsophagite, cancer gastro-intestinal, hémorragie gingivale, hemorragie rectale, ténesme, coloration anormale de la langue et ulcère duodénal.

hemorragie rectale, tenesme, coloration anormale de la langue et ukère duodénal.

Troubles gastro-intestinaux : Fréquents: Défécation impérieuse, candidose orale, hypertrophie des glandes salivaires, carie dentaire et stomatite ulcéreuse.

Systèmes hématopoî́tique et lymphatique : Peu fréquents : Leucopénie, anémie, cyanose, éosinophilie, hẻmatémèse, lymphœdème, pancytopénie et splénomégalie.

Troubles métaboliques et nutritionnels : Peu fréquents : Perte pondérale, intolérance à l'alcool, syndrome de Cushing, goutte, anomalies de la cicatrisation et xanthome.

Appareil musculosquelettique : Peu fréquents : Arthrite, atrophie musculaire, douleur osseuse, bursite, douleur rénale, troubles musculaires, myopathie, osteomyélite, douleur tendineuse et tenosynovite.

Système nerveux : Fréquents: Rêves inhabituels, instabilité émotionnelle et stupeur. Peu fréquents: Aphasie, ataxie, convulsion, paresthesie péribuccale, dépersonnalisation, hallucinations, hostilité, hypocinésie, coma, troubles de la concentration, paralysie faciale, diminution de la libido, réaction maniaque, troubles de la memoire, myoclonie, nevralgie, reaction paranoide, paraplégle, depression psychotique et supeur transitoire. Appareil respiratoire : Fréquent: Hyperventilation, rhume des foins. Peu fréquents : Asthme, pneumonie, epistaxis, hypoventilation et modification de la voix,

Peau et annexes cutanées : Fréquents : Eczema, zona, éruption pustuleuse, atrophie cutanée et verrues. Peu fréquents : Sécheresse cutanée, hypertrophie cutanée, dermatite, furonculose, psoriasis, angio-øedème, eczema de contact, erythème noueux, dermatite fongique, éruption maculopapuleuse, pigmentation, turneur cutanee benigne, cancer de la peau, vergetures et eruption vesiculobulleuse.

Organes des sens : Fréquents : Atteinte du champ visuel. Peu fréquents : Sécheresse oculaire, otite externe, ptose, cataractes, ulcere de la cornee, mydriase, nevrite optique, photophobie et agueusie.

voies urogénitales : Fréquents : Aménorrhée, hématurie, impuissance, menorragie, anomalies des résultats du test de Papanicolaou, pollakiurie et hémorragie vaginale. Peu fréquents : Vaginite, douleur au fianc (rein), avortement, engorgement mammaire, hypertrophie mammaire, douleur mammaire, cancer in situ du col de

l'utérus, mastose sclérokystique,

Effets indésirables rapportés après la commencialisation et qui n'avaient pas déjà été notés lors des essais cliniques

L'expérience de postcommercialisation a dégagé un profil d'effets indésirables similaire à celui présenté cidessus. Après la mise sur le marché, on a sigrialé des effets indésirables, autres que celles indiquées ci-dessus,
qui sont survenues pendant le traitement par COPAXONE\$ (acétate de glatiramére pour injection). Ces réacqui sont survenues pendant le traitement par COPAXONE (acétate de glatiramere pour
tions, qui peuvent avoir ou non un lien de causalité avec le médicament, comprennent

Organisme dans son ensemble : Septicémie, syndrome lupoide, hydrocéphalie, distension de l'abdomen, Organisme dans son ensemble : Septicémie, syndrome lupoide, hydrocephalie, distension de l'abdomen,
hypersensibilité au point d'injection, réaction allergique, réaction anaphylactoide, infection bactérienne, hypersensibilite au point d'injection, réaction allergique, reaction anaphylactoide, infection bacterenne,

Appareil cardiovasculaire : Thrombose, maladie vasculaire périphérique, épanchement péricardique, infarctus du myocarde, thrombophlébite extensive, occlusion coronarienne, insuffisance cardiaque congestive, cardiomyopathie, cardiomégalie, arrythmie, angine de poitrine et tachycardie.

Appareil digestif: IEdème de la langue, hémorragie gastrique d'origine ulcéreuse, altération de la fonction hépatique, atteinte hépatique, hépatite, éructation, cirrhose du foie, calculs biliaires, diarrhée et troubles gastro-intestinaux.

Systèmes hématopoiétique et tymphatique : Thrombocytopénie, réaction de type lymphome et leucémie aiguë. Troubles métaboliques et nutritionnels: Hypercholestérolémie.

Appareil musculosquelettique : Polyarthrite rhumatoïde et spasme généralisé

Système nerveux: Myélite, méningite, néoplasme du SNC, accident vasculaire cérébral, œeđème cérébral, rêves thabituels, aphasie, convulsion, névralgie, anxiété, pied tombant, nevvosité, trouble de l'élocution et vertige. Appareil respira

Peau et annexes cutanées : Herpès, prurit, éruption cutanée et urticaire.

Organes des sens : Claucome, cécité et atteinte du champ visuel.

Voies urogénitales: Néoplasme des voies urogénitales, anomalie urinaire, cancer des ovaires, néphrose, insuffisance rénale, cancer du sein, cancer de la vessie et pollakiurie.

Des surdosages de COPAXONE ${ }^{3}$ ont eté signales chez trois patients. Un patient s'est injecté quatre doses (soit un total de $80 \mathrm{mg}$ ) de COPAXONE's à la fois. Aucune sequelie n'a été notée. Deux autres patients, un 政 cardiaque ni de sa température. Le suivi téléphonique effectué plusieurs heures plus tard n'a pas révélé d'effets indésirables dans un cas comme dans l'autre.
POSOLOGIE ET MODE D'ADMINISTRATION

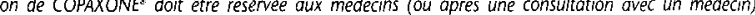
qui connaissent à fond le diagnostic et la prise en charge de la sclérose en plaques

La dose recommandée de COPAXONE (acétate de glatiramere pour injection ou acétate de glatiramère injectable) dans le traitement de la SEP rémittente est de une injection quotidienne de $20 \mathrm{mg}$ par voie sous-cutanée.
Directives d'administration : Pour reconstituer le lyophilisat de COPAXONE avant l'injection, utiliser une 
seringue et un adaptateur de flacon stériles afin de prélever $1,1 \mathrm{~mL}$ du diluant fourni (eau stérile pour injection) et de l'injecter dans le flacon de COPAXONE ${ }^{*}$. Agiter très délicatement, par un mouvement de rotation, le flacon de COPAXONE lyophilisat. Inspecter visuellement le produit reconstitué et le jeter ou le retourner au pharmacien avant 'utilisation s'il renferme des particules. Administrer dans les huit heures suivant la reconstitution. Prélever 1,0 mL de la solution à l'aide d'une seringue stérile. Retirer l'adaptateur de flacon, connecter une aiguille de calibre 27 et injecter la solution par voie sous-cutanée. Les points d'auto-administration comprennent les bras, I'abdomen, les fesses et les cuisses. Un flacon ne convient qu'à une seule utilisation; toute portion inutilisée doit être jetée (voir INFORMATION A L'INTENTION DU PATIENT, Produit reconstitue).

Pour obtenir les directives concernant la préparation et l'injection de COPAXONE préremplie, voir INFORMATION A L'INTENTION DU PATIENT, Seringue préremplie.

RENSEIGNEMENTS PHARMACEUTIQUES

Substance médicamenteuse :

Nom propre:

Denomination

Chimique :

Acétate de glatiramère

Description :

L'acétate de glatiramère est le sel acétate de polypeptides synthétiques.

L'acétate de glatiramère est préparé par réaction chimique des dérivés activés de quatre acides aminés: l'acide L-glutamique (L-Glu), la L-alanine (L-Ala), la L-tyrosine (L-Tyr) et la L-yysine (L-yys) dans une proportion spécifique. La fraction molaire de chaue résidu d'acide amine sechelonne comme suit : L-Glu, de 0,129 à 0,$153 ; L-$-Ala, de 0,392 à 0,$462 ; L-T y r$, de 0,086 à 0,100 et L-Lys, de 0,300 à 0,374

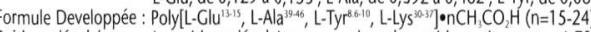

Poids moléculaire: Le poids moléculaire moyen du polypeptide se situe entre 4700 et 11000 daltons, au moins $68 \%$ du matériel se situant entre 2500 et 22500 daltons.

Description Physique : Lyophilisat de couleur blanche à légèrement jaunâtre.

Solubilité : Légèrement soluble dans l'eau, insoluble dans l'acéton $\quad$ le

Le pH d'une solution à $0,5 \% \mathrm{p} / \mathrm{V}$ d'acétate de glatiramère dans de l'eau se situe entre 5,5 et 8,0 .

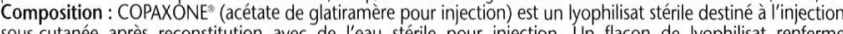
sous-cutanée après reconstitution avec de l'eau stérile pour injection. Un flacon de lyophilisat renferme $20 \mathrm{mg}$ d'acétate de glatiramère et un surtitrage de $2 \mathrm{mg}$ pour tenir compte des pertes possibles pendant la reconstitution et le préevenent ainsi que $40 \mathrm{mg}$ de mannitol. Un llacon d eau stérile pour injection renterme $1,1 \mathrm{~mL}$ d'eau sterile pour injection et un surtitrage de $0,35 \mathrm{~mL}$ pour tenir compte des pertes possibles pendan coronstition et pe prevement.

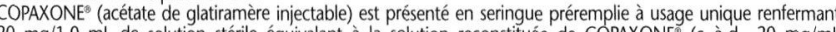
mg/1,0 mL de solution sterile équivalant à la solution reconstituée de COPAXONE (c.-à-d., $20 \mathrm{mg} / \mathrm{mL}$ (a)

NE doivent être réfrigérés (entre ure ambiante (entre 15 et $30^{\circ} \mathrm{C}$ ) pendant

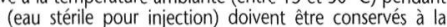
température ambiante.

Les seringues préremplies de COPAXONE ${ }^{*}$ doivent être réfrigérées dès leur réception (entre 2 et $8^{\circ} \mathrm{C}$ ). CONGELER.

$S^{\prime} i l$ n'est pas possible de conserver les seringues préremplies de COPAXONE ${ }^{\circ}$ au réfrigérateur, elles peuvent être conservées à la température ambiante (entre 15 et $30^{\circ} \mathrm{C}$ ) pendant un maximum d'une semaine. Ne pas conserver les seringues préremplies de COPAXONE à la température ambiante pendant plus de sept jours. Remarque : ce médicament est sensible à la lumière, le protéger de la lumière lorsqu'on ne fait pas d'injection. Une seringue préremplie ne doit servir qu'une seule fo pro

Reconstitution du lyophilisat : Pour queconstituer le lyophilisat de COPAXONEs, avant l'injection, utiliser une seringue et un adaptateur de flacon stériles a fin de prélever le diluant fourni (eau stérile pour iniection) et de l'injecter dans le flacon de COPAXONE' Agiter très délicatement, par un mouvement de rotation, le et de de COPAXONE et le laisser reposer à la température ambiante jusqu'à dissolution complète du lyophilisat. Inspecter visuelement le produit reconstitué et le jeter ou le retourner a pharmacien avant l'ut lisation silisat. Inspecter visuellement le produit reconstitue et le jeter ou le retourner au pharmacien avant l'utilisation síl d'une seringue stérile. Retirer l'adaptateur de flacon, connecter une aiguille' de calibre 27 et iniecter la solution par voie sous-cutanée. Un flacon ne convient qu'à une seule utilisation; toute portion inutilisée doit être jetée. La solution reconstituée ne doit pas être conservée plus de huit heures à la température ambiante. Produits parentéraux : COPAXONE

\begin{tabular}{|c|c|c|c|}
\hline $\begin{array}{c}\text { Format du } \\
\text { flacon }\end{array}$ & $\begin{array}{c}\text { Volume de diluant à } \\
\text { ajouter }\end{array}$ & $\begin{array}{c}\text { Volume à } \\
\text { injecter }\end{array}$ & $\begin{array}{c}\text { Concentration } \\
\text { nominale par } \mathrm{mL}\end{array}$ \\
\hline $2 \mathrm{~mL}$ & $1,1 \mathrm{~mL}$ & $1,0 \mathrm{~mL}$ & $20 \mathrm{mg}$ \\
\hline
\end{tabular}

\section{PRÉSENTATION}

COPAXONE ${ }^{\oplus}$ (acétate de glatiramère pour injection) est offert sous la forme d'une dose de $20 \mathrm{mg}$ de lyophilisat stérile d'acétate de glatiramere avec du mannitol, le produit étant conditionné dans des flacon unidoses de $2 \mathrm{~mL}$ de couleur ambre. Un deuxième flacon renfermant $1,1 \mathrm{~mL}$ de diluant (eau stérile pour injection) et un surtitrage de $0,35 \mathrm{~mL}$ accompagne chaque flacon de médicament et est inclus dans la trousse d'auto-administration. COPAXONE (acelate de glatiramere pour injection) est offert en emballages de 32 flacons de couleur ambre renfermant le lyophilisat sterile destine a 'injection sous-cutanée. Le diluant (eau stérile pour injection) accompagnant COPAXONE' est offert en emballages de 32 flacons transparents qui sont inclus dans la trousse d'auto-administration.

COPAXONE" (acétate de glatiramère injectable) est présenté en seringues préremplies à usage unique renferman $20 \mathrm{mg} / 1,0 \mathrm{~mL}$ de solution stérile equivalant à la solution reconstituee de COPAXONE. . COPAXONE (acétate de glatiramère injectable) est offert en emballages de 30 seringues en verre préremplies à usage unique (20 mg/1,0 mL), accompagnées de 33 tampons d'alcool.

Monographie fournie sur demande.

Bibliographie :

1. Monographie de COPAXONE ${ }^{3}$ (acétate de glatiramère), Teva Neuroscience.
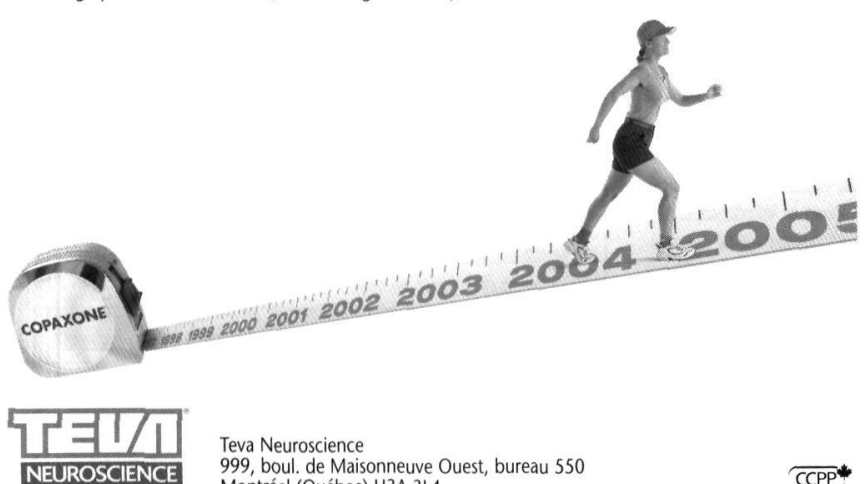

Teva Neuroscienc

999 boul de Maisonneuve Ouest, bureau 550

Montréal (Québec) H3A 3 L4

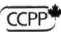

\section{Subscribe Now!}

YES! Please send me a one-year

subscription to the Journal, now including the ONLINE version at www.cjns.org

Complete the enclosed subscription form and send by mail, fax or e-mail to:

Subscriptions

Canadian Journal of Neurological Sciences

PO Box 5456, Stn. A

Calgary AB Canada T2H 1 X8

Tel: (403) 229-9575

Fax: (403) 229-1661

E-mail: journal@cjns.org

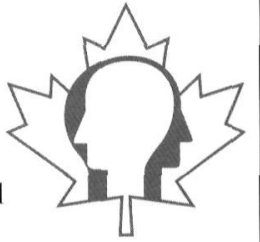

\section{SUBSCRIPTION RATES (Print and Online) 2003}

\begin{tabular}{llll} 
& Canada* & US & $\begin{array}{l}\text { Other } \\
\text { Countries }\end{array}$ \\
\hline Non-Member Individual & \$C 80.00 & \$US 80.00 & \$US 85.00 \\
Non-Member Student & $\$ C 40.00$ & \$US 40.00 & \$US 42.50 \\
Institutions & \$C 90.00 & \$US 90.00 & \$US 95.00
\end{tabular}

$*$ add $7 \%$ GST or $15 \%$ HST

Agent discount 5\%

\begin{tabular}{ll}
\hline Subscription Rate & $\$$ \\
\hline$*$ Tax: GST 7\%/ HST 15\% & $\$$ \\
\hline TOTAL & $\$$ \\
\hline
\end{tabular}

\section{PAYMENT METHODS:}

$\square$ Cheque

(\$C drawn on a Canadian bank and \$US drawn on a US bank)
$\square$ Visa
Mastercard

Credit Card No:

Expiry date

Signature:

Telephone:

Last Name:

First Name:

Address:

City:

Province/State:

Country:

Postal Code: 


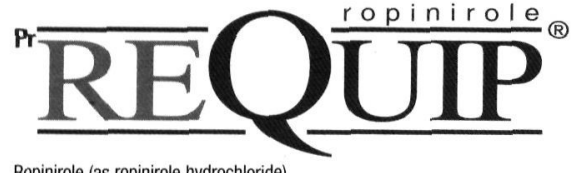

Ropinirole (as ropinirole hydrochloride)

TABLETS: $0.25 \mathrm{mg}, 1.0 \mathrm{mg}, 2.0 \mathrm{mg}, 5.0 \mathrm{mg}$

THERAPEUTIC CLASSIFICATION: AntiParkinsonian Agent / Dopamine Agonist INDICATIONS AND CLINICAL USE: REQUIP" (ropinirole hydrochloride) is indicated in the treatment of the signs and symptoms of idiopathic Parkinson's disease. REQUIP can be used both as early therapy, without concomitant levodopa and as an adjunct to levodopa. Three year and five year activecomparator controlled clinical trials have been conducted.

CONTRAINDICATIONS: REQUIPo (ropinirole hydrochloride) is contraindicated in patients with a known hypersensitivity to ropinirole hydrochloride or the excipients of the drug product.

WARNINGS: Sudden Onset of Sleep - Patients receiving treatment with REQUIPe (ropinirole hydrochloride), and other dopaminergic agents have reported suddenly falling asleep while engaged in activities of daily living, including operating a motor vehicle, which has sometimes resulted in accidents. Although some of the patients reported somnolence while on REQUIP ${ }^{\circledR}$, others perceived that they had no warning signs, such as excessive drowsiness, and believed that they were alert immediately prior to the event. Physicians should alert patients of the reported cases of sudden onset of sleep, bearing in mind that these events are NOT limited to initiation of therapy. Patients should also be advised that sudden onset of sleep has occurred without warning signs. If drowsiness or sudden onset of sleep should occur, patients should immediately contact their physician. Until further information is available on the management of this unpredictable and serious adverse event, patients should be warned not to drive or engage in other activities where impaired alertness could put themselves and others at risk of serious injury or death (e.g., operating machines). Episodes of falling asleep while engaged in activities of daily living have also been reported in patients taking other dopaminergic agents, therefore, symptoms may not be alleviated by substituting these products. Presently, the precise cause of this event is unknown. It is known that many Parkinson's disease patients experience alterations in sleep architecture, which results in excessive daytime sleepiness or spontaneous dozing, and that dopaminergic agents can also induce sleepiness. There is insufficient information to determine whether this event is associated with REQUIPक all dopaminergic agents or Parkinson's disease itself. Orthostatic Symptoms - Dopamine agonists appear to impair the systemic regulation of blood pressure with resulting orthostatic symptoms of dizziness or lightheadedness, with or without documented hypotension. These symptoms appear to occur especially during dose escalation. Therefore, patients treated with dopamine agonists should be carefully monitored for signs and symptoms of orthostatic hypotension, especially during dose escalation (see DOSAGE and ADMINISTRATION) and should be informed of this risk. Hallucinations - Early Therapy: In placebo- controlled trials, REQUIP (ropinirole hydrochloride) caused hallucination in $5.1 \%$ of patients during early therapy (1.4\% in the placebo group). Hallucination was of sufficient severity that it led to discontinuation in $1.3 \%$ of patients. The incidence of hallucination was dose-dependent. In a 5-year study comparing REQUIP ${ }^{\varpi}$ with levodopa in early Parkinson's patients, the overall incidence of hallucinations was $17.3 \%$ $(31 / 179)$ for patients treated with REQUIP ${ }^{\infty}$ and $5.6 \%(5 / 89)$ for levodopa patients. Hallucinations led to discontinuation of the study treatment in $5.0 \%$ of REQUip and $2.2 \%$ of levodopa patients. In a 3-year study comparing REQUIP with another dopamine agonist, the overall incidence of hallucinations was $9.5 \%$ (16/168) for patients treated with REQUIP® and 9.0\% (15/167) for patients receiving active comparator. Hallucinations led to discontinuation of the study treatment in $2.4 \%$ of REQUIP patients and $3.0 \%$ of comparator patients. Concomitant Selegiline: In a 5-year study. REQUIP ${ }^{\infty}$ patients receiving concomitant selegiline reported a higher incidence of hallucinations $(23.5 \%)$ than did those without (12.2\%); this subpopulation effect was not seen in the L-dopa arm (hallucinations with concomitant selegiline $=2.0 \%$ vs hallucinations without selegiline $=8.0 \%$ ). Adjunct Therapy: Hallucinations were experienced by $10.1 \%$ of patients receiving REQUIP' and levodopa, compared to $4.2 \%$ receiving placebo and levodopa. Hallucinations were of sufficient severity that it led to discontinuation in $1.9 \%$ of patients. The incidence of hallucinations was dose dependent PRECAUTIONS: Cardiovascular - Since REQUIP ${ }^{\varpi}$ (ropinirole hydrochloride) has not been studied in patients with a history or evidence of significant cardiovascular disease including myocardial infarction, unstable angina, cardiac decompensation, cardiac arrhythmias, vaso-occlusive disease (including cerebral) or cardiomyopathy, it should be used with caution in such patients. There is limited experience with REQUIP in patients treated with antihypertensive and antiarrhythmic agents. Consequently, in such patients, the dose of REQUIP ${ }^{\infty}$ should be titrated with caution. Orthostatic Symptoms Orthostatic symptoms of dizziness or lightheadedness as well as somnolence may occur during REQUIPe therapy. Neuroleptic Malignant Syndrome - A symptom complex resembling the neuroleptic malignant syndrome (characterized by elevated temperature, muscular rigidity, altered consciousness, and autonomic instability), with no other obvious etiology, has been reported in association with rapid dose reduction, withdrawal of, or changes in anti-Parkinsonian therapy. A single spontaneous report of a symptom complex resembling the neuroleptic malignant syndrome has been observed in a 66 year old diabetic male patient with Parkinson's disease, who developed fever, muscle stiffness, and drowsiness 8 days after beginning REQUIPo treatment. The patient also experienced acute bronchitis, which did not respond to antibiotic treatment. REQUIP" was discontinued three days before the patient died. The reporting physician considered these events to be possibly related to REQUIP treatment. (see DOSAGE AND ADMINISTRATION). A single spontaneous report of severe muscle pain has been reported in a 66 year old male patient around his thigh. The reporting physician considered the event to be probably related to REQUIP treatment. Retinal Pathology in Rats - In a two year carcinogenicity study in albino Sprague-Dawley rats, retinal atrophy was observed at incidences of $0 \%, 1.4 \%, 1.4 \%$ and $10 \%$ of male rats and $0 \%, 4.4 \%, 2.9 \%$ and $12.9 \%$ of female rats dosed at $0,1.5,15$ and $50 \mathrm{mg} / \mathrm{kg} /$ day respectively. The incidence was significantly higher in both male and female animals dosed at $50 \mathrm{mg} / \mathrm{kg} / \mathrm{day}$. The $50 \mathrm{mg} / \mathrm{kg} / \mathrm{day}$ dose represents a 2.8 fold greater exposure (AUC) and a 13.1 fold greater exposure $\left(C_{\max }\right)$ to ropinirole in rats than the exposure would be in humans at the maximum recommended dose of $24 \mathrm{mg} /$ day. The relevance of this finding to humans is not known. Pregnancy - The use of REQUIP ${ }^{\oplus}$ during pregnancy is not recommended. REQUIP given to pregnant rats during organogenesis (gestation days 8 through 15) resulted in decreased fetal body weight at $60 \mathrm{mg} / \mathrm{kg} /$ day (approximately 3-4 times the AUC at the maximal human dose of $8 \mathrm{mg}$ t.i.d.), increased fetal death at $90 \mathrm{mg} / \mathrm{kg} /$ day (approximately 5 times the AUC at the maximal human dose of $8 \mathrm{mg}$ t.i.d.) and digital malformations at $150 \mathrm{mg} / \mathrm{kg} / \mathrm{day}$ (approximately $8-9$ times the AUC at the maximal human dose of $8 \mathrm{mg}$ t.i.d.). These effects occurred at maternally toxic doses. There was no indication of an effect on development of the conceptus at a maternally toxic dose of $20 \mathrm{mg} / \mathrm{kg} / \mathrm{day}$ in the rabbit. In a perinatal-postnatal study in rats, $10 \mathrm{mg} / \mathrm{kg} /$ day of REQUIPB (approximately $0.5-0.6$ times the AUC at the maximal human dose of $8 \mathrm{mg}$ ti.d.) impaired growth and development of nursing offspring and altered neurological development of female offspring. Nursing Mothers - Since REQUIP ${ }^{5}$ suppresses lactation, it should not be administered to mothers who wish to breast-feed infants. Studies in rats have shown that REQUIP and/or its metabolites cross the placenta and are excreted in breast milk. Consequently, the human fetus and/or neonate may be exposed to dopamine agonist activity. Use in Women Receiving Estrogen Replacement Therapy- In female patients on long-term treatment with conjugated estrogens, oral clearance was reduced and elimination half-life prolonged compared to patients not receiving estrogens. in patients, already receiving estrogen replacement therapy, REQUIP ${ }^{\circ}$ may be titrated in the recommended manner according to clinical response. However, if estrogen replacement therapy is stopped or introduced during treatment with REQUIP' adjustment of the REQUIP ${ }^{\circ}$ dosage may be required. Pediatric Use - Safety and effectiveness in the pediatric population have not been established. Renal and Hepatic Impairment - No dosage adjustment is needed in patients with mild to moderate renal impairment (creatinine clearance of 30 to $50 \mathrm{~mL} / \mathrm{min}$ ). Because the use of REQUIP in patients with severe renal impairment or hepatic impairment has not been studied, administration of REQUIP' to such patients is not recommended. Drug Interactions - Psychotropic Drugs: Neuroleptics and other centrally active dopamine antagonists may diminish the effectiveness of REQUIP ${ }^{\oplus}$. Therefore, concomitant use of these products is not recommended. Based on population pharmacokinetic assessment, no interaction was seen between REQUIP ${ }^{\circ}$ and tricyclic antidepressants or benzodiazepines. Anti-Parkinson Drugs: Based on population pharmacokinetic assessment, there were no interactions between REQUIP and drugs commonly used to treat Parkinson's disease, i.e., selegiline, amantadine, and anticholinergics. Levodopa: The potential pharmacokinetic interaction of levodopa/ carbidopa (100 mg/10 mg b.id) and REQUIP® $(2 \mathrm{mg}$ ti.d.) was assessed in levodopa naive (de novo) male and female patients with Parkinson's disease ( $n=30$, mean age 64 years). The rate and extent of availability of REQUIP at steady state were essentially the same with or without levodopa. Similarly, the rate and extent of availability of levodopa, as well as its elimination half-life, were essentially the same in the presence and absence of REQUIPe Inhibitors of CYP1A2: Ciprofloxacin: The effect of ciprofloxacin ( $500 \mathrm{mg}$ b.i.d.) on the pharmacokinetics of REOUIPe (2 mg ti.d.) was studied in male and female patients with Parkinson's disease $(n=12$, mean age 55 years). The extent of systemic availability of REQUIP was significantly increased when coadministered with ciprofloxacin (AUC increased by 1.84 fold). Thus, in patients already receiving CYP1A2 inhibitors such as ciprofloxacin, REQUIP therapy may be instituted in the recommended manner and the dose titrated according to clinical response. However, if therapy with a drug known to be an inhibitor of CYP1A2 is stopped or introduced during treatment with REQUIP ${ }^{\infty}$, adjustment of the REQUIP ${ }^{\oplus}$ dosage will be required. Substrates of CYP1A2: Theophylline: The effect of oral theophylline $(300 \mathrm{mg}$ b.i.d.) on the pharmacokinetics of REQUIP $(2 \mathrm{mg}$ t.i.d.) was studied in male and female patients with Parkinson's disease $(n=12$, mean age 59 years). There was no marked change in the rate or extent of availability of REQUIP ${ }^{\circledast}$ when coadministered with theophylline. Similarly, coadministration of REQUIP with intravenous theophylline $(5 \mathrm{mg} / \mathrm{kg})$ did not result in any marked change in the pharmacokinetics of theophylline. It is therefore unlikely that substrates of CYP1A2 would significantly alter the pharmacokinetics of REQUIP ${ }^{\circledR}$, and vice-versa. Digoxin: The effect of REQUIP ${ }^{\circledR}(2 \mathrm{mg}$ t.i.d.) on the pharmacokinetics of digoxin $(0.125-0.25 \mathrm{mg}$ 0.d.) was studied in male and female patients with Parkinson's disease ( $n=10$, mean age 72 years). Coadministration at steady state with REQUIP ${ }^{\circledast}$ resulted in a $10 \%$ decrease in digoxin AUC although mean trough digoxin plasma concentrations were unaltered. However, the effect of higher recommended doses of REQUIP ${ }^{\text {*i }}$ on the pharmacokinetics of digoxin is not known. Alcohol: No information is available on the potential for interaction between REQUIP ${ }^{\oplus}$ and alcohol. As with other centrally active medications, patients should be cautioned against taking REQUIP' with alcohol. Psycho-Motor Performance - (see WARNINGSSudden Onset of Sleep).

ADVERSE REACTIONS: Adverse Reactions Associated with Discontinuation of Treatment - Of 1599 patients who received REQUIP (ropinirole hydrochloride) during the premarketing clinical trials, $17.1 \%$ in arly-therapy studies and $17.3 \%$ in adjunct-therapy studies discontinued treatment due to adverse reactions. The events resulting in discontinuation of REQUIP ${ }^{s}$ in $1 \%$ or more of patients were as follows: Early therapy: nausea $(6.4 \%)$, dizziness $(3.8 \%)$, aggravated Parkinson's disease $(1.3 \%)$, hallucination $(1.3 \%)$, headache $(1.3 \%)$, somnolence $(1.3 \%)$ and vomiting $(1.3 \%)$. Adjunct therapy: dizziness $(2.9 \%)$, dyskinesia $(2.4 \%)$, confusion $(2.4 \%)$, vomiting $(2.4 \%)$, hallucination $(1.9 \%)$, nausea $(1.9 \%)$, anxiety $(1.9 \%)$, and increased sweating (1.4\%). Patients over 75 years of age $(n=130)$ showed slightly higher incidences of withdrawal due to hallucination, confusion and dizziness than patients less than 75 years of age. Most Frequent Adverse Events - Adverse events occurring with an incidence of greater than, or equal to, 10\% were as follows: Early therapy: nausea, dizziness, somnolence, headache, peripheral edema, vomiting, syncope, fatigue and viral infection. Adjunct therapy: dyskinesia, nausea, dizziness, somnolence and headache. Dopamine agonists, with an ergoline chemical structure have been associated with adverse experiences such as retroperitoneal fibrosis, erythromelalgia and pulmonary reactions. REQUIP ${ }^{\circledast}$ has a novel, non-ergoline chemical structure and no reports of such events have been observed in clinical trials. Incidence of Adverse Events in Placebo Controlled Trials - The incidence of postural hypotension, an event commonly associated with initiation of dopamine agonist therapy, was not notably different from placebo in clinical trials. However, decreases in systolic blood pressure to $<90 \mathrm{mmHg}$ have been observed in 13\% (<65 years), $16 \%$ ( $65-75$ years) and $7.6 \%$ (>75 years) of patients treated with REQUIP ${ }^{\infty}$. Table $\mathbf{2}$ lists adverse events that occurred at an incidence of $1 \%$ or more among REQUP -treated patients who participated in placebo-controlled trials for up to one year. Patients were dosed in a range of $0.75 \mathrm{mg}$ to $24 \mathrm{mg} / \mathrm{day}$. Reported adverse events were classified using a standard World Health Organization (WHO)-based dictionary terminology. The prescriber should be aware that these figures can not be used to predict the incidence of adverse events in the course of usual medical practice where patient characteristics and other factors differ from those which prevailed in the clinical trials. Similarly, the cited frequencies can not be compared with figures obtained from other clinical investigations involving different treatments, uses and investigators. The cited figures, however, do provide the prescribing physician with some basis for estimating the relative contribution of drug and non-drug factors to the adverse events incidence rate in the population studied.

\begin{tabular}{|c|c|c|c|c|}
\hline \multicolumn{5}{|c|}{$\begin{array}{l}\text { TABLE } 2 \\
\text { Adverse events with incidence } 21 \% \text { from all placebo-controlled } \\
\text { early and adjunct therapy studies }\end{array}$} \\
\hline & \multicolumn{2}{|c|}{ Early Therapy } & \multicolumn{2}{|c|}{ Adjunct Therapy } \\
\hline & $\begin{array}{l}\text { REQUPP } \\
N=157 \\
\text { Occcurrence }\end{array}$ & $\begin{array}{l}\text { Placebo } \\
\mathrm{N}=147 \\
\% \text { occurrence }\end{array}$ & $\begin{array}{c}\text { REQUPP" } \\
N=288 \\
\% \text { occurence }\end{array}$ & $\begin{array}{c}\text { Placebo } \\
N=120 \\
\% \text { occurrence }\end{array}$ \\
\hline \multicolumn{5}{|l|}{ Autonomic Nervous System } \\
\hline Sweating Increased & 6.4 & 4.1 & 7.2 & 1.7 \\
\hline Mouth Dry & 5.1 & 3.4 & 5.3 & 0.8 \\
\hline Flushing & 3.2 & 0.7 & 1.4 & 0.8 \\
\hline \multicolumn{5}{|l|}{ Body as a Whole General } \\
\hline Peripheral Edema & 13.4 & 4.1 & 3.9 & 2.5 \\
\hline Fatigue & 10.8 & 4.1 & $-"$ & - \\
\hline Injury & - & - & 10.6 & 9.2 \\
\hline Pain & 7.6 & 4.1 & 5.3 & 3.3 \\
\hline Asthenia & 6.4 & 1.4 & - & - \\
\hline Drug Level Increased & 4.5 & 2.7 & 6.7 & 3.3 \\
\hline $\begin{array}{l}\text { Chest Pain } \\
\text { (n) }\end{array}$ & 3.8 & 2.0 & - & - \\
\hline \multirow{2}{*}{\multicolumn{5}{|c|}{$\begin{array}{l}\text { Malarse } \\
\text { Therapeutic Response }\end{array}$}} \\
\hline & & & & \\
\hline Decreased & 1.9 & 0.7 & - & - \\
\hline Cellulitis & 1.3 & 0.0 & - & - \\
\hline Influenza-like Symptoms & - & - & 1.0 & 0.0 \\
\hline Fever & - & - & 1.4 & 0.0 \\
\hline \multicolumn{5}{|l|}{ Cardiovascular General } \\
\hline Syncope & 11.5 & 1.4 & 2.9 & 1.7 \\
\hline Hypotension Postural & 6.4 & 4.8 & - & - \\
\hline Hypertension & 4.5 & 3.4 & 3.4 & 3.3 \\
\hline Hypotension & 1.9 & $\begin{array}{l}.4 \\
0.0\end{array}$ & $\begin{array}{r}.44 \\
2.4\end{array}$ & 0.8 \\
\hline Cardiac Failure & - & - & 1.0 & 0.0 \\
\hline \multicolumn{5}{|c|}{ Central and Peripheral Nervous System } \\
\hline Dizziness & 40.1 & 21.8 & 26.0 & 15.8 \\
\hline Dyskinesia & - & - & 33.7 & 12.5 \\
\hline $\begin{array}{l}\text { Headache } \\
\text { Hease }\end{array}$ & 17.2 & 17.0 & 16.8 & 11.7 \\
\hline Ataxia (Falls) & - & - & 9.6 & 6.7 \\
\hline Tremor & - & - & 6.3 & 2.5 \\
\hline Paresthesia & - & - & 5.3 & 2.5 \\
\hline Hyperesthesia & 3.8 & 2.0 & - & - \\
\hline Dystonia & - & - & 4.3 & 4.2 \\
\hline Hypokinesia & - & - & 5.3 & 4.2 \\
\hline $\begin{array}{l}\text { Paresis } \\
\text { Paid }\end{array}$ & - & - & 2.9 & $\begin{array}{l}0.2 \\
0.0\end{array}$ \\
\hline Speech Disorder & - & - & 1.0 & 0.0 \\
\hline Vertigo & 1.9 & 0.0 & - & - \\
\hline Carpal Tunnel Syndrome & 1.3 & 0.7 & - & _- \\
\hline \multicolumn{5}{|l|}{ Gastrointestinal System } \\
\hline Nausea & 59.9 & 21.8 & 29.8 & 18.3 \\
\hline Vomiting & 12.1 & 6.8 & 7.2 & 4.2 \\
\hline Dyspepsia & 9.6 & 4.8 & 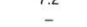 & ${ }_{-}^{4.2}$ \\
\hline Constipation & 8.3 & 7.5 & 5.8 & 3.3 \\
\hline Abdominal Pain & 6.4 & 2.7 & 8.7 & 7.5 \\
\hline $\begin{array}{l}\text { Diarrhea } \\
\text { Diant }\end{array}$ & - & - & 4.8 & 2.5 \\
\hline Anorexia & 3.8 & 1.4 & ${ }^{4.0}$ & - \\
\hline Flatulence & 2.5 & 1.4 & 1.9 & 0.8 \\
\hline Tooth Disorder & 1.9 & 0.7 & 1.0 & 0.8 \\
\hline Saliva Increased & - & - & 2.4 & 0.8 \\
\hline Colitis & 1.3 & 0.0 & 2.4 & 0.0 \\
\hline Dysphagia & 1.3 & 0.0 & 2.4 & 0.8 \\
\hline $\begin{array}{l}\text { Deriodontitis } \\
\text { Pyphes }\end{array}$ & 1.3 & 0.0 & $\begin{array}{l}.2 .4 \\
1.4\end{array}$ & $\begin{array}{l}0.8 \\
0.8\end{array}$ \\
\hline Eructation & - & - & 1.4 & 0.0 \\
\hline Fecal Incontinence & - & - & 1.0 & 0.0 \\
\hline Hemorrhoids & - & - & 1.0 & 0.0 \\
\hline Gastroesophageal Reflux & - & - & 1.0 & 0.0 \\
\hline Gastrointestinal Disorder (NOS) & S) - & - & 1.0 & 0.0 \\
\hline Tooth Ache & - & - & 1.0 & 0.0 \\
\hline \multicolumn{4}{|l|}{ Hearing and Vestibular } & - \\
\hline \multicolumn{5}{|l|}{$\begin{array}{l}\text { Tinnitus } \\
\text { Heart Rate and Rhythm }\end{array}$} \\
\hline $\begin{array}{l}\text { Pealpitation } \\
\text { Pan }\end{array}$ & 3.2 & 2.0 & 2.9 & 2.5 \\
\hline
\end{tabular}




\begin{tabular}{|c|c|c|c|c|}
\hline & \multicolumn{2}{|c|}{ Early Therapy } & \multicolumn{2}{|c|}{ Adjunct Therapy } \\
\hline & $\begin{array}{c}\text { AEQU1P० } \\
N=157 \\
\% \text { occurrence }\end{array}$ & $\begin{array}{c}\begin{array}{c}\text { Placabo } \\
N=147 \\
N=17 \\
\% \text { occurrence }\end{array}\end{array}$ & $\begin{array}{c}\text { REQulFo } \\
N=208 \\
\% \text { Decurrence }\end{array}$ & 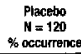 \\
\hline \multicolumn{5}{|c|}{ Heart Rate and Phythm } \\
\hline $\begin{array}{l}\text { Extrasystoles } \\
\text { Tachycardia }\end{array}$ & 1.9 & $\begin{array}{l}0.7 \\
0.0\end{array}$ & $\overline{1.0}$ & $\overline{0.0}$ \\
\hline Fibrillation Atria & 1.9 & 0.0 & - & - \\
\hline Tachycardia Supraventricular & 1.3 & 0.0 & - & - \\
\hline Bradycardia & - & - & 1.0 & 0.0 \\
\hline \multicolumn{5}{|l|}{ Liver and Billiary System } \\
\hline Gamma - GT Increased & 1.3 & 0.7 & 1.0 & 0.0 \\
\hline Hepatic Enzymes Increased & 1.3 & 0.0 & - & - \\
\hline \multicolumn{5}{|l|}{ Metabolic and Nutritional } \\
\hline Alkaline Phosphate Increased & d 2.5 & 1.4 & 1.0 & 0.0 \\
\hline Weight Decrease & - & - & 2.4 & 0.8 \\
\hline Hypoglycemia & 1.3 & 0.0 & - & - \\
\hline \multicolumn{5}{|l|}{ Misculoskeletal Sysfem } \\
\hline Arthralgia & - & ... & 6.7 & 5.0 \\
\hline Anthritis & - & - & 2.9 & 0.8 \\
\hline Arthritis Aggravated & 1.3 & 0.0 & 1.4 & 0.0 \\
\hline \multicolumn{5}{|c|}{ Myocardial, Endocardlal, Pericardial Valve } \\
\hline Myocardial Ischemia & 1.3 & 0.7 & - & - \\
\hline \multicolumn{5}{|l|}{ Psychiatric } \\
\hline Somnoience & 40.1 & 6.1 & 20.2 & 8.3 \\
\hline Anxiety & - & - & 6.3 & 3.3 \\
\hline Confusion & 5.1 & 1.4 & 8.7 & 1.7 \\
\hline Hallucination & 5.1 & 1.4 & 10.1 & 4.2 \\
\hline Nervousness & - & - & 4.8 & 2.5 \\
\hline Yawning & 3.2 & 0.0 & - & - \\
\hline Amnesia & 2.5 & 1.4 & 4.8 & 0.8 \\
\hline Dreaming Abnormal & - & - & 2.9 & 1.7 \\
\hline Depersonatization & - & - & 1.4 & 0.0 \\
\hline Paranoid Reaction & - & - & 1.4 & 0.0 \\
\hline Agitation & 1.3 & 0.7 & 1.0 & 0.0 \\
\hline Concentration Impaired & 1.9 & 0.0 & 1.0 & 0.0 \\
\hline Illusion & 1.3 & 0.0 & - & - \\
\hline Thinking Abnormal & - & - & 1.4 & 0.8 \\
\hline Apathy & - & - & 1.0 & 0.0 \\
\hline Increased Libido & - & - & 1.0 & 0.0 \\
\hline Personality Disorder & - & - & 1.0 & 0.0 \\
\hline \multicolumn{5}{|l|}{ Red Blood Cell } \\
\hline Anemia & - & - & 2.4 & 0.0 \\
\hline Reproductive Mals & & & & \\
\hline Impotence & 2.5 & 1.4 & - & - \\
\hline Prostatic Disorder & - & - & 1.0 & 0.0 \\
\hline Penis Oisorder & - & - & 1.3 & 0.0 \\
\hline Resistance Mechanism & & & & \\
\hline Upper Respiratory Iract Infection & ion - & - & 8.7 & 8.3 \\
\hline Infection Viral & 10.8 & 3.4 & 7.2 & 6.7 \\
\hline Respiratory System & & & & \\
\hline Pharyngitis & 6.4 & 4.1 & - & - \\
\hline Fhinitis & 3.8 & 2.7 & - & - \\
\hline Sinusitis & 3.8 & 2.7 & - & - \\
\hline Dyspnea & 3.2 & 0.0 & 2.9 & 1.7 \\
\hline Eronichitis & 2.5 & 1.4 & - & - \\
\hline Respiratory Disorder & 1.9 & 1.4 & 1.9 & 0.0 \\
\hline Pneumonia & 1.3 & 0.7 & 1.0 & 0.8 \\
\hline Coughing & - & - & 1.4 & 0.8 \\
\hline $\begin{array}{l}\text { Skin/Appendages } \\
\text { Pruritis }\end{array}$ & - & _- & 10 & 0.0 \\
\hline Urinary System & & & & \\
\hline Urinary Tract Infection & 5.1 & 4.1 & 6.3 & 2.5 \\
\hline Cystitis & 1.3 & 0.7 & - & - \\
\hline Micturition Frequency & - & - & 1.4 & 0.0 \\
\hline Pyuria & - & - & 1.9 & 0.8 \\
\hline Urinary Incontinence & - & - & 1.9 & 0.8 \\
\hline Urinary Retention & 1.3 & 0.7 & - & - \\
\hline Dysuria & - & - & 1.0 & 0.0 \\
\hline $\begin{array}{l}\text { Vascular Extracardiac } \\
\text { Peripheral Ischemia }\end{array}$ & 2.5 & 0.0 & - & - \\
\hline Vision & & & & \\
\hline Vision Abnormal & 5.7 & 3.4 & ـ & - \\
\hline Eye Abnormality & 3.2 & 1.4 & - & - \\
\hline Diplopia & - & - & 1.9 & 0.8 \\
\hline Xerophthalmia & 1.9 & 0.0 & 1.4 & 0.8 \\
\hline Cataract & - & - & 1.4 & 0.8 \\
\hline Lacrimation Abnormal & - & - & 1.4 & 0.0 \\
\hline White Cell and Reticuloentol & 1othelial s & & & \\
\hline Eosinophilia & - & - & 1.4 & 0.0 \\
\hline
\end{tabular}

Post-Marketing Experience - Patients treated with REQUIP' have rarely reported suddenly falling asleep while engaged in activities of daily living, including operation of motor vehicles which has sometimes resulted in accidents (see WARNINGS).

DOSAGE AND ADMINISTRATION: REOUIP" (ropinirole hydrochloride) should be taken three times daly. While administration of REQUIPo with meals may improve gastrointestinal tolerance, REQUIP\% may be taken with or withou food. The recommended starting dosage is $0.25 \mathrm{mg}$ three times daily. Based on individual patient response, dosage should then be titrated by weekly increments of $0.25 \mathrm{mg}$ per dose as described in the table below. After week 4, daily dosage may be increased by 0.5 to $1.0 \mathrm{mg}$ per dose on a weekly basis until an optimal therapeutic response is established. Smaller dose increments are recommended for patients who may be at risk for orthostatic symptoms.

\begin{tabular}{|lcccc|}
\hline & \multicolumn{5}{c|}{ Week } \\
\hline & 1 & 2 & 3 & 4 \\
\hline Unit Dose (mg) & 0.25 & 0.5 & 0.75 & 1.0 \\
\hline Total Daily Dose (mg) & 0.75 & 1.5 & 2.25 & 3.0 \\
\hline
\end{tabular}

In clinical trials, initial benefits were observed with $3 \mathrm{mg} /$ day and higher doses. Doses greater than $24 \mathrm{mg} /$ day have not been included in clinical trials. In a 5year, double-blind study of early therapy in Parkinson's disease patients, the average daily dose of REQUIPos (based on the observed data set) was $10.1 \mathrm{mg}$ at 6 months (median dose $=9.0 \mathrm{mg}$ ), $14.4 \mathrm{mg}$ at 3 years (median dose $=15.0$ $\mathrm{mg}$ ), and $16.6 \mathrm{mg}$ at 5 years (median dose $=18.0 \mathrm{mg}$ ), regardless of levodopa supplementation. When REQUIPs is administered as adjunct therapy to levodopa, the dose of levodopa may be decreased gradually as tolerated once a therapeutic effect with REQUIPo has been observed. REQUIP should be discontinued gradually over a 7-day period. The frequency of administration should be reduced from three times daily to twice daily for 4 days. For the remaining 3 days, the frequency should be reduced to once daily prior to complete withdrawal of REQUIP\% . Renal and Hepatic Impairment: In patient with mild to moderate renal impairment, REDUPP may be titrated in the recommended manner according to clinical response. Patients with severe renal impairment or on hemodialysis have not been studied and administration of REQLIP to such patients is not recommended. Patients with hepatic impairment have not been studied and administration of REQUiP ${ }^{\infty}$ to such patients is not recommended. Estrogen Replacement Therapy: In patients already receiving estrogen replacement therapy, REQUIPs may be titrated in the recommended manner according to clinical response. However, if estrogen replacement therapy is stopped or started during treatment with REQUIP', adjustment of the REQUIPs dosage may be required. AVAILABILITY OF DOSAGE FORM: REQUIP ${ }^{\circledR}$ is supplied as a pentagona film-coated Tiltab ${ }^{\infty}$ tablet with beveled edges containing ropinirole (as ropinirole hydrochloride) as follows: $0.25 \mathrm{mg}$ - white imprinted with $\mathrm{SB}$ and $4890 ; 1.0 \mathrm{mg}$ - green imprinted with SB and 4892; $2.0 \mathrm{mg}$ - pale pink imprinted with $\mathrm{SB}$ and $4893 ; 5.0 \mathrm{mg}$ - blue tablets imprinted with $\mathrm{SB}$ and 4894. REQUIP ${ }^{\mathrm{B}}$ is available in bottles in the pack size of 100 tablets. Full Product Monograph available to practitioners upon request.

GlaxoSmithKline Inc.

7333 Mississauga Road North

Mississauga, Ontario

L5N 6L4

REQUIP is a registered trademark, used under license by Glaxo Smithkine Inc. Date of preparation: June 18,200

Date of revisions: July 31,2002

1. Rascol 0 et al. A five-year study of the incidence of dyskinesia in patients with early Parkinson's disease who were treated with ropinirole or levodopa. N Eng J Med 2000;342(20):1484-1491. 2. Product Monograph of ReQuip (ropinirole hydrochloride), GlaxoSmithKline, Jully 31, 2002.

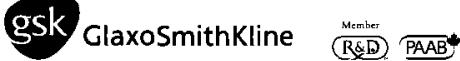

Hepatic Impairment

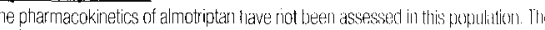
maximum decrease expected in the clearance of almotrintian due to hev rial

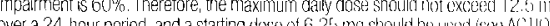
AND C AND CLINCAL PHARMACOLOGY, Special Pogulations and PRECAUIIONS).

\section{Renal Impairment}

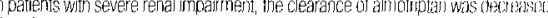

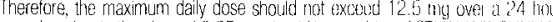

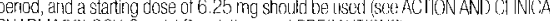
PHARMACOLOGY, Special POpulations and PRECAUIIONS)

\section{PHARMACEUTICAL INFORMATION}

Drug Substance

Proner Narne:

Chemical Namle:

almotriptan malat

Structural Formula:

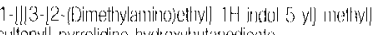
sulfonyl-pyrodidine-hydoxybutianedioate

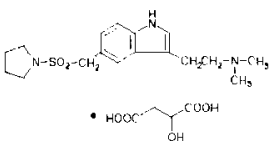

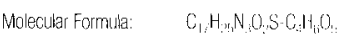

Molecular Weight: $\quad 46956$

Physicat Form:

Amotriptan is a while lo slientity yellow crystalline nowde. Solubility:

pka:

Melting Point

pH:

Partition Coefficient:

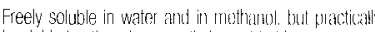
insoluble in ethan al ano methylene chloride

8.77 at $22 \pm 200$

$167-17300$

$1 \%$ solution in purified water hets $2 \mathrm{H} 4.1$

A partition coefticient of 0.008 betwe(n) wctinlol allnt

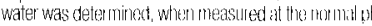
value $[5.4 .6 .3)$ tor polified widt?

Composition

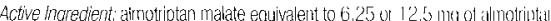

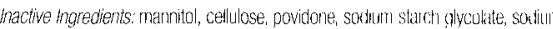

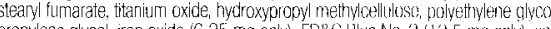

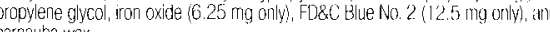

Stability and Storage Recommendations

AXERT tatbets should be stored between $153^{\circ} 0^{\circ} \mathrm{C}$

\section{AVAILABILTY OF DOSAGE FORMS}

AXERT (amotipten malate) tablets are avalable throught prescription only AXERT $6.25 \mathrm{mg}$ tablet contains $6.25 \mathrm{mg}$ of almotriptan and is a whittes, circuld biconvex tablet, printed in red with the code "2089". Avaliable in unit dose 'aluminilum! blister pack) of 6 it tablets.

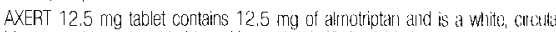
iconvex tablet, printed in blue with a stylized "A". Avalabble in unit dose taluminus blister packj of 6 tablets.

AXcrit is a schedule F drug

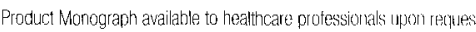

\section{JANSSEN-ORTHO}

JANSSEN-ORTHO InC

Toronto, Ontario M3C $1 \mathrm{LS}$

Date of Issuance: October 2003

Licensed from: Almirall

AXP1041006A

C 2003 JANSSEN-ORTHO inc

* All trademark rights used under license 8005 (R\&D) 


\section{AVONEX \\ (Interferon beta-1a)}

\section{PRESCRIBING INFORMATION THERAPEUTIC CLASSFICATION mmunomodulator}

\section{INDICATIONS AND CUINICAL USE}

\section{Relapsing Forms of Multiple Sclerosis:}

AVONEX"' (Interferon beta-1a) is indicated for the treatment of relapsing forms of multiple sclerosis (MS) to slow the progression of disability, decrease the frequency of clinical exacerbations, and reduce the number and volume of active brain lesions identified on Magnetic Resonance Imaging (MRl) scans. Single Demyelinating Event:

AVONEX" is also indicated for the treatment of people who have experienced a single demyel inating event, accompanied by abnormal Magnetic Resonance Imaging (MRI) scans with lesions typical of MS, to delay the onset of clinically definite multiple sclerosis (as determined by a second demyelinating event) and to decrease the number and volume of active brain lesions and overall disease burden (as identified by MRI scans). Before initiating treatment with AVONEX, alternate diagnoses should first be excluded.

Safety and efficacy have not been evaluated in patients with chronic progressive multiple sclerosis.

\section{CONTRAINDICATIONS}

VONEX (Intefen beta-1a) is contraindicated in patients with a history of hypersens itivity to natural or recombinant interferon beta, human albumin, o any other component of the formulation.

\section{WARNINGS}

should be used under the supervision of a physician. The first injection should be performed under the supervision of an appropriately qualified health care protessional (see DOSAGE AND ADMINISTRATION

\section{Depression and Suicide}

AVONEX" (Interferon beta-1a) should be used with caution in patients with depression. Depression and suicide have been reported to occur in patients receiving other interferon compounds. Depression and suicidal ideation are krown to occur at an increased frequency in the MS population. A relationship between the occurrence of depression and/or suicidal ideation and the use of AVONEX" has not been established. An equal incidence of depression was seen in the placebo-treated and the AVONEX -treated patients in the placebo controlled study of relapsing MS patients. In the study of patients with a single demyelinating event AVONEX"'-treated patients were more likely to experience depression than placebo-treated patients ( $p=0.05$ ). Suicidal tendency occurred in one subject treated with placebo, and there were no reports of suicide attempts. Patients treated with AVONEX should be advised to report immediately any symptoms of depression and/or suicidal ideation to their prescribing physicians. If a patient develoos depression, antideoressant therapy or cessation of AVONEX theraoy should be considered.

Anaphylaxis

Anaphylaxis has been reported as a rare comolication of AVONEX 4 se. Other allergic reactions have included dyspnea, orolingual edema, skin rash and urticaria (see ADVERSE EVENTS)

\section{Decreased Peripheral Blood Counts}

Decreased peripheral blood counts in all cell lines, including very rare pancytopenia and thrombocytopenia have been reported from post-marketing experience (see ADVERSE EVENTS). Some cases of thrombocytopenia have had nadirs below $10,000 / \mathrm{hL}$. Some cases reoccur with re-challenge. Patients should be monitored for signs of these disorders (see PRECAUTIONS Laboratory Tests

\section{Pregnancy and Lactation}

AVONEX should not be administered in case of pregnancy and lactation. There are no adequate and wel:-controlled studies of AVONEX in pregnant women. Patients should be advised of the abortifacient potential of AVONEX Fertile women receiving AVONEX" should be advised to take adequate contraceptive measures. It is not known it interferons alter the efficacy of oral contraceptives (see PRECAUTIONS: Information to Patients) If a woman becomes pregnant or plans to become pregnant while taking AVONEX"', she should be informed of the potential hazards to the fetus, and it should be recommended that the woman discontinue therapy. The reproductive toxicity of AVONEX" has not been studied in animals or humans. In pregnant monkeys given interferon beta at 100 times the recommended weekly human dose (based upon a body surface area comparison), no teratogenic or other adverse effects on fetal development were observed. Abortifacient activity was evident following 3 to 5 doses al this level. No abortifacient effects were observed in monkeys treated at 2 times the recommended weekly human dose (based upon a body surface area comparison). Although no teratogenic effects were seen in these studies, it is not known if teratogenic effects would be observed in humans. There are no adequate and well-controlled studies with intel ferons in pregnant women.

\section{Nursing Mothers}

It is not known whether AVONEX is excreted in human milk. Because of the potential of serious adverse reactions in nursing infants, a decision should be made to either discontinue nursing or to discontinue AVONEX

\section{PRECAUTIONS}

\section{General}

Patients should be informed of the most common adverse events associated with interferon beta administration, including symptoms of the flu-i ike syndrome (see ADVERSE EVENTS). These symptoms tend to be most prominent at the initiation of therapy and decrease in trequency and severity with continued treatment (see PRECAUTIONS: intormation to Patients)

Seizures

Caution should be exercised when administering AVONEX (Interferon beta-1a) to patients with pre-existing seizure disorder. In the two placebo-controlled studies of MS 4 patients receiving AVONEX experienced seizures, while no seizures occurred in the placebo group. Of these 4 patients, 3 had no prio history of seizure. It is not known whether these events were related to the effects of MS atone, to AVONEX , of to a combination of both. For patients with no prior history of seizure who devetoped seizures during therapy with AVONEX an etiologic basis should be established and appropriate anti-convulsant therapy instituted orior to considering resumption of AVONEX treatment. The effect of AVONEX ${ }^{\mathbb{2}}$ administration on the medical management of patients with seizure discrder is unknown.

\section{Cardiac Disease}

Patients with cardiac disease, such as angina, congestive heart failure or arihythmia, should be closely monitored for worsening of their clinica condition during initiation and continued treatment with AVONEX.5. Whil AVONEX $X^{(a)}$ does not have any known direct-acting cardiac toxicity, during the post-marketing period infrequent cases of congestive heart failure cardiomyopathy and cardiomyopathy with congestive heart failure have been reported in patients without known predisposition to these events or other known etiologies. In rare cases, these events have been temporally related to the administration of $A V O N E X^{5}$ and have recurred upon re-challenge in patien with known predisposition

\section{Autoimmune Disorders}

As with other interferon treatment, autoimmune disorders of multiple target organs have been reported post marketing including idiopathic thrombocytopenia, hyper and hypothyroidism, and rare cases of autoimmune hepatitis have also been reported. Patients should be monitured for signs o these disorders (see PRECAUTIONS: Laboratory Tests) and appropriate treatment implemented when observed.

\section{Hepatic Injury}

AVONEX, like other interteron beta products, has the potential for causing severe liver injury (see ADVERSE EVENTS). Hedatic injury inc luding elevated serum hepatic enzyme levels and hepatitis, some of which have been severe, has been reported post-marketing. In some patients a recurrence of elevated serum levels of hepatic enzymes have occurred upon AVONEX $X^{*}$ re-challenge. In some cases, these events have occurred in the presence of other drugs that have been associated with hepatic injury. The potential of additive effects from multiple drugs or other hepatotoxic agents (e.g., alcohol) has not been determined. Patients should be monitored tor signs of hepatic injury (see PRECAUTIONS: Laboratory Tests) and caution exercised when AVONEX: is used concomitantly with other drugs associated with hepatic injury

\section{Laboratory Tests}

Laboratory abnormalities are associated with the use of interferons. During the placebo-controlled trials in multiple sclerosis, liver function tests were performed at least every 6 months. Liver function tests including serum AL are recommended during AVONEX therapy and should be performed a baseline, monthly at months 1 through 6 , and every 6 months thereafter AVONEX should be initiated with caution in patients with a history of significant liver disease, clinical evidence of active liver disease, alcoho abuse, increased serum ALT ( $>2.5$ times ULN), and in patients rece ving concomitant medications associated with hepatic injury. These palients may require more rrequent monitoring of serum hepatic enzymes. Discontinuation or interruption of AVONEX should be considered if ALT rises above 5 times the ULN. Treatment with AVONEX ${ }^{a}$ should be stopped if jaundice or othe clinical symptoms of liver dysfunction appear. In addition to those laboratory tests normally required for monitoring patients with $\mathrm{MS}$, and in acdition to liver enzyme monitoring (see PRECAUTIONS: Hepatic Injury) complete blood cell counts and white blood cell differential, platelet counts, and blood chemistries, including thyroid function tests, are recommended during

AVONEX ${ }^{n-1}$ therapy (see WARNINGS: Decreased Peripheral Blood Counts and ADVERSE EVENTS). These tests should be pertormed at baseline, months $1,3,6$, and every 6 months thereatter. Patients with myelosuppression may require more intensive monitoring of complete blood cell counts, with differential and platelet counts

\section{Immunogenicity}

Serum neutralizing antibodies were reported to develop in only $2 \%$ to $6 \%$ AVONEX -treated patients. Although the exact clinical signiticance of antibodies has not been fully establ ished, there are multiple literature reports indicating that the occurrence of reutralizing antibodies with beta interferon treatmen impacts cl inical efficacy, MRI measures and the induction of biological markers

\section{Drug Interactions}

No tormal drug interaction studies have been conducted with AVONEX? In the placebo-controlled study, corticostercids or ACTH were administered for treatment of exacerbations in some patients concurrently receiving AVONEX In addition some patients receiving AVONEX were also treated with anti-depressant therapy and/or oral contraceptive therapy. No unexpected adverse events were associated with these concomitant therapies.

Other interferons have been noted to reduce cycochrome $\mathrm{P}-450$ oxidase-mediated drug metabolism. Formal hepatic drug metabolism studies with AVONEX in humans have not been conducted. Hepatic microsomes isolated from AVONEX -treated thesus monkeys showed no influence of AVONEX ${ }^{*}$ on hepatic $P-450$ enzyme metabol ism activity.

As with all interferon products, proper monitoring of patients is required if AVONEX is given in combination with myelosuppressive agents.

\section{Carcinogenesis and Mutagenesis}

Carcinogenesis: No carcinogenicity data for Interferon beta-1a are avallable in animais or humans.

Mutagenesis: Interferon beta-1a was not mutagenic when tested in the Ames bacterial test and in an in vitro cytogenetic assay in human lymphocytes in the presence and absence of metabolic activation. These assays are designed to detect agents that interact directly with and cause damage to cellular DNA. Interferon beta-1a is a glycosylated prote in that does not directly bind to DNA.

\section{Impairment of Fertility}

No studies were conducted to evaluate the effects of interferon beta on fertility in normal wormen or women with MS. It is not known whether AVONEX can affect human reproductive capacity. Menstrual irregularities were observed monkeys administered interferon beta at a dose 100 times the recommended weekly hurnan dose (based upor a body sufface area comparison). Anovulation

and decreased serum progesterone levels were also noted transiently in some animals. These effects were reversible after discontinuation of drug. Treatment of monkeys with interferon beta at 2 times the recommended weekly human dose (based upon a body surface area comparison) had no effects on cycle duration or ovulation.

The accuracy of extrapolating animal doses to human doses is not known. In the placebo-controlled study, $6 \%$ of patients receiving placebo and $5 \%$ of patients receiving AVONEX" experienced menstruai disorder. If menstrual irregularities occur in humans, it is not known how long they will persist following treatment

\section{Pediatric Use}

Safety and effectiveness have not been established in pediatric patients below the age of 18 years.

\section{Information to Patients}

Patients should be intormed of the most common adverse events associated with AVONEX administration, including symptoms associated with flu syndrame (see ADVERSE EVENTS

Symptoms of flu syndrome are most prominent at the initiation of therapy and decrease in frequency with continued treatment. In the placebo-controller study, palients were instructed to take $650 \mathrm{mg}$ acelaminophen immediately prior to injection and for an additional 24 hours after each injection to modulate acute symptoms associated with AVONEX: administration.

Patients should be advised not to stop or modify their treatment unless structed by their physician.

Patients should be cautioned to report depression or suicidal ideation see WARNINGS).

Patients should be informed about the risk of decreased blood counts including white blood cells and platelet coun's and of the recuirement for periodic laboratory testing (see WARNINGS). Patients should be advised to report immediately any clinical symptoms associated with blood count abnormalities and laboratory testing should be performed according to standard medical practice (see WARNINGS). Patients with myelosuppression may requife more intensive monitoring of complete blood cell counts, with differential and platelet counts.

Patients should be informed of the potential risk of liver injury with AVONEX therapy, and of the requirement for frequent laboratory testing (see PRECAUTIONS). Patients should be informed of the symptoms suggesting liver dysfunction, such as loss of appetite accompanied by other symptoms such as nausea, vomiting, and jaundice, and advised to consult with their physician immediately should such syrnptoms arise.

Patients should be instructed to report any symptoms of thyroid dysfunction (hypo or hyperthyroidism) and thyroid function tests should be performed according to standard medical practice (see PRECAUTIONS

Female patients should be advised about the abortifacient potential of AVONEX and instructed to take adequate contraceptive measures (see PRECAUTIONS) When a physician determines that AVONEX" can be used outside of the physician's office, persons who will be administering AVONEX" should receive instruction in reconstitution and injection, including the review of the injection procedures. If a patient is to self-administer, the physical ability of that patient to self-inject intramuscularly should be assessed. if home use is chosen, the first injection should be performed under the supervision of a cualified health care professional. Patients should be advised of the importance of rotating sites of injection with each dose, to minimize the likelihood of injection site reactions. A puncture-resistant container for disposal of needles and syringes should be used. Patients should be instructed in the technique and importance of proper syringe and needle disposal and be cautioned against reuse of these items.

\section{ADVERSE EVENTS}

\section{Relapsing Multiple Sclerosis}

The safety data describing the use of AVONEX" (Interferon beta-1a) in MS patients are based on the placebo-controlled trial in which 158 patients with relapsing multiple sclerosis randomized to AVONEX" were treated tor up to

The 5 most common adverse events associated (at $p<0.075$ ) with AVONEX treatment were flu-like symptoms (otherwise unspecified), muscle ache, fever chills, and asthenia. The incidence of all 5 adverse events diminished with continued treatment.

One patient in the placebo group attempled suicide; no AVONEX"-treated patients attempted suicide. The incidence of depression was equal in the 2 treatrnent groups. However, since depression and suicide have beer reported with other interferon products, AVONEX"' should be used with caution in patients with depression (see WARNINGS)

In the placebo-controlled study 4 patients receiving AVONEX" exoerienced seizures, while no seizures occurred in the placebo group. Of these 4 patients. 3 had no prior history of seizure. It is not known whether these events were retated to the effects of MS alone, to AVONEX'; or to a combination of both (see PRECAUTIONS)

Table 1 enumerates adverse events and selected laboratory abnormalities that occurred at an incidence of $2 \%$ or more among the 158 patients with relapsing MS treated with $30 \mathrm{mcg}$ of AVONEX"' once weekly by IM injection Reported adverse events have been classified using standard COSTART terms. Terms so general as to be uninformative or more common in the placebo-treated patients have been excluded

Table 1 
Table 1 (continued) Adverse Events and Selected Laboratory Abnormalities

$\begin{array}{lcc}\text { Adverse Event } & \text { Placebo } & \text { AVONEX } \\ & (N=143) & (N==158)\end{array}$

Abdominal pain

Chest pain

Injection site reaction

Malaise

Iniection site inflammation

Hypersensitivity reaction

Ovarian cyst

Ecchymosis injection site

Cardiovascular System

Syncope

Vasodilation

Digestive System

Nausea

Diarrhea

Dyspepsia

Anorexia

Hemic and Lymphatic System

Anemia*

Eosinophils $\geq 10^{\circ}$

HCT $(\%) \leq 32$ (fermales) or $\leq 37$ (males)

Metabolic and Nutritional Disorders

SGOT $\geq 3 \times$ ULN

Musculoskeletal System

Muscie ache*

Arthralgia

Nervous System

Sleep difficult

Diziness

Muscle soasm

Suicidal tendency

Seizure

Speech disorder

Ataxia

Respiratory System

Upper respiratory tract infection

Sinusitis

Dyspnea

Skin and Appendage

Urticaria

Alopecia

Nevus

$(N=143) \quad(N=158)$

\begin{tabular}{|c|c|c|}
\hline $6 \%$ & & \\
\hline $4 \%$ & & \\
\hline $1 \%$ & & \\
\hline $3 \%$ & & \\
\hline $0 \%$ & & \\
\hline $0 \%$ & & \\
\hline $0 \%$ & & \\
\hline $1 \%$ & & \\
\hline $2 \%$ & & \\
\hline $1 \%$ & & \\
\hline $23 \%$ & & \\
\hline $10 \%$ & & \\
\hline $7 \%$ & & \\
\hline $6 \%$ & & \\
\hline $3 \%$ & & \\
\hline $4 \%$ & & \\
\hline $1 \%$ & & \\
\hline $1 \%$ & & \\
\hline $15 \%$ & & \\
\hline $5 \%$ & & \\
\hline $16 \%$ & & \\
\hline $13 \%$ & & \\
\hline $6 \%$ & & \\
\hline$\uparrow \%$ & & \\
\hline $0 \%$ & & \\
\hline $0 \%$ & & \\
\hline $0 \%$ & & \\
\hline $28 \%$ & & \\
\hline $17 \%$ & & \\
\hline $3 \%$ & & \\
\hline $2 \%$ & & \\
\hline $1 \%$ & & \\
\hline & & \\
\hline
\end{tabular}

Table 1 (continued)

Table 1 (continued)
$\begin{aligned} & \text { Adverse Events and Selected Laboratory Abnormalities } \\
& \text { in the Placebo-Controlled Study of Relapsing MS }\end{aligned}$
\begin{tabular}{lcc} 
Adverse Event & Placebo & AVONEX \\
& $(\mathrm{N}=143)$ & $(\mathrm{N}=158)$ \\
\hline
\end{tabular}

Herpes zoster $\quad 2 \%$

Herpes simplex

Special Senses

Otitis media

Hearing decreased $\quad 0 \%$

Urogenital

Vaginitis

$\begin{array}{ll}2 \% & 3 \% \\ 1 \% & 2 \% \\ & \\ 5 \% & 6 \% \\ 0 \% & 3 \% \\ 2 \% & 4 \%\end{array}$

* Significantly associated with AVONEX treatment $(p \leq 0.05)$.

Post-Marketing Experience

Anaphylaxis and other allergic reactions have been reported in patients using

AVONEX (see WARNINGS: Anaphylaxis). Decreased peripheral blood

counts have been reported in patients using AVONEX (see WARNINGS:

Decreased Peripheral Blood Counts). Seizures, cardiovascular adverse events, and autoimmune disorders also have been reported in association with the USe of AVONEX: (see PRECAUTIONS)

\section{Single Demyelinating Event}

The adverse events observed in the placebo-controlled study of patients with a single dernyelinating event were similar to those observed in the placebo-controlled study of relapsing MS patients. Patients in this trial $(N=193)$ initiated AVONEX: treatment while on oral prednisone, which was used to treat the initial demyelinating event. The most common adverse events associated with AVONEX $(p \leq 0.05)$ during the first 6 months of treatment were flu-like syndrome (AVONEX: $39 \%$, placebo: $22 \%$ ), tever (AVONEX: $17 \%$, placebo: $6 \%$ ), and chills (AVONEX $: 17 \%$, placebo: $3 \%$ ) A higher proportion of patients treated with AVONEX $(20 \%)$ experienced depression, as compared with placebo $(13 \%)(p=0.05)$ (see WARNINGS)

\section{DOSAGE AND ADMINISTRATION}

The recommended dosage of AVONEX (Interferon beta-1a) is $30 \mathrm{mcg}$ injected intramuscularly once a week. AVONEX is intenced for use under the guidance and supervision of a physician. Patients may self-inject only if their physician determines that it is appropriate and with medical fo low-up, as necessary after proper training in IM injection technique.

Before initiating a patient on AVONEX therapy, please note the following CONTRAINDICATIONS.

- AVONEX is contraindicated in patients with a known hypersensitivity to natural or recombinant interferon beta, al bumin (human), or any other component of the formulation. Anaphylaxis has been observed with the uSE of AVONEX
Please also review the WARNINGS and PRECAUTIONS sections and ensure appropriate moniloring of patients with depression, hepatic dysfunction, a history of seizures, cardiac disease, thyroid dystunction, myelosuppression, and female patients of child-bearing potential.

Patients should be advised of the side-effects of AVONEX" and instructed on the use of aseptic technique when administering AVONEX". The AVONEX Patient Leat let should be carefully reviewed with all patients, and patients should be educated on self-care and advised to keep the Leaflet for continued reference during AVONEX $X^{\circ i}$ theraoy.

\section{AVAILABILITY OF DOSAGE FORMS}

AVONEX (Interferon beta-1a) is available as:

Package (Administration Pack) containing 4 Admin istration Dose Packs (each containing one vial of AVONEX:', one $10 \mathrm{~mL}(10 \mathrm{cc})$ diluent vial, two alcohol wipes, one 3cc syringe, one Micro Pin", one needle, one adhesive bandage one gauze pad).

Product Monograph ava iable upon recuest.

\section{REFERENCES}

1. Galetta SL, Markowitz C, Lee AG. Immunomodulatory agents for the treatment of relapsing multiple sclerosis. Arch intern Med 2002 $162.2161-2169$

2. Bertolotto A, Malucchi S, Sala A, et al. Differential effects of three interferon betas on neutralizing antibodies in patients with multiple sclerosis a follow-up study in an independent laboratory. J Neurol Neurosurg Psychiatry 2002:73:148-153

3. Giovannoni $G$, Munschauer $F E$, Deisenhammer $F$. Neutralizing antibodies to interferon beta during the treatment of multiple sclerosis. $J$ Neurol Neurosurg Psychiatry 2002; 73:465-469

4. Rudick RA, Simonian NA, Alam JA. Incidence and significance of neutralizing antibodies to interferon beta-1a in multiple sclerosis. Neurology 1998:50:1266-1272

5. AVONEX Product Monograph, 2003

\section{biogen idec}

3 Robert Speck Parkway, Suite 300, Mississauga, 0ntario L4Z 2G5 (C) 2004 Biogen Idec Canada Inc. All rights reserved

Biogen Idec Canada Inc. is a trademark of Biogen Idec MA Im AVONEX is a registered trademark of Biogen Idec MA Inc. Micro Pin" is a registered tradernark of B. Braun Medical Inc

7022-1 Can

See pages A-14, A-15

\section{Continued from page A-58}

\section{DOSAGE AND ADMINISTRATION}

REMINYL (galaniamine hydrobromide) tabbets should only be prescribed by (or following consuitation with clinicians who are experienced in the diagnosis and management of Alzheimer's Disease

Adults

The dosage of REMINYL shown to be effective in controlled clinical trials is $16-32 \mathrm{mg} /$ day given as twice daily dosing. As the dose of $32 \mathrm{mg} /$ day is less well tolerated than lower doses and does not provide increased effectiveness, the recommended dose range is $16-24 \mathrm{mg} /$ day given in a b.i.d. regimen. The dose of $24 \mathrm{mg} /$ day did not provice a statstically significant greater clinical benefit than $16 \mathrm{mg} /$ day. It is possible, however, that a daily dose of $24 \mathrm{mg} \mathrm{of}$ REMINYL might provide additional benefit for some patients.

The recommended starting dose of REMNYL is $4 \mathrm{mg}$ twice a day ( $8 \mathrm{mg} / \mathrm{day}$ ). Atter a minimum of 4 weeks of treatment, if this dose is well tolerated, the dose should be increased to $8 \mathrm{mg}$ twice a day $(16 \mathrm{mg} / \mathrm{day}$ ). A further increase to $12 \mathrm{mg}$ twice a day $24 \mathrm{mg} / \mathrm{day}$ ) after a minimum of 4 weeks at the previous dose may be considered following appropriate assessment of clinical benefit and tolerability.

REMINYL should be administered twice a day, preferably with morning and evening meals.

Patients and caregivers should be warned that if therapy has been interrupted for several days or longer, the patient should be restarted at the lowest dose and the dose escalated to the current dose.

The abrupt withdrawal of REMINYL in those patients who had been receiving doses in the effective range was not associated with an increased frequency of adverse events in comparison with those continuing to receive the same doses of that drug. The beneficial effects of REMINYL are lost, however, when the drug is discontinued.

\section{Concomitant Treatment}

In patients treated with potent CYP2D6 or CYP3A4 inhibitors, dose reductions can be considered.

\section{Special Pooulations}

Dose escalation, for elderly patients (>85 years old) with low body weight (especially females) or serious comorbid diseases should be undertaken with particular caution.

Hepatic !mpairment

Galantamine plasma levels may be increased in patients with moderate to

severe hepatic impairment. in patients with moderately impaired hepatic function (Child-Pugh score of 7-9), dosing could begin with $4 \mathrm{mg}$ once daly for at least 1 week. Then the dosage should be increased to $4 \mathrm{mg}$ twice a day for at least 4 weeks. In these patients, daily doses should not exceed $8 \mathrm{mg}$ twice a day (16 $\mathrm{mg} /$ day). Since no data are available on the Use of REMINYL in patients with severe hepatic impairment (Ch Id-Pugh score of 10-15). REMINYL is not recommended for this population (see PRECAUTIONS)

Renal Impairment

For patients with renal impairment (creatinine clearance of 9 to $60 \mathrm{~mL} / \mathrm{min}$ ) dose escalation should proceed cautiously and the maintenance dose should generally not exceed $16 \mathrm{mg} /$ day. Since no data are avalable on the use of REMINYL in patients with a creatinine clearance less than $9 \mathrm{~mL} / \mathrm{min}$, REMINYL is not recommended for this population (see PRECAUTIONS)

In a population of cognitively-impaired individuals, safe use of this and all other medications may require supervision.

\section{PHARMACEUTICAL INFORMATION}

\section{Drug Substance}

Trade Name:

Common Name:

Chemical Name:

Structural Formula:

Molecular Formula Molecular Weight: Ionization Constant: Partition Coefficient: Description:
REMINYL

galantamine hydrobromide

$(4 \mathrm{aS}, 6 R, 8 \mathrm{aS})-4 \mathrm{a}, 5,9,10,11,12$. hexahydro-3-methoxy-11-methyl-6 6 benzofuro[3a,3,2-eff[2]benzazepin-6-ol hydrobromide

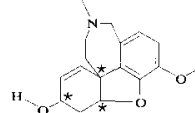

[4aS- $\left.\left.44 \mathrm{aa}_{1}, 6 \mathrm{~b}, 8 \mathrm{aR} \mathrm{R}^{*}\right)\right]$ Hydrobromide $(1: 1)$

$\mathrm{C}_{1}, \mathrm{H}_{2}, \mathrm{NO}_{3} \cdot \mathrm{HBr}$

368.27

pKa $=8.2$ (azepine miviety)

$\log P=1.09$, between $n-o c t a n o l$ and an aqueous buffer solution at $\mathrm{pH}=12.0$

$257.3^{\circ} \mathrm{C}$

Galantamine hydrobromide is a white to

almost white powder. It is freely soluble in water $(\mathrm{pH}=5.2), 0.1 \mathrm{~N}$ hydrochloric acio $(\mathrm{pH}=1.0)$ and $0.1 \mathrm{~N}$ sodium hydroxide $(\mathrm{pH}=8.3)$.

\section{Composition}

REMINYL (galantamine hydrotromide) tablets are available in three strengths containing 4, 8, $12 \mathrm{mg}$ of galantarnine per tablet, as galantamine hydrobromide. The inactive ingredients are lactose monohydrate, microcrystal ine cellulose, collodal anhydrous silica, crospovidone, magnesium stearate, hydroxypropyl methyicellulose, propylene glycol, talc, and titanlum dioxide. The $4 \mathrm{mg}$ tablet also contains yellow ferric oxide. The $8 \mathrm{mg}$ tablet aiso contains red ferric oxide. The $12 \mathrm{mg}$ tablet also contains red ferric oxide and FD \& C yellow \#6 (also known as orange yellow $S$ aluminum lake).

\section{Stability and Storage Recommendations}

REMINYL tablets should be stored between $15^{\circ} \mathrm{C}-30^{\circ} \mathrm{C}$

\section{AVAILABILITY OF DOSAGE FORMS}

REMINYL igalantamine hydrobromide), expressed as galantamine base, is available as film-coated tablets in the following strengths

$4 \mathrm{mg}$ tablets which are off-white, circular, biconvex tablets with the inscription "JANSSEN" on one side and "G4" on the other side

$8 \mathrm{mg}$ tablets which are pirk, circular, biconvex tablets with the inscription "JANSSEN" on one side and "G8" on the other side;

$12 \mathrm{mg}$ tablets which are orange-brown, circular, biconvex tablets with the inscription "JANSSEN" on one side and "G12" on the other side.

REMIML is avalable in bottles of 60 tablets and in blisters of 56 tablets per carton. Product Monograph available to healthcare professionals upon request.

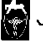

\section{JANSSEN-OATHO}

19 Green Belt Drive, Toronto, Ontario M3C 119

Date of Issuance: September 2003

RMPI031032A

C) 2003 JANSSEN-ORTHO InC

*All trademark rights used under license 


\section{World Focus on Stroke}

\section{$5^{\text {th }}$ WORLD STROKE CONGRESS \\ VANCOUVER, B.C., CANADA, JUNE $23-26,2004$}

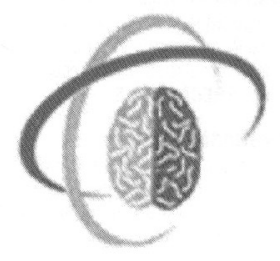

The Scientific Program will include the following:

Plenary Sessions, Course, Breakfast Sessions, Workshops, Platform Sessions

Congress Chairs:

v. Hachinski, Canada

J.W. Norris, Canada

President International Stroke Society:

J.F. Toole, USA

Chairman Canadian Stroke Consortium:

P.A. Teal, Canada

Sponsored by: International Stroke Society

Hosted by: Canadian Stroke Consortium

Co-hosts:

NSA National Stroke Association

.

Canadian Stroke Network

Deadline for abstracts: January 15, 2004

ORGANIZERS AND SECRETARIAT

Kenes International

17 Rue du Cendrier, B.P. 1726, CH-1211 Geneva 1, Switzerland e-mail: stroke2004@kenes.com

You can also visit us on the web!! http://www.kenes.com/stroke2004 


\section{GRAND RIVER HOSPITAL}

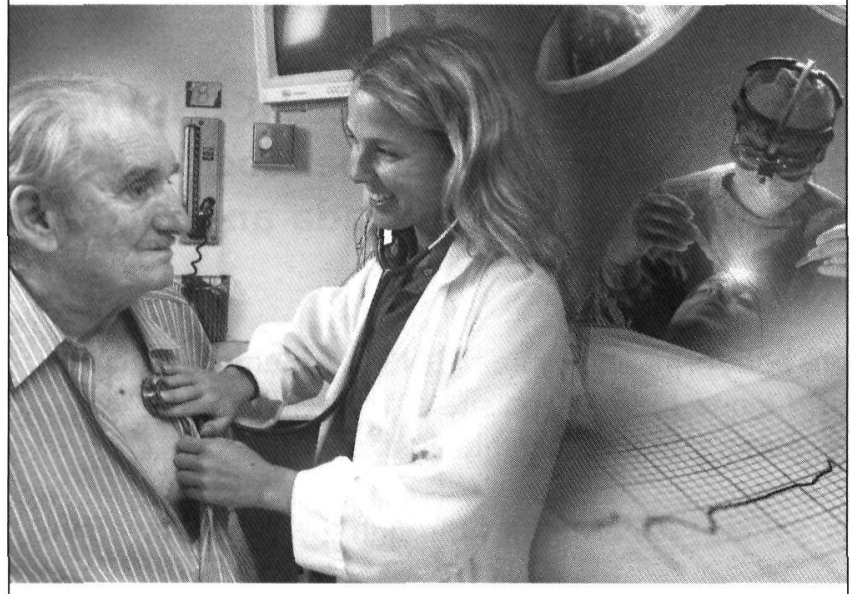

Located in the heart of South-Western Ontario, Grand River Hospital is designated as the district stroke centre, and is home to the region's hospital based MRI and the area's largest emergency department. Our 2,300 staff, 500 physicians and 800 volunteers provide quality health care for Waterloo Region, a community rich in opportunity, diversity and healthy lifestyle choices.

To meet our growing needs we have openings for:

\section{Full Time Neurologists}

Our community based neurology deparment has opportunities available for full time neurologists to become involved in clinical practice, the District Stroke program and clinical research. Particular needs for the community exist in the areas of neuromuscular diseases, MS, epilepsy and stroke. A multidisciplinary outpatient neurology clinic with emphasis on movement disorders, stroke and MS is about to be launched with full hospital support. Candidates are expected to be involved in this clinic and to share neurology and stroke call. Currently, clinical research projects in stroke, MS and headache are available for interested individuals. Please send your resume and a summary of your areas of interest to: Dr. D. J. Stewart, Medical Director of Neurological Sciences, Grand River Hospital.

\section{GRAND RIVER HOSPITAL}

835 King Street West, Kitchener, ON N2G 1G3 Fax: 519.579.9226• Email: dstewart2549@rogers.com www.grandriverhospital.on.ca

\section{Palliser Health Region}

\section{NEUROLOGIST}

The Palliser Health Region invites applications for a Neurologist position.

Activities would be concentrated at Medicine Hat Regional Hospital, a 213 acute care bed regional referral centre, in a community of 51,000 located in southeastern Alberta, and a referral area with a population of 105,000.

Candidate should possess a recognized Fellowship and be eligible for licensure by The College of Physicians and Surgeons of Alberta. Attractive relocation package with site paid visits for approved candidates. Remuneration is fee for service.

Inquiries and c.v. can be directed to :

Dr.V.L. Di Ninno, B.Sc., Ph.D., M.D., C.C.F.P.

Vice President - Medical Services

PALLISER HEALTH REGION

666 - 5 Street S.W.

Medicine Hat, Alberta, TIA 4H6

Tel: 403-529-8024; Fax: 403-529-8998

e-mail: chiefofstaffpalliserhealth.ca

www.palliserhealth.ca
Caritas St. Elizabeth's Medical Center of Boston 736 Cambridge Street, Boston, MA 02135

\section{Post-doctoral position in the newly established neuroscience center}

Caritas St. Elizabeth's Medical Center, affiliated with Tufts University School of Medicine, department of neurology invites applications from post-doctorate candidates in the life sciences to meet the demand in the growing neuroscience center with a special focus on neurodegenerative disease research. Opportunities are available in the lab of Henry Querfurth, M.D., Ph.D., an established neuroscience laboratory investigating the cell and molecular biology of Alzheimer's disease, amyloid angiopathy, inclusion body myositis and related neurodegenerative conditions. Postdoctoral fellow applicants: Experience in basic cell culture, microscopy, subcloning, Western and nucleic acid separation procedures required. Work will include preparation and use of viral vectors for gene delivery and metabolic labeling studies. Working knowledge of PC or Macintosh platforms expected; familiarity with sub-cellular fractionation, chromatography and transgenic models a plus. Applicants are asked to submit a curriculum vitae, a brief description of research accomplishments and three letters of reference directly to either: Henry Querfurth, M.D., Ph.D., Chief, Neurology Research at hquerfur@opal.tufts.edu, or to Caritas St. Elizabeth's Medical Center, 736 Cambridge Street, CBR4, Boston, MA 02135 . Candidates must be available for interview. Caritas St. Elizabeth's offers competitive salary, benefits and an outstanding collaborative research environment. 


\section{Queens}

\section{Department of Medicine and Centre for Neuroscience Studies}

\section{A Tier 1 Canada Research Chair (Tenure-track position) In Clinical NEUROSCIENCES}

The Department of Medicine and Centre for Neuroscience Studies at Queen's University in Kingston, Ontario, Canada is seeking a senior investigator/scholar in the clinical neurosciences to fill a Tier I Canada Research Chair in Clinical Neuroscience. The successful candidate must be an MD with certification in the specialty of Neurology and must have an internationally recognized research program in neuroscience that ideally links to other research strengths, which include stroke, neuroimaging, motor control and movement disorders, pain, neurodegenerative disorders, regeneration, cognitive/behavioural neuroscience, and infectious disease. It is expected that the successful candidate will provide leadership in one or more fields of clinical neuroscience research. Successful candidates must be eligible for licensure in Ontario.

Queen's is ranked among the top "doctorate-level" universities in Canada; successfully merging the collegiality of a medium-sized university with an academic rigour that has enabled members of the Faculty of Health Sciences to achieve world-class distinction.

Kingston is one of Canada's most beautiful and historic cities - bordered by the calm, blue waters of Lake Ontario and the St. Lawrence River. Housing prices compare favourably with the rest of Canada, with no part of the City of Kingston more than a twenty-minute drive to Queen's. Kingston's 147,500 residents enjoy a calendar full of festivals and a variety of cultural and recreational activities appealing to people of all ages. Located only two and a half hours from the major Canadian centres of Toronto and Montreal, two hours from Canada's capital of Ottawa, and just a 20-minute drive from the American border, Kingston is easily accessible.

Queen's University is committed to employment equity and welcomes applications from all qualified candidates, including women, aboriginal people, people with disabilities and visible minorities.

Please submit a letter of application, curriculum vitae, the names and addresses of three referees, copies of recent publications and a one page statement of current research interests and future plans to Dr. J.L. McCans, Professor and Head, Department of Medicine, Rm. \#3033 Etherington Hall, Queen's University, Kingston, Ontario, Canada K7L 3N6. Fax: (613)533-6695; e-mail: koenn@post.queensu.ca. Review of applications will commence on May 01, 2004 and will continue until the position is filled. 
The Department of Internal Medicine, Faculty of Medicine, University of Manitoba, and the Winnipeg Regional Health Authority Medicine Program invite applications for the position of Head of the Section of Neurology, one of 17 sections in the Department of Internal Medicine providing patient care, undergraduate, postgraduate and continuing education and research. The individual will also be the medical leader for the Winnipeg Regional Health Authority for neurology. Position No: AJJ 760

This is a major academic position with substantial resources within the region, primarily at two academic health centres. Significant planning for an enhanced stroke neurology program is being developed for the region. There are presently 9 full-time academic neurologists within the section with major clinical and investigative responsibilities in EMG, EEG, MS, and general neurology.

The successful applicant will have proven leadership abilities, a record of continuing achievement in basic or applied research, and a demonstrated capacity to collaborate with related disciplines. He/she must also have clinical and teaching skills to further the aims of undergraduate and postgraduate teaching in neurology. The applicant will have an important role in creating an outstanding neurology research program by adding clinical research expertise and by enhancing existing clinical programs.

This is a geographical, full-time, contingent position commencing October 1, 2004, or as soon thereafter as possible, for a term of five years, renewable upon favourable review. Salary and rank will be dependent upon qualifications and experience.

Candidates must have senior specialty qualifications in Neurology in the country of current practice and must be eligible for registration with the College of Physicians and Surgeons of Manitoba. Certification in Neurology by the Royal College of Physicians and Surgeons of Canada is preferred.

The University of Manitoba is a major research university located in the city of Winnipeg. The city has a rich sports and cultural environment with symphony, opera, dance, theatre and ethnic festivals. The region also provides ample opportunities for outdoor recreation in all seasons.

The University of Manitoba encourages applications from qualified women and men, including members of visible minorities, Aboriginal peoples, and persons with disabilities. All qualified candidates are encouraged to apply; however, Canadians and permanent residents will be given priority

Interested applicants should submit a curriculum vitae, a list of publications, and the names of three references to:

$$
\begin{aligned}
& \text { Dr. Dan Roberts, Professor and Head } \\
& \text { Department of Internal Medicine } \\
& \text { Room GC430, Health Sciences Centre } \\
& 820 \text { Sherbrook Street } \\
& \text { Winnipeg, MB Canada R3A 1R9 }
\end{aligned}
$$

Application materials, including letters of reference, will be handled in accordance with Manitoba's Freedom of Information and Protection of Privacy Act.

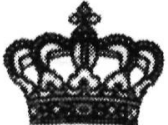

KING MEDICAL

THE CANADIAN ELECTRODE PLACE

- AMBU Blue Sensor • Neuroline

- CHALGREN Bar/Ring/Clip Electrodes

- CLASS A Monopolar Needles

- KENDALL Adhesive $\cdot$ NuTab

- KING MEDICAL Cables \& Adapters

- MAVIDON Lemon \& Green Skin Prep

- MEDTRONIC Mono/Conc. Needles

- PARKER LAB. Electrode Paste

- 3M CANADA Micropore - Transpore

-D.O. WEAVER Ten20 • NuPrep

Bo-ject ${ }^{\mathrm{TM}} \cdot$ Chalgren $\cdot$ Inoject $^{\mathrm{TM}}$ Large stock of Hypodermic Needles

Tel 905-833-3545

Fax 905-833-3543

E-mail: soren@kingmedical.com Web Site: www.kingmedical.com

King Medical Ltd.

145 Kingsworth Road

King City • Ontario L7B 1K1
M8 lives here.

\section{There's one} thing you can predict in life. MS makes life unpredictable. 18 Multiple Sclerosis Society of Canada $1 \cdot 800 \cdot 268 \cdot 7582$ www.mssociety.ca

CLOSING DATE: June 30, 2004 


\section{$\%$ of Attacks Reduced to Zero Pain ${ }^{\mathrm{TM} \dagger}$}

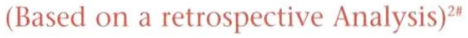

- IMITREX ${ }^{\circledR}$ is effective at any stage of migraine pain ${ }^{\prime A}$

- IMITREX ${ }^{\circledR}$ at the first sign of pain reduced most attacks to ZERO ${ }^{2 t}$

- Nearly 1 out of 2 attacks reduced to ZERO PAIN $^{\mathrm{TM}}$ at 1 hour

- 2 out of 3 attacks reduced to ZERO PAIN ${ }^{\mathrm{TM}}$ at 2 hours

- 9 out of 10 attacks reduced to ZERO PAIN ${ }^{\mathrm{TM}}$ at 4 hours

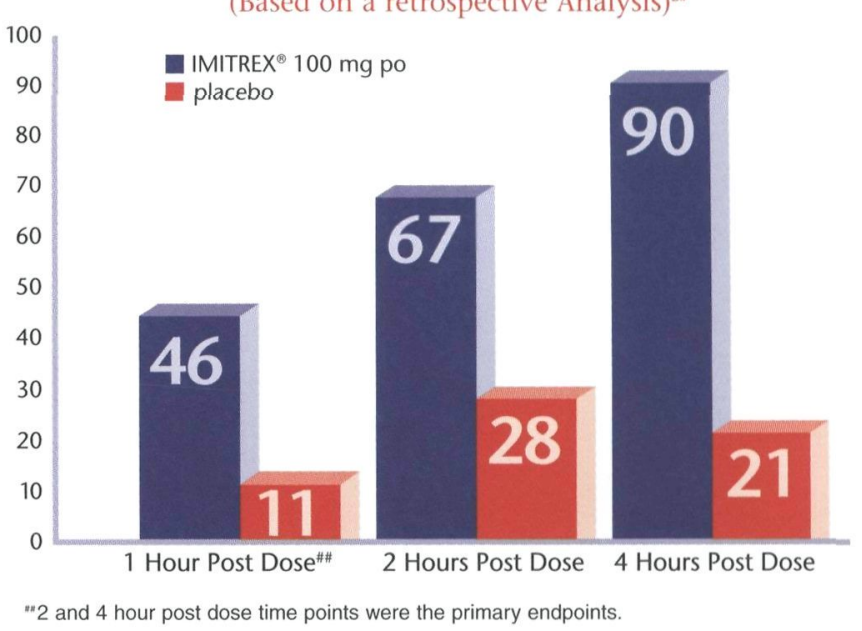

\section{SUCCESS WITH JUST ONE DOSE}

- When IMITREX ${ }^{\circledast}$ was taken at first sign of pain $^{\ddagger}, 80 \%$ of migraine attacks did not require a second dose ${ }^{2}$

- Reduced need for a second dose = Potential cost savings (acquisition cost only)
$\%$ of attacks that did not require a second dose when treated early with IMITREX ${ }^{\circledR}$

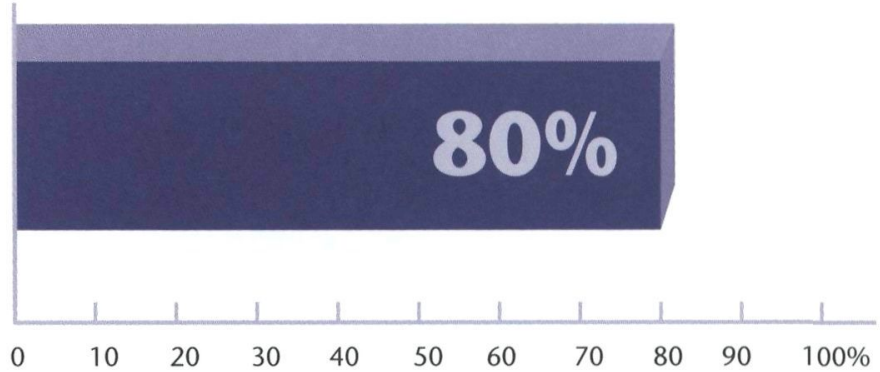

IMITREX $^{\circledast}$ (sumatriptan succinate/sumatriptan) is a selective 5- $\mathrm{HT}_{1}$ receptor agonist indicated for the acute treatment of migraine attacks with or without aura. ${ }^{1}$ IMITREX $^{\circledR}$ is not indicated for prophylactic therapy of migraine, or for the management of hemiplegic, basilar or ophthalmoplegic migraine. Safety and efficacy have not been established for cluster headache.'

IMITREX ${ }^{\circledast}$ is contraindicated in patients with history, symptoms, or signs of ischemic cardiac, cerebrovascular, or peripheral vascular syndromes, valvular heart disease or cardiac arrhythmias. In addition, patients with other significant underlying cardiovascular diseases should not receive IMITREX ${ }^{\oplus}$. IMITREX ${ }^{\oplus}$ is also contraindicated in patients with uncontrolled or severe hypertension.

The most common adverse events with IMITREX ${ }^{\oplus} 100 \mathrm{mg}$ tablets included: nausea (11.0\% vs. $5.8 \%$ placebo), malaise/fatigue $(9.5 \%$ vs. $5.1 \%$ placebo), sensations (body regions unspecified) (9.0\% vs. $4.5 \%$ placebo).

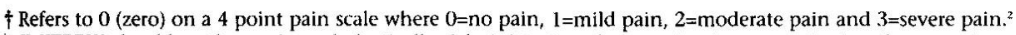

$\triangle$ IMITREX ${ }^{\star}$ should not be used prophylactically. Administration during migraine aura prior to other symptoms occurring may not prevent the development of a headache.

\# Early intervention = treatment initiated at first sign of pain - when pain was mild, before progression to moderate-severe pain.

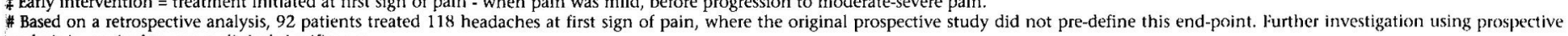
analysis is required to prove clinical significance.

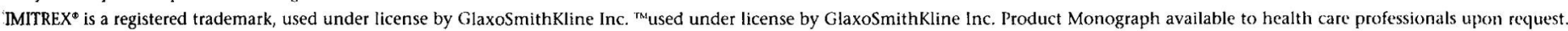
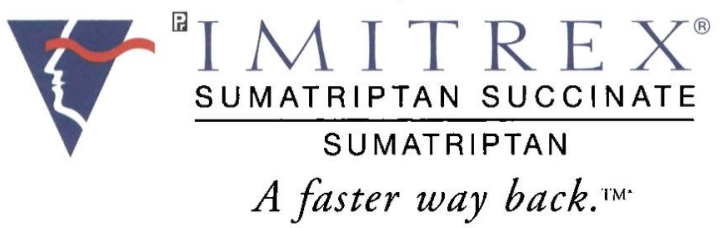

A faster way back. ${ }^{\mathrm{rM}}$.

* Onset of action: 10-15 min. subcutaneous, $15 \mathrm{~min}$. nasal spray, $30 \mathrm{~min}$. tablet. 
There's nothing better

than showing her grandchildren

how to play a winning hand.

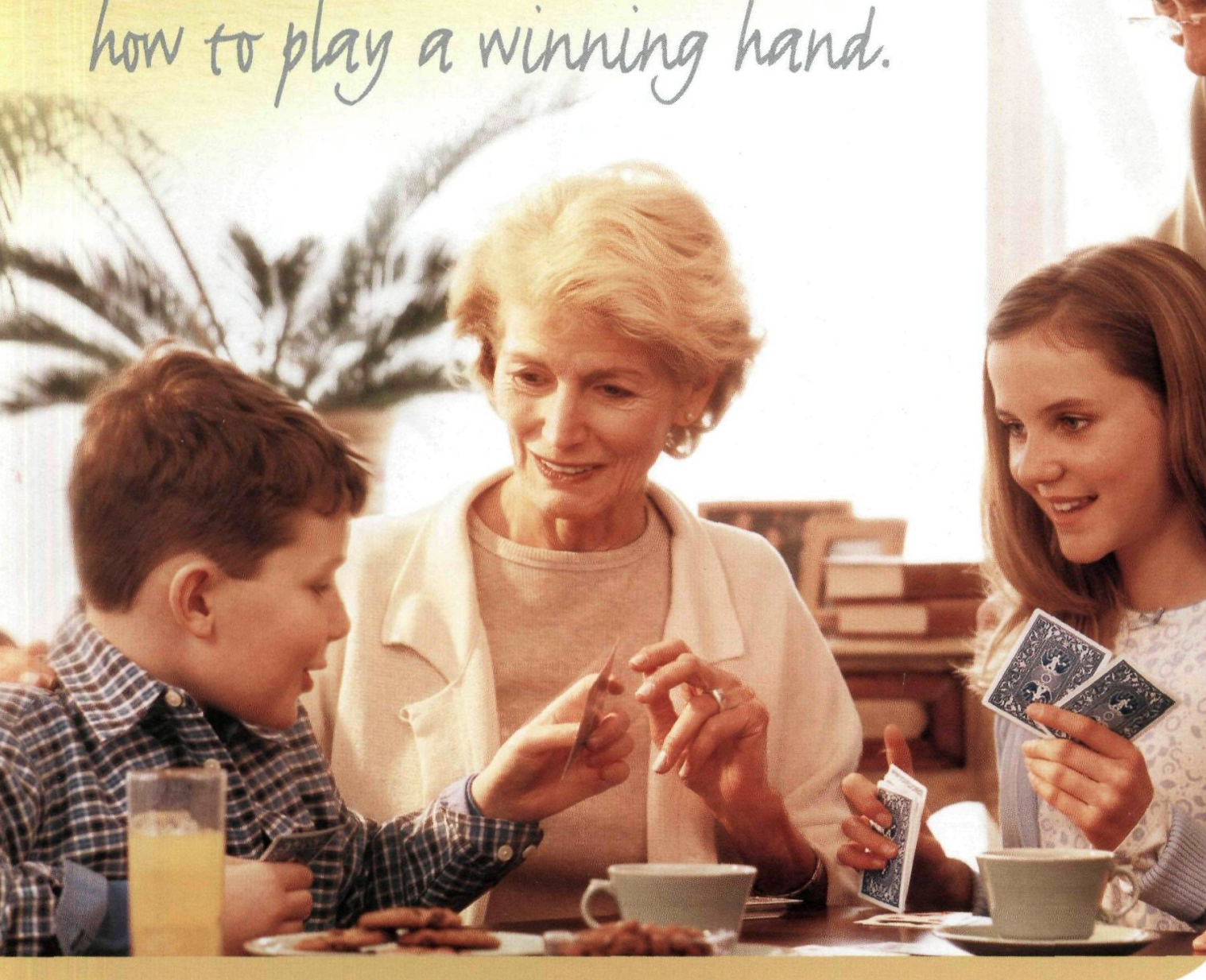

Since its launch, Aricept* sales and prescriptions have been leading the way in the fight against dementia of the Alzheimer's type.

- Over six years of excellent efficacy supported by more than 1.4 billion patient days worldwide ${ }^{1-4 t+\$}$

- Excellent safety and tolerability profiles ${ }^{5}$

- Convenient once-a-day dosing ${ }^{5}$

- A wealth of clinical studies

Aricept is indicated for the symptomatic treatment of patients with mild-to-moderate dementia of the Alzheimer's type, and does not change the underlying course of the disease.

With appropriate dose escalation, $5 \mathrm{mg} / \mathrm{d}, 10 \mathrm{mg} / \mathrm{d}$ and placebo were shown to have comparable adverse events, the most common being: diarrhea, nausea, insomnia, fatigue, vomiting, muscle cramps and anorexia. These are usually mild and transient, resolving with continued treatment without need for dose modification.

IT IS

NO WONDER

THAT ARICEPT*

IS THE \# 1

PRESCRIBED

AD TREATMENT

IN CANADA.
† In a 52-week, multicentre, double-blind, placebo-controlled study, 286 mild-to-moderate AD patients were randomized to receive Aricept* 5 mg/d for 28 days ( $n=142$ ), followed by $10 \mathrm{mg} / \mathrm{d}$, as per clinician's judgement, or placebo $(n=144)$.

‡ In a 54 -week, multicentre, double-blind, placebo-controlled study, 431 mild-to-moderate AD patients were randomized to receive Aricept" 5 mg/d for 28 days and $10 \mathrm{mg} / \mathrm{d}$ thereatter, or placebo.

$\S$ In a 24-week, randomized, double-blind, placebo-controlled study of Aricept" in 207 moderate AD patients (MMSE 10-17). Patients received either Aricept $5 \mathrm{mg} / \mathrm{d}$ for the first 28 days and $10 \mathrm{mg} / \mathrm{d}$ thereafter, as per clinician's judgement $(n=102)$, or placebo $(n=105)$.

Product Monograph avallable on request.

* TM Eisai Co. Ltd., Tokyo, Japan, Pfizer Canada Inc., licensee (C) 2004, Pfizer Canada Inc., Kirkland, Quebec H9.J 2M5

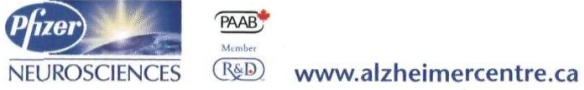

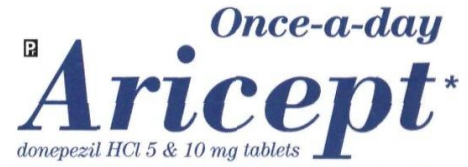

Experience defines us. 